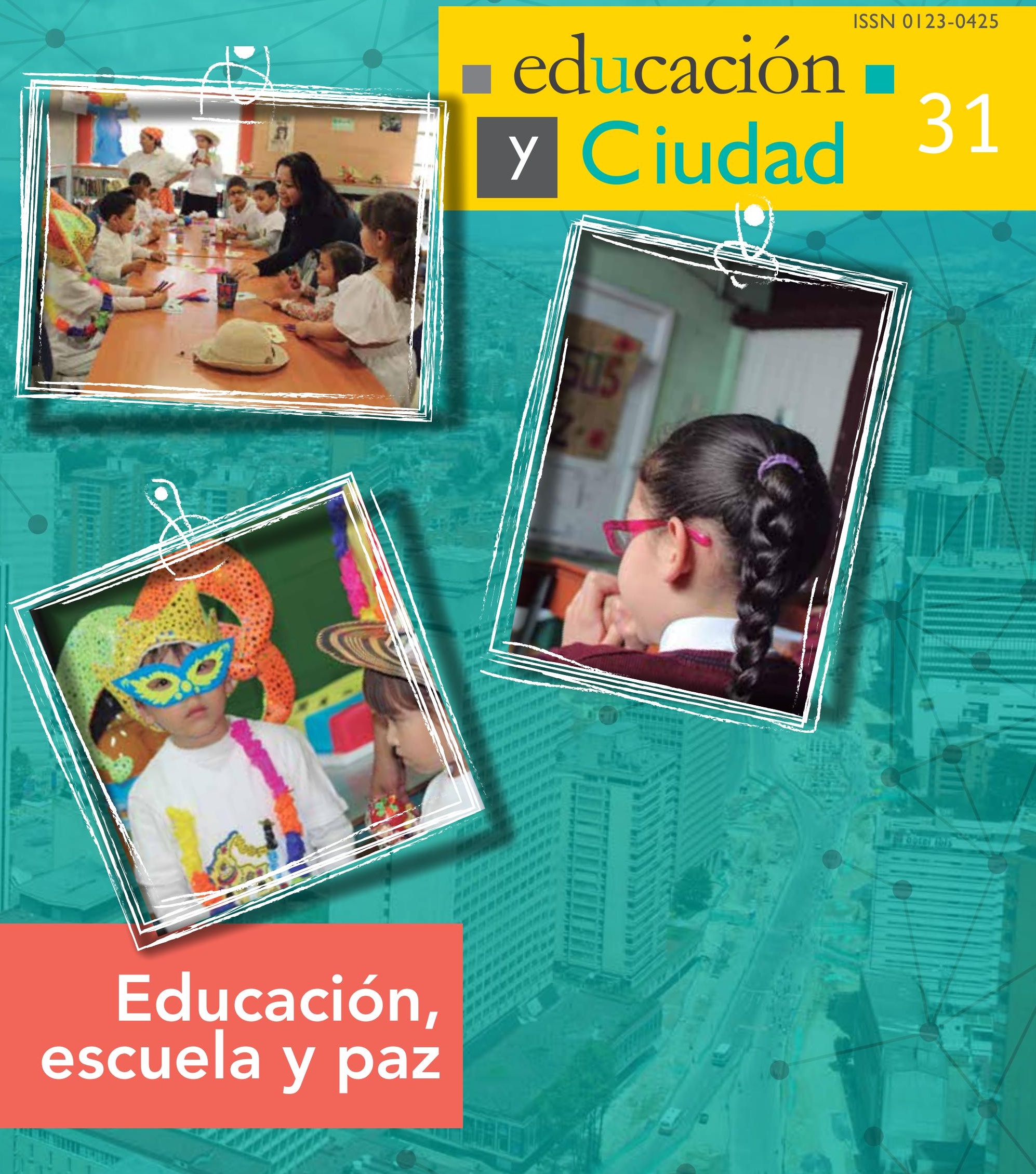




\section{Instituto para la Investigación Educativa}

y el Desarrollo Pedagógico, IDEP

\section{EDUCACIÓN}

\section{REVISTA EDUCACIÓN Y CIUDAD No. 31 \\ TEMA MONOGRÁFICO: EdUCACIÓN, ESCUELA Y PAZ}

Segundo Semestre: Julio - Diciembre de 2016

ISSN:

0123-0425 / Impresión

2357-6286 / Web-Online

Directora: Claudia Lucía Sáenz Blanco

Asesores de Dirección: Martha Ligia Cuevas Mendoza,

Consejo Directivo: María Victoria Angulo

Myriam Lucía Ochoa Piedrahita

Jorge Iván González Borrero

María Cristina Cermeño

Editores académicos invitados:

Jorge Alberto Palacio Castañeda, Ruth Amanda Cortés Salcedo, Alba Nelly Gutiérrez Calvo

Editor: Cooperativa Editorial Magisterio

Diseño, diagramación e ilustraciones:

.Coordinadora de Comunicación y Editorial IDEP:

Taller de Edición • Rocca® S. A.

Diana María Prada Romero

Impresión:

Subdirección Imprenta Distrital -DDDI

Tiraje: 1000 ejemplares

Revista indexada:

Iresie - Ulrich's, Latindex, e revis@as,

Dialnet, Actualidad Iberoamericana

Donde lo público - Credi - Ebsco, Clase, WorldCat, Rebiun.

Fotografías de portada: proyectos Colombia, cuenta un cuento de paz y Club de lectura Apapaches de las profesoras Blanca Lilia Medina y Eucaris Garzón, Colegio Gabriel Betancourt Mejía.

Publicación semestral del IDEP

Subdirección Académica - Comunicación, Divulgación y Socialización

Correspondencia, información, canjes y suscripciones

Avenida Calle 26 No. 69D-91. Centro Empresarial Arrecife. Torre Peatonal, Oficinas 805 - 806.

Teléfono PBX: (57 1) 2630603

Bogotá, Colombia

Correo electrónico: idep@idep.edu.co - educacionyciudad@idep.edu.co

Página Web: www.idep.edu.co

Los conceptos y opiniones de los artículos son de exclusiva responsabilidad de sus autores y no comprometen

la política institucional del IDEP. El Comité Editorial agradece los artículos enviados voluntariamente y se reserva la decisión de su publicación en la revista. Se autoriza la reproducción de los artículos citando la fuente

y los créditosde los autores; se agradece el envío de la publicación en la cual se realice la reproducción.

Impreso y hecho en Colombia 
Educación, escuela y paz 


\section{Contenido}

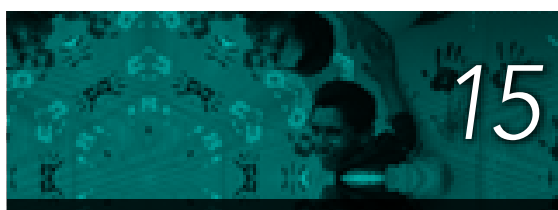

Atributos que humillan. Un enfoque relacional sobre las humillaciones entre estudiantes de educación secundaria Agustina Mutchinick
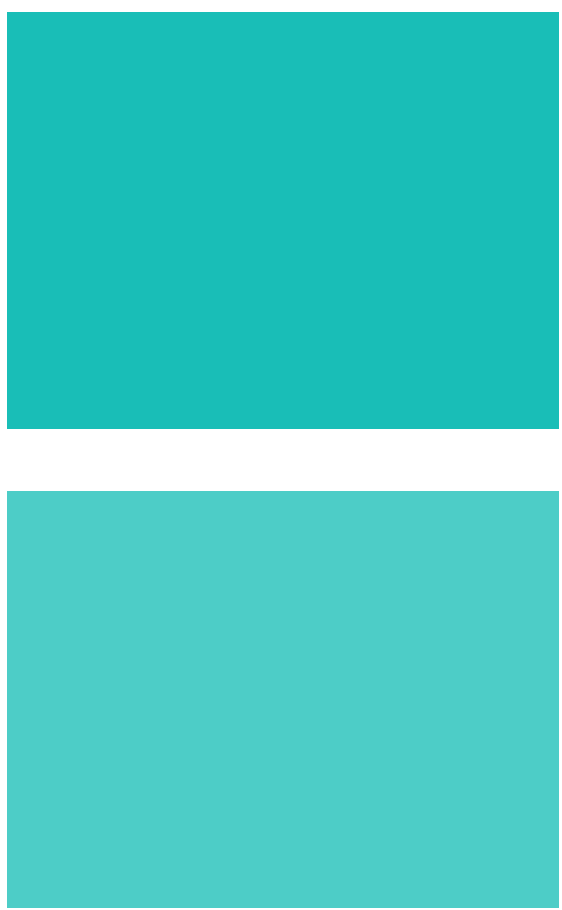

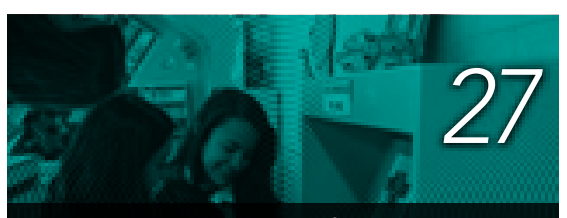

Hacia una convivencia pacífica en la escuela: percepciones sobre violencia escolar y tramitación de conflictos

Sindy Paola Díaz Better

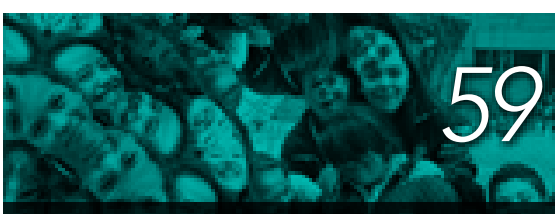

Relación del clima de aula y las

emociones morales: culpa y empatía

Mary luz Esquivel Fajardo - Martha Liliana Gutiérrez Herrera - Angélica María Mercado Roa - Yeimy Pachón

Forero - Gloria Patricia Ortega Roa

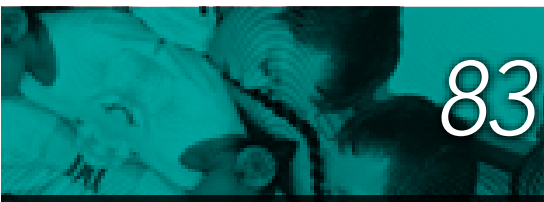

Escuela de liderazgo para niñas y mujeres jóvenes en el sector educativo: una apuesta política para la construcción de paz

Guisset Stephanny Parra Ordoñez de Valdés - Jessica Nathalie Corpas Figueroa

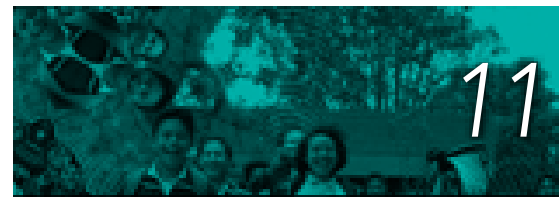

Editorial

Educación, escuela y paz
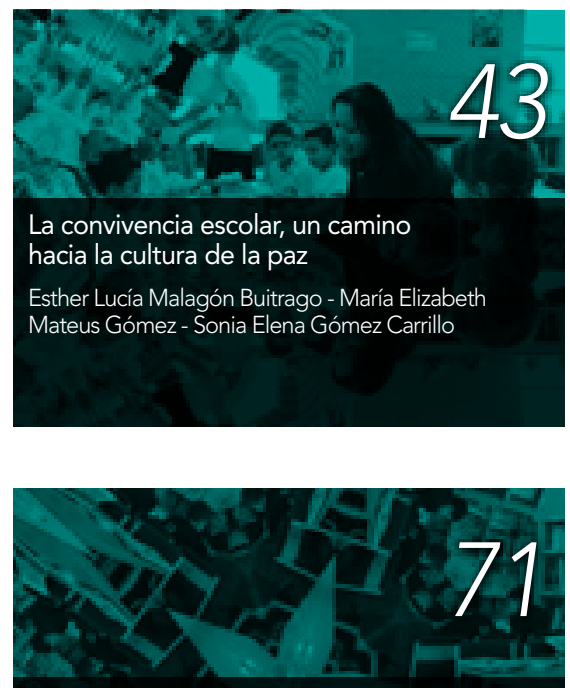

Romper estereotipos de género en

la identidad profesional docente:

una propuesta de paz

Luisa Pinzón Varilla

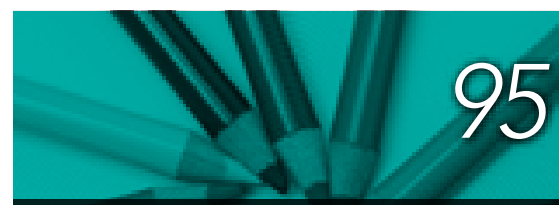

La lectura en voz alta de cuentos, un camino para cambiar la percepción de agresividad

Liliana Turriago Rincón - Carolina González Herrera Nelsy Peña Guerrero 


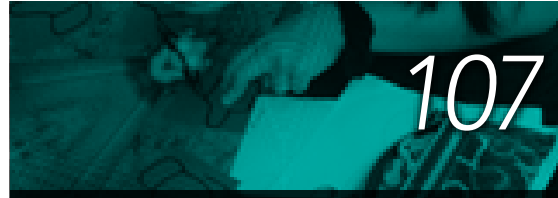

La escuela como escenario facilitador de paz: panorama de trabajos sobre una formación ética en escolares, para la construcción de mejores relaciones de convivencia dentro y fuera del aula

Ingrid Rivas Buitrago
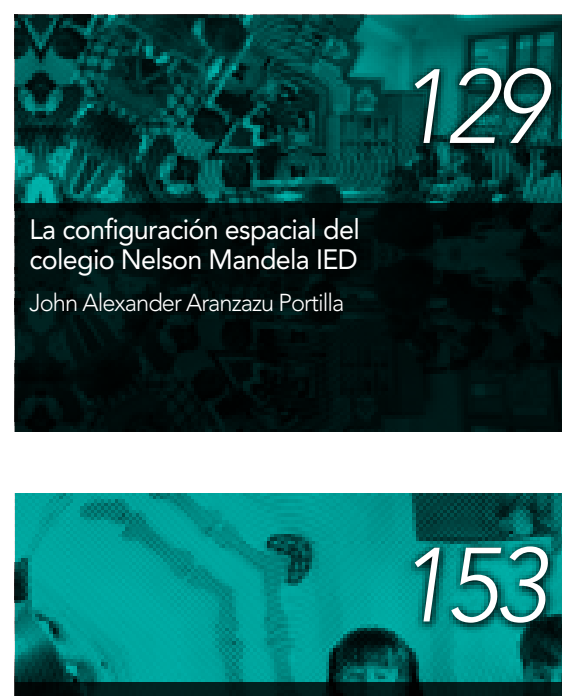

Yoga para niños: mediación que

minimiza la violencia escolar

Nidya Soraya Páez Martínez - Ruth Milena Páez Martínez

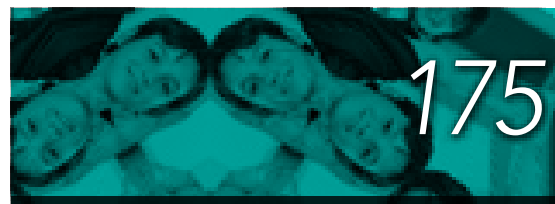

Tras bambalinas. Un momento para la reflexión. Importancia de la recuperación de la memoria histórica y las masacres en Colombia a través del teatro

Angélica María Valencia Murillo
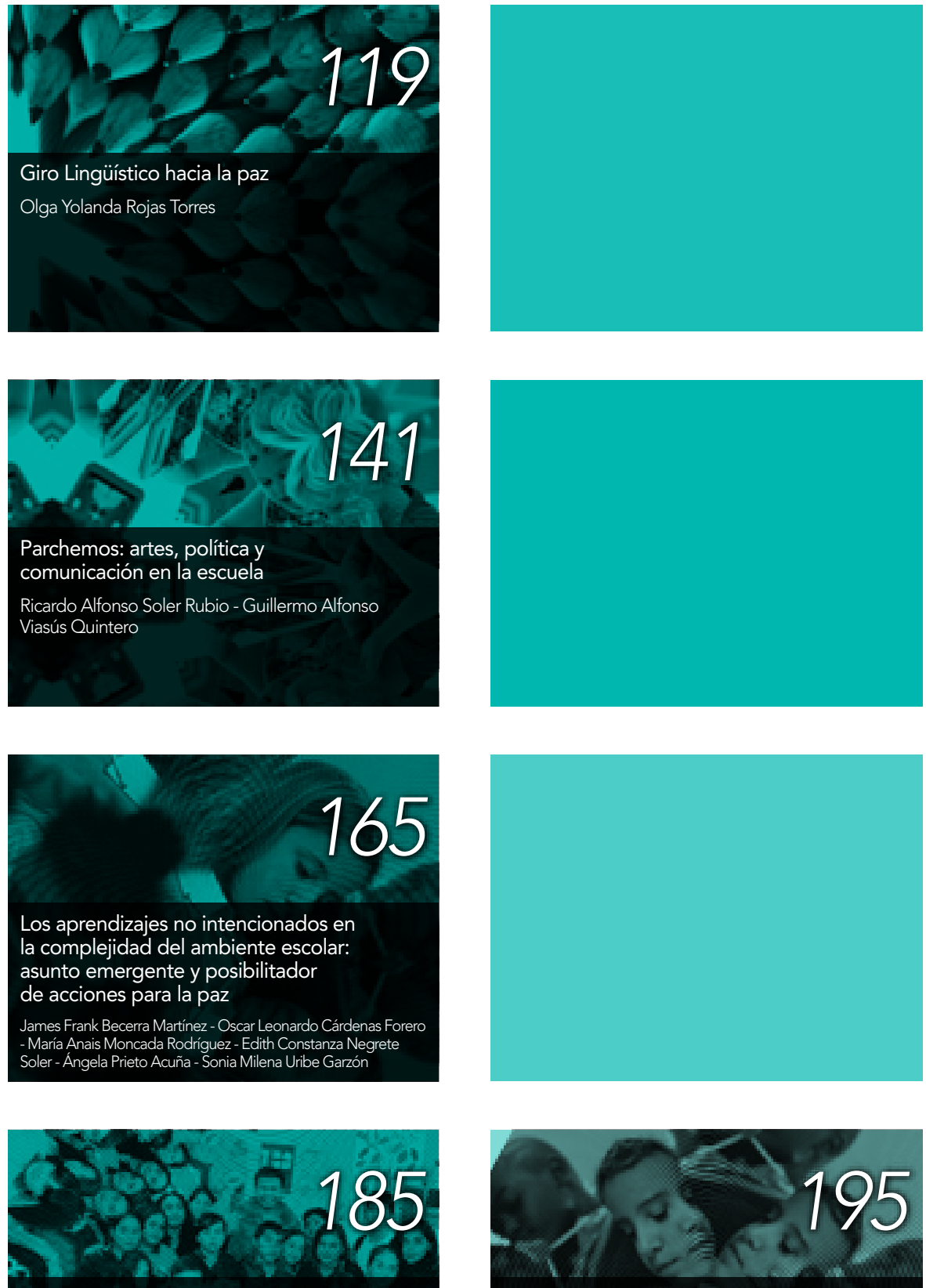

Otra escuela es posible: subjetividades políticas y retos en el post-acuerdo

Giordano Alvarado Silva - Diana Beltrán Bermeo - Enrique Blanco García - Yesid González Perdomo -

Javier lbagón Martín

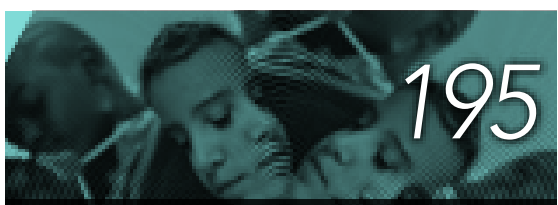
Educación y Ciudad del IDEP
Parámetros de publicación Revista 


\section{Comité Científico}

\section{ARACELI TERESA DE TEZANOS CASTIÑEIRAS \\ Formación Académica}

Doctora en Lettres et Sciences Humaines, Université de Paris X

Nanterre. Maestría Investigación Educativa, Universidad

Iberoamericana.

Especialización Certificatto in Pedagogia, Università degli Studi de

Firenze.

Especialización Diplôme d' Études Approfondies en estudios Ibéricos e Iberoamericanos, Université de Paris X Nanterre.

Filiación Laboral

Université de Paris X - Nanterre.

Nacionalidad

Uruguaya

atezanos@club-internet.com

\section{CARLOS OBANDO ARROYAVE}

\section{Formación Académica}

Doctor en Investigación Pedagógica y TIC de la URL-Blanquerna, Barcelona, España. Maestría en Comunicación Audiovisual Digital, Universidad Internacional de Andalucía, Sevilla, España. Especialista en Semiótica-Estética, Universidad Nacional, Colombia. Comunicador Social- Periodista, Universidad de Antioquia, Colombia.

\section{Filiación Labora}

Coordinador y Docente Máster en Diseño y Producción Audiovisual, Universidad Autónoma de Barcelona, España. Miembro del grupo de Investigación en PSiTIC, Universidad Ramon Llull-Blanquerna, Barcelona, España.

Nacionalidad

Colombiana

carloso@carloso-bcn.com

\section{EDUARDO GUTIÉRREZ}

\section{Formación Académica}

Doctor en Historia, Universidad Nacional de Colombia (en curso). Maestría en Comunicación, Pontificia Universidad Javeriana. Licenciatura en Lenguas Español-Inglés, Universidad Pedagógica Nacional.

\section{Filiación Laboral}

Profesor asistente del Departamento de Comunicación, Pontificia Universidad Javeriana.

Nacionalidad

Colombiana

clasehistoria@gmail.com
INÉS DUSSEL

Formación Académica

Ph.D., Department of Curriculum \& Instruction, University of Wisconsin-Madison. Maestría en Educación y Ciencias Sociales, Facultad Latinoamericana de Ciencias Sociales, Argentina. Licenciada en Ciencias de la Educación, Facultad de Filosofía y Letras, Universidad de Buenos Aires, Argentina. Área de formación focalizada: Historia de la Educación.

Filiación Laboral

Investigadora Titular del DIE-CINVESTAV de México.

Nacionalidad

Argentina

idussel@cinvestav.mx

\section{FEDERICO REVILLA}

\section{Formación Académica}

Doctor en Filosofía y Letras (Sección Historia del Arte)

Universidad de Barcelona. Licenciado en Ciencias de la Información

(Real Decreto 1.201/1977).

\section{Filiación Laboral}

Miembro del "Claustro de Doctores" de la Universidad de Barcelona.

Director del Centro de Estudios Post-universitarios. Miembro

del Comité Consultivo de la Sociedad Española de Emblemática.

Presidente de la Fundación Cultural de las Américas.

\section{Nacionalidad}

Española

amigos@cultuamericas.org

\section{GLORIA PÉREZ SERRANO}

Formación Académica

Doctora en CC de la Educación, Universidad Complutense de Madrid (UCM). Licenciada en Filosofía y Letras. Sección Pedagogía, UCM.

\section{Filiación Laboral}

Catedrática de Pedagogía Social UNED. Dirige la revista interuniversitaria Pedagogía Social y el Máster en Intervención Educativa en Contextos Sociales de la UNED. Catedrática de la Universidad

Pablo de Olavide, Sevilla.

Nacionalidad

Española

gloriaperez@edu.uned.es 
JOSÉ ÁNGEL LÓPEZ HERRERÍAS

\section{Formación Académica}

Doctor en Filosofía.

Filiación Laboral

Profesor de Pedagogía General y Social de la Facultad de Educación de la Universidad Complutense de Madrid.

Nacionalidad

Española

jherrer@edu.ucm.es

\section{JAUME TRILLA BERNET}

Formación Académica

Doctor en Pedagogía de la Universidad de Barcelona.

Filiación Laboral

Catedrático de la Facultad de Pedagogía y miembro del grupo de Investigación en Educación Moral (GREM) de la Universidad de Barcelona.

\section{Nacionalidad}

Española

jtrilla@ub.edu

\section{ROCÍO RUEDA ORTIZ}

Formación Académica

Doctora en Ciencias de la Educación, Universidad de Las Islas Baleares. Maestría en Tecnologías de la Información Aplicada, Universidad Pedagógica Nacional. Licenciatura en Psicología y

Pedagogía Universidad Pedagógica Nacional.

Filiación Laboral

Doctorado Interinstitucional en Educación, Universidad Pedagógica Nacional.

Nacionalidad

Colombiana

rruedaortiz@yahoo.com

JAVIER OCAMPO LÓPEZ

Formación Académica

Doctor en Historia, Colegio de México.

Especialización Historia de las Ideas,

Universidad Nacional Autónoma de México.

Filiación Laboral

Universidad de Cartagena. Doctorado en Interinstitucional en Educación

Universidad Pedagógica y Tecnológica de Colombia.

Nacionalidad

Colombiana

javierocampo11@yahoo.es 


\section{CLAUDIA LUCÍA SÁENZ BLANCO}

Formación Académica

Maestría en Educación. Psicóloga,

Universidad Nacional de Colombia.

Filiación Laboral

Directora del Instituto para la Investigación

Educativa y el Desarrollo Pedagógico, IDEP.

Nacionalidad

Colombiana

csaenz@idep.edu.co

\section{ALEJANDRO ÁLVAREZ GALLEGO}

\section{Formación Académica}

Doctor en Historia de la Educación y

Educación Comparada, Universidad Nacional de Educación a Distancia. Maestría Estudios

Políticos, Pontificia Universidad Javeriana.

Licenciatura en Ciencias Sociales,

Universidad Pedagógica Nacional

Filiación Laboral

Docente de la Universidad Pedagógica

Nacional, Facultad de Educación.

Nacionalidad

Colombiano

rizoma.alejandro@gmail.com

\section{RUTH AMANDA CORTÉS SALCEDO}

\section{Formación Académica}

Doctora en Educación, Universidad

Pedagógica Nacional. Maestría en Desarrollo Educativo y Social, CINDE. Especialización en Enseñanza de la Historia, Pontificia

Universidad Javeriana. Licenciatura en Ciencias Sociales, Universidad Pedagógica Nacional.

Filiación Laboral

Investigadora del Instituto para la Investigación

Educativa y el Desarrollo Pedagógico, IDEP.

Nacionalidad

Colombiana

amandacortes2006@yahoo.es

\section{MARCO RAÚL MEJÍA}

\section{Formación Académica}

Doctor Programa Interdisciplinar Investigación en Educación. Proyecto Interdisciplinario en Investigaciones Educativas. Maestría en Desarrollo Educativo y Social, CINDE. Licenciatura en Filosofía y Letras, Pontificia Universidad Javeriana. Filiación Laboral

Planeta Paz.

Nacionalidad

Colombiano

marcoraulm@gmail.com

\section{ADELA MOLINA ANDRADE}

Formación Académica

Doctora en Educación, Universidad de Sao

Paulo. Maestría en Educación con Énfasis en

Evaluación, Pontificia Universidad Javeriana.

Licenciatura en Educación con Énfasis en Biología,

Universidad Distrital Francisco José de Caldas.

Filiación Laboral

Docente Universidad Distrital

Francisco José de Caldas.

Nacionalidad

Colombiana

amolina@udistrital.edu.co

\section{RUTH MILENA PÁEZ MARTíNEZ}

Formación Académica

Doctora en Educación, Universidad

Pedagógica Nacional de Colombia. Magíster

en Educación, Pontificia Universidad

Javeriana. Licenciada en Educación Básica

Primaria, Pontificia Universidad Javeriana.

Filiación Laboral

Docente Maestría en Docencia y Doctorado en

Educación y Sociedad de la Universidad de La Salle.

Nacionalidad

Colombiana

milenapaez@yahoo.es

\section{ROSALBA PULIDO DE CASTELLANOS}

\section{Formación Académica}

Doctora en Educación, Área Ciencias Naturales, Universidad Pedagógica Nacional. Maestría en Biología, Universidad de Los Andes. Maestría en Dirección Universitaria, Universidad de Los Andes. Licenciatura en Ciencias de la Educación, Universidad Pedagógica Nacional. Filiación Laboral

Docente de la Universidad Pedagógica Nacional. Nacionalidad

Colombiana rpulido@pedagogica.edu.co

\section{MARTHA LIGIA CUEVAS MENDOZA}

Formación Académica

Maestría en Psicología.

Filiación Laboral

Asesora del Instituto para la Investigación

Educativa y el Desarrollo Pedagógico, IDEP.

Nacionalidad

Colombiana

mcuevas@idep.edu.co

\section{GLADYS JAIMES DE CASADIEGO}

Formación Académica

Doctora en Ciencias Pedagógicas, Universidad Central de Las Villas. Maestría en Lingüística Teórica y Formal, Universite De Paris VIII.

Maestría en Lingüística Hispanoamericana, Instituto

Caro y Cuervo. Especialización en Lingüística,

Instituto Caro y Cuervo. Licenciatura en Ciencias

de la Educación, Universidad Pedagógica Nacional.

Filiación Laboral

Consultora IDEP.

Nacionalidad

Colombiana

\section{EDWIN FERLEY ORTIZ MORALES}

Formación Académica

Doctor en Educación.

Filiación Laboral

Asesor del Instituto para la Investigación

Educativa y el Desarrollo Pedagógico, IDEP.

Nacionalidad

Colombiano

eortiz@idep.edu.co

\section{DIANA MARÍA PRADA ROMERO}

Formación Académica

Maestría en Desarrollo

Educativo y Social, CINDE. Especialista en Periodismo y Ciencias de la Comunicación,

Universidad Autónoma de Barcelona.

Especialista en Comunicación - Educación, Universidad Central. Comunicadora Social

- Periodista, Universidad Central.

Filiación Laboral

Instituto para la Investigación Educativa

y el Desarrollo Pedagógico, IDEP.

Nacionalidad

Colombiana

dprada@idep.edu.co

\section{MARÍA DEL PILAR UNDA BERNAL}

Formación Académica

Doctora en Cultura y Educación en América Latina, de la Universidad de Artes y Ciencias

Sociales. Maestría en Educación con

Especialización en Investigación Educativa y Análisis Curricular, de la Universidad Javeriana.

Psicóloga de la Universidad Javeriana.

Filiación Laboral

Docente e Investigadora de la

Universidad Pedagógica Nacional.

Nacionalidad

Colombiana

pilunda@gmail.com 


\section{Pares Evaluadores}

\author{
Alberto Montalvo Castro \\ Formación Académica \\ Doctorado Instituto Pedagógico Latinoamericano y Caribeño \\ Doctorado en Ciencia Pedagógicas \\ Filiación Laboral \\ Fundación Universitaria del Área Andina \\ almocastro1@gmail.com
}

\section{María Helena Ramírez}

Formación Académica

Doctora en Ciencias de la Educación, Instituto

Pedagógico Latinoamericano y Caribeño, IPLAC

Filiación Laboral

Universidad Del Área Andina

maheracab@gmail.com

\section{Luis Ernesto Vásquez Alape}

Formación Académica

Doctorando en Comunicación, Universidad De La Plata, Argentina

Filiación Laboral

Universidad De La Salle. Bogotá

lvasquez@unisalle.edu.co

\section{Alfredo Manuel Ghiso Cotos \\ Formación Académica \\ Especialización Universidad St Fx Xavier, \\ Especialización En Desarrollo Social \\ Filiación Laboral \\ Docente-investigador \\ amghiso@gmail.com}

\section{Ana Brizet Ramírez Cabanzo}

Formación Académica

Candidata a Doctora en Educación, Universidad Pedagógica Nacional

Filiación Laboral

Universidad Francisco José de Caldas

anabrizet@gmail.com

\section{Andrés Castiblanco Roldán \\ Formación Académica \\ Doctorado en Ciencias Humanas y Sociales, \\ Universidad Nacional de Colombia \\ Filiación Laboral \\ Universidad Distrital Francisco José de Caldas \\ proteoandante@gmail.com}

\section{Gladys Milena Vargas Beltrán}

Formación Académica

Maestría en educación de la Corporación Universitaria Minuto de Dios y

Maestra en Educación del Instituto Tecnológico de Monterrey de México

Filiación Laboral

Universidad Pedagógica Nacional

gvargas@magisterio.com.co

\section{Omaira Tapiero Celis}

Formación Académica

Doctorado Ecole Des Hautes Etudes En Sciences Sociales

Sciences du langage

Filiación Laboral

Universidad Distrital Francisco José de Caldas

otapiero@udistrital.edu.co

\section{Rubén Darío Gómez Lorduy}

Formación Académica

Maestría en Lingüística, Universidad de Antioquía

Filiación Laboral

Docente de tiempo completo de la secretaría de

educación del Municipio de Medellín

glorduy@gmail.com

\section{Mónica Yasmin Cuineme Rodríguez}

Formación Académica

Maestría en investigación Social, Universidad

Distrital Francisco José de Caldas

Filiación Laboral

Docente Secretaría de Educación Distrital, Bogotá mycuineme@gmail.com

\section{Roberto Esteban Hoyos Martínez}

Formación Académica

Maestría en Educación y Desarrollo Humano-

Universidad de Manizales CINDE

Filiación Laboral

Docente del municipio de Medellín

estehoyos78@gmail.com

\section{Constanza Amézquita Quintana}

Formación Académica

Doctorado en Estudios Políticos y Relaciones

Internacionales, Universidad Nacional de Colombia

Filiación Laboral

Universidad Externado de Colombia

constanza.amezquita@gmail.com

\section{Luz Elena Acevedo Lopera}

Formación Académica

Maestría en Historia del Arte, Universidad de Antioquía

Filiación Laboral

Docente I.E. Lola González, Medellín

luzelenaacevedolopera@yahoo.com

Daniel F. Torres P.

Formación Académica

Edición de libros Universidad de Buenos Aires

Filiación Laboral

Director Editorial Revista Internacional Magisterio

directorrevista@magisterio.com.co 



\section{Educación, escuela y paz}

El presente número de la Revista Educación y Ciudad trabaja la ineludible relación entre educación, escuela y paz, uniéndose así a un interés común que ha cobrado fuerza gracias a los recientes acuerdos de La Habana. Sin embargo, los motivos que han llevado a esta publicación no se relacionan únicamente con la coyuntura que atravesamos como sociedad, ni se acomodan a un discurso porque está de moda; se dirigen a la raíz del sentido de nuestra profesión, ya que los esfuerzos de profesoras y profesores de todo el país por alcanzar mejores mecanismos de comunicación, de paz y convivencia, no se inscriben en el oportunismo político del presente, en el que "algunos” actores pescan en río revuelto para sacar dividendos y dividir, hacen parte de un esfuerzo continuado por crecer con y en comunidad desde lo cotidiano, desde la libre expresión que nos define como humanos.

Dicho esto, es imposible desconocer que los fenómenos vinculados a la agresión hacen parte de lo cotidiano en la escuela, y que como integrantes de los ambientes escolares los profesores jugamos un papel importante en la construcción de los distintos escenarios, discursos y comportamientos que favorecen o desvirtúan la convivencia y los espacios de paz. Es esa función de participación la que, como academia, guía nuestro intento permanente por estar a la vanguardia de la refrendación de la paz en la escuela, y es en ese sentido que ponemos a disposición del lector una serie de trabajos que le permitirán acercarse a distintas perspectivas de los esfuerzos del magisterio, y del IDEP, por interpretar y acercar a la escuela los múltiples sentidos de la paz y la convivencia.

Hacerlo implica transitar por temas que van, desde la importancia de la recuperación histórica del país en la escuela, hasta las formas de resolver conflictos cotidianos, pasando por las diferentes prácticas que pueden favorecer la comprensión entre los actores educativos; sin olvidar el papel del profesor y del alumno a la hora de incorporar nuevos lenguajes que posibiliten la inclusión de la diferencia, y del otro, en el escenario plural de los ambientes de aprendizaje.

Los textos en este número trabajan, desde diferentes matices, el papel de la escuela como agente de cambio, de reflexión y de tratamiento de la convivencia para escenarios de paz, considerando distintos contextos de los procesos educativos, pues tanto la escuela, como el maestro y los estudiantes, se redefinen desde imaginarios e interacciones que pueden o no favorecer la comunicación con el otro. Así, este tipo de relación implica un estudio interdisciplinar que potencie lugares de encuentro, esa ha sido nuestra intención.

Un recorrido que en primer lugar se detiene en aquellos artículos que trabajan la violencia en el aula desde distintas perspectivas; tal es el caso de "Atributos que humillan. Un enfoque relacional sobre las humillaciones entre estudiantes de educación secundaria", texto que expone la humillación como expresión no física presente en la escuela; se complementa con el análisis propuesto en "Hacia una convivencia pacífica en la escuela: Percepciones sobre violencia escolar y tramitación de conflictos", que revisa las 
herramientas de los estudiantes para manejar asertivamente los conflictos y el tipo de enfoques necesarios para favorecer escenarios de negociación. Junto a estas propuestas se ubica "La convivencia escolar, un camino hacia la cultura de la paz", estudio que busca identificar los factores de agresión para elaborar una propuesta que promueva la cultura de la paz; mientras que "Relación del clima de aula y las emociones morales: culpa y empatía", determina el vínculo entre dichos elementos para destacar el sentido de lo moral como posible constructor de escenarios de paz.

El segundo punto de encuentro gira alrededor del género como estructura que define comportamientos explícitos e implícitos de agresión en la escuela. En el caso de "Romper estereotipos de género en la identidad profesional docente: una propuesta de paz", se busca comprender la forma en que la visión de las identidades profesionales afecta el ejercicio de la profesión docente, llevando a estereotipos de género que funcionan como agentes de discriminación hacia las profesoras. Como complemento, "Escuela de liderazgo para niñas y mujeres jóvenes en el sector educativo: una apuesta política para la construcción de paz", expone las reflexiones que se dan luego de implementar un proceso pedagógico para fortalecer las ciudadanías de las mujeres en la escuela, potenciando sus habilidades para participar, liderar y re-significar su relación con el poder.

En tercer lugar, el presente número ofrece un bloque que podríamos llamar de formas para ver la violencia en la escuela a través de la palabra, el cual abarca textos como "La lectura en voz alta de cuentos, un camino para cambiar la percepción de agresividad", que busca incluir la lectura en voz alta como elemento para cambiar la agresividad en los estudiantes, a partir del vínculo entre lectura, escucha y vida cotidiana, entendiendo que la paz, como la lectura, es un acto inmerso en las prácticas sociales. Por su parte, en "La escuela como escenario facilitador de paz" se hace una revisión de documentos que han abordado el problema de la violencia escolar en las escuelas del país, para ofrecer un panorama útil, no solo como bibliografía, sino como mapa de los distintos esfuerzos que demuestran el interés continuado de los maestros por la paz; en el "Giro Lingüístico hacia la paz" se insiste en la pertinencia de construir tejidos sociales más comprensivos desde la palabra, que se relaciona con la paz al ofrecer la posibilidad de escuchar al otro hasta ser un nosotros.

Un cuarto conjunto que podríamos destacar de todo el cuerpo reunido en esta, su revista, es el que se ocupa del espacio en tanto agente que interviene en la violencia de la escuela. En este sentido, se destaca el texto "La configuración espacial del colegio
Nelson Mandela IED”, que analiza a la escuela como escenario que desde sus condiciones físicas afecta los sentidos espaciales de los estudiantes, y como atmósfera que, decretada por lo institucional, promueve situaciones de vulnerabilidad y exclusión a partir de prácticas espaciales que dan lugar a un teatro escolar de regulación constante de la conducta, limitando las posibilidades de participación. Desde otra orilla encontramos "Parchemos: artes, política y comunicación en la escuela”, un artículo que presenta un proyecto de investigación desarrollado para fortalecer las prácticas ciudadanas en el contexto escolar, a partir de ejercicios con artes musicales y visuales, entendiéndolas como agentes que potencian la comunicación y facilitan transformaciones subjetivas que dan paso a la diversificación de voces y al reconocimiento del otro como posibilidad de ampliar saberes y experiencias.

La última parada serían los artículos que trabajan alternativas para manejar la agresión en la escuela; podríamos comenzar con "Yoga para niños: mediación que minimiza la violencia escolar", cuyo punto de partida es una experiencia que emplea este ejercicio como aparato pedagógico en el aula para potenciar la salud exterior e interior de los niños y la interacción sin violencia. En "Los aprendizajes no intencionados en la complejidad del ambiente escolar", se revisan las relaciones en la escuela para destacar los aprendizajes que implican lo no explícito pero visible en la convivencia estudiantil, entendiéndolos como esenciales porque pueden potenciar o inhibir actos de paz. "Tras bambalinas" es una propuesta que expone el papel formador del teatro desde su facultad para fomentar procesos de rescate de la memoria histórica de nuestro país, a partir de la puesta en escena de las masacres más determinantes del siglo XX. Por último, "Otra escuela es posible: subjetividades políticas y retos en el post-acuerdo", expone y analiza cinco experiencias pedagógicas en Bogotá que reflexionan sobre el conflicto armado y la otredad, para transformar las subjetividades políticas de los estudiantes. Nada mejor que terminar con este referente para pensar en un futuro que, desde ya, enfrenta el mejor reto posible, el de la paz desde la escuela.

Nuestro contexto nos obliga a reconocer que la paz es verdaderamente un asunto de todos, y que involucra todos los espacios del saber y todos los escenarios, mucho más el de la escuela, pues ella juega un papel trascendental en el futuro de eso que hoy intentamos construir; nuestro ánimo por llevar a buen término la paz está definido por lo cotidiano en el aula, por la esperanza y el trabajo diario. Es justamente en este marco que se inscribe la presente publicación, buscando responder, desde las reflexiones de nuestros profesores, a los distintos retos que ofrece la convivencia. 


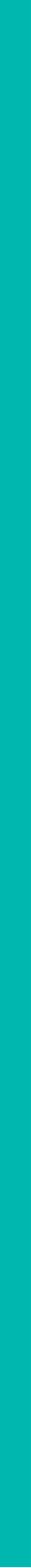




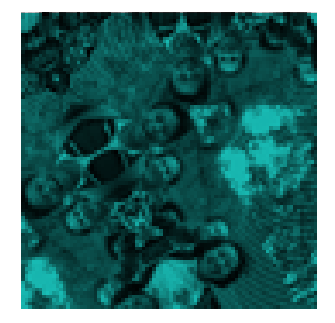




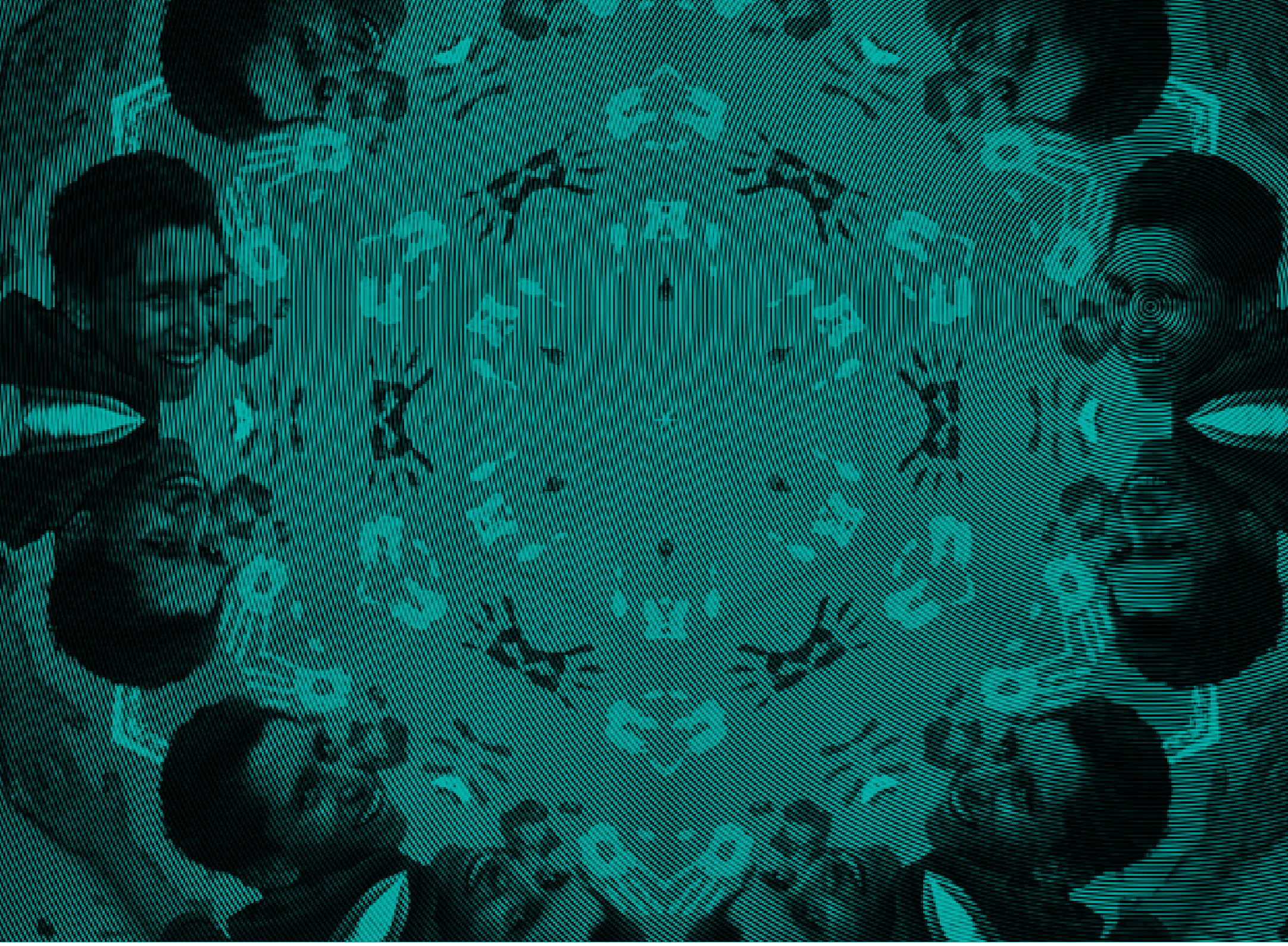

\section{Atributos que humillan. Un enfoque relacional sobre las humillaciones entre estudiantes de educación secundaria}

Attributes that humiliate. A relational approach on humiliations among high school students

Atributos que humilha. Uma abordagem relacional sobre as relacionais das humilhações entre alunos de educação secundária 
Agustina Mutchinick 1
1. Investigadora del Instituto de Investigaciones en Ciencias de la Educación, Universidad de Buenos Aires, y de la Facultad de Humanidades y Ciencias Sociales de la Universidad Nacional de Misiones. Doctora, Universidad de Buenos Aires, Área de Ciencias de la Educación; correo electrónico: agustinamutchinick@gmail.com

Fecha de recepción: 18 de abril de 2016 / Fecha de aceptación: 16 de septiembre de 2016

\section{Resumen}

El presente artículo expone los resultados de una investigación cualitativa que exploró las relaciones de humillación entre estudiantes de secundaria, particularmente de los atributos que hacen evidentes tales modos de vincularse, entendiendo que la producción de dichas modalidades de sociabilidad se da en un entramado de configuraciones específicas. La investigación analizó desde un enfoque relacional dos grupos escolares de dos escuelas secundarias estatales, empleando para ello entrevistas en profundidad, individuales y grupales, a los alumnos de dichos grupos. Los resultados señalan que los atributos básicos para el desarrollo de las humillaciones varían en las condiciones estudiadas; antes que cualidades universales, similares en los distintos contextos, los términos humillantes se definen en función de las relaciones de fuerza entre los grupos interdependientes.

Palabras clave: Violencia, humillaciones, configuraciones educación secundaria argentina.

\section{Summary}

The paper presents results of a qualitative and exploratory study that analyse the relations of humiliation among high school students. In particular, reference is made to the attributes on which manifest these humiliations. Understanding that it is in the framework of specific configurations where the production of these forms of sociability is structured, the research analyzed, from a relational approach, two school groups of two public high schools. We carry out individual and group interviews to the students of those school groups. The results indicate that the attributes vary in the studied configurations. More than universal qualities, similar in different contexts, humiliating terms are defined depending of power relations established between the interdependent groups.

Keywords: Violence, humiliations, configurations argentine high school.

\section{Resumo}

O trabalho apresenta resultados de um estudo qualitativo de caráter exploratório sobre as relações de humilhação entre os alunos do ensino médio. Em particular, ele faz referência aos atributos em que estes modos de ligação é manifesto. Entendendo que é no quadro de configurações específicas em que a produção dessas formas de sociabilidade está estruturado, a pesquisa analisou a partir de uma abordagem relacional dois grupos escolares de dois escolas públicas secundárias. Foram realizadas entrevistas individuais e em grupo em profundidade aos alunos desses grupos escolares. Os resultados indicam que os atributos sobre os que se baseian as humilhação variam nas configurações estudadas. Mais que qualidades universais, semelhante em diferentes contextos, termos humilhantes são definidos em função de as relações de poder estabelecidas entre os grupos interdependentes.

Palavras chave: Violencia, humilhações, configurações educação secundária argentina. 


\section{Introducción}

El tema de las violencias en el ámbito escolar ha adquirido recientemente una gran relevancia en los medios de comunicación masiva. La espectacularización de ciertos episodios como el uso de armas, abusos sexuales o golpizas ha hecho de la escuela, especialmente de la escuela secundaria estatal, un escenario atravesado por la "violencia física" (Brener y Kaplan, 2006). Sin embargo, diversos trabajos dan cuenta de que son las violencias no físicas (insultos, burlas, apodos ofensivos, discriminaciones, humillaciones, etc.), las que determinan el llamado "clima de violencia" en las escuelas, y las que dan cuenta de manera más pertinente de las violencias cotidianas presentes en las interacciones sociales del sistema escolar (Debarbieux, 1996, 2001, 2002; Carra y Sicot, 1997; Charlot, 1997; Debarbieux, et al., 1999; Viscardi, 2003; Kornblit, 2008; Observatorio Argentino de Violencia en las Escuelas, 2008 y 2010; Kaplan 2009a; García, 2010).

Es en este sentido que se decidió abordar las humillaciones en el ámbito escolar, como un intento por visibilizar lo cotidiano sobre lo excepcional y dar cuenta de uno de los mayores problemas en la escuela. Este texto expone los resultados de una investigación más amplia que analizó las relaciones de humillación entre estudiantes de las escuelas secundarias estatales de la provincia de Buenos Aires (Argentina), para contribuir a la producción de argumentos teóricos, y con base empírica, sobre el problema, desde una perspectiva socioeducativa; particularmente interesa abordar una de las dimensiones trabajadas en la investigación: los atributos a los cuales se refieren las humillaciones; sosteniendo como hipótesis que los términos utilizados durante este tipo de vínculo no son universales, sino que adquieren especificidades y varían en las distintas configuraciones.

Distintos estudios han probado que las humillaciones son una problemática extendida en el ámbito escolar (Merlé, 2006; García, 2010; Suarez Pazos, 2004; D’Angelo y Fernández, 2011) y que constituyen modos de vincularse que inciden negativamente, no solo en las trayectorias y experiencias escolares de los estudiantes, sino en su vida social fuera de la escuela (Merlé, 2006, Kaplan, 2009b). Aunque este tipo de violencia tiene una fuerte presencia en las escuelas, tiende a pasar inadvertida por profesores y directivos (D’Angelo y Fernández, 2011). Así, las humillaciones en la escuela son, desde una perspectiva socioeducativa, un objeto de estudio escasamente abordado ${ }^{2} \mathrm{y}$, a pesar de que en ocasiones los

2 Incluso los trabajos que abordan esta temática se centran principalmente en las relaciones docente-alumnos, siendo insuficientes los estudios que den cuenta de cómo esta modalidad de interacción tiene lugar entre estudiantes. análisis sobre la violencia en la escuela se refieren al tema como una de las modalidades que le afectan, no la abordan como objeto de estudio específico (Debarbieux, 1996 y 2002; Gómez Nashiki, 1996; Charlot, 1997; Kaplan, 2009a; García, 2010).

A pesar de lo dicho, diversos trabajos analizan los motivos que llevan a los estudiantes a discriminar, humillar, hostigar o burlarse de sus pares (García, 2010; Observatorio Argentino de Violencia en las Escuelas, 2014). Esos análisis dan cuenta de las características por las cuales los alumnos son menospreciados por sus compañeros y, en este sentido, resultan un aporte significativo para comprender la problemática; sin embargo, como veremos más adelante, nuestro estudio indaga las características de las humillaciones, teniendo en cuenta los distintos contextos en los cuales se dan estas modalidades de relación, pues entendemos que dichas cualidades son relacionales y, por lo tanto, particulares de cada espacio social.

\section{Las relaciones de humillación en la escuela}

La humillación es una relación social entre una persona (o grupo) que trata a otra como inferior, y esa otra persona (o grupo) se siente agraviada (Kaplan, 2009b). Es un acto y un sentimiento. Humillar tiene su origen en la palabra bumus (tierra), se refiere a bajar, poner en el suelo o rebajar (Diez Mateo, s.f.) y expresa una práctica cultural subyacente de distinción. La humillación supone una diferencia de poder entre grupos interdependientes; un grupo tiene la capacidad de humillar a otro cuando tiene "recursos de poder" más fuertes y, como afirma Elias (2003), solo puede estigmatizar efectivamente si está bien instalado en posiciones de poder a las que el otro grupo tiene negado el acceso: "Es la condición decisiva de toda estigmatización efectiva de un grupo forastero por parte de un grupo establecido" (p. 224). Incluso si el grupo menos forastero dispone de un término estigmatizador para referirse al más poderoso (establecido), éste es inservible porque no causa daño a los miembros (Elias, 2003).

Los términos para estigmatizar otros grupos solo resultan significativos en un contexto de relaciones de poder específicas; su incidencia depende de la conciencia por parte del hablante y del receptor de que la humillación viene respaldada por un grupo poderoso y se dirige a un grupo receptor con recursos de poder más débiles (Elias, 2003). Así, aunque existen importantes cualidades 
desacreditadoras "en casi toda nuestra sociedad" (Goffman, 2006, p. 14), un atributo que estigmatiza a un sujeto puede confirmar la normalidad de otro y no es honroso ni ignominioso en sí mismo. Es posible que haya signos cuyo significado varíe de un grupo a otro, por lo que en realidad se necesita un lenguaje de relaciones, no de atributos.

La tendencia a discutir el problema de la estigmatización social como si se tratase solo de una cuestión de individuos que muestran un profundo rechazo hacia otros, implica percibir únicamente el nivel individual, algo que no puede ser comprendido sin considerar simultáneamente el nivel de grupo (Elias, 2003). La capacidad de un grupo de apuntalar la inferioridad humana del otro grupo, y de hacerla valer, es una función de una figuración específica que ambos grupos forman entre sí; por lo tanto su análisis requiere

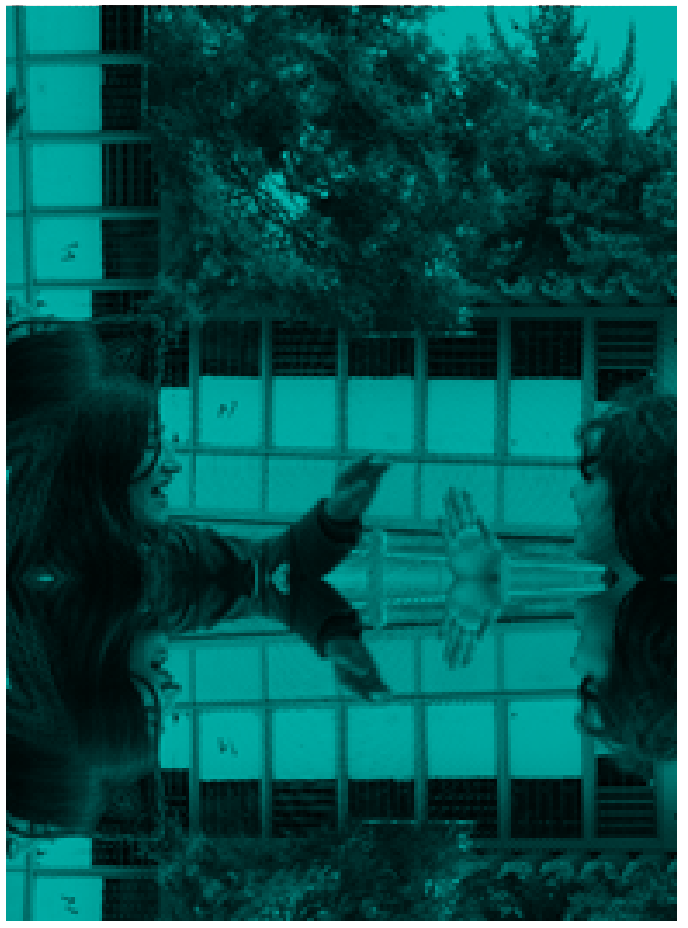

mañana) en dos escuelas estatales urbanas ${ }^{4}$, mixtas, de la provincia de Buenos Aires, que, como veremos, se diferencian entre ellos por los sectores socioeconómicos de pertenencia y las trayectorias educativas. La selección se realizó para analizar las humillaciones en contexto, como un intento de dar cuenta de las diferencias y recurrencias de sus sentidos y prácticas.

Para continuar, es necesario aclarar el término de configuración ${ }^{5}$, retomado de la obra de Elias (1970), quien lo entiende como un estado en el que intervienen grupos interdependientes de personas: los seres humanos están orientados unos con otros y unidos de las más diversas maneras, constituyendo "telas de interdependencia" (p. 15) o configuraciones de muchos tipos, como familias, escuelas, ciudades, estratos o estados ${ }^{6}$; de esa interdependencia se deriva un orden que, al tiempo que es relativamente autónomo frente al orden dominante, es más fuerte y más coactivo que la voluntad y la razón de los individuos aislados que lo constituyen (Elias, 1987). Gracias a su fundamental interdependencia los seres humanos se agrupan siempre en figuraciones específicas: dependen unos de otros y cumplen, unos para otros, unas funciones (Weiler, 1998).

Las acciones de una pluralidad de personas interdependientes se conectan para formar una estructura entretejida con ciertas propiedades, tales como cuotas de poder, ejes de tensión, sistemas de clase y estratificación, deportes, guerras y crisis económicas (Elias y Dunning, 1992). El equilibrio de poder constituye un elemento

naturaleza del problema de investigación llevó a realizar estudio exploratorio a partir de una estrategia de investigación cualitativa (Vasilachis de Gialdino, 2006), por considerar que dicha metodología se ajusta a nuestro interés por contribuir, a partir de datos empíricos, a la elaboración de un saber interpretativo sobre las relaciones de humillación de los estudiantes en el ámbito escolar. Mediante un muestreo intencional se seleccionaron dos grupos de estudiantes de dos cursos de segundo año de secundaria ${ }^{3}$ (turno

3 Los años de secundaria mencionados se refieren a los establecidos con la nueva Ley de Educación Nacional (Ley 26.206) sancionada en 2006. La provincia de Buenos Aires implementó una secundaria de 6 años.
4 Se seleccionaron colegios urbanos, ya que trabajos anteriores como los de Carra y Sicot (1997), Debarbieux, Dupuch y Montoya (1997), Waiselfisz (1998), o Kaplan (2006 y 2009b), advierten que el problema de las violencias en la escuela se encuentra especialmente ligado al ámbito urbano. configuración, figuración y composición se emplean para describir fenómenos semejantes, y este trabajo los utiliza como sinónimos.

6 En este sentido, Elias señala que dicho concepto puede ser aplicado a grupos relativamente pequeños y a sociedades de miles o millones de personas interdependientes.
5 En los escritos consultados en castellano, inglés y portugués los conceptos de 
integral de todas las relaciones humanas; por grandes o pequeñas que sean las diferencias de poder, este equilibrio siempre está presente donde quiera que haya una interdependencia funcional entre personas, el poder:

Es una característica estructural [...] de todas las relaciones humanas $[\ldots]$ Dependemos de otros; otros dependen de nosotros. En la medida en que dependamos de otros más de lo que ellos dependen de nosotros, tienen poder sobre nosotros, independientemente de que hayamos caído bajo su dependencia porque ellos emplearon la fuerza o por nuestra necesidad de ser amados, nuestra necesidad de dinero, consuelo, estatus, una carrera o, simplemente, de emoción (Elias y Dunning, 1992, p. 21).

La investigación tuvo como objetivo general comprender las relaciones de humillación entre estudiantes en la escuela secundaria desde su perspectiva. Interesaba, entre otras cuestiones, caracterizar y comparar las relaciones de humillación en configuraciones particulares que consideraron dimensiones como: prácticas, sentimientos y motivaciones ligadas a la humillación; los atributos o cualidades a los cuales se refieren; las respuestas de los estudiantes que son destinatarios y las intervenciones de escuela ante las humillaciones. Como se ha dicho, se dará cuenta de una de estas dimensiones: los atributos que se utilizan para humillar a los compañeros.

El trabajo de campo se desarrolló en 2011 y partió de una entrevista a las autoridades de las escuelas y de una consulta de su documentación (proyecto institucional), con el objetivo de conocer mejor a la institución y su población; luego se seleccionaron los dos grupos escolares, uno de cada escuela. La recolección de datos se hizo a través de entrevistas en profundidad, individuales y grupales, a los estudiantes de los grupos ${ }^{7}$ con una guía semi-estructurada ${ }^{8}$; además se realizaron observaciones participantes para ahondar en los relatos. Se entrevistó a "tres columnas" (Sirvent, 2003) un total de 51 estudiantes usando esta técnica porque permite "conocer la perspectiva del sujeto estudiado, comprender sus categorías mentales, sus interpretaciones, sus percepciones y sentimientos, los motivos de sus actos" (Corbetta, 2007, p. 344). Se quiso entender estas formas de violencia desde la voz de los estudiantes, teniendo en cuenta que sus percepciones están construidas socialmente y situadas socio-históricamente.

7 Las entrevistas eran optativas.

8 Los nombres de los estudiantes se han modificado para resguardar su anonimato.
Las técnicas de análisis de información empírica se dieron en función de las dimensiones establecidas en los objetivos; a partir de allí se fueron identificando las categorías cercanas a lo empírico y con ellas surgieron otras con mayor grado de abstracción. El programa Atlas.ti., fue empleado para estudiar los datos recogidos y la indagación se realizó en un ida y vuelta entre la teoría y lo empírico, buscando poner en tensión nuestras premisas teóricas y los datos del trabajo de campo.

\section{Configuraciones analizadas}

La primera configuración analizada fue un grupo escolar que llamamos 1, conformado por alumnos de un curso de segundo año de secundaria de una escuela estatal céntrica que, creada durante la década del 60, tiene como objetivo la inclusión de estudiantes con trayectorias educativas interrumpidas (abandono, repitencia) y con dificultades para respetar los marcos disciplinarios escolares. El grupo de 22 estudiantes, 13 varones y 9 mujeres, fue entrevistado en su totalidad; la mayoría de ellos pertenece a sectores socioeconómicos bajos y medios bajos y la repitencia atraviesa sus trayectorias educativas: 14 habían repetido al menos un año escolar ( 8 una vez, 4 dos veces, 1 tres veces y 1 cuatro veces) y el grupo era entendido por docentes, directivos, preceptores y los propios alumnos, como "difícil", con un bajo rendimiento académico y problemas de comportamiento y trato con las autoridades.

La segunda configuración (2) estuvo integrada por estudiantes de un curso de segundo año (turno mañana) de educación secundaria, pertenecientes a una escuela estatal céntrica y tradicional con casi 100 años de historia, una de las entidades más solicitadas y prestigiosas de la zona. Se entrevistaron 19 de los 36 alumnos del grupo, en su mayoría de clase media, 18 mujeres (se entrevistaron 15) y 18 varones (se entrevistaron 14); solo uno de los 29 educandos había repetido un año, y esta baja tasa de repitencia se asocia en cierta medida a la política institucional de que quienes repiten pierden su cupo en el turno de la mañana, pasando al turno de la tarde o siendo expulsados de la escuela. En palabras de un directivo: "En esta escuela... repetidores nunca quisieron". En cuanto al vínculo entre estudiantes y autoridades de la institución, los alumnos afirman que por lo general se comportan con respeto cuando se dirigen a ellas, en sus relatos incluso se advierte una especie de sumisión. 
Esta información permite concluir que los atributos implícitos en las humillaciones no son universales, sino que cada configuración presenta cualidades particulares por las cuales un sujeto humilla a otro. Desde nuestra perspectiva, y siguiendo a autores como Norbert Elias y Pierre Bourdieu ${ }^{13}$, consideramos que las percepciones y prácticas de los individuos están atravesadas por las condiciones objetivas en las que se sitúan. Los sujetos están marcados por circunstancias objetivas que funcionan a la vez como condiciones limitantes y como puntos de referencia para sus emociones y actuaciones. Las humillaciones también están atravesadas por las características de la configuración, por las interdependencias propias de cada grupo escolar, que dan lugar a valoraciones específicas. Así, aunque algunos atributos por los cuales los estudiantes son humillados coinciden en ambos grupos, no se puede afirmar que las cualidades sobre las que se asientan son similares en los distintos contextos.

La segunda cuestión a subrayar, estrechamente vinculada con lo anterior, es que los atributos que tienen presencia en uno u otro grupo se definen en función de las relaciones de fuerza. La sociodinámica de la relación (Elias, 2003), entre quienes humillan y los humillados, viene determinada por la forma de su vínculo, no por las características de los grupos afectados. Las cualidades por las cuales unos estudiantes o grupos de estudiantes humillan a otros, se definen en función de quiénes ocupan las posiciones dominantes y quiénes no en ese grupo escolar particular, o, en palabras de Elias (2003), en función de quiénes se encuentran bien instalados en posiciones de poder a las que el otro no tiene acceso.

En el grupo escolar 1 (clase baja y media baja) los entrevistados afirman que quienes ostentan posiciones dominantes se identifican, por un lado, con pertenecer a sectores sociales de bajos ingresos (vivir en villas y barrios populares, usar vestimenta asociada con lo humilde -gorrita, aros y ropa holgada-) y por el otro, con tener mala conducta y mal desempeño escolar. Los más respetados, o con posición de liderazgo, son asociados con tipologías que podríamos denominar "marginales", en el sentido de que se alejan de ciertas normas valoradas como positivas en la escuela, como tener buenas notas, respetar a docentes y directivos, tener buena posición económica, etc. Es el grupo de "los chicos de la ventana" o de los "quilomberos", que faltan el respeto a los profesores, golpean a sus pares, gritan, se pegan entre ellos y consumen drogas. Ellos

13 Las teorías de estos autores no se desarrollan en este escrito por una cuestión de espacio. asumen esta caracterización definiéndose como los "peores de la clase"; el líder es Leandro y es temido por algunos estudiantes.

E: ¿Por qué creés que Leandro es el líder?

Tatiana: Leandro pega dos gritos en el salón y se callan todos [...] la mayoría como lo ven así... él todo el tiempo está hablando de cosas, de que va a robar y todo eso, capaz le tienen miedo [...] Se piensa que el vivir en un barrio de negros, que vistiéndose así, que robar y todo eso, es ser mejor que los demás.

Son los estudiantes que se identifican con estos rasgos los que humillan a sus pares y los que no son humillados.

Los entrevistados también mencionaron que quienes ocupan posiciones menos legitimadas presentan o se identifican con cualidades opuestas a las de los más respetados, como "tener buena conducta"; "tener más plata"; "saber todo (el contenido escolar)"; "sacarse buenas notas". Estos alumnos son señalados por sus compañeros como los menos respetados o valorados del curso.

$\mathrm{E}:$ ¿Y quién sería el menos respetado del curso?

Marcos: Y... los que se portan bien, los que nunca molestan, nada. Damián: Acá a los que no estudian los valoran más.

La identificación con esas "características marginales" se debe en parte a que los jóvenes las vinculan con la posibilidad de generar miedo en el resto de compañeros. Puede pensarse que existe una estética y unas cualidades marginales asociadas a la taxonomía de joven violento, y que para ciertos estudiantes resultan prestigiosas. En un estudio anterior (Kaplan, Krotsch y Orce, 2012) se observan hallazgos que refuerzan la idea del estrecho vínculo entre atributos como vestirse con ropa deportiva o vivir en barrios humildes, y ser considerado violento en el discurso de los jóvenes.

Vivencias, estéticas y conductas que no son valores positivos hegemónicos de la sociedad, sino estimaciones prestigiosas para ciertos estudiantes, acentuadas por ellos en su práctica cotidiana: vestirse con gorrita, arito y ropa holgada emulando cierto estereotipo humilde; la realización de actividades delictivas; el consumo de drogas o vivir en barrios populares. Lo que se observó es que características que en nuestra sociedad se pueden considerar como "marginales" son asumidas como prácticas jerarquizantes por ciertos alumnos.

En consonancia con lo que plantea Bourgois (2010), muchos jóvenes eligen construir la marca de identidad sobre atributos que la sociedad desvaloriza: robo, delitos, consumo de drogas; lo que les permite subvertir el orden social aunque solo sea en su red de relaciones. Las relaciones de humillación establecidas por los estudiantes con sus compañeros podrían estar siendo utilizadas por algunos jóvenes como mecanismo de desafío y resistencia a los 
valores hegemónicos, tanto escolares (buen desempeño académico, respeto por las normas y autoridades), como sociales (pertenencia a sectores sociales y económicos acomodados).

En el grupo escolar 2 quienes ostentan las posiciones dominantes se identifican con características como tener una buena posición socioeconómica, altas calificaciones o saber el contenido escolar. El grupo más respetado, aquel que los entrevistados identifican como el "más popular", está constituido por alumnos de clase media con un buen desempeño escolar (la alumna más estudiosa y con mejores calificaciones del curso pertenece a este grupo).

Micaela: Es popular por tener cosas caras, de moda.

Claudia: Porque se viste bien se juntan con esa para ser más populares y porque una sea más humilde no se juntan.

Las características de quienes ostentan las posiciones dominantes y quienes no, de los que humillan y son humillados, varían en los dos grupos escolares analizados. En parte ello podría explicar las diferencias en cada configuración sobre las cualidades que sustentan las humillaciones.

\section{Conclusiones}

El análisis realizado es un importante punto de partida en el intento de dar cuenta de la manera en que los atributos que susten$\tan$ las humillaciones, antes que ser cualidades universales similares en los distintos contextos, están definidos por las particularidades de las configuraciones donde estas relaciones tienen lugar, por los recursos de poder de los grupos en cada configuración; por la diferencia de poder entre ellos (Elias, 2003). Las características de los humillados y de los que humillan se definen por la posición que ocupan en el marco de unas relaciones de poder determinadas.

Lo que nos interesa subrayar es que las características de las humillaciones, y de los lugares que los sujetos ocupan en esa relación social, están determinadas por los vínculos y relaciones de fuerza que se establecen entre los grupos, al interior de cada configuración, y no por las cualidades de los individuos con independencia de ellos. Las humillaciones deben ser comprendidas en su dimensión relacional; por lo tanto, se pierde de vista la clave del problema cuando se indaga exclusivamente en la estructura de personalidad de sujetos concretos.

Este enfoque disputa sentidos a aquellos estudios que abordan la temática de la violencia en la escuela desde una mirada individualizante y se concentran en el acosador y en la víctima (también en el grupo de alumnos o en sus familias), describiendo las características particulares (sobre todo los atributos psicológicos) que, por lo general, tienen quienes asumen estos roles, sin considerar el contexto que da lugar a estas interacciones. Así mismo, acarrea el peligro de focalizar las soluciones en los estudiantes involucrados, patologizándolos, y de desresponsabilizar a la escuela y a las mediaciones que realiza. 


\section{Referencias}

Bourgois, P. (2010). En busca de respeto: vendiendo crack en Harlem. Buenos Aires: Siglo XXI.

Brener, G., y Kaplan, C. (2006). Violencias, escuela y medios de comunicación. En Kaplan, C. (Dir.), Violencias en plural: Sociologia de las violencias en la escuela. Buenos Aires: Miño y Dávila, pp. 77-101.

Carra, C., y Sicot, F. (1997). Una autre perspective sur les violences scolaires: L'expérience de victimation. En Charlot, B., y Emin, J. (Coords.), Violences a l'ecole - etat des savoirs. París: Armand Colin Mason, pp. 61-82.

Charlot, B. (1997). Introduction. Violences scolaires: Représentations, pratiques et normes. En Charlot, B., y Emin, J. (Coords.), Violences a l'école: État des savoirs. París: Armand Colin, pp. 1-13.

Corbetta, P. (2007). Metodología y técnicas de la investigación social. Madrid: MacGrawHill.

D’Angelo, L., y Fernández, D. (2011). Clima, conflictos y violencia en la escuela. Buenos Aires: Fondo de las Naciones Unidas para la Infancia (UNICEF), Facultad Latinoamericana de Ciencias Sociales (FLACSO).

Debarbieux, E. (1996). La violence en milieu scolaire: I- État des lieux. París: ESF éditeur.

Debarbieux, E. (2001). A violência na escola francesa: 30 anos de construção social do objeto (1967-1997). Educação e Pesquisa (Brasil), Vol. XXVII, No. 1, pp. 163-193.

Debarbieux, E. (2002). Cientistas, políticos e violência: rumo a uma comunidade científica européia para lidar com a violência nas escolas? En Debarbieux, E., y Blaya, C. (Coords.), Violência nas escolas: Dez. abordagens européias. Brasília: Unesco, pp. 13-33.

Debarbieux, E., Dupuch, A., y Montoya, Y. (1997). Pour en finir avec le handicap socio-violent: une aproche comparative de la violence en milieu scolaire. En Charlot, B., y Emin, J. (Coords.), Violences à $\square$ école: État des savoirs. Paris: Armand Colin, pp. 17-40.

Debarbieux, E., Garnier, A., Montoya, Y., y Tichit, L. (1999). La violence en milieu scolaire: Le désordre des choses, Vol. 2. París: ESF éditeur.
Díez Mateo, F. (s.f.). Diccionario español etimológico del siglo XX. (S.C.): Academo.

Elias, N. (1970). Introdução à Sociologia. Lisboa: Edições 70.

Elias, N. (1987). El proceso de la civilización: Investigaciones sociogenéticas y psicogenéticas. Madrid: Fondo de Cultura Económica.

Elias, N. (2003). Ensayo acerca de las relaciones entre establecidos y forasteros. Reis. Revista española de investigaciones sociológicas (España), pp. 219-251.

Elias, N., y Dunning, E. (1992). Deporte y ocio en el proceso de la civilización. México: Fondo de Cultura Económica.

García, S. (2010). Violencias, incivilidades y miedos en el ámbito educativo: Un estudio socioeducativo sobre la perspectiva de los estudiantes de educación secundaria, Tesis de Maestría, Escuela de Educación, Universidad de San Andrés, Buenos Aires (Argentina).

Goffman, E. (2006). Estigma: La identidad deteriorada. Buenos Aires: Amorrortu.

Gómez Nashiki, A. (1996). La violencia en la escuela primaria. Tesis de Maestría en Sociología Política, Instituto de Investigaciones Dr. José María Luis Mora. (México).

Kaplan, C. (2006). Violencias en plural: Sociología de las violencias en la escuela. Buenos Aires: Miño y Dávila.

Kaplan, C. (2009a). Violencia escolar bajo sospecha. Buenos Aires: Miño y Dávila.

Kaplan, C. (2009b). La humillación como emoción en la experiencia escolar. En Kaplan, C., y Orce, V. (Coords.), Poder, prácticas sociales y proceso civilizador: Los usos de Norbert Elias. Buenos Aires: Novedades Educativas, pp.99-108.

Kaplan, C., Krotsch, L., y Orce, V. (2012). Con ojos de joven: Relaciones entre desigualdad, violencia y condición estudiantil. Buenos Aires: Editorial de la Facultad de Filosofía y Letras, Universidad de Buenos Aires. 
Kornblit, A. L. (2008). Violencia escolary climas sociales. Buenos Aires: Biblos.

Merlé, P. (2006). L'humiliation des élèves: une pratique anti-pédagogique. Éducation \& Management, (31), p. 32. Obtenido desde http://www.educrevues.fr $/ \mathrm{EM} /$ AffichageDoc ument.aspx?iddoc $=34382$

Observatorio Argentino de Violencia en las Escuelas. (2008). Violencia en las escuelas: Un relevamiento desde la mirada de los alumnos. Buenos Aires: Ministerio de Educación de la Nación.

Observatorio Argentino de Violencia en las Escuelas. (2010). La Violencia en las escuelas: Un relevamiento desde la mirada de los alumnos II. Buenos Aires: Ministerio de Educación de la Nación.

Observatorio Argentino de Violencia en las Escuelas. (2014). Relevamiento estadístico sobre clima escolar, violencia y conflicto en escuelas secundarias según la perspectiva de los alumnos. Buenos Aires: Ministerio de Educación de la Nación.
Sirvent, M. T. (2003). El Proceso de Investigación. Investigación y Estadística I. Buenos Aires: Oficina de Publicaciones de la Facultad de Filosofía y Letras (Opfyl).

Suárez Pazos, M. (2004). Los castigos y otras estrategias disciplinarias vistos a través de los recuerdos escolares. Revista de Educación, No. 335, pp. 429-443.

Vasilachis de Gialdino, I. (2006). La investigación cualitativa. Estrategias de investigación cualitativa. Barcelona: Gedisa, pp. 23-64.

Viscardi, N. (2003). Enfrentando la violencia en las escuelas: Un informe de Uruguay. En Werthein, J., Cecilia Braslavsky, C., Tedesco, J., Ouane, A., y Da Cunha, C. (Coords.), Violencia na escola: América Latina e Caribe. Brasília: UNESCO, pp. 153-205.

Waiselfisz, J. J. (1998). Juventude, violencia e cidadania: Os jovens de Brasilia. San Pablo: UNESCO, Cortez Editora.

Weiler, V. (1998). Figuraciones en proceso. Bogotá: Fundación Social. 



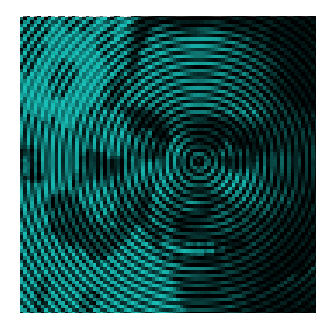




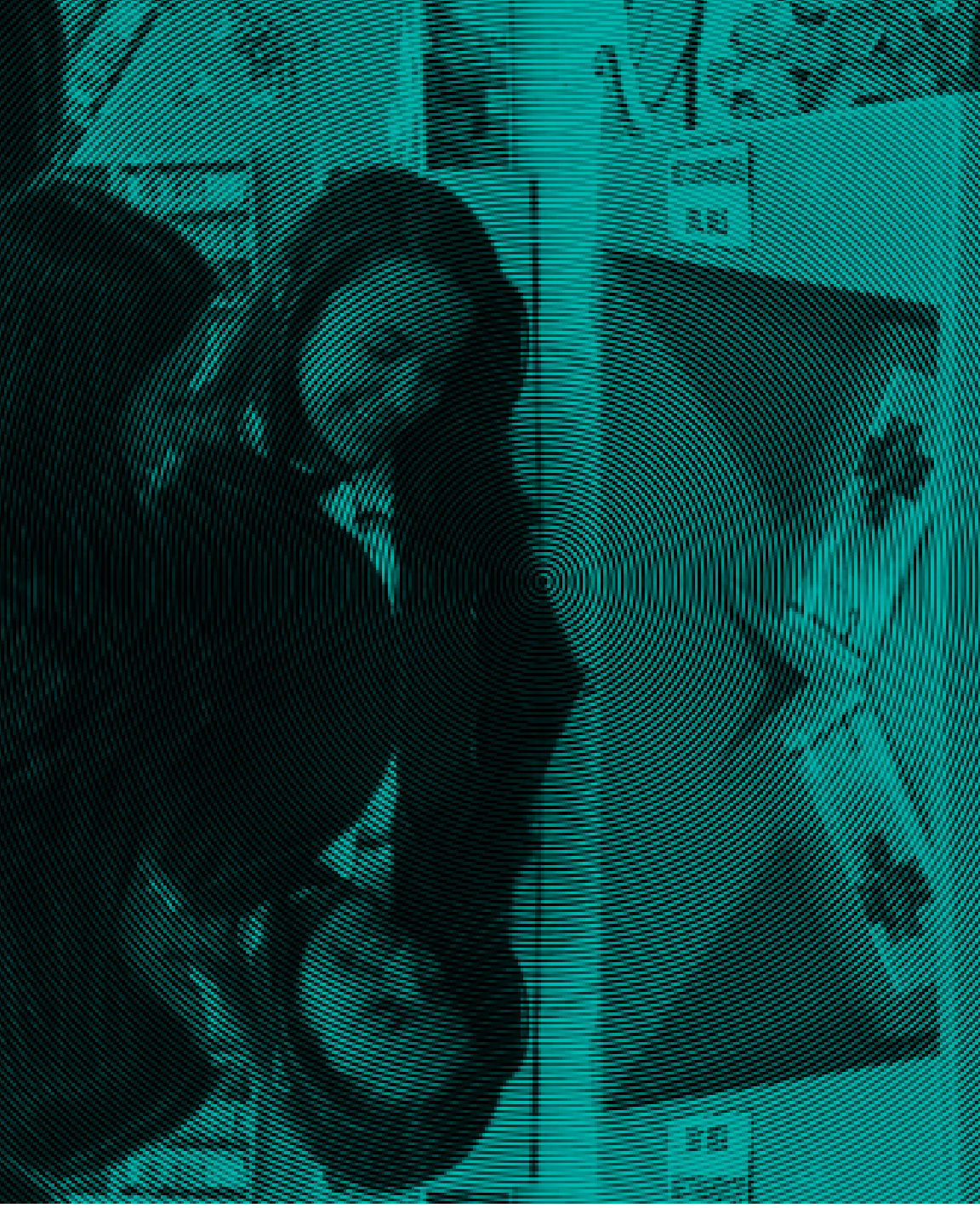

\section{Hacia una convivencia pacífica en la escuela: percepciones sobre violencia escolar y tramitación de conflictos}

Towards a Peaceful Coexistence in school: Perceptions of School Violence and Conflict Handling

Para a uma convivência pacífica na escola: Percepções da violência na escola e tramitação dos conflitos

Sindy Paola Díaz Better 
Sindy Paola Díaz Better 1
1. Colombiana. Magíster en Tecnologías de la Información aplicadas a la educación, Universidad Pedagógica Nacional (UPN). Cursando estudios en el Doctorado Interinstitucional en Educación (DIE) - Sede UPN, Bogotá. Docente de la Secretaría de Educación Distrital; correo electrónico: sp.better@gmail.com

Artículo de reflexión basado en investigación.

Fecha de recepciín: Febrero 26 de 2016 / Fecha de aceptación: 16 de septiembre de 2016

\section{Resumen}

Las reflexiones de este artículo provienen de un análisis de percepciones realizado por un grupo de docentes y estudiantes sobre las manifestaciones de violencia escolar y tramitación de conflictos en su institución educativa, problemática que sustenta la tesis presentada por la autora en el Doctorado Interinstitucional en Educación de la Universidad Pedagógica Nacional, Colombia; cuyo punto de partida fue la premisa de que para construir una convivencia pacífica en las escuelas se requiere fomentar relaciones de alteridad y respeto, legitimando las diversas miradas de sus actores sobre las situaciones que los afectan.

\section{Palabras clave: Alteridad,} convivencia pacífica, percepciones de docentes y estudiantes, tramitación de conflictos, violencia escolar.

\section{Summary}

The reflections presented in this article come from analysis of perceptions of a group of teachers and students about manifestations of school violence and conflict handling in their school, problems that supports the thesis of the author, directed by Dr. Luis Fernando Gomez in the Doctorate in Education (Universidad Pedagógica Nacional, Colombia); based on the premise that to build a peaceful coexistence in schools, it is required foster relationships of alterity and respect, legitimizing the diverse views of the school actors about situations that affect them.

\section{Keywords: Alterity, peaceful} coexistence, perceptions of teachers and students, handling conflicts, school violence.

\section{Resumo}

As reflexões apresentadas neste artigo vêm da análise das percepções de um grupo de professores e estudantes sobre as manifestações da violência escolar e a transação dos conflitos na instituição educativa, questões que apóiam a Tese da autora, dirigida pelo Dr. Luis Fernando Gomez no Doutorado Interinstitucional em Educação (Universidade Pedagógica Nacional, Colômbia); com base na premissa que para construir uma convivência pacífica nas escolas, é necessário fomentar relações de alteridade e respeito, legitimando os diferentes olhares de seus atores sobre as situações que os afetam.

Palavras chave: Alteridade, convivência pacífica, percepções dos profesores e estudantes, tramitação dos conflitos, violência escolar. 


\section{Introducción}

$\mathrm{Al}$ hablar de violencia en las escuelas ${ }^{2}$ encontramos una situación generalizada que requiere de miradas contextualizadas para comprenderla y emprender acciones que puedan mitigarla o evitarla. Aunque exista una presencia permanente de los padres de familia y roles de dirección; son los docentes y los estudiantes quienes continuamente se encuentran de frente con manifestaciones que atentan contra la convivencia escolar, por lo que sus percepciones sobre las situaciones de conflicto son fundamentales.

Los programas de intervención y estrategias de manejo de conflictos están dirigidos principalmente a estudiantes, pero, ¿se toman en cuenta sus percepciones?, ¿`on comunes las percepciones de docentes y estudiantes frente a las situaciones de violencia escolar que se presentan?, ¿qué estrategias identifican unos y otros?, ¿qué se puede inferir a partir de estas estrategias?, estos y otros interrogantes motivan las reflexiones de este texto. Siguiendo a Mockus y Corzo (2003):

La convivencia se puede caracterizar [...] por una combinación de una alta capacidad reguladora de ley, moral y cultura sobre los individuos, con la capacidad de los propios individuos de celebrar y cumplir acuerdos. Esta combinación produce confianza y se fortalece con ella (p. 14).

Llevando este panorama a la escuela, la convivencia es lo que permite que muchos individuos aprendan en la cotidianidad; sin embargo, los entornos escolares se perciben a veces como espacios homogéneos antes que diversos, al no tener en cuenta que, como sujeto, cada estudiante posee cualidades, capacidades e intereses que lo hacen único; lo que en ciertos casos puede favorecer la aparición de situaciones de conflicto.

Aunque es uno de los pilares de la formación en Bogotá (Colombia), en los últimos años la convivencia pacífica de algunos de sus colegios se ha visto afectada por episodios de violencia que perturban el normal transcurrir de las actividades académicas, hechos expuestos en el informe Clima escolar y victimización en Bogotá 2013 (Ávila, Bromberg, Pérez y Villamil, 2014), un estudio sobre condiciones de seguridad y convivencia para los niños, niñas y jóvenes en los colegios y su entorno; donde se discuten además los

2 En este documento se emplean los términos institución educativa, colegio o escuela indistintamente, para referirse a entidades de carácter público (estatal) o privado, cuya finalidad sea la educación (primaria, secundaria y/o media) de niños, niñas o adolescentes. resultados y aprendizajes de dos encuestas anteriores, realizadas en 2006 y $2011^{3}$.

Entre sus hallazgos, Ávila, et al. (2013) mencionan el empleo de insultos, maltrato verbal y un trato impersonal y de carácter soez entre estudiantes (especialmente en los grados inferiores, pp. 215219), y el maltrato físico intencional (reflejado en golpes, cachetadas, empujones o pellizcos), en porcentajes similares al uso de insultos que causan daño, independientemente de si el colegio es público o privado (pp. 227-232). Estos indicadores también se han hecho presentes en una institución educativa distrital de la Localidad Rafael Uribe Uribe, a través de eventos relacionados con conflictos interpersonales que escalaron en violencia, involucrando incluso el uso de armas blancas como medio de intimidación y agresión.

Frente a esta situación, y con el objetivo de formular una Tesis Doctoral $^{4}$, se realizó un estudio diagnóstico entre los meses de noviembre de 2013 y agosto de 2014, atendiendo al interrogante ¿Qué manifestaciones y situaciones atentan contra la convivencia escolar en esta institución?, para lo cual se acudió a distintas fuentes: Actas de Comisión y Promoción de estudiantes (año 2013); libros observadores de estudiantes (de tres niveles); entrevista a docentes y encuesta a estudiantes de grado sexto.

Las reflexiones que este artículo presenta se desarrollaron a partir del análisis comparativo de las respuestas de los docentes y estudiantes participantes, con el objetivo de dilucidar similitudes y diferencias en sus percepciones de la violencia escolar, las formas de tramitación de conflictos y las estrategias que proponen frente a este fenómeno; lo cual es necesario y pertinente para establecer un panorama general desde sus miradas, y así proponer una reflexión pedagógica sobre la importancia de valorar los puntos de vista de los otros en la construcción de una convivencia pacífica.

3 Entre los resultados se destaca la existencia de hurtos sin violencia, la presencia de manifestaciones de maltrato emocional, acoso escolar, acoso sexual verbal, porte de armas dentro del colegio y consumo de alcohol y drogas ilícitas (Ávila, et al, 2013, pp. 25, 30, 38).

4 Investigación que pretende aportar al campo de estudio de la convivencia escolar desde una perspectiva propositiva; analizando los imaginarios sobre convivencia en el contexto escolar para desarrollar una intervención pedagógica que emplea el lenguaje literario como mediador en la convivencia pacífica. Es dirigida por el Dr. Luis Fernando Gómez Rodríguez (lfgomez@pedagogica. edu.co). 


\section{Apreciaciones sobre la violencia escolar}

En palabras de Camargo (1996), en la escuela se generan espacios de intolerancia, discriminación, exclusión y marginación, dando lugar a brotes de violencia o a espacios propicios para que se manifieste. Frente a esta situación, se deben implementar estrategias que deben ser desarrolladas a partir del conocimiento de la realidad del contexto de una institución educativa. Por su parte, Castro (2010) indica que la reflexión sobre la violencia escolar implica algunas consideraciones como las posibles raíces violentas de la comunidad próxima a la escuela; también señala que no se deben minimizar los episodios de violencia ni juzgarlos como sucesos aislados o accidentales.

Así, propiciar un reconocimiento de las percepciones y prácticas relacionadas con violencia escolar daría indicios sobre los caminos posibles de acción. Así, Henry (2000), luego de analizar algunos de estos aspectos, propone una definición integrada en la que declara que:

La violencia escolar es el ejercicio de poder sobre otros en los entornos escolares, por alguna persona, organismo o proceso social ${ }^{5}$, que niega a aquellos sujetos para que su humanidad pueda hacer diferencia, ya sea reduciéndolos por lo que son, o mediante la limitación de que se conviertan en lo que podrían ser (p. 21).

Esta definición amplía el espectro de la violencia escolar al involucrar otros actores e identificar entornos que también son permeados por las acciones que se llevan a cabo en la escuela. Por ejemplo, gracias a las tecnologías de la información y la comunicación, estamos interconectados a través de múltiples medios, por lo que manifestaciones de índole simbólico como la humillación, también son difundidas a través de ellos.

Para García, Guerrero y Ortiz (2012), la violencia escolar es una de las manifestaciones de otros tipos de violencia del entorno que incluyen conductas como abuso, trasgresión, intimidación, represión, maltrato o humillación, y que muchas veces pasan desapercibidos en diferentes contextos. Estudios internacionales como los de Martínez y Pérez (2005), Arellano (2007), y Powell y Ladd (2010), coinciden en que a veces los brotes de violencia en los colegios son reflejo de procesos y conductas violentas que viven los estudiantes en su entorno.

5 Henry sostiene que al hablar de violencia escolar por lo general se centra la atención en actores como estudiantes y docentes, sin embargo, se han evidenciado relaciones violentas de directivos hacia docentes y estudiantes.
Por otra parte, como mencionan González, Villalobos y Lauretti (2009), se ha hecho énfasis en la necesidad de atender tempranamente expresiones y conductas agresivas, para evitar perturbar a gran escala la convivencia pacífica, esto porque pueden afectar el clima social, que es uno de los factores que puede incidir en los resultados positivos en la educación de los estudiantes (Allodi, 2010) ${ }^{6}$. Teniendo en cuenta estos y otros aportes teóricos, este trabajo asume la violencia escolar como todas las relaciones de violencia cuyo propósito es maltratar, desde el lenguaje o la acción, a cualquier miembro de una comunidad educativa, y que son evidenciadas por prácticas y expresiones en escenarios presenciales o virtuales.

\section{El conflicto escolar y su tramitación}

El conflicto es una situación donde las partes involucradas perciben la existencia de necesidades, intereses, propósitos u objetivos diferentes y a veces incompatibles (Arellano, 2007); esto lleva a que sus pretensiones, deseos e intereses no puedan lograrse simultáneamente, generándose manifestaciones de diversa índole e intensidad. El contexto escolar es un escenario propicio para que se manifiesten conflictos, ya que se establecen distintos tipos de relaciones sociales mediadas por afectos y sentimientos. Lo que debe verse entonces no es la invisibilidad de esas situaciones, sino la manera como se atienden; es decir, cómo lograr que los alumnos puedan expresar sus necesidades personales sin caer en actitudes que les lastimen a sí mismos o a los otros. Tal como señalan Johnson y Johnson (1999): "lo que determina que los conflictos sean constructivos o destructivos no es su existencia, sino el modo en que se los maneja" (p. 29).

En este sentido, interesa el término tramitación, dado que muchas situaciones de conflicto no llegan a resolverse totalmente, por lo que es primordial comprenderlas y tratar de que cambien a estados donde los efectos negativos para los implicados sean mínimos; haciendo la salvedad de que al no lograrse pueden escalar y manifestarse violentamente. El sentido del conflicto como algo que no debe existir en el medio escolar ha sido superado por la

6 En este estudio se analiza la relación entre el clima social que se vive en ambientes educativos, y los resultados positivos en la educación de los estudiantes; manifestando que el sentirse seguro en las escuelas puede disminuir los casos de violencia que se presentan al interior de las mismas. 
idea de un componente inherente a la convivencia, por lo que es necesario que los actores involucrados en el proceso educativo lo utilicen de una forma constructiva.

Los conflictos son muy importantes para el desarrollo psicosocial, por lo que pueden dejar efectos positivos y negativos a largo plazo (Dincyurek y Civelek, 2008). No se trata de evitarlos, sino de favorecer, desde los contextos escolares, el conocimiento y uso de herramientas para un manejo adecuado de los mismos, que permita a quienes intervienen en ellos, tramitarlos de forma no violenta. En Colombia, frente a la necesidad de legislar respecto de la violencia escolar, se promulgó la Ley 1620 del 15 de marzo de $2013^{7}$, que determina lineamientos generales para tratar casos que afectan la convivencia al interior de la instituciones educativas, estableciendo, entre otros medios, La Ruta de Atención Integral para la Convivencia escolar, en la que aparece la mediación y la negociación para aquellas situaciones conflictivas donde no haya daño a la salud física o mental de los involucrados.

$\mathrm{Al}$ ser las instituciones educativas escenarios formativos, se requiere entender el conflicto como una oportunidad de construcción de relaciones que promueven la democracia, por lo que

7 Por medio de la cual se crea el Sistema Nacional de Convivencia Escolar y formación para el ejercicio de los derechos humanos, la educación para la sexualidad y la prevención y mitigación de la violencia escolar. el desarrollo de cualquier plan de acción en favor de la convivencia pacífica, debe demostrar coherencia entre los supuestos teóricos que lo sustenten y las actividades que se propongan, enmarcados siempre en las características particulares inherentes a cada comunidad educativa, por lo que es pertinente reconocer cómo se percibe la tramitación de los conflictos al interior de la misma.

\section{Metodología}

Este trabajo indagó acerca de las percepciones sobre violencia escolar de estudiantes y docentes de un colegio de Bogotá (Colombia), sus manifestaciones más comunes en la institución, la forma de tratar conflictos y las estrategias que proponen para el manejo de este fenómeno; hace parte del diagnóstico realizado con recursos propios entre noviembre de 2013 y agosto de 2014, con el objetivo de aportar a la formulación de una Tesis Doctoral que, en una de sus fases, contempla una intervención pedagógica para la mejora de la convivencia escolar. Se buscó caracterizar y analizar el panorama de violencia escolar desde la mirada de docentes y estudiantes de una institución educativa urbana de carácter público, nivel de secundaria, donde la investigadora viene trabajando desde 2009.

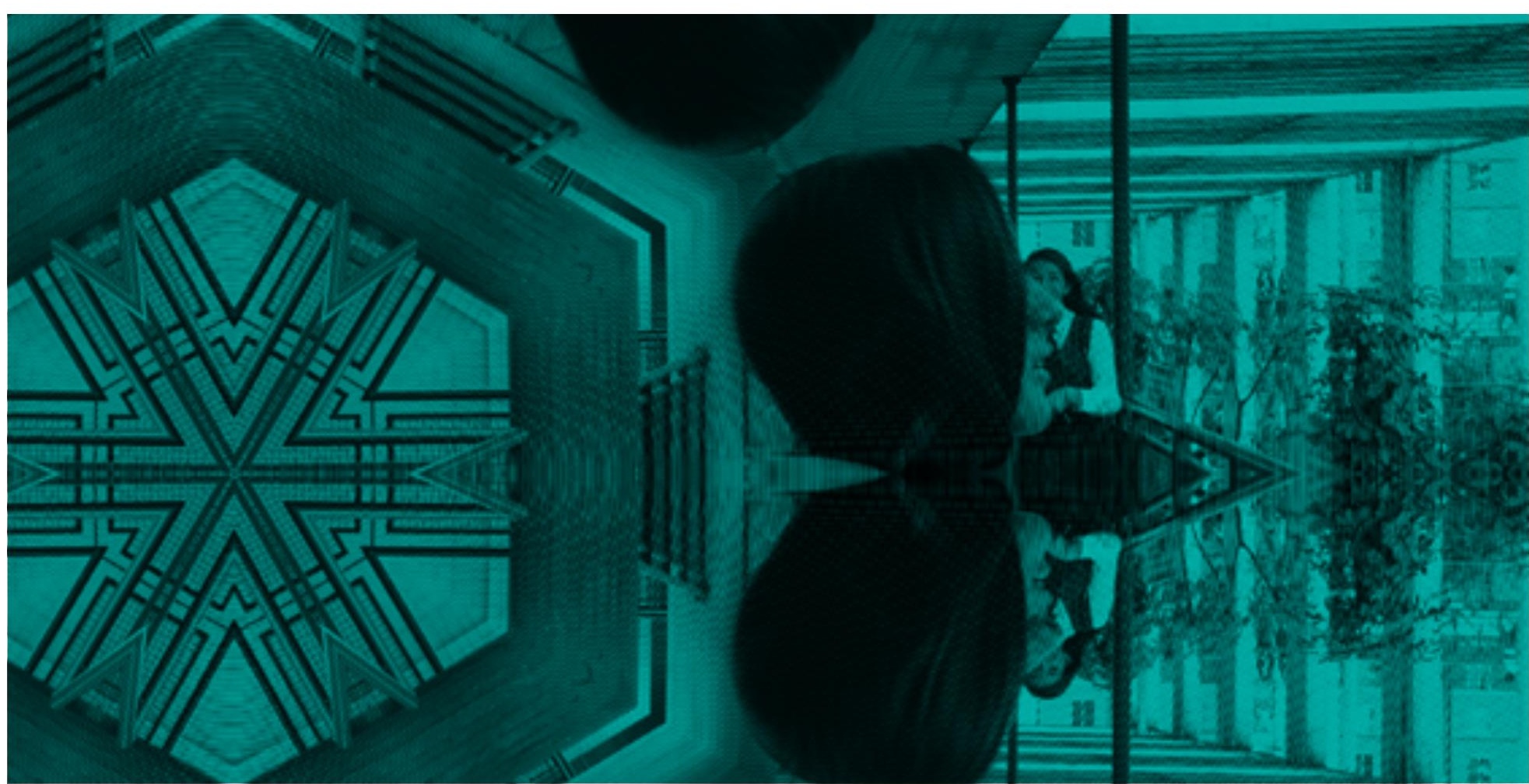


Para este artículo de reflexión se analizaron los datos de las entrevistas $^{8}$ a 21 docentes de la jornada mañana, y de las encuestas aplicadas a 99 estudiantes de cuatro cursos en el grado sexto, para establecer puntos comunes y diferencias en la manera como perciben las situaciones relacionadas con violencia escolar y el tratamiento de conflictos en su institución; el análisis se complementó con notas de campo a partir de la observación directa. Se elaboraron tablas y gráficos como apoyo al análisis y presentación de los hallazgos, tomando las muestras de manera proporcional ${ }^{9}$, y se acudió a respuestas literales de los participantes. La participación fue voluntaria y se mantiene absoluta reserva de los datos recogidos. Los resultados encontrados fueron socializados.

\section{Análisis de resultados}

En cuanto a la caracterización de los docentes, el 48\% de los entrevistados fueron hombres (diez), y el 52\% mujeres (once). Para 2013, laboraban cuarenta docentes y cuatro directivos docentes en la jornada de la mañana del colegio donde se llevó a cabo el diagnóstico; dieciocho docentes $(86 \%$ de la muestra) y tres directivos (el coordinador de convivencia, el rector y la orientadora) fueron entrevistados, preguntando por el año de ingreso a la entidad, pues se considera que este dato es relevante porque permite inferir qué tanto reconocen las problemáticas del lugar. Se observó la presencia de dos grupos mayoritarios de docentes: los que están desde el período de 1985-1995 y los que han llegado desde $2006^{10}$.

La encuesta fue aplicada a 99 estudiantes de grado sexto (60 niños y 39 niñas), cuyas edades oscilaban entre los 10 y 14 años. El $66 \%$ cursaba sexto por primera vez y el $30 \%$ lo hacía por segunda o tercera vez; un 3\% no informó sobre este ítem. Al preguntar a los participantes si habían sido testigos de manifestaciones de violencia escolar en algún escenario (salón de clases, lugares externos al colegio) y momentos de la jornada académica (descansos, cambios de clase), sus respuestas muestran porcentajes similares en los ítems de salón de clases y descansos (entre el 44\% y el 47\%); situación que cambia en los otros escenarios y momentos; pues los docentes perciben que hay mayores expresiones de violencia en los cambios de clase (62\%), lo cual podría explicarse

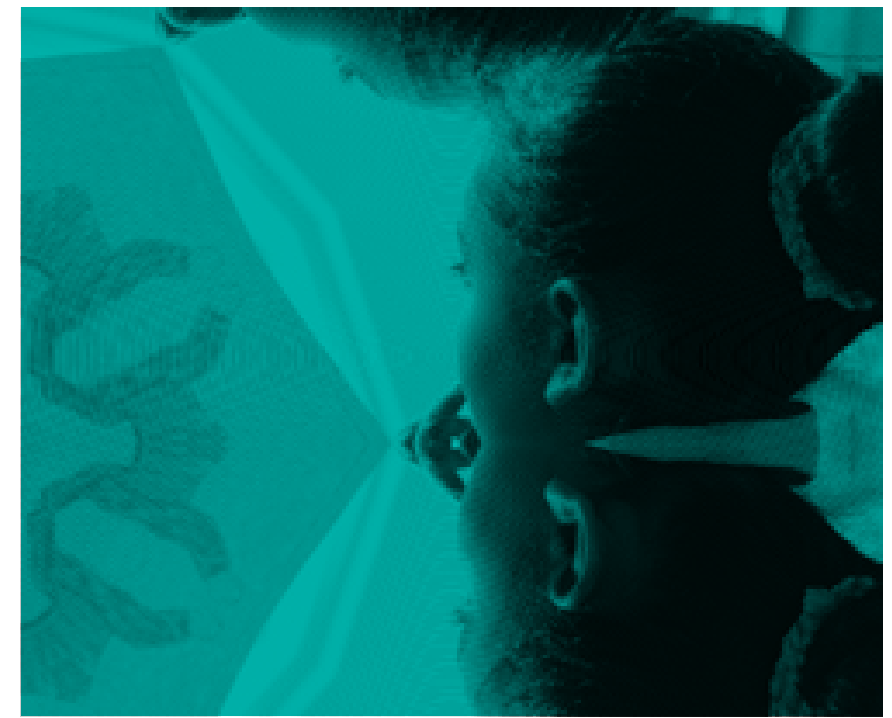

por el hecho de que ellos se movilizan más al culminar una clase, mientras que los estudiantes por lo general permanecen en sus salones (Gráfico 1).

Los participantes coinciden en declarar haber sido testigos de manifestaciones de violencia escolar por fuera de la institución, siendo más alta la percepción de los docentes (81\%), quienes además comentaron que hay estudiantes que se citan a las afueras del colegio para tramitar los conflictos a través de riñas. Estos resultados reflejaron la presencia de expresiones de violencia escolar en varios momentos y escenarios, lo que constituye un hecho preocupante por cuanto se idealiza la escuela como escenario pacífico y armónico, donde el interés primordial de los que allí asisten es llevar a cabo procesos de aprendizaje y convivencia solidaria. El siguiente gráfico presenta el contraste de las respuestas.

8 Las entrevistas a los docentes constaron de 5 preguntas abiertas y, con base en los hallazgos, se desarrolló una encuesta de siete preguntas (dos de ellas abiertas) que fue aplicada a los estudiantes.

9 En el caso de los profesores, se dividió el número de respuestas de cada ítem, entre 21; y las de los estudiantes entre 99.

10 El decreto de creación del Colegio es del año 1977. 


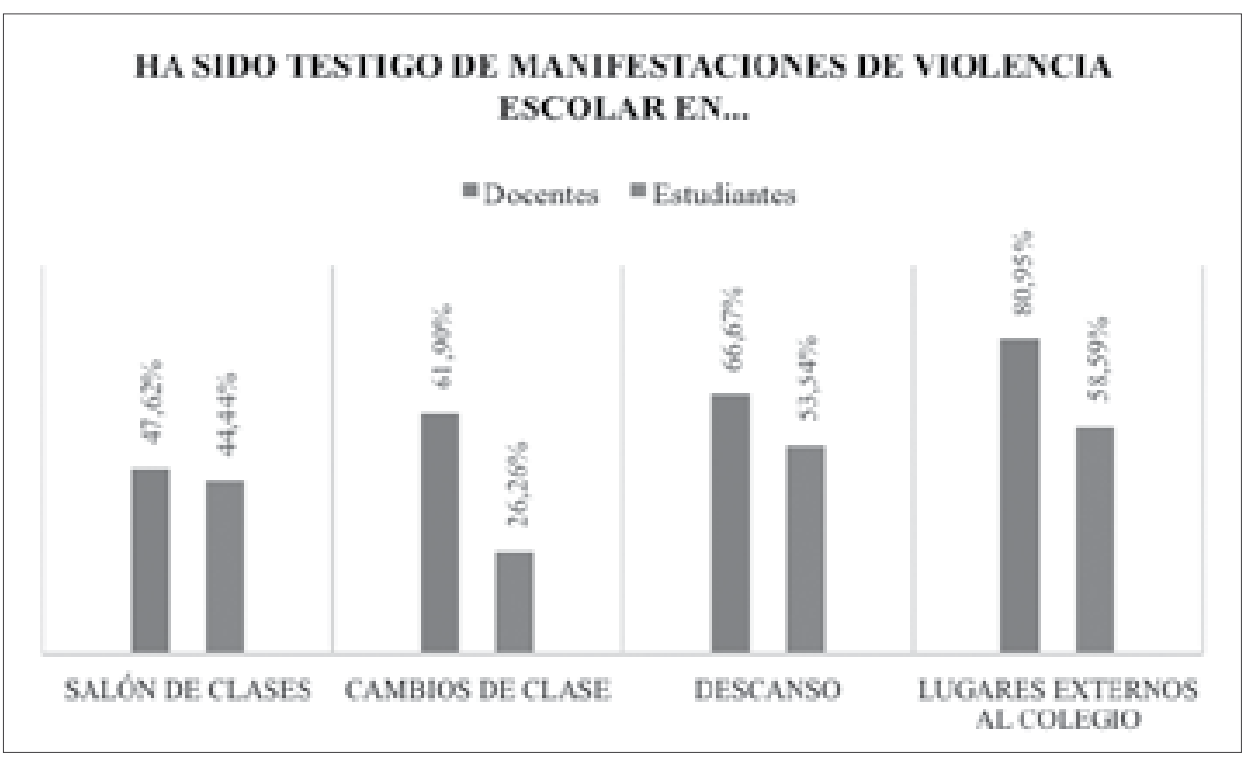

Fuente: Elaboración propia a partir de los hallazgos

Los participantes atribuyen a distintos problemas las manifestaciones de violencia escolar, siendo los porcentajes bastante dispares al realizar una comparación. Los docentes señalaron como principal problemática la falta de tolerancia $(57 \%)$, mientras que

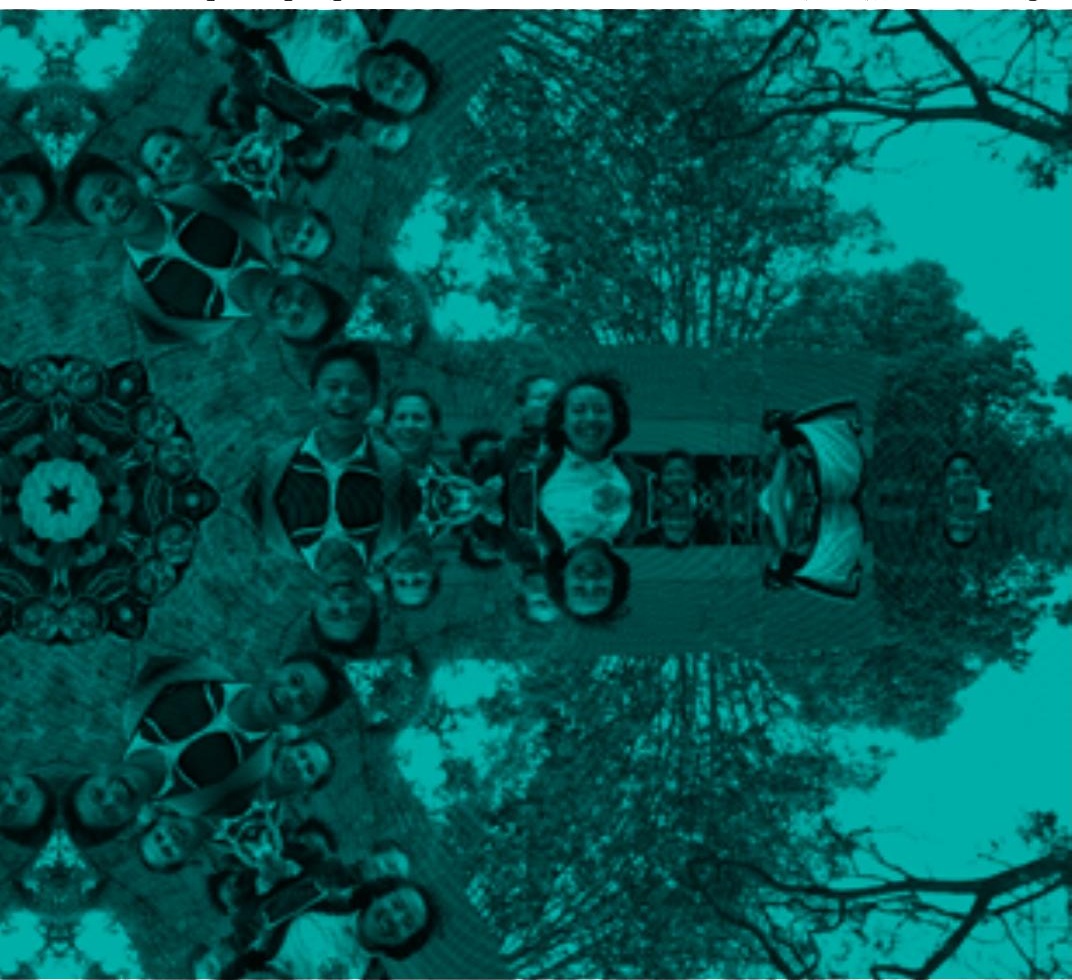

los estudiantes mencionaron el consumo de sustancias psicoactivas (SPA) y el matoneo (ambas con el 59,6\%), los malos entendidos $(49 \%)$ y el mal manejo de la ira. También aparecieron respuestas únicas en cada grupo: los docentes afirmaron que las peleas y la falta de control/autoridad institucional están relacionadas con esas expresiones; mientras que los estudiantes las vincularon con la presencia de barras bravas en la institución (Gráfico 2).

Las respuestas permiten ver que las miradas frente a la violencia escolar dependen del rol que se desempeñe en una institución educativa, por lo que al momento de generar estrategias contextualizadas para abordar eficazmente estas situaciones, se debe tener presente este hecho, valorando los puntos de vista de los actores implicados. Para los estudiantes, por ejemplo, el mal manejo de la ira fue la problemática más asociada a los brotes de violencia, alcanzando un $41 \%$, mientras que para los docentes fue de solo 9\%. Que los estudiantes den tal alta valoración expone la necesidad de trabajar aspectos relacionados con el autocontrol, estrategias de comunicación asertiva y de empatía, para reforzar positivamente la manera como los estudiantes reaccionan frente a un conflicto, claro está, desde un enfoque práctico y reflexivo. 


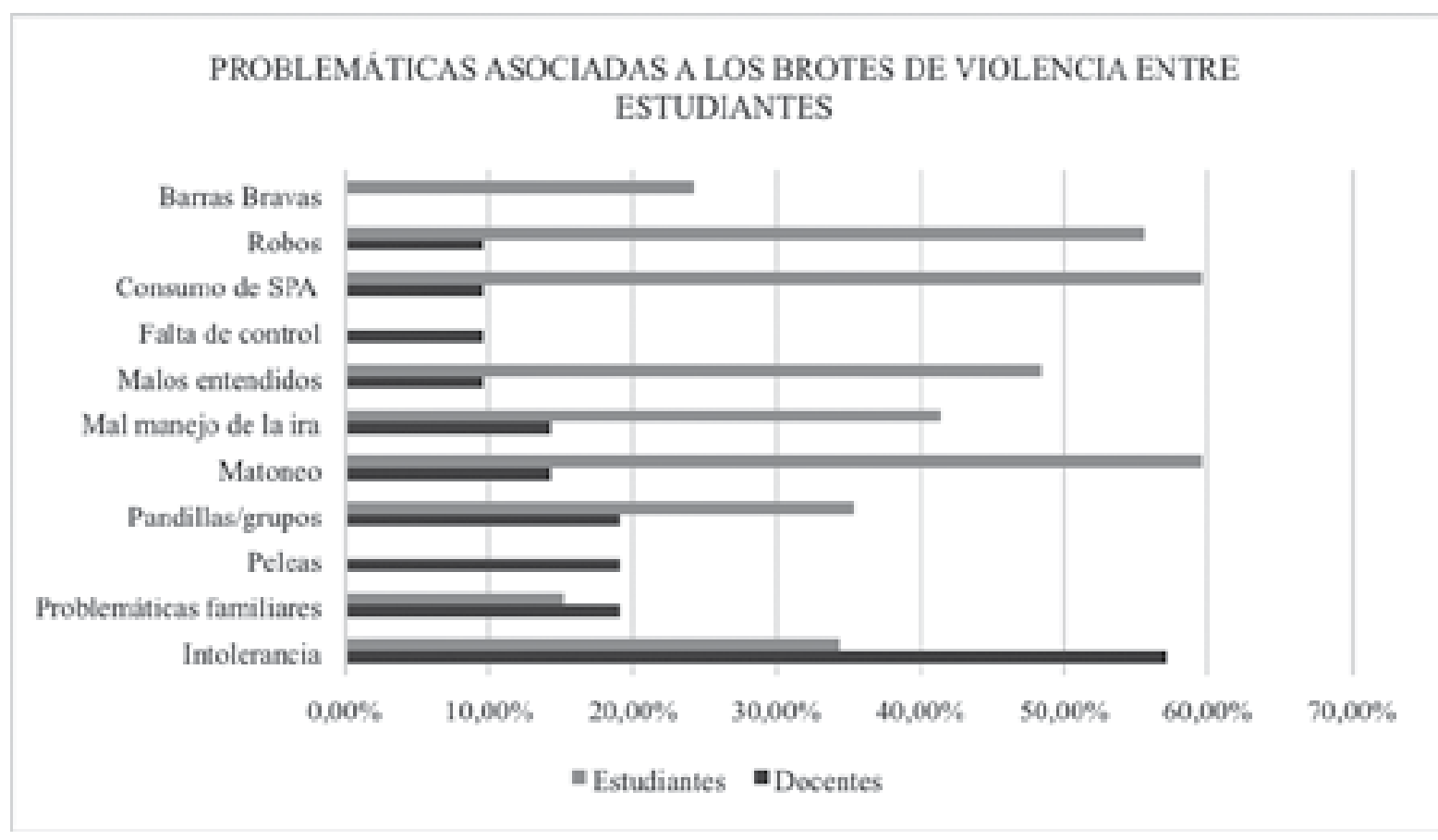

Fuente: Elaboración propia a partir de los hallazgos

Los docentes indican que los conflictos se resuelven con el uso de golpes y violencia física (81\%); mientras que para los estudiantes es más evidente la existencia de acuerdos (52\%) y la confrontación verbal $(39 \%)$. Es necesario considerar que los docentes trabajan con varios niveles, en este caso, los estudiantes de grado sexto no coinciden con su percepción de que los golpes o la violencia física son la manera más frecuente de tramitación. Los diálogos con mediación alcanzaron un porcentaje muy similar (19\%) para docentes y estudiantes, lo cual permite inferir que aunque no son la primera opción, son tenidos en cuenta por algunos estudiantes y esto se podría reforzar. Se percibe el uso de estrategias pacíficas de resolución, pero éstas requieren de la mediación de un tercero. Nuevamente las respuestas revelan diferencias importantes en las percepciones de los participantes (Gráfico 3). 


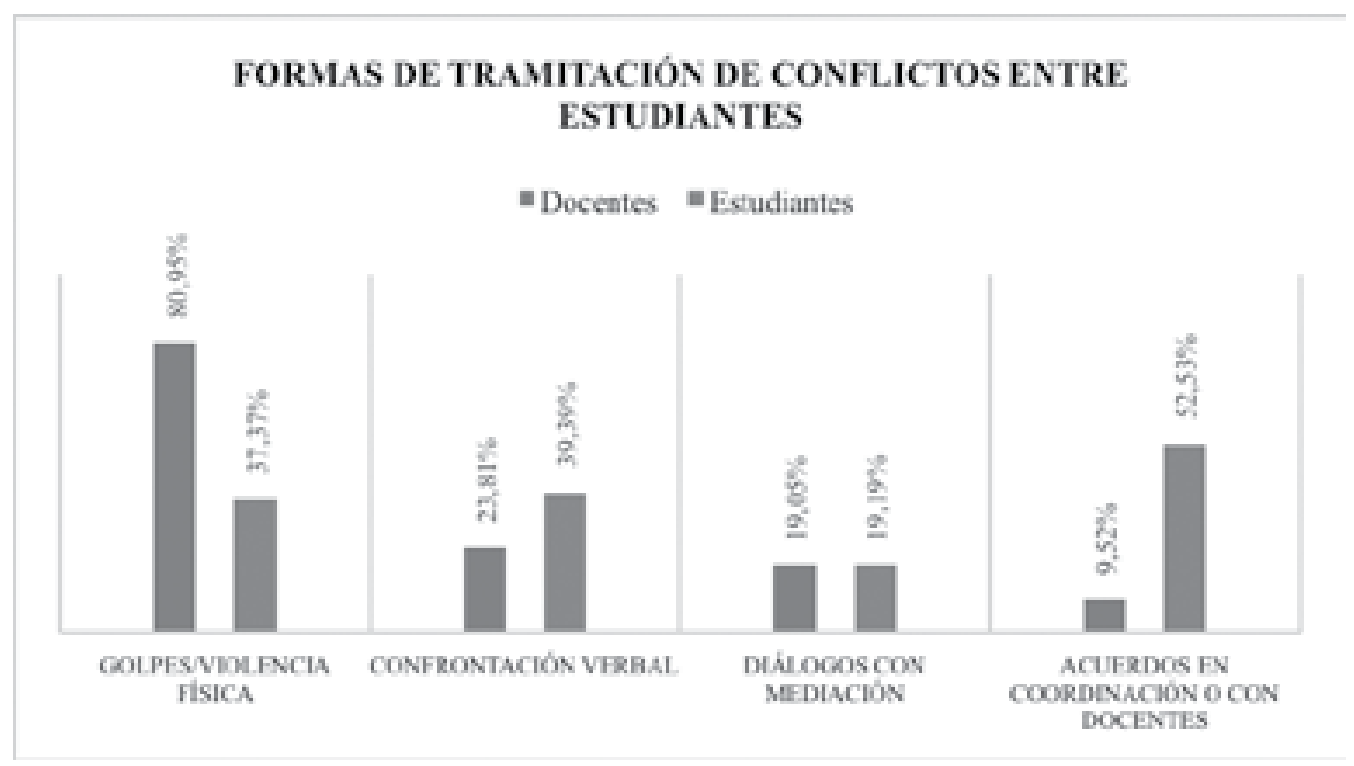

Fuente: Elaboración propia a partir de los hallazgos

$\mathrm{Al}$ preguntar por posibles estrategias para transformar esta situación al interior de la escuela, la mayoría de los docentes refirió estrategias como motivar la reflexión a través de talleres con padres y estudiantes (48\%); el trabajo con valores como el respeto, la tolerancia y la autoestima (24\%); la formación espiritual y la conformación de comités de mediadores en conflictos (29\%). Otras estrategias señaladas fueron la aplicación del manual de convivencia, la remisión a instancias internas ${ }^{11}$ o externas ${ }^{12}$ y la promoción de actos de justicia. Muy pocos se refirieron a sancionar o transformar las relaciones de poder evidentes en la estructura escolar.
El panorama es bastante diferente con los estudiantes, pues su opinión coincide muy poco con las estrategias pacíficas y pedagógicas señaladas por los docentes (entre el 3\% y 15\%); sus opciones se inclinaron especialmente por la expulsión o sanción (14\%), acciones que promuevan la vigilancia (30\%); y un constante acompañamiento de docentes $(20 \%)$, incluso hubo respuestas que sugerían "no hacer nada" (3\%). Un solo estudiante hizo énfasis en la posibilidad de un acto de reconciliación (Tabla 1).

11 Como por ejemplo Orientación escolar o Coordinación de Convivencia.

12 Instituto Colombiano de Bienestar Familiar, comisarías, centros de orientación juvenil e incluso la Policía. 
Tabla 1. Comparación de algunas estrategias de docentes y estudiantes frente a la violencia escolar

\begin{tabular}{|c|c|}
\hline Estrategias sugeridas por docentes & Estrategias sugeridas por estudiantes \\
\hline $\begin{array}{l}\text { - "Conformación de equipos conciliadores o mediadores } \\
\text { en cada ciclo educativo" (Directivo docente, género } \\
\text { femenino, labora desde 1989) } \\
\text { "Hacer tomar conciencia de la importancia de dialogar } \\
\text { y conciliar; aplicar la ley de convivencia" (Docente, } \\
\text { género femenino, labora desde 2007) } \\
\text { "Democratización de la escuela, cambiar las relaciones } \\
\text { de poder" (Docente, género masculino, labora desde } \\
2009, \text { ciclo cinco) } \\
\text { " "Educar primero a los padres" (Docente, género } \\
\text { femenino, labora desde 1991, ciclo tres) } \\
\text { - Sanciones que valgan la pena; más que una } \\
\text { estrategia pedagógica, se necesita que el estudiante } \\
\text { entienda que todo acto, positivo o negativo, tiene } \\
\text { consecuencias" (Docente, género femenino, labora } \\
\text { desde 2009, ciclo cuatro) }\end{array}$ & $\begin{array}{l}\text { - "Para disminuir la violencia escolar, que ayan } \\
\text { campeonato de bokseo para que toda la rabia contenida } \\
\text { y sacarla en el rin" (género femenino, } 14 \text { años, primera } \\
\text { vez en sexto) (sic). } \\
\text { - "No aseptar niños que en su observador se encuentren } \\
\text { aspectos muy malos, en otras palabras, que no asepten } \\
\text { a cualquier niño" (género masculino, } 11 \text { años, primera } \\
\text { vez en sexto) (sic) } \\
\text { "Que se hicieran campañas de la violencia y les } \\
\text { enseñaran a ser tolerantes, y más atención de los } \\
\text { profesores y la coordinadora" (género femenino, } 14 \\
\text { años, segunda vez en sexto) (sic) } \\
\text { "Más vigilamiento, más restricción, más celadores o } \\
\text { más cámaras para tener vigilado a los estudiantes" } \\
\text { (género masculino, } 12 \text { años, primera vez en sexto) } \\
\text { "Me gustaría más atención de los profesores hacia } \\
\text { los estudiantes para evitar más conflictos" (género } \\
\text { femenino, } 14 \text { años, tercera vez en sexto) (sic) }\end{array}$ \\
\hline
\end{tabular}

Fuente: Elaboración propia a partir de los hallazgos

Las estrategias planteadas por los docentes no contemplan intervenciones desde el interior de las áreas del plan de estudios, lo que permite concluir que entienden el problema de la violencia como un factor externo; sus estrategias estuvieron orientadas a acciones propias de los estudiantes, pero prevén muy poco la posible influencia del contexto social y de las relaciones interpersonales entre docentes y estudiantes. Solo un docente se refirió a "democratizar la escuela", hecho que tácitamente evidencia que las relaciones de poder pueden ser generadoras de violencia, tal como lo señalaba el IIDH (2011).

Llama la atención la solicitud reiterada de los estudiantes por una mayor vigilancia de sus docentes como medio efectivo para prevenir conflictos. Esto respalda las premisas de suponer el conflicto como hecho mediado por actos de otros; de no interiorizar y asumir el rol que pueden jugar, tanto en la aparición de esas manifestaciones violentas, como en su prevención y manejo. El siguiente gráfico expone una comparación de los hallazgos. 


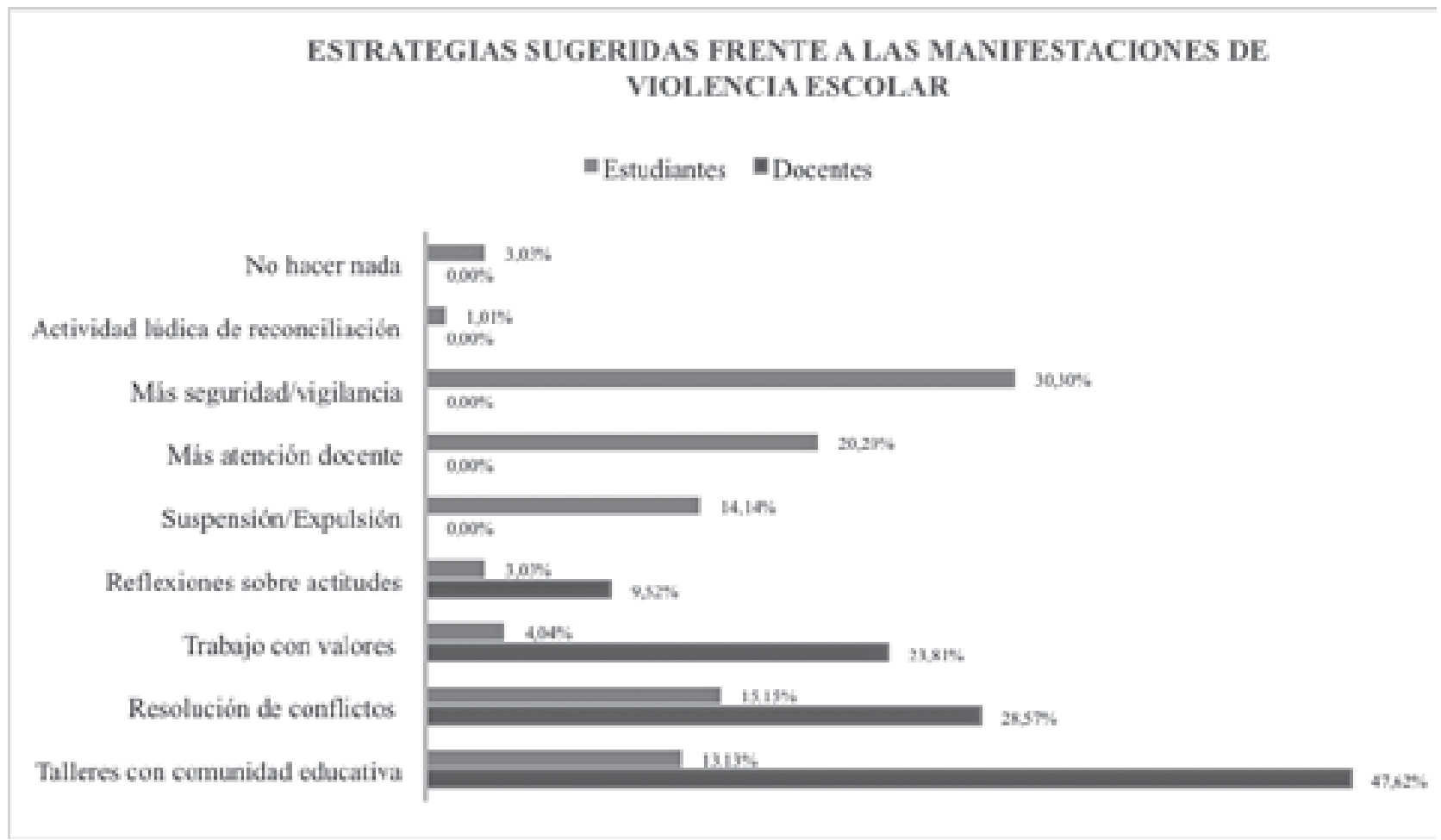

Fuente: Elaboración propia a partir de los hallazgos

\section{Hacia una convivencia pacífica en la escuela}

En las estrategias propuestas se destaca que los docentes asignan gran responsabilidad a las actitudes de los estudiantes y a la necesidad de apoyo de su familia. Al tiempo, fue usual la solicitud de los estudiantes de un otro que regule su conducta, que les vigile, acompañe y actúe tal vez como agente represor; lo cual permite cuestionar la manera en que se están acostumbrando a la intervención externa, antes de optar por una postura autónoma que desestime las expresiones de violencia.

Antes de trazar cualquier plan de intervención, es necesario comprender las expresiones que atentan contra una convivencia pacífica en la escuela, como las relacionadas con la violencia escolar, fenómeno complejo que implica agresiones físicas y simbólicas, y que puede tener consecuencias como el deterioro de las relaciones interpersonales, la pérdida del sentido de identidad con el proyecto de la escuela y la proliferación de antivalores que promueven el "todo vale", al no darle legitimidad al otro en el convivir; lo que genera, en últimas, un clima escolar no favorable para el aprendizaje.

Gracias al auge tecnológico de la sociedad actual, tenemos acceso a un volumen importante de información en distintos formatos; lo que hace indispensable reflexionar sobre una transformación de la escuela donde, tan importante como las actividades académicas, sea el enfocarse en la construcción de relaciones sociales desde la empatía, la solidaridad, el respeto y la tolerancia. Al respecto, Soliá y Graterol (2013) afirman que:

Hoy día el problema no es el conocimiento, ya que éste se encuentra a disposición de la ciudadanía mundial. La situación problemática que se debe resolver es el desarrollo de capacidades, valores y destrezas imprescindibles para convivir sanamente (p. 405). 
Por su parte, Maturana y Vignolo (2001) sostienen que la convivencia de los niños se da de acuerdo con los modelos y conductas que ven en los adultos. Esto pone de manifiesto que se requiere formar ciudadanos que abandonen conductas y prácticas que propician la violencia y vulneración de derechos; hecho que puede y debe ser fomentado en la familia, pero también en la escuela. Otro elemento fundamental es la percepción del conflicto y las formas de manejarlo. En este sentido, es preciso señalar que si no se logran acuerdos favorables a ambas partes cuando aparece un conflicto, se pueden dar actos de vulneración de derechos y de violación de la dignidad humana. Una percepción equivocada o insuficiente sobre el conflicto escolar promueve un manejo ineficaz del mismo, lo cual puede suscitar conductas contraproducentes para la convivencia pacífica.

En los resultados se evidenció que los estudiantes utilizan pocas herramientas que permitan manejar los conflictos de manera asertiva, lo que hace necesario educar bajo enfoques por el respeto a la diversidad y para favorecer escenarios de negociación y mediación. Además, es imprescindible que las estrategias para hacer frente a las problemáticas que atentan contra la convivencia pacífica en nuestras escuelas, no estén orientadas solamente hacia los estudiantes, sino que involucren también a docentes, padres y directivos; pues todos deben estar en capacidad de abordarlas de una manera asertiva.

En el caso particular de los docentes, es importante comprender que son a la vez objeto y sujeto de observación. Como sujetos, prestan atención y concretan acciones (no solo académicas) frente a sus estudiantes, y como objetos de observación, son examinados constantemente por los demás actores, por lo que su proceder puede influir en la manera como se reacciona frente a situaciones específicas de conflicto.

El deseo de imponer genera relaciones de poder; el deseo de compartir genera relaciones dialógicas [...] las relaciones dialógicas se basan en la comunicación que lleva a todos los sujetos implicados a compartir una acción, acuerdo, sentimiento o deseo (Soler y Flecha, 2010, p. 369).

La apuesta por una convivencia pacífica debe partir de este supuesto, sin dejar de lado que se deben tomar posturas críticas y reflexivas frente a las circunstancias que la afectan; tal como señala García (2012) al sugerir que aunque los docentes deben ser gestores de espacios de encuentro y diálogo frente a situaciones de conflicto, también deben conocer y evaluar aquellos elementos de la cultura escolar que potencian comportamientos agresivos en la escuela.
Ahora bien, el propósito de este trabajo no fue identificar quién está o no en lo correcto, sino contrastar las percepciones de docentes y estudiantes frente a una problemática como la violencia escolar, lo que adquiere relevancia por cuanto la convivencia pacífica debe ser manejada como un proyecto conjunto en construcción permanente, que para ello requiere la legitimación de las miradas de sus actores.

Además, es oportuno resaltar que la escuela no influye directamente en las situaciones de la vida cotidiana que rebasan su campo de acción, por lo que no se deben escatimar esfuerzos para propiciar, desde todos sus frentes, una trasformación positiva de la manera como se manejan los conflictos, motivando el reconocimiento y legitimización del otro como una vía necesaria para el encuentro, lo que posibilitaría, en términos de Maturana (2002), las relaciones sociales. Para Pérez (2001), las relaciones pacíficas no serán posibles

Si persisten la competencia desleal; el irrespeto; la intolerancia; la deslegitimación de lo diverso; la despreocupación por el bienestar ajeno; el deseo de borrar la alteridad. Acciones todas que deben replantearse desde la educación, ya que su tarea consiste en facilitar el desarrollo de las personas como seres humanos que se respetan a sí mismos y a los otros con consciencia social y ecológica, de modo que puedan actuar con responsabilidad y libertad en la comunidad a la que pertenecen (p. 83).

Ortega (2013) apunta a lo mismo cuando reflexiona que no puede haber educación sin relaciones de alteridad, por lo que se debe procurar que éstas no sean de dominio-imposición o de indiferencia, sino de respeto y reconocimiento del otro. Lograr una convivencia pacífica en la escuela, y en la sociedad, es posible si se trabaja por el exilio de prototipos que etiquetan y hieren; promoviendo una cultura donde se comprenda que los seres humanos merecen ser tratados con dignidad. No hay fórmulas, pero sí factores comunes: no es posible convivir pacíficamente si hay desprecio por el otro; si se irrespetan y desconocen sus maneras particulares de ver la vida, aunque no se compartan; si se opta por el egoísmo y el uso de violencia de cualquier tipo, lo cual incluye la permisividad e indiferencia frente a su utilización. 


\section{Referencias}

Allodi, M. (2010). Goals and values in school: a model developed for describing, evaluating and changing the social climate of learning environments. Soc Psychol Educ, pp. 207-235.

Arellano, N. (2007). La violencia escolar y la prevención de conflicto. Orbis/Ciencias Humanas. Año 3. No 7, pp. 23-45. Obtenido el 10 de Julio de 2014, desde http://www.redalyc.org/articulo.oa?id=70930703

Ávila, A., Bromberg, P., Pérez, B., y Villamil, M. (2014). Clima escolary victimización en Bogotá, 2013. Encuesta de convivencia escolar. Bogotá: Imprenta Nacional de Colombia. pp. 25, 30, 38, 215-219, 227-232.

Camargo, M. (1996). Violencia escolar y violencia social. Trabajo presentado en el Quinto Congreso Nacional de Prevención y Atención del Maltrato Infantil, noviembre, Bogotá. Obtenido en Octubre de 2013, desde http://www.acosomoral.org/pdf/rce34_03ensa.pdf

Castro, A. (2010). Desencontrándonos. Cuando no se educa para estar bien con los demás. Revista Internacional Magisterio, No. 44, pp. 10-15.

Congreso de la República de Colombia. (2013). Ley 1620 del 15 de maržo. Bogotá. Obteido en Noviembre de 2013, desde http://wsp.presidencia.gov.co/Normativa/Leyes/ Documents/2013/LEY\%201620\%20 DEL\%2015\%20DE\%20MARZO\%20DE\%202013.pdf

Dincyurek, S., y Civelek, A. (2008). The determination of the conflict resolution. Strategies of university students that they use when they have conflicts with people. Behavior Analyst Today, 9 (3-4), pp. 215-233. Obtenido en Septiembre de 2014, desde http:/ / files.eric.ed.gov / fulltext/EJ862245.pdf

García, B. (2012). Violencia y educación. Bogotá: Universidad Distrital Francisco José de Caldas.

García, B., Guerrero, J., y Ortiz, B. (2012). La violencia escolar en Bogotá desde la mirada de las familias. Doctorado Interinstitucional en Educación. No. 3. Serie Grupos. Bogotá: Universidad Distrital Francisco José de Caldas.

González, J., Villalobos, E., y Lauretti, P. (2009). Manejo y resolución de conflictos escolares. Revista Mexicana de Orientación Educativa - Remo,
VI(17), pp. 43-52. Obtenido en Octubre de 2014, desde http:/ /www. remo.ws/REVISTAS/remo-17.pdf

Henry, S. (2000). What is school violence? An Integrated Definition. Annals of the American Academy of Political and Social Science, No. 567, pp. 16-29. Obtenido en Marzo de 2015, desde http://www.jstor.org/ stable/1049491

IIDH. (2011). X Informe Interamericano de la Educación en Derechos Humanos. Desarrollo en las politicas de convivencia y seguridad escolar con enfoque de derechos. Instituto Interamericano de Derechos Humanos. San José, Costa Rica: Segura Hermanos S.A. Obtenido el 14 de Abril de 2015, desde http:/ / www.iidh.ed.cr/multic/UserFiles/Biblioteca/IIDH/9_2012/6860.pdf

Johnson, D., y Johnson, R. (1999). Cómo reducir la violencia en las escuelas. Buenos Aires: Paidós Educador, p. 29

Martínez, V., y Pérez, O. (2005). Conflictividad escolar y fomento de la convivencia. Revista Iberoamericana de Educación, No. 38. Obtenido en Octubre de 2014, desde http://rieoei.org/rie38a02.htm

Maturana, H. (2002). Emociones y lenguaje en educación y política. España: Dolmen.

Maturana, H., y Vignolo, C. (2001). Conversando sobre Educación. Perspectivas- Departamento de Ingeniería Industrial, Universidad de Chile, 4 (2), pp. 249-266. Obtenido en Noviembre de 2014, desde http://www.dii.uchile.cl/ revista/ArticulosVol4-N2/249-266\%2005-H.pdf

Mockus, A., y Corzo, J. (2003). Cumplir para convivir. Factores de convivencia y tipos de jóvenes por su relación con normas y acuerdos. Bogotá: Universidad Nacional de Colombia-Instituto de estudios políticos y relaciones internacionales. Unibiblos, p. 14.

Noguera, P. (1995). Preventing and producing violence: A critical analysis of responses to school violence. Harvard Educational Review, 65(2), pp. 189-212. Obtenido desde http://dx.doi.org/10.17763/ haer.65.2.e4615g5374044q28

Ortega, P. (2013). La pedagogía de la alteridad como paradigma de la educación intercultural. Revista Española de Pedagogía, LXXI (256), pp. 
401-422. Obtenido en Noviembre de 2014, desde https:/ / dialnet.unirioja.es/servlet/articulo?codigo $=4391820$

Pérez, T. (2001). Convivencia solidaria y democrática. Nuevos paradigmas y estrategias pedagógicas para su construcción. Bogotá: Fotolito América, p. 83.

Powell, M., y Ladd, L. (2010). Bullying: A review of the literature and implications for family therapists. The American Journal of Family Therapy (38), pp. 189-206.
Soler, M., y Flecha, R. (2010). Desde los actos de habla de Austin, a los actos comunicativos. Perspectivas desde Searle, Habermas y CREA. Revista Signos, 43(2), pp. 363-375. Obtenido en Septiembre de 2015, desde http://dx.doi.org/10.4067/S0718-09342010000400007

Soliá, R., y Graterol, N. (2013). La alteridad como puente para la trascendencia ética. TELOS. Revista de Estudios Interdisciplinarios en Ciencias Sociales Universidad Rafael Belloso Chacin, 15(3), pp. 400-413. Obtenido en Noviembre de 2014, desde http://www.redalyc.org/pdf/993/99328424008.pdf 



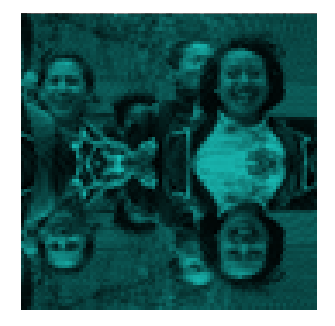




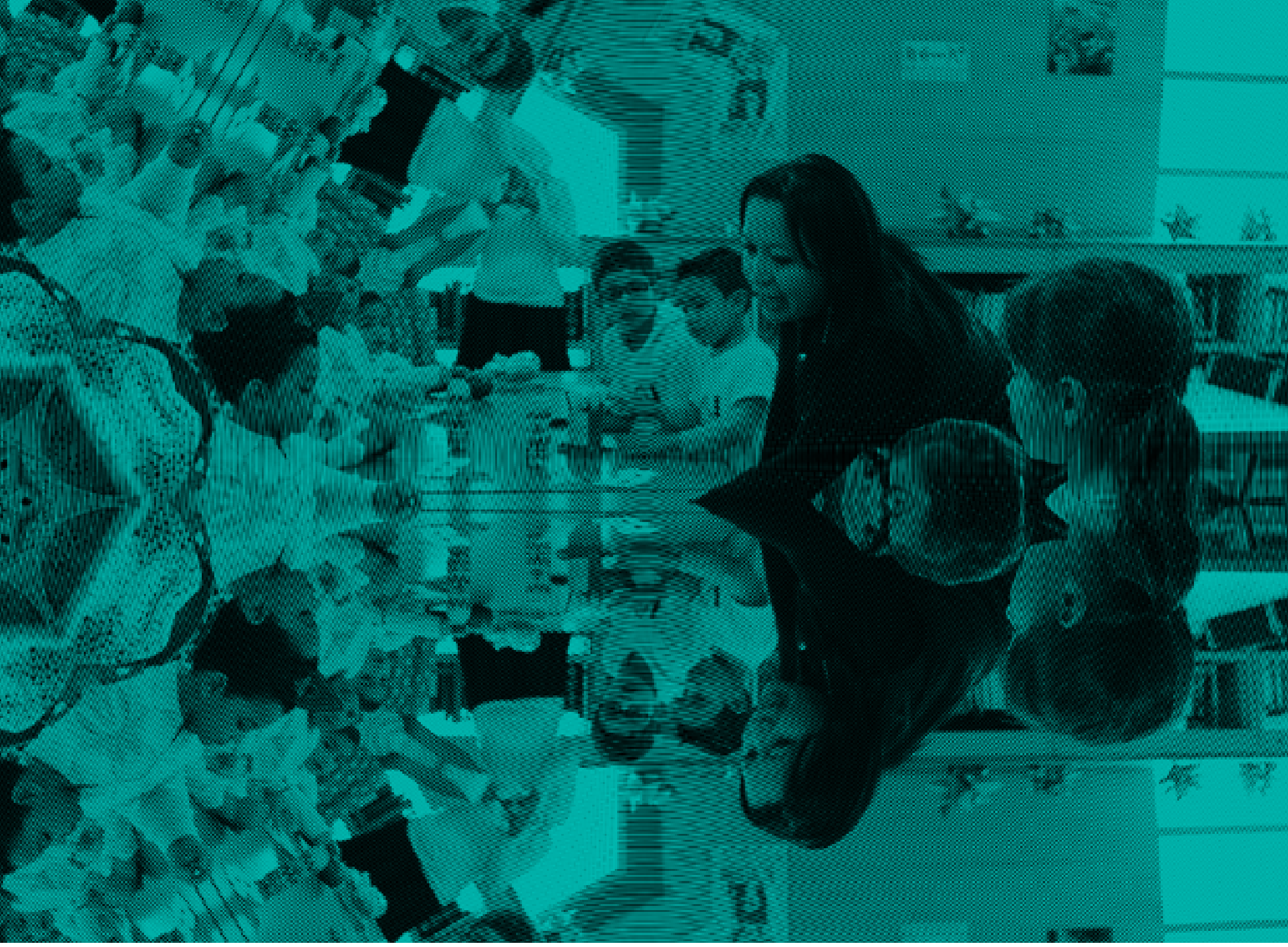

\section{La convivencia escolar, un camino hacia la cultura de la paz}

School of Life, a path to peace culture

Escola da Vida, um caminho para a cultura de paz

Esther Lucía Malagón Buitrago María Elizabeth Mateus Gómez Sonia Elena Gómez Carrillo 


\section{Esther Lucía Malagón Buitrago 1}

María Elizabeth Mateus Gómez 2

Sonia Elena Gómez Carrillo 3
1. Especialista en Gerencia de Proyectos Educativos UCC; Especialista en Educación y Gestión Ambiental. Ingeniera Forestal, Universidad Distrital Francisco José de Caldas. Docente IEM Guillermo Quevedo Zornoza, área Técnica; correo electrónico: galuben13@yahoo.com

2. Especialista en Gerencia de Proyectos educativos UCC. Licenciada en Dibujo Técnico UPN; Docente IEM. Técnico Industrial Zipaquirá, área de Tecnología e informática; correo electrónico: elmagovar26@hotmail.com

3. Especialista en Gerencia de Proyectos educativos UCC. Licenciada en Ciencias Sociales UPN; Docente IEM. Liceo Integrado Zipaquirá, área de Sociales; correo electrónico: Sonyhel@gmail. com
Fecha de recepción: 18 de abril de 2016 / Fecha de aceptación: 16 de septiembre de 2016

\section{Resumen}

El presente artículo expone la investigación realizada en una institución educativa del municipio de Zipaquirá, donde se pretendió identificar los factores de agresión y violencia que afectan la convivencia escolar, para elaborar una propuesta pedagógica que promueva la Cultura de la Paz; el interés partió de una necesidad de la institución y de lo exigido por las normas educativas, especialmente la Ley 1732 de 2014, que establece la Cátedra de la Paz. En la recolección de información se empleó la observación directa y la aplicación de encuestas al $35 \%$ de estudiantes de octavo y noveno.

Palabras clave: Propuesta pedagógica, convivencia escolar, cultura de paz, violencia escolar.

\section{Summary}

This article presents the research carried out in a school of Zipaquirá, where it is intended to identify the factors of aggression and violence that affect its school life in order to make a pedagogical proposal that promotes the Culture of Peace. It started from the need of the institution and the requirement of educational laws, especially Law $1732 / 2014$ that establishes the subject of Peace. For gathering information, it was used direct observation and surveys were applied to $35 \%$ of Eighth and Ninth graders students.

Keywords: Pedagogical proposal, school life, culture of peace, school violence.

\section{Resumo}

Este artigo apresenta pesquisa em uma instituição de ensino do município de Zipaquirá, que se destinava a identificar os fatores de agressão e violência que afetam a vida escolar, para desenvolver uma proposta pedagógica que promove a cultura de paz; o interesse veio de uma necessidade para a instituição e os requisitos das normas educacionais, em especial a Lei 1.732 de 2014, que estabelece o Departamento de Paz. Recolha de informação sobre a observação direta ea realização de estudos de $35 \%$ dos oitavo e nono foi usado.

Palavras chave: Proposta pedagógica, vida escolar, cultura da paz, violência escolar. 


\section{Introducción}

En la actualidad la convivencia juega un papel fundamental en el proceso de enseñanza, desde su función de fortalecer en los educandos los valores, principios y normas necesarios para vivir en comunidad y así lograr una cultura de paz. En los últimos años el fenómeno de violencia en el ámbito escolar ha sido tema de constante debate, ya que su ejercicio se ha incrementado en las últimas décadas, convirtiéndose en una problemática social abordada desde diferentes concepciones metodológicas y teóricas que buscan caracterizar, conceptualizar y/o solucionar este flagelo (Murcia, 2004).

De acuerdo con Rodríguez (2013) la violencia como fenómeno social es resultado de comportamientos, actitudes y relaciones disímiles entre los individuos que, con su actuar, infringen, causan lesión, daño o sufrimiento a alguno o varios miembros de la comunidad educativa; lo cual tiene como consecuencia un ambiente escolar difícil, tenso y estresante que puede causar más violencia. En Colombia las agresiones de tipo físico, verbal, psicológico, virtual y emocional al interior de las instituciones, son protagonizadas por directivos, docentes, padres, acudientes y estudiantes, siendo estos últimos los que presentan índices más altos y frecuentes (Palomero y Fernández, 2001).

Atendiendo a esta problemática, el Ministerio de Educación Nacional plantea una política hacia la consolidación de una cultura de paz que emane de la escuela, como agente responsable de: "enseñar a niños y jóvenes a vivir juntos en armonía y a convivir con base en el respeto a las diferencias y los derechos de los demás" (Ministerio de educacion nacional, s.f, p. 1). La escuela debe fomentar en niños y jóvenes el desarrollo de valores, actitudes, comportamientos y habilidades que promuevan la no violencia, en el marco del respeto y cumplimiento de los Derechos Humanos; además, debe planear e implementar estrategias orientadas hacia el cambio de actitudes violentas por relaciones pacíficas que posibiliten la construcción de una cultura de paz (García, 1998).

La violencia es una manifestación tan compleja que no está conformada solamente por los hechos concretos que la expresan, sino que a ellos subyacen emociones y valores (Prieto, Carrillo y Jiménez, 2005, p. 1031). El inadecuado uso de esas emociones genera violencia escolar, siendo la inteligencia emocional una habilidad que permite su adecuado manejo y, por tanto, la gestión de las mismas en el ámbito escolar se presenta como propuesta para mejorar la convivencia y consolidar una cultura de paz.

La presente investigación diagnóstica parte de lo observado en la Institución Educativa Municipal Guillermo Quevedo Zornoza, del municipio de Zipaquirá (Cundinamarca), que cuenta con una notoria problemática de convivencia escolar, con agresiones de todo tipo durante el desarrollo de la jornada que reflejan una escasa presencia de valores. Esta situación se materializa en actitudes hostiles hacia el entorno y en la mala relación entre compañeros, hechos que impiden una verdadera cultura de paz. Parte de la solución depende de la puesta en marcha de un proyecto que promueva la sana convivencia desde valores como el respeto, la tolerancia y la responsabilidad social.

El objetivo principal de esta investigación es identificar los factores de agresión y violencia que afectan los procesos de convivencia escolar, para diseñar una propuesta pedagógica que promueva una cultura de paz en la Institución Educativa Municipal Guillermo Quevedo Zornoza de Zipaquirá. Así como identificar las acciones pedagógicas adelantadas frente a los problemas de convivencia que influyen en la construcción de una cultura de paz, determinando los comportamientos, actitudes y relaciones que afectan la convivencia.

\section{Fundamentación teórica}

En primer lugar, la presente investigación aborda el concepto y fenómeno de la educación como realidad social y compleja, como ámbito en el cual se evidencian diversos problemas que merecen ser afrontados; luego se analiza la convivencia en el ambiente escolar, los principales factores que la afectan, la violencia y sus formas; después se fundamenta la necesidad de la educación para la paz, entendida como propuesta para fortalecer la convivencia, para luego anotar las principales teorías que han aportado a la investigación y educación para la paz, ofreciendo postulados de solución a la problemática de la violencia, útiles para desarrollar la construcción de una propuesta pedagógica que promueva y consolide la cultura de paz. Convivencia y cultura de paz son vistos como conceptos sociales, de construcción y de mejoramiento, que se enseñan y se aprenden (Ministerio de educacion de Chile, s.f.).

\section{La educación proceso de transformación}

Dependiendo de la disciplina y del contexto la educación ha tenido varias interpretaciones a lo largo de la historia; para el desarrollo del presente proyecto se retoma la idea de la educación como medio de transmisión y conservación de la herencia cultural, 
a través de la enseñanza de un sistema de valores y sentimientos que regulan el comportamiento y pautas del ser humano (Reyes, 2013). Así, la educación es un proceso que tiende a formar al individuo, fortaleciendo sus habilidades y capacidades para actuar conscientemente frente a las diversas situaciones de la vida. En el ámbito de la educación, y con el ánimo de cumplir con sus premisas teóricas, la escuela y las acciones pedagógicas que en ella se orientan juegan un papel clave, tienen unos objetivos y roles específicos que las configuran como ejes centrales en el proceso de formación de los niños y jóvenes. La escuela es el medio de socialización por excelencia, en ella el estudiante no solo aprehende una serie de conceptos y valores sino que los vive en la cotidianidad, siendo capaz de convivir respetando la diferencia, al otro y al entorno, emprendiendo las tareas de cambio y

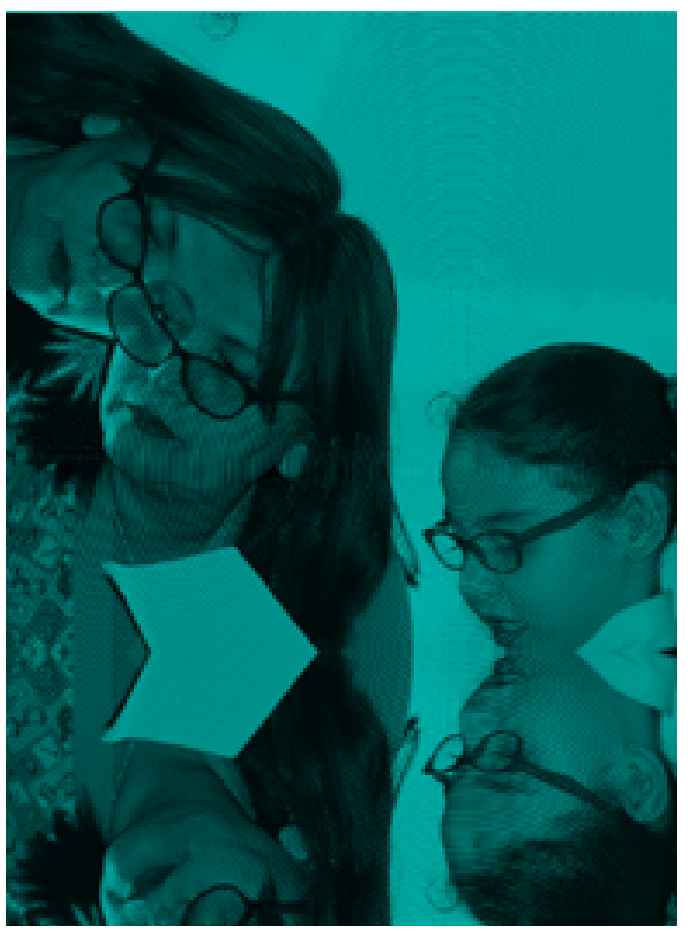
Violencia en el ámbito escolar

En el contexto social y en el ámbito escolar se evidencia un detrimento frente a la práctica de valores relacionados con el respeto de las normas, de la diversidad, de la pluralidad, de la diferencia, de la comunicación; hecho que se manifiesta en actos de violencia de toda índole que afectan negativamente la convivencia de la comunidad educativa, y que está ligado a factores como los sociales/ambientales, los relacionales, los escolares, familiares y personales (Perez, 2005). Al tiempo, se destacan ciertas conductas antisociales en los centros educativos y que son foco de violencia, tales como: Disrupción en las aulas, Indisciplina, vandalismo y daños materiales (Moreno, s.f.) transformación de la realidad.

\section{Convivencia en el ámbito escolar}

En última instancia la convivencia tiene que ver con:

La capacidad de las personas para establecer relaciones sociales y humanas de calidad, fundamentadas en la tolerancia y en el respeto de los demás. Esa calidad de las relaciones individuales y sociales se define no solo desde referentes, éticos, culturales y normativos, sino también desde competencias, habilidades y capacidades de los individuos para interactuar constructivamente (MEN, 2010).

La convivencia en el ámbito escolar, entendida como el entramado de relaciones e interacciones que se dan entre los miembros de la comunidad educativa, implica establecer procesos de comunicación, sentimientos, valores, actitudes, roles, status y poder. Este entramado de relaciones se ve afectado por: la indisciplina, los conflictos interpersonales, el maltrato entre compañeros, la irrupción en el aula, el vandalismo y la pérdida de valores (Ayuntamiento de LEIOA).

\section{La teoría tricerebral y la violencia}

La teoría tricerebral expresa que en cualquier grupo social siempre se presenta alguien que mande, que dirija; este tipo de persona pertenece al llamado subgrupo oficial; también alguien que critica y cuestiona, es decir los llamados subgrupo anti-oficial u opositores frente al primer grupo. Además, hay una gran mayoría que no está ni a favor ni en contra y es el llamado subgrupo oscilante o disponible, el cual fluctúa entre el grupo oficial y el anti-oficial según la conveniencia. Los tres subgrupos se disputan el poder sobre los medios de reproducción y convivencia, y en esta búsqueda pueden tener comportamientos positivos o negativos, proporcionales o desproporcionales (Gregori, 2002).

La lucha por alcanzar satisfacción desata una competencia violenta en la que el subgrupo oficial se caracteriza por buscar ávidamente el poder, persigue depredar y sacar el máximo de los demás con el mínimo riesgo; en esa búsqueda se dan tres tipos de violencia: la primordial, original, que en general está legalizada por el subgrupo oficial camuflada bajo la figura de estado o mercado; la violencia del grupo anti-oficial, que reacciona a la violencia uno y 
es tildada de ilegal y terrorista; y la del grupo oscilante, que sería la violencia callejera (Gregori, 2002).

\section{Educación para la paz}

Atendiendo a la actual situación, el Ministerio de Educación Nacional planteó una política hacia la consolidación de una cultura de paz cuyo eje principal sea la escuela, como agente responsable de: "enseñar a niños y jóvenes a vivir juntos en armonía y a convivir con base en el respeto a las diferencias y los derechos de los demás" (MEN, p. 1). A nivel mundial se ha generalizado la necesidad y el interés de educar para la paz; un concepto que a lo largo de la historia se ha relacionado con el de la guerra, su naturaleza y dimensión han variado de acuerdo al contexto económico, político, social y cultural.

La paz puede ser pensada, sentida y percibida desde diferentes puntos de vista (Muñoz, 2001), esto significa que las condiciones de cada época y las tendencias de pensamiento han planteado distintas teorías acerca de la paz como alternativa para solucionar los episodios de violencia y forjar una sociedad pacífica y justa, basada en el respeto de los Derechos Humanos, de la dignidad y la diversidad, fomentando el diálogo y transformando la realidad. Por ello, a continuación se mencionan los principales aportes de la investigación para la paz (Xexús, 2003), por las contribuciones significativas que realizó para el presente de la educación para la paz y la promoción de la cultura de paz.

\section{Investigación de la paz para "la cultura de paz"}

\section{La paz imperfecta (Muñoz Francisco, 2001)}

La "Paz imperfecta" de Muñoz busca abordar el tema desde la perspectiva del conflicto, refiriéndose a todas las experiencias en las cuales ha sido posible regular las situaciones pacíficamente. La llamó imperfecta porque considera las particularidades inherentes a la especie humana que llevan a que sea conflictiva, hecho que se hace evidente en el choque entre el entramado de intereses y necesidades individuales y la variedad de posibilidades que ofrece la sociedad; también buscaba romper con otras ideas que enmarcan la paz como algo perfecto, utópico e infalible, alcanzable en otro mundo con la mediación de los dioses, fuera del alcance de los humanos.
La paz imperfecta es un proceso inacabado y parte de argumentos como los de Gandhi: "No hay camino para la paz, la paz es el camino", para ver la paz como un principio que se construye cotidianamente. Esta teoría no solo busca la regulación, gestión y resolución de los conflictos de forma pacífica, sino que está relacionada con el poder como capacidad para transformar la realidad y medio para enfrentar los conflictos, buscando un equilibrio entre las tres esferas del poder: integrativa (amor, solidaridad, cooperación), destructiva (guerra y violencia) y productiva (económico).

\section{Teoría de los conflictos, la paz positiva, la paz negativa de Johan Galtung}

El aporte teórico de Galtung se centra en tres ejes: paz, conflicto y violencia, considerando las relaciones entre ellos, especialmente entre los dos últimos; desde su perspectiva la regulación del conflicto por medios no violentos es clave para lograr la paz, de tal manera que resulta fundamental analizar el papel de la cultura y de las estructuras sociales como generadoras de conflictos y de manifestaciones violentas (García, 2009, pp. 154-159). Galtung parte de la premisa de que a lo largo de la historia los conflictos son inherentes a la condición humana y de que, como tal, han contribuido tanto a su progreso como a su destrucción, siendo esta última una causa importante de la total deshumanización (Percy, 2009). Por eso es necesario abordarlo, estudiarlo y analizarlo desde su origen y naturaleza, para teorizarlo en beneficio de la humanidad.

\section{Violencia directa, violencia cultural y violencia estructural}

Para Galtung existen tres formas de violencia que se deben analizar para buscar estrategias de paz:

- Violencia directa: Los efectos visibles de la violencia; un acontecimiento que infringe o causa daño o lesión a alguien y que es visible; en este grupo están todas aquellas manifestaciones cotidianas de agresión (García, 2009, p. 129).

- Violencia cultural: Aspectos de la cultura materializados por medio de la religión, la ideología, el arte el lenguaje y las ciencias, que con sus diferentes manifestaciones legitiman la violencia directa y estructural (García, 2009, p. 130).

- Violencia estructural: Violencia indirecta generada por la injusticia y la desigualdad, es consecuencia de la propia estructura social, y puede darse dentro de ella o entre el conjunto de sociedades (alianzas, relaciones entre estados) (García, 2009, p. 130). 


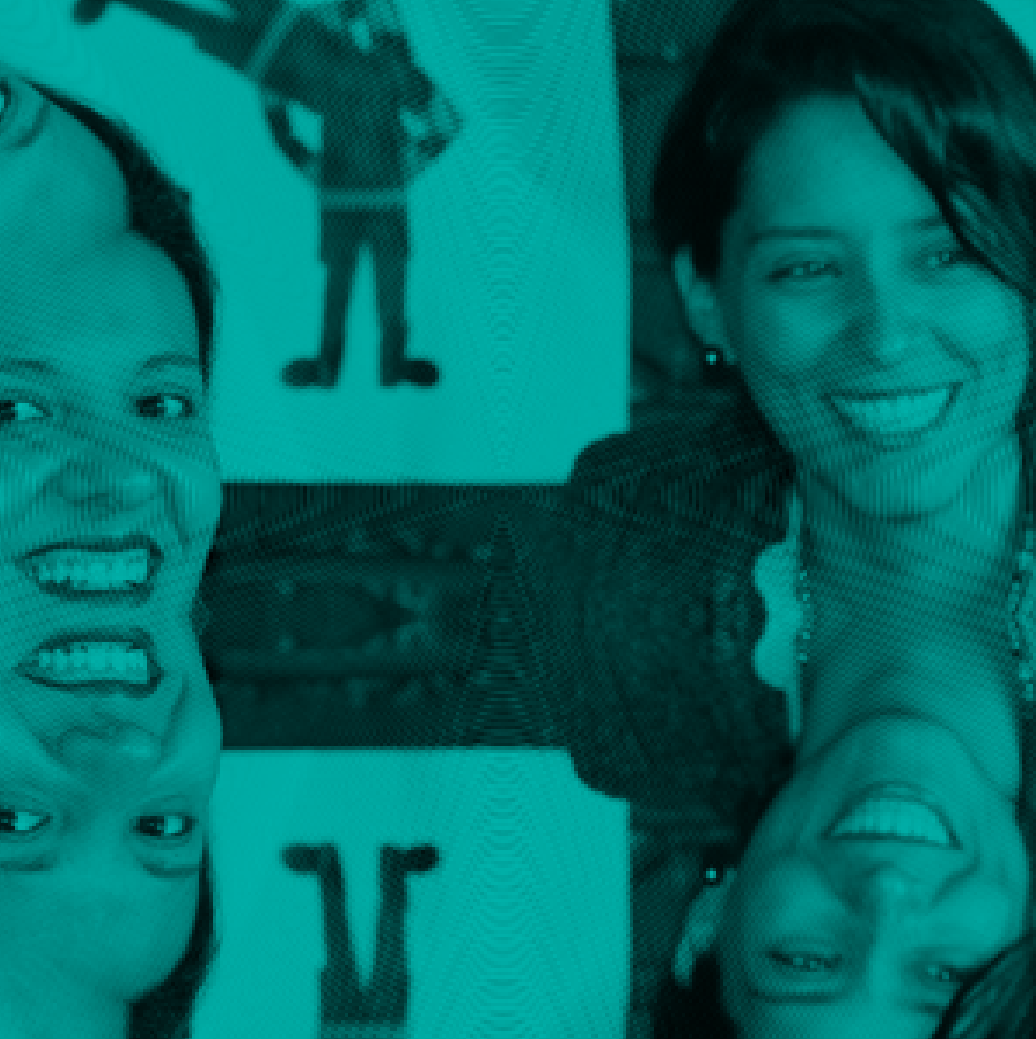

La paz para Galtung se logra cuando los conflictos se solucionan pacíficamente, cuando se coloca en práctica la habilidad para resolverlos de la mejor manera; ésta se debe entender como un proceso dentro de un contexto, una estructura y una organización, es decir que la sociedad requiere de un sistema donde haya una cultura de paz que garantice la resolución de los conflictos por medios no violentos (Percy, 2009). Desde esta perspectiva, la forma más acertada de construir una cultura de paz en las instituciones escolares es generar una conciencia de cambio a partir del compromiso de sus integrantes para emprender, en conjunto, acciones preventivas de los conflictos y de la violencia.

\section{Proporcionalismo}

El Proporcionalismo es planteado Gregori como una nueva justicia tríadica para regular la convivencia, entendiendo que la proporcionalidad es algo innato en los tres tipos de cerebros: para el cerebro derecho es dada por el sentimiento intuitivo-místico de ética, moral, justicia, humanismo, armonía, belleza o arte; para el cerebro izquierdo esta percepción se da a partir de la ley matemática de la media y extrema razón: el punto que las divide es la "sección áurea" o "Punto de Oro", también conocido como la divina proporción, proporción áurea, razón áurea o número de oro porque es un estándar que se repite universalmente; el cerebro central busca la proporcionalidad mediante un esfuerzo organizativo de imponer instituciones reguladoras y preservar el estado de derecho con sus leyes, códigos penales y justicia.

Para el Proporcionalismo no hay nada fijo, estable, inmóvil o lineal, todo ondula, oscila, fluye, se mueve en transformación, con rumbos y resultados más probabilísticos (menos caos) o menos probabilísticos (más caos). Así, el Proporcionalismo se define como una propuesta ético-numérica de vida y justicia social basada en la matemática de la media y la extrema razón, que supone, en todo, medidas aproximadas del 38\% y $62 \%$. Este es el punto de oro conocido como sección áurea (Gregori, s.f.). Cuanto más cercanos al punto de oro, más tendremos paz, disfrute y cooperación social, entre más lejanos, más competencia, guerra, infelicidad, crisis y explosión social.

\section{Hacia la promoción de una cultura de paz}

La UNESCO define la cultura de paz como un conjunto de valores, actitudes, tradiciones y estilos de vida basados en el respeto a la vida y en la práctica de la no violencia a través de la educación, la libertad de expresión, la justicia, la democracia, la tolerancia, la solidaridad, el pluralismo, la diversidad cultural y el entendimiento (UNESCO, 1998). La cultura de paz debe propender principalmente por practicar la no violencia y rechazar la violencia física, sexual, psicológica, económica y social en todos sus aspectos, en particular cuando afecta a los más débiles como niños y adolescentes.

\section{Metodología}

El proyecto parte de las necesidades del entorno, del horizonte institucional y de las exigencias frente al desarrollo de la convivencia; está enmarcado en las normas en educación y la Ley 1732 de 2014, que expone la necesidad de trabajar la cultura de paz en las instituciones educativas. Su desarrollo tuvo en cuenta un proceso de investigación que implicó la recolección y observación de información, datos, hechos, casos, y su posterior proceso, análisis e interpretación. Esto permitió comprender y describir la situación real de convivencia escolar en la Institución Educativa Guillermo Quevedo Zornoza, para fomentar la cultura de paz con la aplicación del Ciclo Cibernético de Transformación (CCT). El proceso de recolección de la información empleó inicialmente la 
observación directa, que se registró en una ficha de observación (instrumento), en segundo lugar se aplicaron encuestas al treinta por ciento de los estudiantes de los grados octavo y noveno (población de estudio), los resultados obtenidos se analizaron y triangularon para finalmente obtener las conclusiones.

\section{Resultados}

El proceso de análisis de datos y triangulación tomó en cuenta los estamentos de estudiantes y docentes; y agrupó distintas categorías: convivencia escolar, cultura de paz y propuesta pedagógica. A continuación se presentan los resultados más relevantes.

\section{Categoría convivencia escolar}

Esta categoría agrupó lo relacionado con la convivencia al interior de la institución, su dinámica y los procesos que se llevan a cabo. Al analizar cuáles son las situaciones de conflicto que afectan la convivencia escolar (Graficas 1 y 2), estudiantes y docentes señalaron que este tipo de actos se da más frecuentemente entre estudiantes ( $76 \%$ de los estudiantes y $88 \%$ de los docentes); y un bajo porcentaje opinó que se da entre estudiantes y docentes $(5 \%$ de los estudiantes y $12 \%$ de los docentes), lo que permite concluir que la interacción alumno-docente es buena, imperando el respeto mutuo (Actores del conflicto).

Los estudiantes desconocen el proceso a seguir frente a un conflicto; aproximadamente el $70 \%$ de ellos acude a algún miembro de la comunidad educativa para atender la situación, pero el $30 \%$ restante se queda callado, lo que impide solucionar el conflicto y puede desencadenar un episodio de violencia. Las situaciones de conflicto con el entorno no son tomadas en cuenta por los docentes, y tan solo un 19\% de los estudiantes las identifica; sin embargo, teniendo en cuenta lo registrado en la ficha de observación, frecuentemente los estudiantes arrojan basura al piso y destruyen la infraestructura del plantel al dañar los pupitres o rayar las paredes.

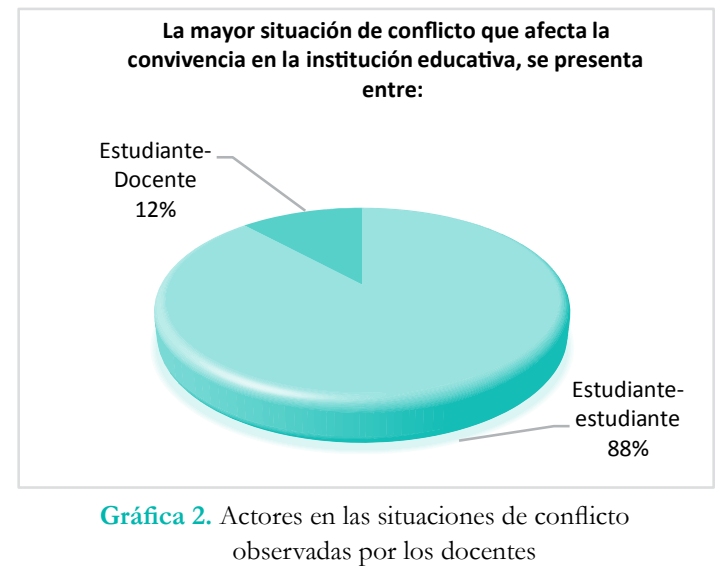

En cuanto al cumplimiento de las normas de convivencia, el manual de convivencia se presenta como una herramienta que no ha sido apropiada por la comunidad educativa; los docentes afirmaron que hay desconocimiento frente a los procesos y acciones pedagógicas correctivas a seguir en caso de conflictos o agresiones; los estudiantes corroboraron lo anterior: el $29 \%$ de ellos expresó que el manual de convivencia no es claro sobre lo que se debe hacer; el 23\% afirmó que presenta los casos de agresión pero que no son claros los procesos y acciones correctivas; y un 18\% dijo que posee unos procesos correctivos claros. Esta situación permite inferir la 
poca funcionalidad del manual de convivencia en la institución, o la falta de divulgación, implementación, apropiación y mejoramiento del mismo. Es necesario reflexionar acerca de su papel y reorientar su funcionalidad.

En el ejercicio de iniciativa y toma de decisiones por parte de los estudiantes, aspecto clave en el proceso de convivencia, se hizo evidente una debilidad en los canales y estrategias de comunicación, debido a que un $52 \%$ de ellos no manifiesta su opinión abiertamente porque teme no ser aceptado y por apatía; el resto lo hace

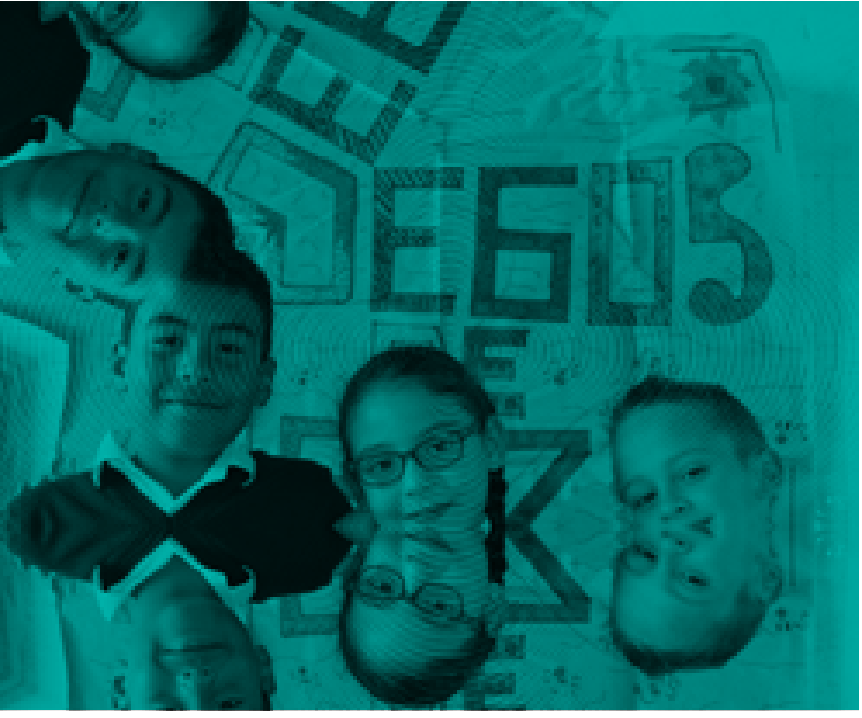

Categoría cultura de paz

Esta categoría tomó en cuenta las preguntas que aportan a la construcción de una cultura de paz, o que, para el caso del presente diagnóstico, dificultan este proceso. Los estudiantes y docentes tienen la percepción de que en el colegio se presentan con mucha frecuencia situaciones de agresión y conflictos (Gráficas 3 y 4); así, hay un porcentaje considerable de situaciones conflictivas que, a su vez, reflejan la carencia de valores como la justicia, la solidaridad, la dignidad y la armonía, hecho que dificulta los procesos de forma particular, ya sea con un profesor o un compañero, para evitar situaciones de burla. Lo anterior lleva a concluir que debe fortalecerse la comunicación en la convivencia escolar, especialmente la participación de los estudiantes en el liderazgo y toma de decisiones en la comunidad.

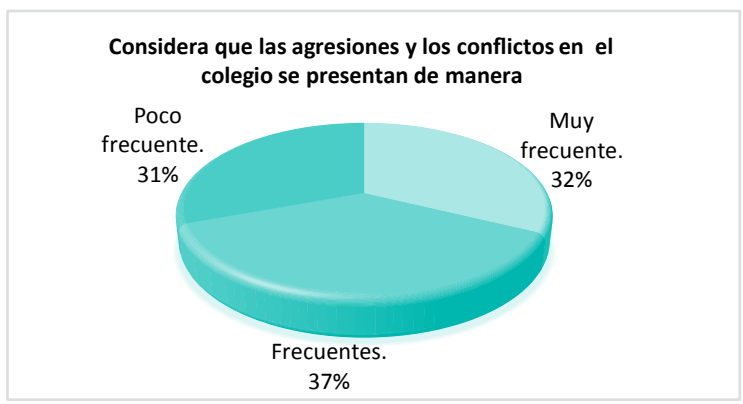

Gráfica 3. Frecuencia con la que se presentan situaciones de agresividad y conflictos según la percepción de los estudiantes

Los docentes y estudiantes encuestados identifican que las situaciones de conflicto más recurrentes entre los estudiantes son las faltas de respeto, que se expresan en agresiones físicas y verbales, insultos y amenazas (estudiantes $43,5 \%$ y docentes $76,4 \%$ ), todo esto desencadena altos índices de violencia. Las agresiones virtuales aparecen con un menor porcentaje con expresiones como: amenazas por redes sociales, acoso o ciberbullying, este menor índice de convivencia y la transformación de mentalidad, de actitudes y comportamientos que promuevan una cultura de paz; si se compara esto con la Gráfica 1, es evidente que los actores principales de los conflictos son los estudiantes, lo cual ratifica el ambiente de violencia que se vive a diario en la institución, que se materializa generalmente en agresiones de tipo físico o verbal.

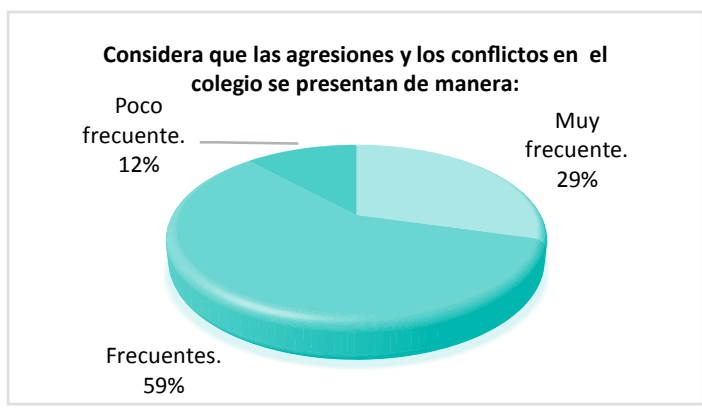

Gráfica 4. Frecuencia con la que se presentan situaciones de agresividad y conflictos

se debe al bajo acceso de los estudiantes a la tecnología, que a su vez se relaciona con su bajo nivel socioeconómico (el 46,8\% de estudiantes ven esta situación como poco recurrente).

El 32,3\% de los estudiantes perciben que el vandalismo es un hecho medianamente recurrente; para ellos esta situación no representa una agresión y es desde allí que no entiendan hechos como arrojar basura, rayar paredes y pupitres, dañar los muebles del 
colegio o desperdiciar agua, como una agresión hacia el entorno; esto refleja una falta de sentido de pertenencia y un consecuente menoscabo del cuidado y protección del medio ambiente; muchas de estas acciones son hábitos adquiridos en el hogar y ocupan un lugar en la vida en sociedad de los individuos. Un 41,2\% de los docentes sí identifican que el vandalismo es una situación medianamente recurrente, y un 29,4\% la entiende como recurrente.

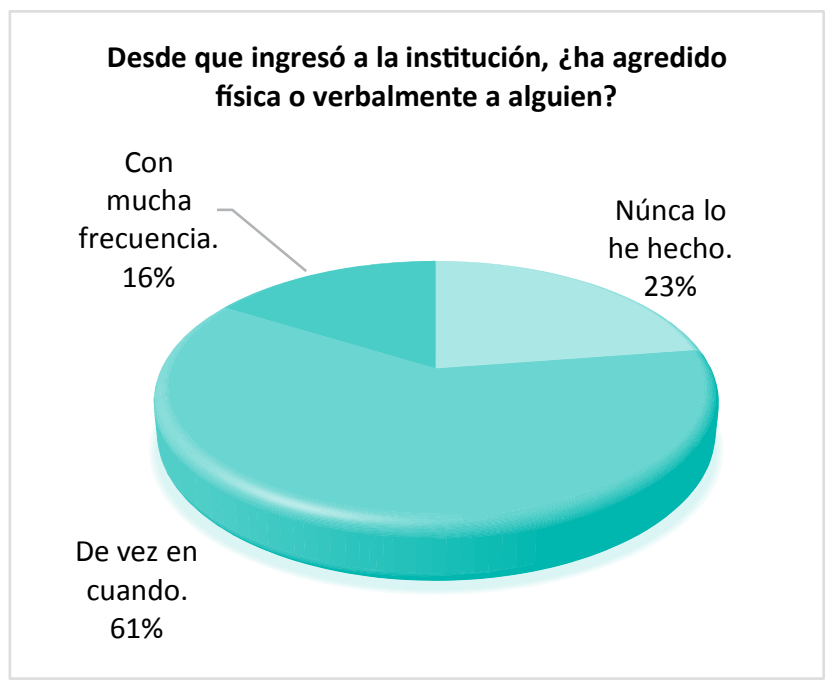

Gráfica 5. Frecuencia con la cual los estudiantes agreden a sus compañeros

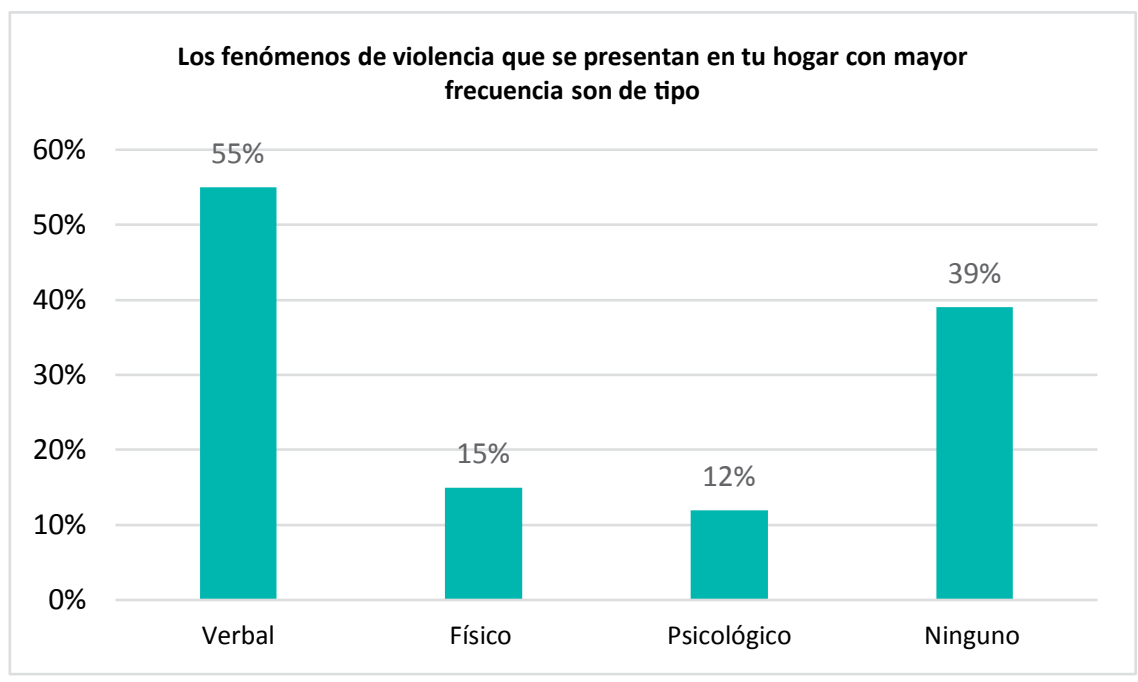

Gráfica 6. Manifestaciones de violencia en el hogar

En cuanto a la frecuencia de agresión, 61\% de los estudiantes encuestados ha agredido a otro compañero (Gráfica 5) de vez en cuando y un $23 \%$ nunca lo ha hecho; un $16 \%$ de los estudiantes reincide en situaciones agresivas de tipo físico o verbal, en muchos casos pueden incitar a otros a situaciones de violencia haciéndolos sus víctimas, llevándolos a situaciones de matoneo, hecho que 
dificulta los procesos de convivencia y la práctica de una cultura de paz.

Solo el 29\% de los docentes expresa que nunca se ha sentido agredido, mientras que un $29 \%$ considera haberlo sido en alguna oportunidad, ya sea por un estudiante o por un acudiente o padre de familia, y un bajo porcentaje ha tenido otro tipo de agresión. Cuando se presentan esas situaciones la mitad de los docentes afirmó no haber contado con apoyo de los directivos o de la Secretaría de Educación, 17\% dijo haber tenido ese apoyo y un 33\% expresó haber sido respaldado por alguna de las partes; esto hace evidente una debilidad por parte de las directivas, pues se permiten faltas de respeto de estudiantes y acudientes hacia los docentes; también destaca el hecho de que los profesores desconocen el funcionamiento del comité de convivencia municipal y la ruta de atención integral.

Cuando se piensa en los motivos por los cuales los estudiantes son agresivos en el colegio, se infiere que muchos de ellos aprenden este tipo de conducta en sus hogares (Gráfica O), donde en su mayoría se sienten agredidos verbal (55\%) y físicamente $(15 \%)$; pocos de ellos no viven situaciones de agresión familiar (39\%). Ello permite concluir que no se viven valores al interior de la familia y que su papel de corresponsabilidad en la educación de niños y jóvenes no está contribuyendo a forjar la cultura de paz.

\section{Categoría de propuesta pedagógica}

Con estas preguntas se buscó tener elementos que permitan identificar los gustos y preferencias de los estudiantes y docentes, para así considerarlos en el diseño de la propuesta pedagógica. Docentes y estudiantes reconocen que las actividades culturales y deportivas son espacios que permiten practicar la sana convivencia, y ese aspecto se tuvo en cuenta como estrategia para la construcción de la propuesta pedagógica. Los estudiantes expresan mayor interés hacia las actividades deportivas (68\%), seguidas de las actividades culturales (37\%); por su parte los docentes prefieren la actividades culturales $(64,7 \%)$ y luego las deportivas (53\%) (Gráfica 7 y 8).

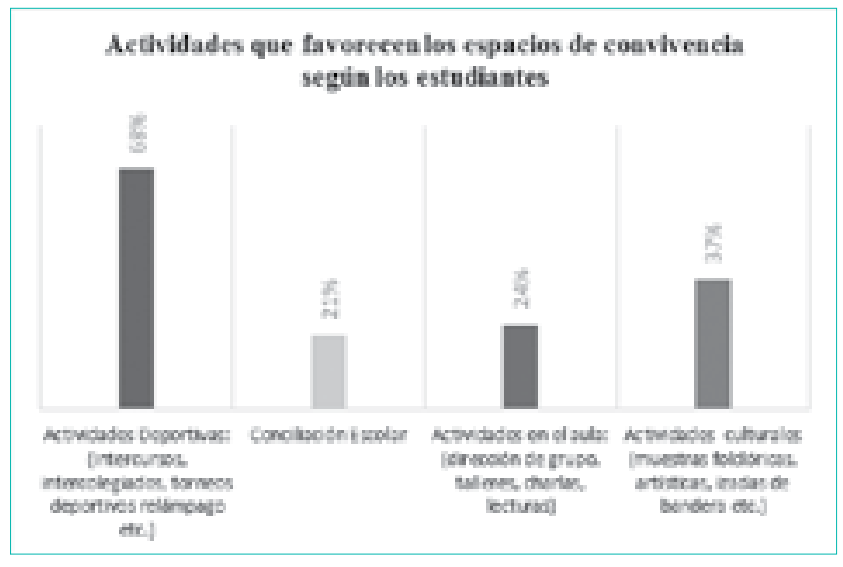

Gráfica 7. Actividades que favorecen los espacios de convivencia según los estudiantes

\section{Actividades que se considera favorecen los espacios de convivencia segun los docentes}

Actividades culburales imuertras foiddricas, arskikas, izadas de barder etc)

Actividalesen diala: [drección de gupe, evlleres, charks bcturas?

Conxili bisen fucelar

Actividades Deportivas (nitercurica

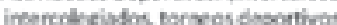
relimpase etc.)

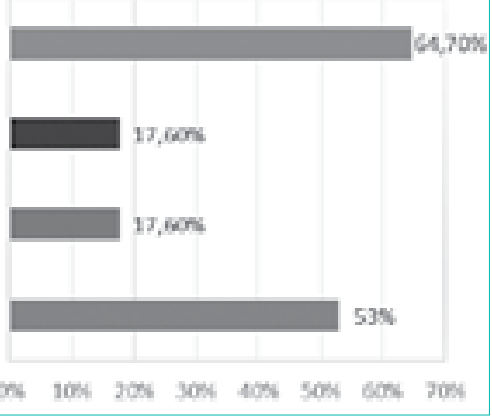

Gráfica 8. Actividades que favorecen los espacios de convivencia según los docentes 


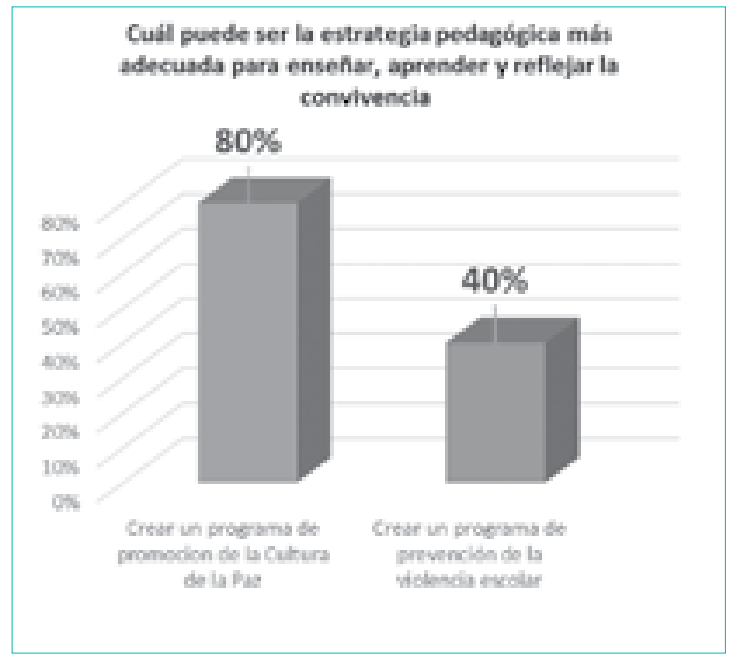

Gráfica 9. Estrategia pedagógica propuesta por los docentes

En su mayoría, los docentes opinan que la estrategia pedagógica más adecuada para enseñar, aprender y reflejar la convivencia es la creación de un programa de promoción de Cultura de Paz (80\%), hecho que se relaciona directamente con lo establecido en la norma frente al tema de la Cátedra de la Paz (Ley 1732 de 2014, Cátedra de la Paz; Decreto 1038 del 25 de Mayo de 2015, reglamentación de la Cátedra de la Paz), y un $40 \%$ prefiere un programa de prevención de la violencia escolar; ambas opciones pueden ser integradas en un único programa. Al tiempo, los estudiantes creen en su mayoría que las soluciones para trabajar la convivencia escolar parten de dialogar de manera efectiva, y proponen la realización de convivencias y campañas sobre la solución de conflictos; de igual forma, resaltan la importancia de promover valores como el respeto y la tolerancia, aspectos que también se convierten en insumos para la construcción de la propuesta pedagógica. Sin embargo, llama la atención sus demandas de tomar medidas correctivas eficientes frente a los agresores y atención de sus maestros (Gráfica 10).

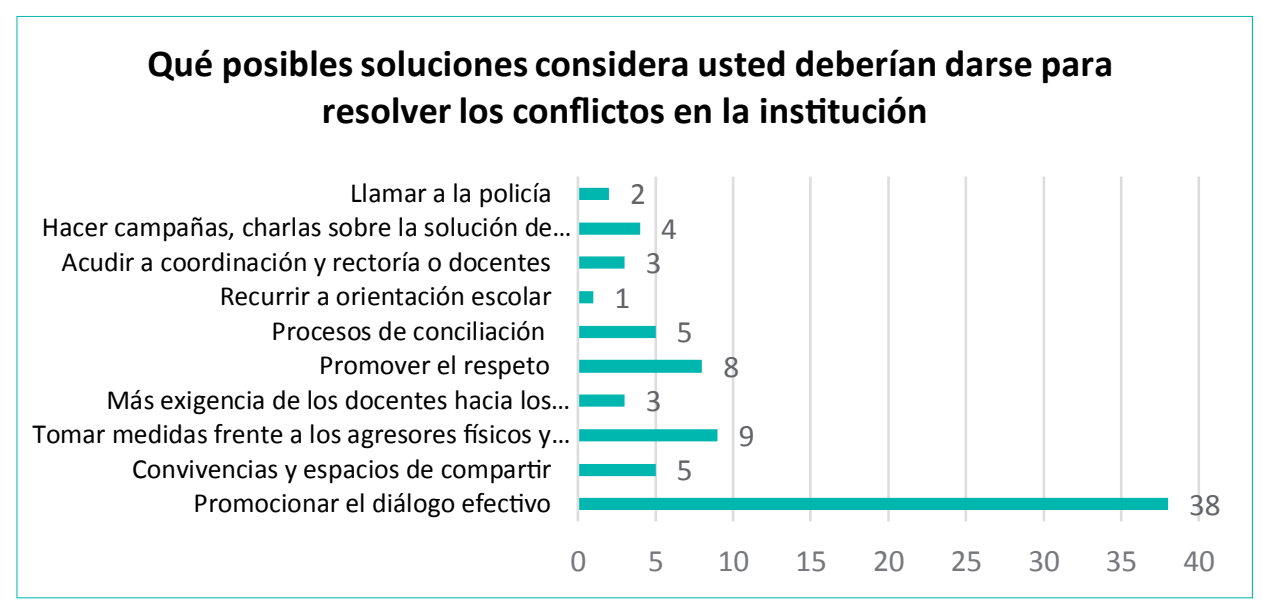

Gráfica 10. Posibles soluciones a los problemas de convivencia, propuestas de los estudiantes 


\section{Discusión de resultados}

Tanto en la ficha de observación como en los resultados de las encuestas se presentó un alto índice de agresividad en la institución, protagonizada generalmente por los alumnos. Este aspecto fue registrado inicialmente en la ficha de observación y corroborado a través de las encuestas. Las agresiones de tipo verbal y físico fueron problemas de convivencia destacados por estudiantes y docentes, observados por el grupo investigador, y registrados en la ficha de observación teniendo en cuenta los diferentes espacios y momentos, como las horas de descanso. A ellas se suma como elemento destacado, registrado y verificado en las encuestas, la actitud de los estudiantes frente al trabajo en equipo y la convivencia sana en la organización y participación de actos culturales y prácticas deportivas. Este aspecto es esencial en la planeación de la propuesta pedagógica, objeto de este proyecto.

En contraste con lo expuesto en el marco teórico, el diagnóstico realizado a estudiantes y docentes de la Institución Educativa Municipal Guillermo Quevedo Zornoza, permitió observar que tanto en la institución analizada como en el país las agresiones de tipo físico, verbal, psicológico, virtual y emocional al interior de las escuelas son protagonizadas por directivos, docentes, padres, acudientes y estudiantes; siendo el índice más alto el de las agresiones estudiante-estudiante (Palomero y Fernández, 2001); según lo expuesto por Gregori en la teoría tricerebral, siempre habrá un juego tríadico. El comportamiento de un subgrupo es positivo cuando toma en cuenta a los a los otros dos y alcanzan una división proporcional de derechos y deberes: gana-gana-gana, si esto se logra se puede hablar de convivencia y solución de conflictos. Docentes y estudiantes de la institución educativa tienen un desconocimiento frente a los procesos de convivencia reglamentados en la ley 1620 de 2013, debido a lo poco funcional del manual de convivencia, que debe ser actualizado, socializado y apropiado por parte de docentes, estudiantes y padres de familia.

Hay distintos factores que dificultan el alcance de una cultura de paz al interior de la institución educativa, como la agresividad, no solo entre estudiantes, sino para con el entorno mediante acciones de vandalismo, relacionadas con el ámbito social y familiar. Indiscutiblemente el primer órgano educativo en la sociedad es la familia, y la situación observada comprueba que los estudiantes enfrentan situaciones de violencia verbal y física en sus hogares, por lo que se puede concluir que la familia no está ejerciendo su función de corresponsabilidad en la educación de niños y jóvenes, y no contribuye a forjar la cultura de paz; la desintegración del grupo familiar, la dispersión de sus miembros y la desatención de los hijos contribuyen a la no cultura de paz.

\section{Conclusiones}

Las diferentes teorías, como la paz imperfecta de Muñoz, la teoría de la paz o el equilibrio de Valdéz y los aportes de Galtung, dan pautas para lograr una verdadera educación para la paz y cultura de paz, a partir de tres ejes básicos: paz, conflicto y violencia, y sus distintas relaciones; en el proceso de investigación diagnostica se abordó el conflicto desde su regulación y gestión, como una oportunidad para que se dé el diálogo, los valores, y la prevención de la violencia; la convivencia escolar se convierte así en un entramado de interacciones entre la comunidad educativa: estudiantes, docentes, directivos, padres, madres y acudientes, y el conflicto será una oportunidad de mejoramiento. Cuando en una institución, como la analizada, no se da esa relación en un marco de respeto mutuo, solidaridad y tolerancia, se generan gran cantidad de conflictos que desencadenan expresiones de violencia, afectando el clima escolar. Ese es el caso de la Institución Educativa Municipal Guillermo Quevedo Zornoza de Zipaquirá, donde los problemas de convivencia no permiten que se forje la cultura de la paz.

Los problemas se dan especialmente entre estudiante-estudiante, quienes comúnmente agreden y han sido agredidos por otro; las agresiones más frecuentes son las físicas y verbales, causadas por la intolerancia entre ellos, y el vandalismo. Cuando se presentan conflictos los estudiantes manifiestan que no cuentan con apoyo y que no informan la situación por miedo a que no les presten atención o a sufrir burlas; también expresan que los procesos de comunicación son deficientes para sortear conflictos, porque pocas veces se solucionan por medio del diálogo. Estos problemas de comunicación no solo son de la institución sino que se dan en las relaciones familiares; los jóvenes admiten que son frecuentemente sometidos en casa a agresiones verbales y físicas.

Partiendo de la realidad institucional verificada con el diagnóstico, es evidente la necesidad de construir una propuesta pedagógica que permita mejorar la convivencia escolar, brindando espacios de socialización guiados, donde el desarrollo de actividades pedagógicas enfocadas al deporte, la cultura y el arte, sean espacios de aprendizaje para enseñar, aprender y reflejar la sana convivencia escolar, facilitando a los estudiantes la posibilidad de practicar valores como el respeto, la tolerancia y el trabajo en equipo, generando cambios de mentalidad que se reflejen en actitudes y 
comportamientos socialmente favorables. Los docentes comparten esta perspectiva, pues piensan que la promoción de la cultura de paz puede contribuir a mejorar los procesos de convivencia.

Estos aspectos no son ajenos a los enunciados teóricos, pues autores como Reyes (2013) reconocen que los espacios educativos transmiten una herencia cultural, inculcan valores y facilitan regular el comportamiento. Esta postura es ratificada por instituciones como la Universidad Rafael Landivar (2010), cuando aseguran que el individuo debe actuar de manera consiente frente a diversas situaciones de la vida, y que ello exige soluciones creativas; eso es lo que se busca a través de la propuesta pedagógica: brindar a la comunidad educativa una oportunidad de crear soluciones pacíficas a sus diferencias, aprendiendo a aprender, a construir una cultura de paz.
La triangulación de resultados y un exhaustivo análisis permitieron comprobar que el diseño de una propuesta pedagógica, que promueva la cultura de la paz, es la estrategia más adecuada para mejorar la convivencia en la institución. Además, el cruce ascendente de las categorías con el marco teórico, permitió inferir que la propuesta pedagógica debe estar enfocada en una etapa de prevención del conflicto y la violencia, para lo cual es importante considerar la posición de los docentes, quienes en un $80 \%$ creen que la estrategia pedagógica más adecuada, entendiendo el contexto de la institución, es la creación de un Programa de promoción de la Cultura de Paz, mientras un $40 \%$ se inclina por un programa de prevención de la violencia escolar; ambas opciones pueden ser integradas en un único programa. 


\section{Referencias}

Ayuntamiento de LEIOA. (s.f.). Programas y estrategias para la Convivencia Escolar. Obtenido desde http://www.leioa.net/vive_doc/guia_convivencia_cast.pdf

Fisas, V. (2006). Cultura de pazy gestión de conflictos. Barcelona: Ediciones Unesco.

García Correa, A. (1998, Octubre 20). Un aula pacífica para una cultura de paz. Revista electrónica interuniversitaria de formación del profesorado, 1(1), p. 2.

García, V. H. (2009). La transformación de los conflictos por medios pacificos. Obtenido desde file://C:/Users/pearl_000/AppData/Local/ Microsoft/Windows/INetCache/IE/G0K ER7WQ /Dialnet-JohanGaltung-595158.pdf

Gregori, W. D. (2002). Construcción familiar escolar de los tres cerebros. Bogotá: Kimpres.

Gregori, W. D. (s.f.). Neuroeducación para el éxito. Bogotá.

Instituto de paz y conflictos, Departamento de historia antigua. (2001). La paz imperfecta. Granada. http://wdb.ugr.es/ fmunoz/index.php/ paz-imperfecta.html

MEN. (2010). Politica educativa para la formación escolar en la convivencia. Obtenido desde http://www.mineducacion.gov.co/1621/articles-90103_ archivo_pdf.pdf

Ministerio de Educación de Chile. (s.f.). La convivencia escolar. Obtenido el 12 de Diciembre de 2015, desde http://www.convivenciaescolar.cl/ index2. php?id_seccion $=3375 \&$ id_portal $=50 \& i d \_$contenido $=13803$

Moreno Olmedilla, J. M. (s.f.). Comportamiento antisocial en los centros escolares: una visión desde Europa. Revista Iberoamericana de Educación (18).

Muñoz Francisco. (2001). La paz imperfecta. Obtenido desde http://wdb. ugr.es/ fmunoz/index.php/paz-imperfecta.html

Murcia, F. V. (2004, Enero-Junio). Conflicto y violencia escolar en Colombia: lectura breve de algunos materiales escritos. Guillermo de okhan, 7.
Organización de los Estados Iberoamericanos para la Educación la Ciencia y la Cultura. (OEI). (2011). Educación y cultura de la paz: Obtenido desde http://www.oei.es/valores2/palos1.htm

Palomero Pescador, J. E., y Fernández Domínguez, M. R. (2001-Agosto). La Violencia Escolar, un punto de vista global. Revista interuniversitaria de formación del profesorado, 41, pp. 19-38.

Percy, C. C. (2009). Teoría de los conflictos de Johan Galtung. Paøy Confictos(2), pp. 1-22.

Pérez, V. (2005). Conflictividad escolar y fomento de la violencia. Revista iberoamericana de educación (38), 33-52.

Prieto Quezada, M. T., Carrillo Navarro, J. C., y Jiménez Mora, J. (2005-Octubre). La violencia escolar, un estudio en el nivel medio superior. Revista Mejicana de investigación educativa RMIE, 10(27).

Reyes, J. C. (2013). Educación, interdisciplinariedad y pedagogía. Revista Mexicana de Investigación Educativa, 2.

Rodríguez, H. (2013-Septiembre). La violencia en la escuela; elementos para su discusión como objetos de estudio. Obtenido el 01 de feberero de 2015, desde http://soda.ustadistancia.edu.co/enlinea/paginaimagenes/PRESENTACIONESyPONENCIAS/Memorias\%20Ponencias/Bogota/ Educacion $\% 20 y \% 20$ derechos $\% 20$ humanos/Mesa\%201\%20Septiembre $\% 2020 /$ Paola $\% 20$ Herrera $\% 20$ Rodriguez.pdf

Rodríguez, J. P. (2011). Educación y Cultura de Paz: Obtenido desde http:// www.oei.es/historico/valores2/palos1.htm

UNESCO. (1998). Manual del buen explorador e iniciativas de Cultura de Pa\%: Obtenido desde http://escolapau.uab.cat/img/programas/cultura/ manual_explorador.pdf

Valdéz Medina, J. (2009). Teoría de la paz o equilibrio. México: Edamex.

Xexús R, J. (2003). Educación para la Paz, su teoria y su práctica. Madrid: Popular. 



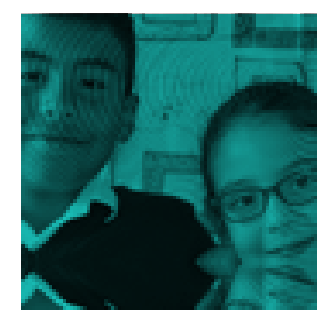




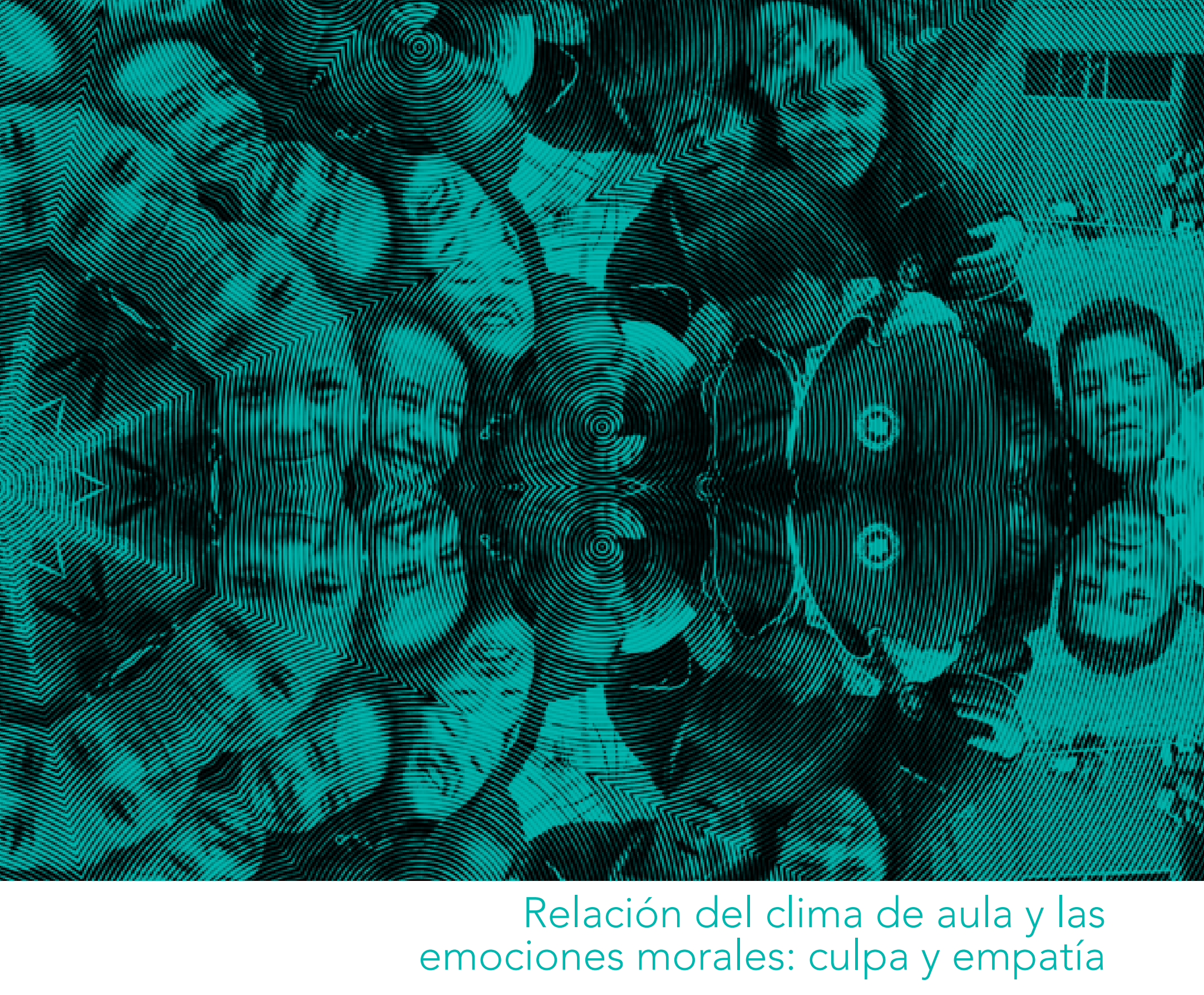

The relation between classroom environment and moral emotion: empathy and guilt

Relação do ambientes educacionais e as emoções morais: culpa e empatía

Mary luz Esquivel Fajardo Martha Liliana Gutiérrez Herrera Angélica María Mercado Roa Yeimy Pachón Forero Gloria Patricia Ortega Roa 


\section{Mary luz Esquivel Fajardo 1 Martha Liliana Gutiérrez Herrera 2 Angélica María Mercado Roa 3 Yeimy Pachón Forero 4 Gloria Patricia Ortega Roa 5}

1. Correo electrónico: soyhumana@gmail.com

2. Correo electrónico: marthagu3@gmail.com

3. Correo electrónico: angiemr55@gmail.com

4. Correo electrónico: emylin.4@gmail.com

5. Correo electrónico: patriciaylucia@gmail.com

Agradecimientos a: Gloria Inés Rodríguez Directora de la tesis de grado. Doctora en Psicología.

Grupo de Trabajo. Docentes de la Secretaría de Educación del Distrito, Bogotá y Magister en Educación de la Pontificia Universidad Javeriana

Fecha de recepción: 18 de abril de 2016 / Fecha de aceptación: 16 de septiembre de 2016

\section{Resumen}

La investigación pretende determinar la relación entre el clima de aula y las emociones morales de empatía y culpa en estudiantes de grado sexto. El enfoque metodológico fue cuantitativo de tipo exploratorio, la muestra seleccionada estuvo compuesta por 189 estudiantes con un promedio de edad de 11 años. Se aplicó un cuestionario con escala tipo Likert previamente piloteado y validado. Los resultados de las correlaciones mostraron una asociación significativa positiva pero baja entre clima de aula y empatía, y una relación significativa positiva moderada entre clima de aula y culpa.

Palabras clave: Clima de aula, empatía, culpa, educación para la paz.

\section{Summary}

The investigation interest to determinate the relation between classroom environment and moral emotion related with empathy and guilt in students that are in sixth. The methodological investigation was focused by quantitative research based in exploratory, the selected sample has 189 students with an average age of 11 years old. An questionnaire using likert scale was applied with a previous pilot study and was validated. The correlation in research results was high, positive but with low incidence between classroom environment and empathy, while in the other side the same result shows a significant moderate positive relation between classroom environment and guilt.

\section{Keywords: Classroom} environment, Moral emotions, empathy, guilt, education for the peace.

\section{Resumo}

A investigação pretende determinar a relação entre ambientes educacionais e a presença de emoções morais: empatía e culpa em estudantes de grau sexto. $O$ enfoque metodológico da investigação foi quantitativo de tipo exploratorio, a mostra seleccionada esteve composta por 189 estudantes com uma média de idade de 11 ano. Aplicou-se um questionário com escala tipo Likert previamente piloteada e validado. Os resultados das correlações mostraram uma associação significativa, positiva mas baixa entre ambientes educacionais e empatía, enquanto este mesmo tipo de análise indicou uma relação significativa positiva moderada entre clima de sala e culpa.

Palavras chave: Ambientes educacionais, empatía, culpa, educação para a paz. 


\section{Introducción}

Una de las preocupaciones constantes de los maestros y maestras es el clima de aula y las relaciones que allí se gestan, dado que en el contexto escolar emergen múltiples maneras de solucionar conflictos a través de la agresión y la violencia, configurando relaciones destructivas y poco asertivas que en muchas ocasiones van en contravía de la moralidad, la justicia y el reconocimiento del otro; por esta razón es evidente que los procesos formativos deben incluir estrategias que permitan el desarrollo de habilidades interpersonales, promoviendo prácticas educativas en ambientes favorables y construyendo relaciones justas en el medio escolar; esto es importante si se piensa que una labor fundamental de la escuela es educar ciudadanos que convivan de forma pacífica y constructiva en sus comunidades.

Las investigaciones que se han llevado a cabo en este ámbito empiezan en los años 90s con Martínez (1996) y, posteriormente, Sánchez (2009) y Chaux (2012). Los autores convergen en que la importancia del clima de aula radica en la adecuada atmósfera de trabajo y la calidad de las relaciones entre pares (estudiantes) y docentes, así como en la institución de normas consensuadas. Elementos que pueden propiciar un desarrollo en las diferentes dimensiones del ser humano como lo social, cultural, moral e intelectual. En este orden de ideas, el interior de las aulas de clase es uno de los escenarios en los cuales se pueden propiciar relaciones de cuidado y bienestar o, por el contrario, generar ambientes de hostilidad y hasta agresión.

El estudio más reciente acerca del tema es la encuesta realizada por la Secretaría de Educación de Bogotá (2013), que ofrece un panorama sobre el clima escolar en las instituciones educativas, otorgando importancia a las interacciones, las relaciones y la cotidianidad creada en el aula, condicionada al tipo de práctica pedagógica. Los datos evidencian que en un $46 \%$ los estudiantes toleraron burlas, interrupciones y conversaciones de otros en clase, lo cual genera múltiples distracciones, indicando que un $44 \%$ de los estudiantes percibían que no se podía dictar clase. Es posible que estos resultados sean el indicativo de cómo un deteriorado clima de aula afecta, tanto el proceso de aprendizaje de los estudiantes y las relaciones de convivencia, como las condiciones de los maestros y maestras que tienen que enfrentar ambientes de hostilidad y estrés.

Otro elemento importante para el desarrollo del clima de aula son las emociones morales, que han mostrado ser importantes para establecer relaciones prosociales y de cuidado entre los seres humanos; toda vez que lo moral tiene que ver con comprender la manera en que los seres humanos sienten, piensan, dicen y actúan con respecto a las normas sociales, y lo que es aceptable o no socialmente. El concepto de moral tiene varias categorías: el componente racional, donde el sujeto puede analizar y decidir sobre lo correcto o incorrecto dependiendo de las ideas, juicios y habilidades cognitivas; la interiorización de las normas, que depende de los contextos sociales donde se desenvuelve dicho sujeto; y el desarrollo emotivo, es decir, las diferentes emociones y sentimientos como base del comportamiento moral (Rodríguez, 2003).

Ahora bien, para esta investigación se tomó como referente las emociones morales que, de acuerdo a los planteamientos de Nussbaum (2008), nos permiten tener vínculos conscientes con los demás seres humanos a partir de procesos de reflexión intersubjetiva de lo que el sujeto valora y es moralmente aceptado, por ello son cognitivo-evaluadoras y fenómenos sociales que se construyen en un determinado contexto social. Las emociones morales han mostrado ser importantes para establecer relaciones prosociales y de cuidado entre los seres humanos. En estudios realizados por Hoffman (2002), y Bilbo, Urquijo, Barón, Rebollo y Sánchez (2009), se ha evidenciado que el desarrollo de la culpa y la empatía evitan el maltrato y promueven el bienestar de los demás.

Por un lado, la culpa es una emoción ligada a los valores de las personas y a la manera como se reacciona para reparar el daño y ser responsable con el otro (Rojas, 2009). Esta emoción tiene dos formas de asumirse: una positiva, relacionada con la toma de perspectiva y control de impulsos frente a conductas que generan daño individual o colectivo, buscando una acción que repare el daño causado; y otro negativo, que tiene que ver con la capacidad de sentir miedo, dolor y angustia, convirtiéndose en una carga tormentosa, lo que no permite trascender a tener un efecto reparador hacia el daño causado. Por lo tanto, la culpa manejada de manera positiva ayuda a construir relaciones sociales y tener conciencia del otro: "En la culpa, el agente acepta una responsabilidad por un comportamiento que viola estándares internalizados de conducta religiosa, moral o ética; se focaliza en condenar el hecho deseando enmendarlo o compensarlo o castigar al yo" (Rodríguez, 2003, p.26).

Por otro lado, la empatía es la acción de sentir algo que es más congruente con la situación de otro (Hoffman, 2002; Bilbo, Urquijo, Barón, Rebollo y Sánchez, 2009); se trata de una emoción congruente con el estado emocional del otro, es decir, colocarse en su lugar como una respuesta emocional que procede de comprender su estado o situación y es similar a lo que ese otro está sintiendo, 
es una variable importante en la conducta prosocial (Batson, citado por Fernández, 2008).

Frecuentemente en la cotidianidad escolar se ve que algunos estudiantes con problemas de agresividad muestran comportamientos poco empáticos; la aparición de la culpa en estos casos está asociada a la transgresión de normas y castigos impuestos por los adultos, más que como resultado de procesos dialógicos y de reflexivos sobre el bienestar colectivo y las relaciones de cuidado que se puedan dar en el aula. Así, un clima positivo en el aula toma gran relevancia a partir de dos componentes fundamentales: La estructura de la clase y el cuidado de las relaciones (Chaux, 2012); a los que se suma el componente normas como otro elemento importante.

La estructura de clase tiene que ver con la adecuación del ambiente, el mobiliario, los contenidos pedagógicos, materiales didácticos, y un conjunto de interrelaciones personales que implica una serie de acuerdos y normas que se desarrollan de manera conjunta entre docentes y estudiantes. Por su parte, las relaciones de cuidado son el conjunto de acciones que buscan atender las necesidades del otro por encima de las propias, e implican un desplazamiento motivacional en el marco de una comunicación de doble vía (Noddings, citado por Rivera, 2009, p. 29); así: “Cuidar y ser cuidado es una necesidad básica humana. El sentirse recibido por otras personas y el saberse capaz de motivar la respuesta de otros frente a una necesidad propia, son elementos centrales en la vida de cualquier individuo" (Chaux, Daza y Vega, 2008, p. 4).

Como docentes es importante considerar que en las relaciones de cuidado se deben tener en cuenta aspectos como: la preocupación mutua, la calidez, el afecto y la comunicación clara y abierta; los cuales llevan a relaciones de bienestar donde el docente, como orientador de la clase, debe garantizar que estos factores estén presentes en el clima de aula. La relación del profesor con sus estudiantes está tradicionalmente ligada a la idea de que los maestros son el factor crucial de la educación en el aula, pues a través de su práctica pedagógica pueden generar una atmósfera tranquila, ordenada y orientada al aprendizaje; al respecto:

La labor de enseñanza y el modelo de persona que el profesor proporciona a sus alumnos, contribuye [...] a la formación de la personalidad de los que serán, a su vez, los protagonistas del futuro. [...] Para ser eficaz como educador, el profesor puede y debe darse cuenta de lo que hace y de lo que puede hacer en su aula para crear un ambiente favorecedor de una buena autoestima de sus alumnos y de una convivencia que facilite esta labor (Voli, 2004, p. 78).

El docente es un agente facilitador y generador de emociones y relaciones adecuadas en el aula, porque las entiende como eje principal que impacta y es modelo para las acciones y relaciones

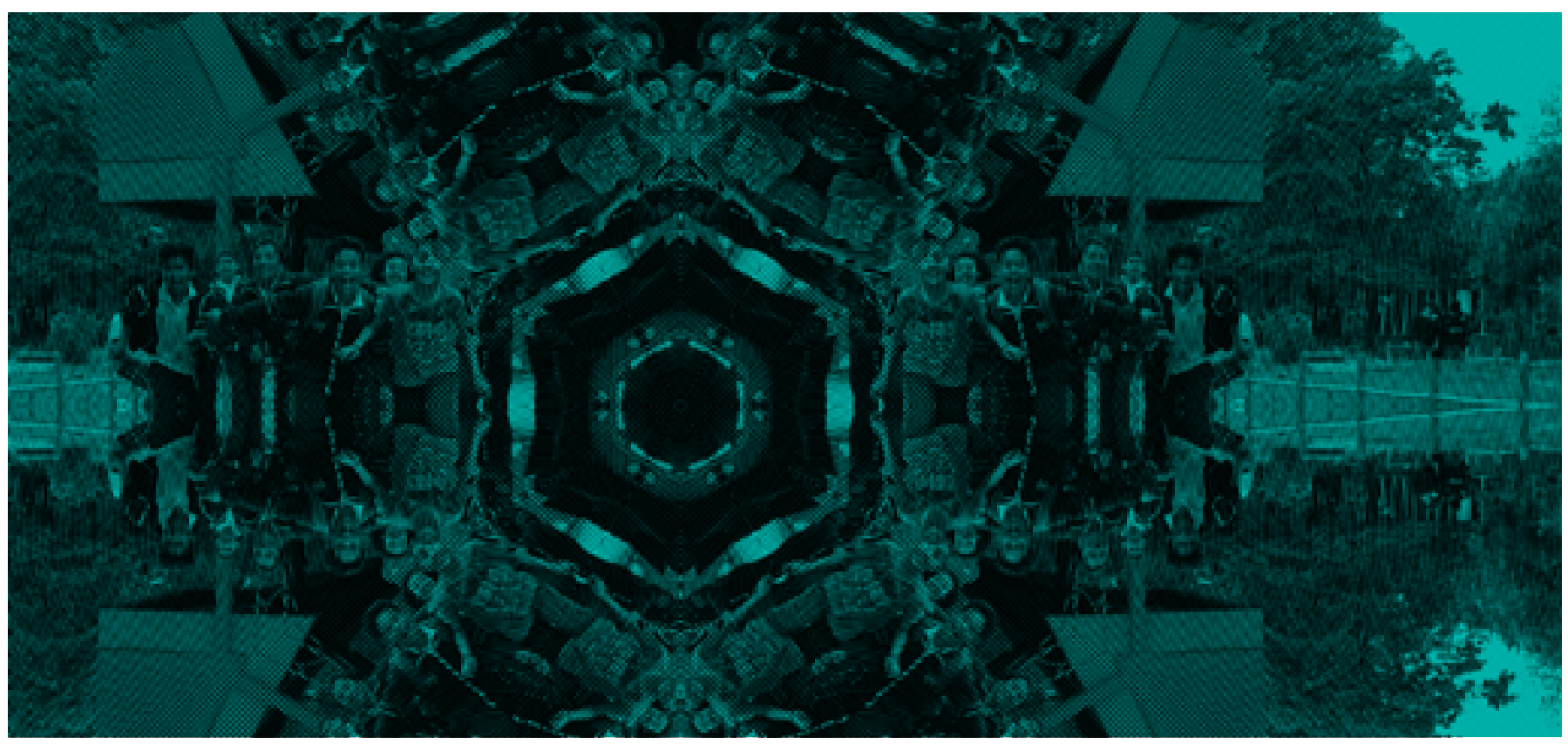


de sus estudiantes; el clima que se genere en el aula promoverá o no este tipo de relaciones entre ellos. Es pertinente pensar que los estilos autoritarios en los que muchos hemos crecido y que con frecuencia se reflejan también en la escuela, son contradictorios con la generación de ambientes de cuidado, ya que promueven relaciones de sumisión y miedo, en donde las necesidades de cada uno y el bienestar común pasan a segundo plano.

En el clima de aula también influyen las normas, la forma en que se establecen en el aula de clase hará que se entiendan como una imposición o como una forma de autorregulación indispensable para propiciar el bien común; en un clima de aula positivo, las normas, antes que imposiciones o parámetros para buscar utilidad, se constituyen en decisiones conscientes y reflexivas de los individuos a partir de preferencias y creencias (Bicchieri, 2006). Esto refuerza la idea de generar relaciones democráticas al interior del aula, que permitan la participación y la reflexión de los estudiantes alrededor de las normas necesarias para lograr el bienestar común. Las normas son inherentes a la convivencia en sociedad $y$, al interior del aula, deben ser consensuadas, conocidas y aceptadas a partir de un diálogo de confianza entre docentes y estudiantes (Carrasco, et al, 2011).

Identificar la relación entre el clima de aula positivo y las emociones de empatía y culpa en estudiantes, permitirá ahondar en la comprensión del clima de aula y su relación con el fomento de las emociones morales; al tiempo que en el diseño de estrategias e implicaciones prácticas que mejoren el clima en el aula y promuevan la convivencia escolar pacífica.

\section{Muestra}

La investigación se desarrolló en la Localidad de San Cristóbal con cuatro instituciones distritales de la ciudad de Bogotá, trabajó una muestra de 189 estudiantes de los grados sextos de educación básica secundaria, 90 del género femenino y 99 del masculino, con edades comprendidas entre los 10 y los 14 años: 1 estudiante de 10 años, 75 de 11 años, 61 de 12 años, 40 de 13 años y 12 de 14 años. Para determinar el número de estudiantes de cada institución se usó un muestreo aleatorio simple, con confiabilidad del 95\% y error de estimación del 5\%.

\section{Procedimiento}

La muestra fue seleccionada por conveniencia, pues las investigadoras tienen acceso directo a los grupos en las instituciones donde laboran. En las cuatro entidades educativas se aplicó un cuestionario a la muestra seleccionada, y se elaboró un consentimiento informado donde los padres de familia daban el aval para que sus hijos lo presentaran. Para la aplicación del instrumento se procedió a crear un protocolo de instrucciones para las investigadoras, con el fin de mantener criterios similares en su aplicación en cada una de las instituciones.

\section{Instrumentos}

Se diseñó un cuestionario que incluyó una escala tipo Likert con las tres categorías de estudio: Clima de aula, culpa, y empatía. El resultado final del instrumento fue de 54 preguntas: cincuenta para contestar con la escala tipo Likert (siempre (5), casi siempre (4), algunas veces (3), casi nunca (2), nunca (1)), y cuatro para contestar con respuesta de Sí o No. Se realizó un análisis de confiabilidad o consistencia interna a partir del alfa Cronbach, donde se encontró una consistencia de 0,746 para la dimensión de clima de aula, en la dimensión de empatía fue de 0,771, y en la de culpa fue de 0,733 .

\section{Resultados}

Para responder a la pregunta ¿Existe relación entre el clima de aula positivo y la presencia de emociones de empatía y culpa en estudiantes de sexto grado de la ciudad de Bogotá?, en primer lugar se realizó un análisis de correlación entre las variables: clima de aula, culpa y empatía; debido a que todas las variables mostraron una distribución normal, se utilizó el coeficiente de correlación de Pearson. En la Tabla 1 pueden observarse los resultados. 
Tabla 1. Correlaciones entre las variables clima, empatía y culpa

\begin{tabular}{|l|l|r|r|r|}
\hline \multicolumn{5}{|c|}{ Correlaciones } \\
\hline \multirow{3}{*}{ Clima } & Correlación de Pearson & 1 &, $296^{\star \star}$ &, $572^{\star \star}$ \\
\cline { 2 - 5 } & Sig. (bilateral) & &, 000 &, 000 \\
\cline { 2 - 5 } & $\mathrm{N}$ & 165 & 163 & 162 \\
\hline \multirow{3}{*}{ Empatía } & Correlación de Pearson &, $296^{\star \star}$ & 1 &, $567^{\star \star}$ \\
\cline { 2 - 5 } & Sig. (bilateral) &, 000 & &, 000 \\
\cline { 2 - 5 } & $\mathrm{N}$ & 163 & 185 & 180 \\
\hline \multirow{3}{*}{ Culpa } & Correlación de Pearson &, $572^{\star \star}$ &, $567^{\star \star}$ & 1 \\
\cline { 2 - 5 } & Sig. (bilateral) &, 000 &, 000 & \\
\cline { 2 - 5 } & $\mathrm{N}$ & 162 & 180 & 184 \\
\hline \multirow{2}{*}{ ** La correlación es significativa al nivel 0,01 (bilateral). } \\
\hline
\end{tabular}

Según los análisis existe una correlación significativa positiva alta entre las variables clima de aula y culpa $(r=0.57, p=.00)$, mientras que las variables clima de aula y empatía presentan una correlación significativa y positiva, aunque baja $(r=0,29, p=0.00)$.

En segundo lugar, se realizó un análisis de regresión lineal entre las variables, debido a que las correlaciones indicaron la existencia de relación entre clima de aula y culpa, y entre clima de aula y empatía; se realizaron algunos modelos de regresión lineal para determinar si las variables dependientes, culpa y empatía, eran explicadas por la independiente: clima de aula (Ver tabla 2)

Tabla 2. Resumen del modelo entre la variable independiente, clima de aula, con las variables dependientes culpa y empatía

\begin{tabular}{|l|r|r|r|r|}
\hline \multicolumn{1}{|c|}{ Modelo 1 } & R & R2 & R2 Corregido & $\begin{array}{c}\text { Error tip. De la } \\
\text { estimación }\end{array}$ \\
\hline Clima de aula - Culpa &, $572 a$ &, 328 &, 323 &, 54154 \\
\hline Clima de aula - Empatía &, $296 a$ &, 088 &, 082 &, 60242 \\
\hline
\end{tabular}

Debido a que el clima de aula explica la presencia de culpa en el aula de clase en $32,8 \%$, y de igual forma explica la presencia de empatía en un $8,8 \%$, se decidió hacer un análisis de regresión lineal múltiple entre las variables dependientes y las variables independientes; los componentes del clima incluidos en este estudio fueron: estructura de clase, relaciones de cuidado y normas. 


\section{Tabla 3. Resumen del modelo entre Clima de Aula y sus componentes con las variables dependientes culpa y empatía}

\begin{tabular}{|l|r|r|r|r|}
\hline \multicolumn{1}{|c|}{ Modelo 1 } & R & R2 & R2 Corregido & $\begin{array}{c}\text { Error tip. De la } \\
\text { estimación }\end{array}$ \\
\hline $\begin{array}{l}\text { Variables componentes de Clima } \\
\text { de aula con culpa }\end{array}$ &, $657 b$ &, 431 &, 420 &, 50123 \\
\hline $\begin{array}{l}\text { Componentes normas, Relaciones } \\
\text { de cuidado - culpa }\end{array}$ &, $654 \mathrm{c}$ &, 428 &, 421 &, 58439 \\
\hline $\begin{array}{l}\text { Variables componentes de Clima } \\
\text { de aula con empatía }\end{array}$ &, $397 \mathrm{~b}$ &, 157 &, 141 &, 59384 \\
\hline $\begin{array}{l}\text { Componentes estructura de clase, } \\
\text { relaciones de cuidado - empatía }\end{array}$ &, $404 d$ &, 164 &, 153 &, \\
\hline
\end{tabular}

Los resultados demuestran que el modelo completo de clima de aula fue significativo y explica un $43,1 \%$ de la culpa $(R=.65$ $p=, 000)$; de la misma forma, exponen que el modelo completo de clima de aula explica un $15,7 \%$ de la empatía $(R=.397, p=, 000)$.

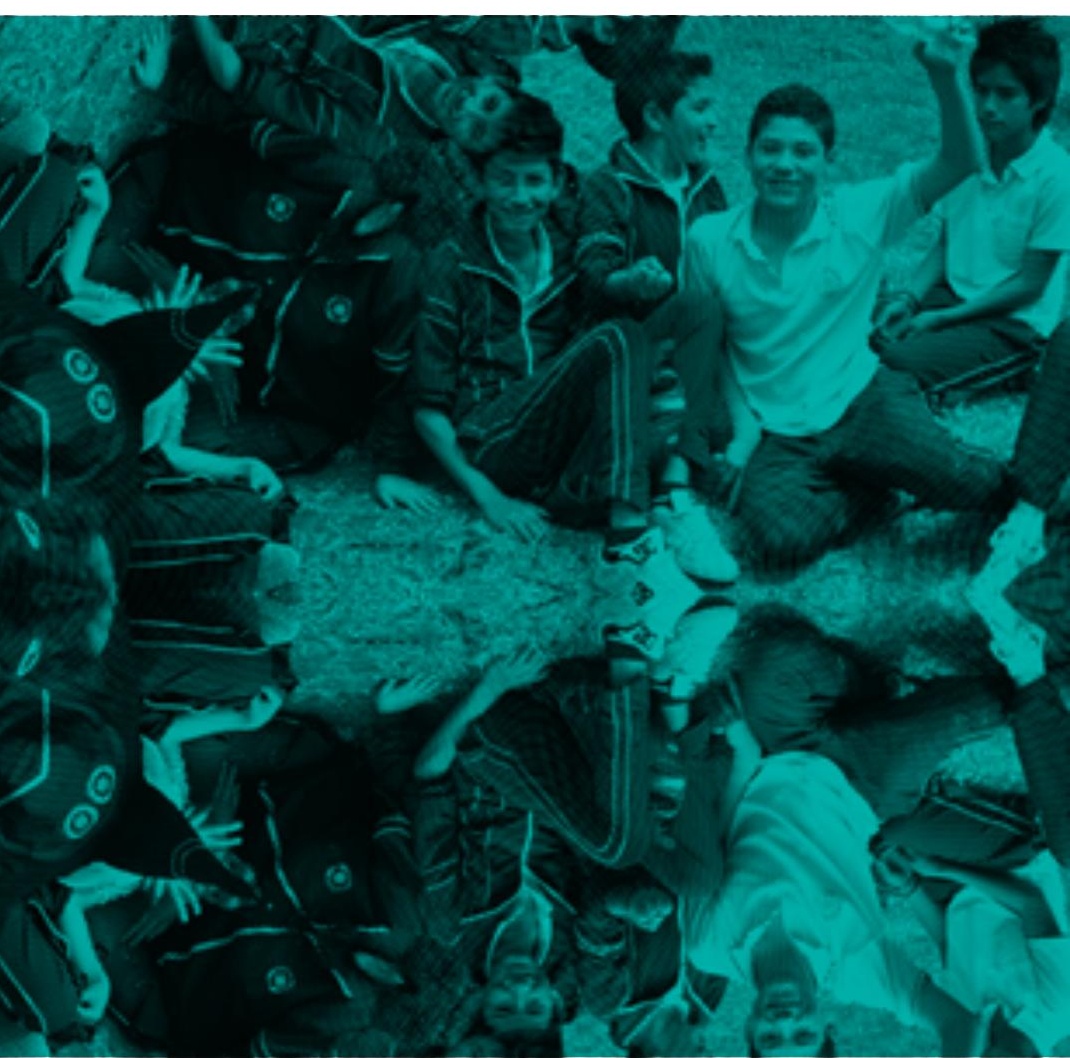

Sin embargo, se evidenció que los resultados de los componentes normas $(p=0.000 y \beta=.40$ ) y relaciones $(p=0,000, \beta=.38)$, tienen más relación con la culpa, y por lo tanto sí explican la presencia de esta emoción en los estudiantes en un $42,8 \%$, en comparación con los tres componentes de clima de aula que la explican en un 32,8 , presentando así un aumento del $10 \%$ al quitar al componente "estructura" $(p=0,824>0,05)$, por no presentar un aporte al modelo de regresión. Finalmente, la variable dependiente "empatía" muestra una relación significativa con los componentes "relaciones de cuidado" ( $(=.466, \mathrm{t}=4.8, p<.005)$ y "estructura" $(\beta=-.189, \mathrm{t}=-2,1, \mathrm{p}=<.005)$ mientras que las "normas" $(\beta=.004$, $t=.044, p=.965)$ no aportan al modelo.

\section{Discusión}

El presente estudio pretendió abordar la relación entre el clima de aula y la influencia de las emociones morales: empatía y culpa. Los principales resultados muestran que hay relación positiva entre clima de aula y emociones morales, debido a que éstas juegan un importante papel dentro del aula, pues son las que permiten regular las acciones y las relaciones entre iguales y entre docentes y estudiantes. Esta convivencia diaria permite ver cómo el clima de aula influye sobre las emociones, ya sea en forma directa, con las acciones educativas que se ven en la estructura de las clase o la organización de normas, o en forma indirecta, que se desarrolla dentro de un currículo oculto con las acciones no programadas 
que se pueden observar en el aula con las diferentes relaciones que se gestan allí, motivadas por los diferentes estilos manejados por los docentes.

\section{Clima de aula: su} relación con empatía, relaciones de cuidado y estructura de clase

En nuestra investigación la relación directa entre clima de aula y empatía es positiva, la escuela es uno de los escenarios para que los jóvenes socialicen y adquieran capacidad empática. En esta obtención las prácticas pedagógi-

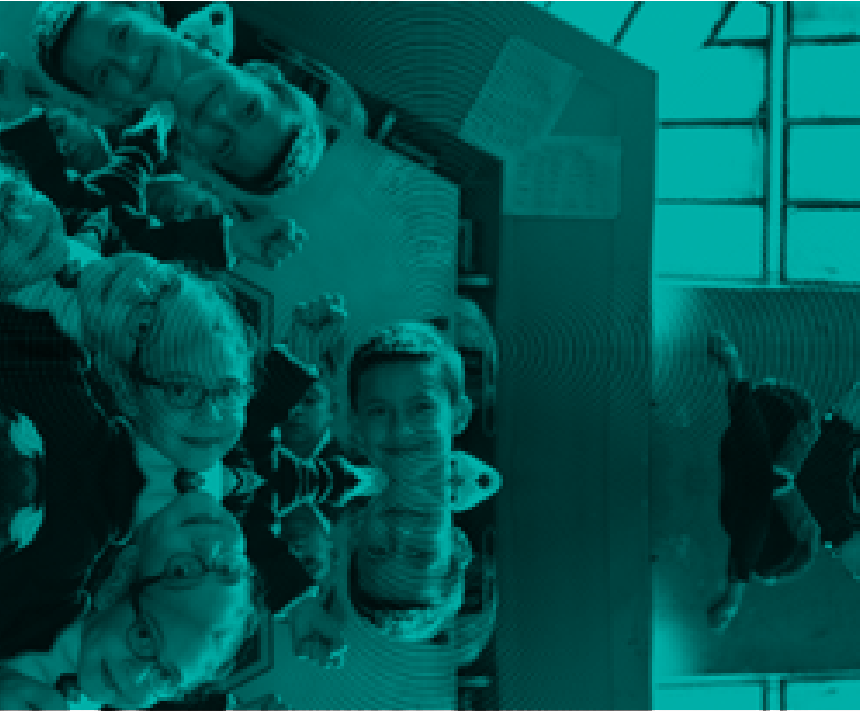

prevalencia del estilo negligente, debido a que hay una despreocupación por las normas y el afecto, y por lo tanto una desconexión entre docente y estudiante.

Los resultados de esta investigación, frente a la relación entre clima de aula y empatía, sugieren un desafío para la institución escolar; es importante incluir a la familia y al estudiante en procesos pedagógicos que estimulen la adquisición de esta emoción, especialmente en la escuela primaria. Lo anterior se sustenta en autores como Cepeda (2004), quien afirma que la empatía se adquiere cuando el niño tiecas y el clima de aula, promovido por el docente, son los elementos fundamentales para que, desde la cotidianidad escolar y las experiencias vividas, se desarrolle esta capacidad. Huegun (2009) reafirma nuestro estudio cuando señala que: "La generación de un clima relacional se sustenta en el respeto y la aceptación de las experiencias que comunican los jóvenes, y se plasma a través de las respuestas interaccionales y verbales concretas que ofrece el educador" (p, 16).

Las relaciones de cuidado dentro del aula permitirán afianzar la capacidad empática, pues los estudiantes se sentirán en un ambiente de confianza, de respeto entre profesores y pares, y evitarán agresiones, promoviendo un clima de aula positivo. Estudios como el de Eisenberg (2000) señalan que la sensibilidad empática puede favorecer el altruismo y reprimir la agresión. Otra categoría dentro del clima de aula es la estructura, que para esta población es negativa, situación que podría indicar que las estrategias metodológicas usadas por los docentes pueden no promover trabajos cooperativos, así como las respuestas empáticas ante situaciones de aislamiento de compañeros de clase, o de interacción con compañeros diferentes al grupo de pares habitual.

En el estudio los estudiantes manifestaron que, en situaciones que ameritan una intervención para dirimir posibles interrupciones de clase, la mayoría de docentes hace caso omiso y no manifiesta respuestas empáticas ante situaciones de malestar y maltrato en el grupo. Teniendo en cuenta la clasificación del estilo docente de Chaux (2012), los resultados del estudio permiten concluir que la práctica educativa de los docentes se puede caracterizar por la ne una serie de condiciones, en su entorno familiar y escolar, que le permitan experimentar y expresar sus emociones y entender las de los demás, saliendo del egocentrismo.

Estudios como el de Moreno, Estevez, Murqui y Musito (2009) sugieren que existe un vínculo entre el clima familiar y el comportamiento empático del estudiante en su contexto escolar; si al interior de la familia se presentan conflictos, falta de comunicación y cohesión afectiva, éste tendrá dificultades para relacionarse con sus pares y profesores en la toma de perspectiva y en la capacidad de comprender los sentimientos del otro. Nuestros resultados confirman dicha idea, toda vez que analizando las relaciones de cuidado y el clima de aula, con respecto a la empatía, se observó una relación positiva. Lo anterior debe ser considerado cuidadosamente, pues aunque los resultados obtenidos son estadísticamente significativos, las correlaciones entre las variables son bajas y moderadas para la muestra.

\section{Clima de aula, su relación con la culpa, relaciones de cuidado y normas}

La relación culpa y clima de aula presenta una asociación significativa positiva. Para nuestra investigación la culpa fue abordada desde la perspectiva de una emoción asociada con una respuesta empática hacia otros, que ofrece la posibilidad de poner en perspectiva los acontecimientos. En esta medida, se puede considerar como una emoción guardián de nuestra conducta y nos sirve de guía, funciona como un controlador de nuestros impulsos. 
La culpa es un conjunto emocional con diversos componentes, no únicamente implica las cuestiones morales; sus alcances están relacionados con normas y metas que tienen su origen en las preocupaciones intrapersonales. Así pues, en nuestro estudio se evidenció que el clima de aula tiene una mayor relación con la culpa, posiblemente porque gran mayoría los preadolescentes han interiorizado las normas en sus diferentes espacios sociales, incluido el del aula: la culpa en los adolescentes se presenta cuando se incumplen leyes sociales, obviando las cuestiones tradicionales que causa (mentir, hacer trampa).

Las relaciones de cuidado con respecto a la culpa y el establecimiento de normas fueron significativas; aunque la culpa es una emoción auto-evaluativa, se afianza a través de procesos de socialización, configurándose en una práctica de grupo, lo cual es de gran importancia en el aula de clases, dado que allí sí se construyen relaciones más cercanas, haciendo que ésta sea comprendida más allá de la perspectiva de una moral del deber ser (Rojas, 2009).

La norma, como suceso de respuesta a otros por la valoración del bien común, y no desde su perspectiva jurídica-legal, que implica seguir la sanción y el castigo, se refiere a un criterio ético de participación, reflexión y reparación. En este sentido, a través ella el maestro promueve procesos de miedo al castigo o enfocados en la culpa reparadora (Bustelo, 1998).

Para finalizar, es indudable la necesidad de afianzar la educación moral dentro del aula para fortalecer las relaciones de convivencia entre pares y entre estudiantes y docentes. Uno de los aportes a destacar en esta investigación fue la exploración de un nuevo campo dentro del contexto educativo, poco abordado en nuestro país, que permitirá generar nuevas investigaciones. A su vez, fue posible construir un instrumento base para evaluar la relación entre el clima de aula y las emociones morales. Aunque debemos tomar con precaución los resultados obtenidos debido a que la muestra es pequeña, son útiles como referencia para reflexionar sobre cómo se percibe la relación entre clima de aula y las emociones morales, de tal manera que mejore la práctica docente. 


\section{Bibliografía}

Abarca Castillo, M. (2003). La Educación Emocional en la educación primaria: currículo y práctica. Tesis de Doctorado no publicada. Universidad de Barcelona

Arias y Delgado. (2009). Educación en valores y ciudadania desde una perspectiva cotidiana. Bogotá IDIE, pp. 44-62.

Barreda Gómez, S. (2012). El docente como gestor del clima de aula. Factores a tener en cuenta. Tesis de Maestría no publicada. Formación del profesorado Educación secundaria. Universidad de Cantabria. España.

Berkowitz, W. (1995). Educar la persona moral en su totalidad. Revista Iberoamericana de Educación (8), pp. 73-101.

Bermúdez, B. (2011). La construcción de la confianza en la relación estudiante-docente en la Facultad de Administración de la UNAL de Colombia. Tesis de Maestría no publicada. Universidad Nacional de Colombia.

Bicchieri, C. (2006). La gramática de la sociedad. La naturaleza y la dinámica de las normas sociales. Cambridge: Cambridge UniversityPress.

Bilbo, I., Urquijo, P., Barón, M., Rebollo, M., y Sánchez, F. (2009). Emociones morales y conducta en niños y niñas. Revista de psicología y educación, Edupsykhé, Vol. 8, No. 1, p. 3.

Bonilla, E. (1997). Más allá del dilema de los métodos. La investigación en Ciencias Sociales. Barcelona: Uniandes.

Bustelo, E. (1998). Todos entran: propuesta para sociedades incluyentes. Bogotá: Santillana.

Carrasco, N., Orozco, M., Pino, S., y Vargas, V. (2011) ¿Qué relación existe entre el clima emocional de aula y el rendimiento escolar de niños y niñas de $2^{\circ}$ año de básico de una escuela Municipal de Cerro Navia. Tesis de Maestría no publicada. Universidad Academia de Cristianismo Humano. Santiago.

Casassus, J. (2003). La escuela y la (des) igualdad. Santiago: Colección Escafandra.

Cepeda, M. J. (2004). Ciudadanía y Estado Social de Derecho. Trabajo presentado en el Foro Educativo Nacional de Competencias Ciudadanas.
Bogotá, octubre 25. Obtenido desde http://www.mineducacion.gov. co/1621/articles-116042_archivo_pdf4.pdf

Cepeda, A. (2004). La relación inversa entre empatía y agresión. Bogotá: Universidad de los Andes.

Cortina, A. (1996). Ética minima.: Introducción a la filosofía práctica. Madrid: Tecnos.

Chaux, E., Daza, B., Vega, L. (2008). Las relaciones de cuidado en el aula y la institución educativa. Obtenido desde: http://www.colombiaaprende.edu. co/html/mediateca/1607/articles-168209_archivo.pdf

Chaux, E. (2012). Educación, convivencia y agresión escolar. Bogotá: Taurus.

Daza, Bertha. (2009). Educación en valores y ciudadania desde una perspectiva cotidiana. Bogotá: IDIE, pp. 32-41.

De Zubiría, J. (2006). La violencia en los colegios de Bogotá. Obtenido desde http://www.institutomerani.edu.co/publicaciones/articulos/2009/ La_violencia_en_los_colegios_de_Bogot $\%$ C3\%A1.pdf.

Echeburúa, Corral y Amor. (2001). Estrategias de afrontamiento ante los sentimientos de culpa. Revista Análisis y modificación de conducta, Vol. 27, No. 116.

Einsenberg, N. (1976). Conducta prosocial. Obtenido el 6 de septiembre de 2014, desde http://reeduca.com/desarrollomoral-altruismoeisenb.aspx

Einsenberg, N. (2000). Emotion, regulation and moral development. Annu. Rev. Psychol, 51, pp. 665-697.

Fernández, P. (2008-diciembre). Empatía: Medidas, teorías y aplicaciones en revisión. Anales de psicología, Vol. 24, No. 2. Universidad Autónoma de Madrid.

García, Haro, J. (2015). Tres concepciones de la culpa escolar como factor de calidad. Madrid: Narcea ediciones.

Gutiérrez, M. (2008). Batería de instrumentos para la evaluación del clima escolar en escuelas primarias. México: Instituto Nacional para la Evaluación 
de la educación INEE. Obtenido desde http://blog.educastur.es/ autoevaluacion/files/2008/02/bateria-de-instrumentos-para-la-evaluacion-del-clima-escolar.pdf

Hansberg, O. E. (1996). De las emociones morales. México: Universidad Autónoma de México.

Hoffman, M. L. (2002). Desarrollo moral y empatía: implicaciones para la atención y la justicia. Cornellà del Lobregat: Idea Books.

Huegun, A. (2009, octubre-diciembre). La importancia de la empatía en el trabajo del educador para unas relaciones saludables. A tu salud. Revista de la Universidad Vasca (67-68), pp.15-19.

Laorden Gutiérrez, C. (2005). Educar emociones: un instrumento para trabajar el sentimiento de culpa. Revista Pulso, No. 28, pp. 125-138.

Martínez, M. (1996). El clima de la clase. Barcelona: Wolters Kulwer.

Monje, C. (2011). Metodología de la investigación cuantitativa y cualitativa. Neiva: Universidad Sur Colombiana. Colombia.

Moreno, D., Estevez, E., Murqui, S., y Musito, G. (s.f.). Relación entre el clima familiar y el clima escolar: el rol de la empatía y la actitud hacia la autoridad en la conducta de violencia en la adolescencia. International Journal Psychology and Psychological Therapy, 9(1), pp. 125-133.

Nussbaum, M. (2006). El ocultamiento de lo bumano. Buenos Aires: Katz.

Nussbaum, M. (2008). Paisajes del pensamiento. La inteligencia de las emociones. Barcelona: Paidós.

Olson, C.O., y Wyett, J. L. (2000). Teachers need affective competencies. Education, Vol. 120. Obtenido desde http:// findarticles.com/p/articles/mi_qa3673/ is_200007/ai_n8902469

Ortega y Del Rey. (2007). Violencia escolar: claves para comprenderla y afrontarla. Revista Departamento de Psicología Evolutiva y de la Educación. 10, pp. 77-89. Universidad de Córdoba.

Pérez, L. (2012). Normas de aula y proactividad. Hacia la disciplina positiva. Navarra: Gobierno de Navarra.
Placarte, R. (2015). ¿Son racionales las normas sociales? Revista estudios sobre Estado y sociedad, 22(64), pp. 10-40.

Rawls, J. (2003). Teoría de la justicia. México: Fondo de Cultura Económica.

Rivera, C. (2008). El cuidado: Una alternativa en la educación moral. Bogotá: Universidad Javeriana.

Rodríguez, G. (2003). Infuencia del desarrollo moral, las emociones y la identidad sobre la acción moral. Tesis Maestría en Psicología no publicada. Bogotá. Universidad de los Andes.

Rodríguez, G. (2008). Sentimientos y actitudes en la escuela, en educación, valores y ciudadanía. Madrid: OEI.

Rojas, L. (2009). El sentimiento de culpa. Madrid: Aguilar.

Sánchez, J., y Sanz, A. (2011). ¿Qué es una norma social? Una discusión de tres aproximaciones analiticas. Revista internacional de sociología, 69 (3), pp. 661-583.

Sánchez, I. (2009, octubre 8). Clima escolar y resolución de conflictos. Obtenido desde https://inmasanchez.wordpress.com/2009/12/27/ clima-escolar-y-resolucion-de-conflictos/

Secretaría de Educación de Bogotá (SED). (2010). Reorganización curricular por ciclos. Referentes conceptuales y metodológicos. Bogotá: SED.

Secretaría de Educación de Bogotá (SED). (2013). Encuesta de clima escolar y victimización. Bogotá: SED.

Smetana, J. (1997). Crianza y el desarrollo de conocimiento social reconceptualizado: Análisis en el dominio social. En las relaciones y la internalización de los valores para niños. Nueva York.

Villegas de Posada. (2002). Educación para el desarrollo moral. Bogotá: Universidad de los Andes y Alfaomega.

Voli, F. (2004). Sentirse bien en el aula. Manual de convivencia para profesores. Madrid: Educar. 


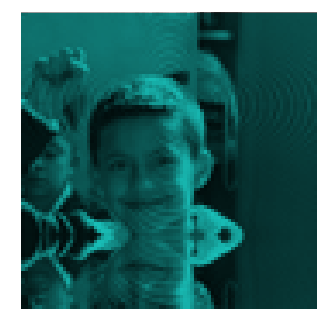




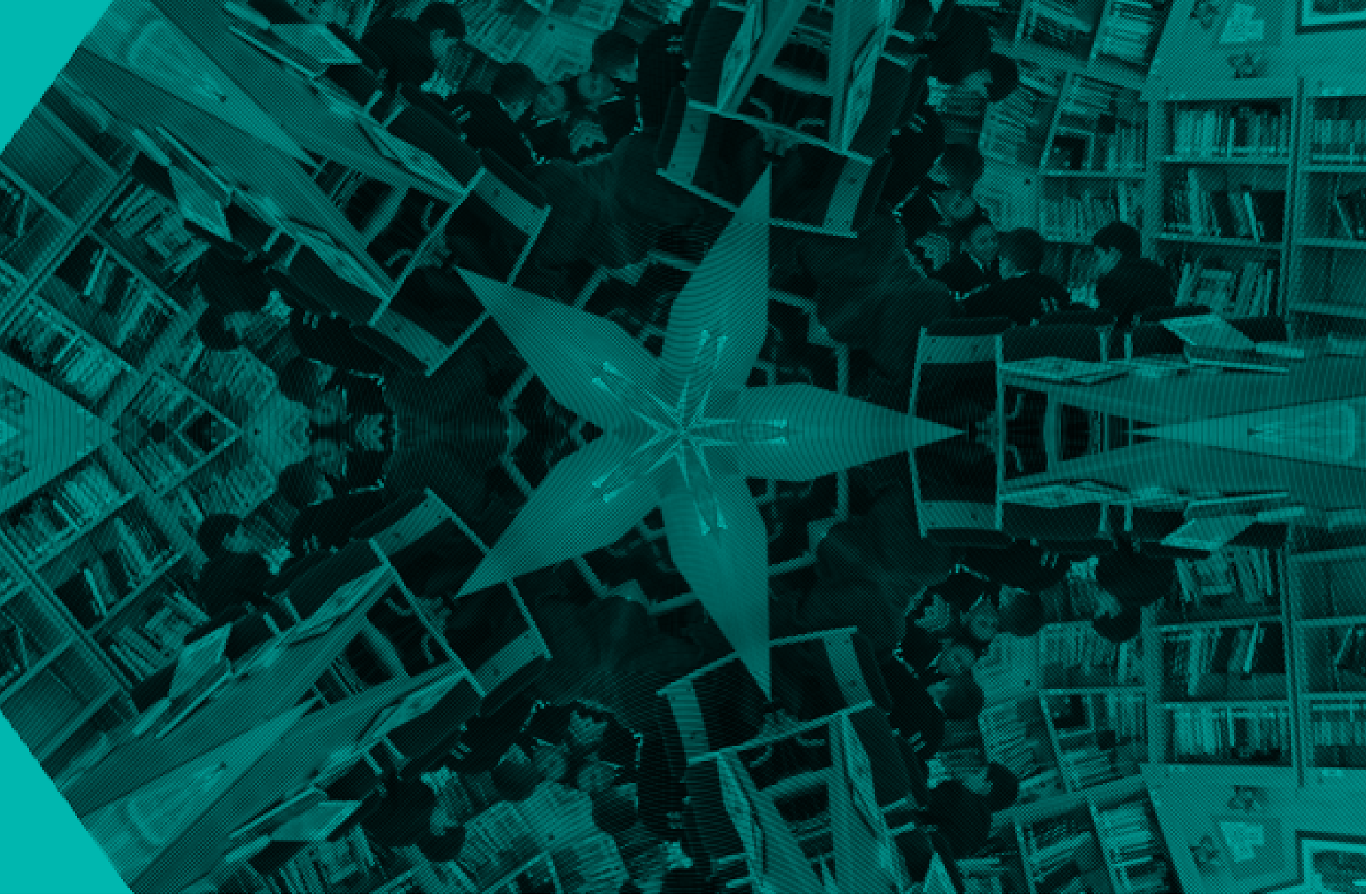

Romper estereotipos de género en la identidad
profesional docente: una propuesta de paz

Breaking gender stereotypes in teacher professional identity: a peace proposal

Quebrar os estereótipos de género na identidade profissional do professor: uma proposta de paz

Luisa Pinzón Varilla 
Luisa Pinzón Varilla 1
1. Licenciada en Lingüística y Literatura, Universidad Distrital Francisco José de Caldas; Magister en Educación, Pontificia Universidad Javeriana; docente de la Secretaría Distrital de Educación; estudiante del Doctorado Interinstitucional Universidad Distrital; correo electrónico: lu_pinzonv@hotmail.com

Artículo de reflexión basado en investigación.

Fecha de recepción: 26 de febrero de 2016 / Fecha de aceptación: 16 de septiembre de 2016

\section{Resumen}

El objetivo de este artículo es presentar un avance de los resultados de la investigación doctoral "Narrativas de la identidad profesional docente en perspectiva de género", que se centró en la comprensión de las identidades profesionales de los y las docentes del Distrito Capital de Bogotá (Colombia). El estudio analizó e interpretó un corpus de narrativas biográficas acerca de las experiencias de género que se viven en el ejercicio de la profesión docente. Metodológicamente se adoptó el enfoque de investigación cualitativa de corte hermenéutico.

Palabras clave: Identidad, narrativa, género, identidad narrativa, estereotipos.

\section{Summary}

The aim of this paper is to present a preview of the results of the doctoral research: "Narratives of teacher professional identity in gender perspective".

This research focused on understanding the professional identities of the teachers of the Capital District of Bogota (Colombia). The study analyzed and interpreted a corpus of biographical narratives about experiences of gender that are experienced in the exercise of the teaching profession. Methodologically, the qualitative research approach was adopted hermeneutic.

Keywords: Identity, narrative, gender, narrative identity, stereotypes.

\section{Resumo}

O objetivo deste trabalho é apresentar uma pré-visualização dos resultados da pesquisa de doutorado: "Narrativas de identidade profissional do professor na perspectiva de gênero". Esta pesquisa centrou-se na compreensão das identidades profissionais dos professores do Distrito Capital de Bogotá (Colômbia). O estudo analisado e interpretado um corpus de narrativas biográficas sobre as experiências de gênero que são experientes no exercício da profissão docente. Metodologicamente, a abordagem de pesquisa qualitativa foi adotada hermenêutica.

Palavras chave: Identidade, género, narrativo, identidade narrativa, estereótipos. 


\section{Introducción}

La presente investigación estudia las narraciones, de maestras y maestros, sobre las experiencias de género que acontecen en el ejercicio de su práctica profesional, en el contexto de las instituciones de enseñanza básica y media del Distrito Capital de Bogotá. Se trata de comprender las identidades profesionales docentes desde una perspectiva de género. El presente artículo se refiere a la experiencia relacionada con los estereotipos de género y su incidencia en la discriminación de género, que acontece en el ejercicio de la docencia y su relación con la identidad profesional docente.

En concordancia con el objeto de investigación, el tema de la identidad se abordó desde la perspectiva epistémica de la "Hermenéutica del sî" de Paul Ricoeur (2008), la cual busca comprender al sujeto desde una ruptura con la tradición cartesiana moderna, que supone la vigencia de un sujeto inalterable a la experiencia y no es tocado por los avatares biográficos; en la filosofía riqueriana esta capacidad identificadora del sujeto se ancla en el tiempo mediante una "identidad narrativa".

De acuerdo con los objetivos de la investigación, se identificaron las experiencias de género como acciones situadas en un escenario cultural en el que acontece la práctica de la profesión docente. Estas experiencias permitieron identificar siete casos, entre ellos, uno referido a los estereotipos de género, que presentamos en este artículo.

\section{Referentes conceptuales}

El tema de la identidad ocupa hoy un lugar preponderante en los debates académicos. Autores como Arostegui (2004) han llamado la atención sobre un marcado interés por los "sujetos y las identidades" en nuestros tiempos. Interés que responde a la presencia de otro mundo cultural que no entra en las coordenadas de uniformidad exigidas por los estándares de la globalización, y en este panorama han surgido otros modos de reivindicación de las identidades. Al respecto, Arfuch (2005) ha planteado que este interés por las identidades reúne los cambios ocurridos en el mapa mundial y la crisis de ciertas concepciones universalistas y sus consecuentes replanteamientos deconstructivos.

La llamada "vuelta al sujeto" de la teoría social, y el renovado interés por la investigación histórica, están ligados a la "reclamación" de identidades locales y grupales y a la resolución de conflictos internos en cada región o contexto, de manera que hoy día no cabe duda de que las identidades hacen parte de nuestra cultura y su constitución; en el caso de los docentes es importante en la conformación de nuevas formas de relaciones para dotar a la escuela de herramientas conceptuales y metodológicas que contribuyan a la construcción de una sociedad en paz. Bauman (2004) también enfatiza en este interés reciente por la reivindicación de todo tipo de identidades:

Solo hace unas décadas la "identidad" no ocupaba ni mucho menos un lugar destacado en nuestros pensamientos, limitándose a ser objeto de meditación filosófica. No obstante, hoy la "identidad" constituye "la comidilla de la ciudad", el tema candente que está en la boca y en la mente de todos (2004, p. 42).

El autor describe la identidad como un "amasijo de problemas" comunes a todos los hombres y mujeres de los tiempos de la globalización o de la "moderna era líquida", que se caracteriza por los desequilibrios e incertezas propias de un proyecto en el que todo está sujeto a los cambios en el mapa de las inestabilidades políticas, sociales y culturales de la globalización y de los procesos de resolución de conflictos en términos locales y globales.

A partir de lo expuesto, en una época de "fluidez" o "líquida", se advierte el carácter inestable y preponderante de la identidad, que: "se ha convertido en un prisma a través del cual se descubren, comprenden y examinan todos los demás aspectos de interés de la vida contemporánea" (Bauman, 2004, p. 161). Esta inestabilidad de las identificaciones nos conduce a buscar una alternativa a través del lenguaje, que ancle al sujeto en una historia, una opción que surge con la posibilidad de superar las aporías del tiempo por medio de una historia narrada.

\section{Hacia el concepto de "identidad narrativa" en la filosofía de Paul Ricoeur}

En Sí mismo como otro (2008), Ricoeur se propone elaborar una comprensión del hombre mediante la "Hermenéutica del sí mismo", una propuesta que se concentra en comprender la identidad personal mediante la permanencia en el tiempo, sin evadir las contingencias y los cambios propios de lo que acontece con el paso de la vida. La "Hermenéutica del sî" emerge entre dos tradiciones filosóficas opuestas respecto al tratamiento de la identidad: una, cercana al proyecto epistemológico moderno, que compromete al sujeto con una búsqueda de claves esenciales que desestiman el recurso de la ficción; la otra, cercana al proyecto de la postmodernidad, de la eficacia de la invención para dar cuenta de un "yo" 
tocado por la irrefrenable contingencia propuesta por Nietzsche (Ricoeur, 2008).

Ricoeur plantea que disponemos de dos modelos para permanecer en el tiempo, el "carácter" ${ }^{2}$ y la "palabra dada", en los cuales se reconoce una permanencia que nos permite decir que somos nosotros mismos. En esta polaridad entre el carácter y la fidelidad a la palabra es en la que Ricoeur va a fundamentar la intervención de la "identidad narrativa" como alternativa para evadir los avatares del tiempo en la construcción de la identidad, la cual se debate entre lo que permanece y lo que cambia en nosotros con el paso del tiempo, con una vida vivida.

En la filosofía de Ricoeur la alteridad o presencia de lo otro, está dada en la identificación con las figuras heroicas y con los valores que éstas representan, y es a partir de esta identificación como la lealtad y la fidelidad se incorporan al carácter y éste se inclina hacia la conservación de sí, evidenciándose de esta manera que no se puede pensar el idem (lo mismo) de la persona sin el ipse (lo otro, lo que se adquiere). A estos rasgos se integran a su vez los aspectos de preferencia evaluativa, que son los que van a definir el aspecto ético del carácter, dando origen a las preferencias, apreciaciones y estimaciones, de modo tal que la persona también se reconoce en sus disposiciones valorativas o evaluativas (ética).

En esta aparente paradoja entre la identidad ídem y la identidad ipse es donde Ricoeur ubica la identidad narrativa como mediación entre un límite inferior, donde la permanencia en el tiempo expresa la confusión del ídem (el sí mismo) y del ipse (la alteridad), y un límite superior, en el que el ipse plantea la cuestión de su identidad sin la ayuda y el apoyo del ídem. Es decir que el ipse, esa dimensión que debería ser contingente porque está relacionada más con lo otro que consigo mismo, también guarda una dimensión de permanencia en el tiempo, que se da a través de la palabra mantenida ante la alteridad. En pocas palabras, la promesa permite mantenernos fieles en presencia de la contingente alteridad.

Es en su propuesta de la triple mímesis en donde Ricoeur (2004) explica la manera como se configura la identidad narrativa, explica que la Mímesis I atiende los rasgos de la acción práctica, sus estructuras inteligibles o redes conceptuales de comprensión, y contiene fines, motivos, agentes, circunstancias, interacciones y

2 Entiendo aquí por carácter el conjunto de signos distintivos que permiten identificar de nuevo a un individuo humano como siendo él mismo. Por los rasgos descriptivos que vamos a expresar, acumula la identidad numérica y cualitativa, la continuidad ininterrumpida y la permanencia en el tiempo. De ahí que designe de forma emblemática la mismidad de la persona (Ricoeur, 2006, p. 113). resultados. En otros términos, la historia no narrada. La Mímesis II se pasa a la operación de la configuración, es decir, empezamos a posicionar la identidad narrativa como una mediación entre acontecimientos e historia, en un proceso que se constituye en el paso de la sucesión a la configuración de estructuras inteligibles; en pocas palabras, la historia narrada. Finalmente, la Mímesis III es otra vuelta hacia la vida: "La narración tiene su pleno sentido cuando es restituida al tiempo del obrar y del parecer" (Ricoeur 2004, p. 132). En esta medida, se constituye en la intersección del mundo del texto con el del lector, en el momento de la lectura y de su aplicación, en términos de "fusión de horizontes", y también en la transformación del texto en obra.

Para Ricoeur, es el lector el operador por excelencia que asume mediante su hacer la acción de leer, la unidad del proceso de Mímesis I a Mímesis III, a través de Mímesis II. Es con esta dinámica de construcción de la trama como vamos encontrando la entrada del problema entre tiempo y narración.

El giro hacia las narrativas ha sido uno de los mayores cambios a los que hemos asistido en el campo de la investigación educativa. La narración posee una forma, una estructura, a partir de la cual se pueden ensamblar, mediante la trama, las situaciones más heterogéneas del ámbito escolar: "La narrativa es una capacidad humana fundamental, y por eso el papel que desempeña en la educación merece la mayor atención” (McEwan, 2005, p. 9). En ese mismo sentido, Bruner (2006) ha defendido que la única forma de describir el tiempo vivido es la narrativa; para Ricoeur (2008) la vida se puede comprender como un proyecto biográfico que puede ser narrado o leído. Narrar a sí mismo o a otros lo que ha sido, o va a ser el proyecto personal de vida, es una estrategia para construir una identidad.

\section{Lucha por el reconocimiento de las identidades: feminismo y género}

La identidad o identidades introducen otras cualidades centrales y también problemáticas de la teoría feminista. Esta categoría, central en la presente investigación, aporta interrogantes como: ¿la identidad es una esencia que constituye a los sujetos?; ¿es una construcción constituida por los sujetos?; ¿es ambas cosas? Si es una construcción, ¿se descarta?; ¿se elige?; ¿es posible hacerlo?; ¿es estable? En fin, son muchos los aspectos a tratar cuando se cruza el tema de identidad y género y su incidencia en la educación. 


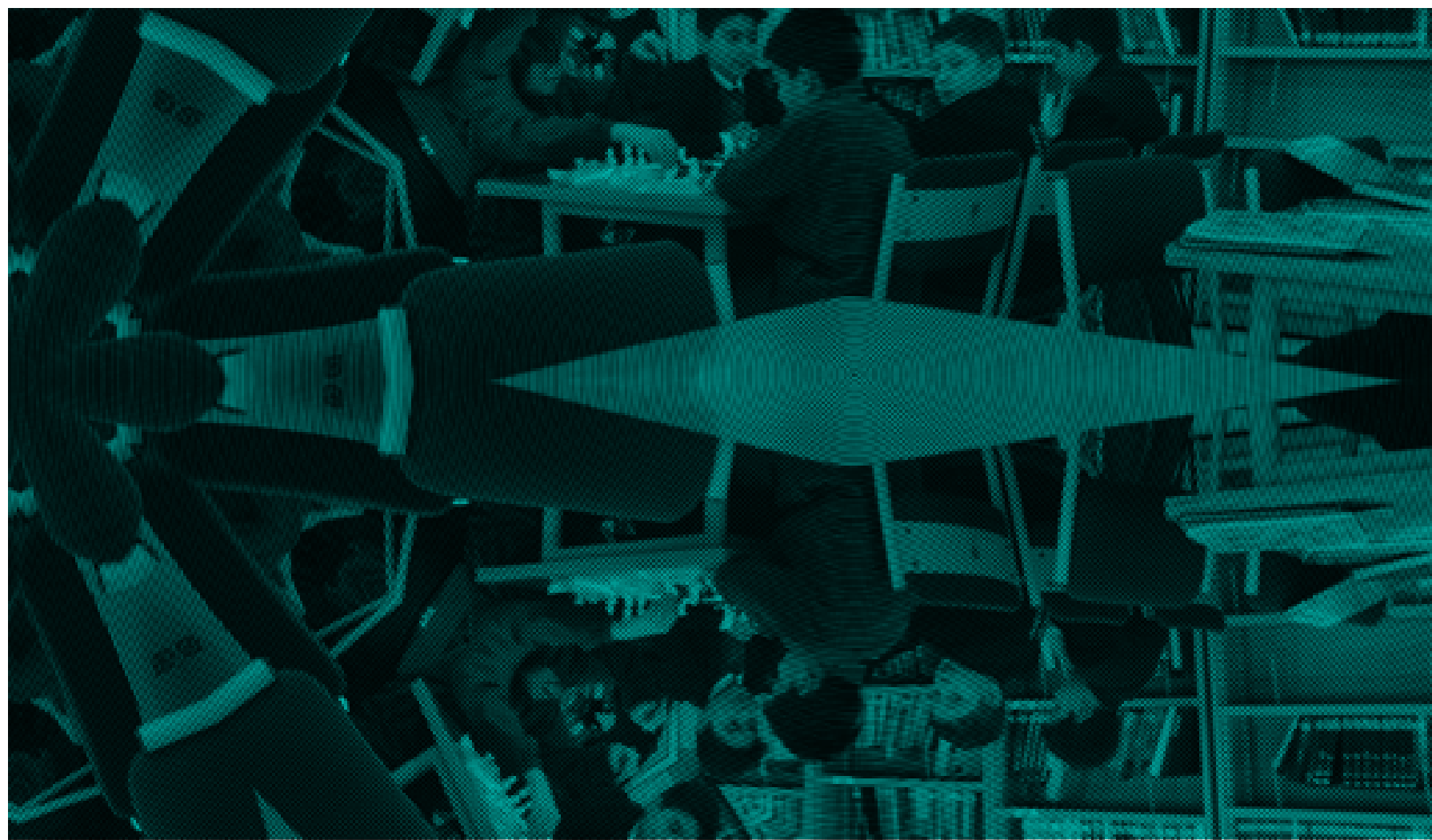

Mientras algunas teorías postulan la necesidad de reconocer todas las identidades y las diferencias entre las mujeres, otras afirman que estos discursos forman una "engañosa retórica" que solo conduce a una fragmentación del poder en términos amplios (Scott, 2000). Para algunas autoras que reivindican la diferencia, es importante hacer aclaraciones contextuales, ya que hay que interrogarse por los aspectos que definen la diferencia, por los parámetros y tipos de comparaciones que se establecen y, sobre todo, por cómo se construye su significado. Al respecto, Scott (2000) plantea que es fundamental atender las diferencias e insistir en ellas, pero sin caer en una sustitución de las diferencias binarias por las múltiples, ya que no se trata de invocar un pluralismo facilista.

Los anteriores debates surgen en los mismos orígenes del feminismo, con las propuestas de reivindicación de las mujeres que buscaban un reconocimiento en condiciones de igualdad política (Wollstonecraft, 1977). La vindicación solo es posible previa existencia de un corpus de ideas filosóficas, morales y jurídicas con pretensiones universalistas aplicables a toda la especie humana
(Amorós, 2000). También podemos señalar que, además de una búsqueda de la identidad política de las mujeres, la noción de género plantea diversos debates acerca de las diferencias sexuales, las relaciones de poder, el sujeto, la raza y la clase.

La categoría género alude a la simbolización que cada cultura elabora de la diferencia sexual, estableciendo normas y expectativas sociales sobre los papeles de las conductas y los atributos de las personas a partir de sus cuerpos, para explicar la desigualdad social y las relaciones de poder entre hombres y mujeres. Una noción más completa entiende el género como una estructura de relaciones de poder, basada en las diferencias que distinguen a los sexos (Scott, 2000). Al ser el género una estructura relacionada con el poder, se explican los niveles de violencia que genera la exclusión de las mujeres y de otros sectores marginados de las instancias de poder en el ejercicio de la experiencia docente. Asumir una cultura para la paz implica incluir en la escuela otras formas de comprender las diferencias sexuales, que no sean la violencia y la exclusión. 


\section{Metodología}

Para comprender los procesos de constitución de las identidades profesionales docentes y su relación con la discriminación de género, en este estudio se optó por el enfoque de investigación cualitativa, la cual analiza casos particulares atendiendo al espacio-tiempo en que acontecen las experiencias y acciones de las personas. Esta investigación, antes que buscar generalizaciones, quiere comprender las singularidades que acontecen en las experiencias de género presentes en el ejercicio de la docencia.

Otro valor de la investigación cualitativa consiste en articular una propuesta filosófica centrada en el lenguaje como forma de conversación, es decir, en el diálogo, para dar cuenta de lo que acontece en la experiencia, y de cómo esa experiencia situada en el mundo de la vida conforma unas identidades que se van constituyendo en el diálogo infinito del lenguaje, que obliga a dar la palabra al otro y a lo otro que en el lenguaje se expone.

Para dar cuenta de lo enunciado nos basamos en la filosofía de Paul Ricoeur, centrada en el valor del lenguaje narrativo como forma constitutiva de la identidad personal. Aquí se asume que toda identidad se constituye a través del lenguaje y en contextos sociales compartidos, en los cuales se pone en juego la relación con el otro. Este concepto de identidad, dado como una relación en el lenguaje, y que se provee entre la mismidad y la otredad, ha sido nombrado por Ricoeur (2008) “el sí mismo como otro". En la misma línea, Gadamer (2006) ha dicho que es darle validez al otro.

La centralidad del lenguaje narrativo en los procesos de construcción de las identidades, indica el carácter hermenéutico de esta investigación, la cual otorga valor a la praxis y al mundo social considerando el punto de vista de los actores, sus significados, el contexto, la interpretación, la comprensión y la reflexividad (Vasilachis, 2006). Se optó por el carácter hermenéutico porque estamos insertos en un mundo-lenguaje que precisamos comprender, entendida la comprensión como la condición permanente de lo humano y no como una metodología o una opción entre otras (Gadamer, 2006). La sistematización de las narrativas, recogidas mediante un cuestionario biográfico, se desarrolló en cuatro momentos de acuerdo con la propuesta de Quintero (2011).

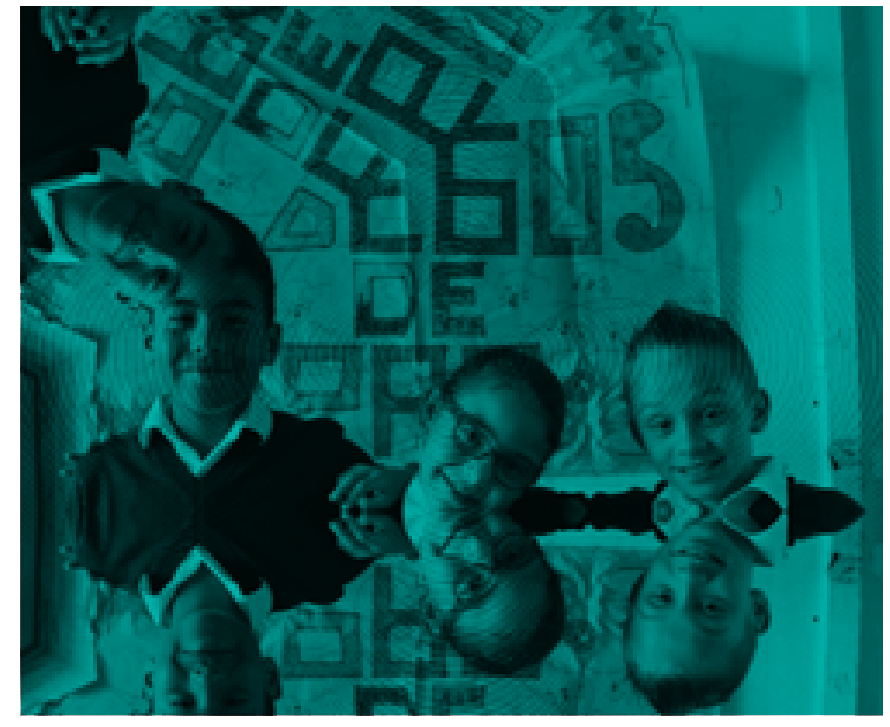

\section{Hallazgos}

A partir de la identificación de las experiencias de género que acontecen en la práctica de la profesión docente, se configuraron siete casos que dieron cuenta del entramado cultural en el que acontecen y se constituyen las identidades de la profesión docente. A continuación presentamos el caso referido a los estereotipos de género.

\section{Experiencias relacionadas con estereotipos de género: "Ellas permisivas, ellos inflexibles"}

Los estereotipos son como marcas o etiquetas superficiales que no profundizan la naturaleza de la significación; llegan a generalizarse de tal manera que son compartidos por un amplio número de personas, aunque la estereotipia normalmente se basa en tres características principales: la edad, el sexo y la raza, en esta investigación nos centramos en los estereotipos de género. Entendemos como estereotipos de género la generalización que hacemos sobre una persona en razón de su sexo y lo que se espera de su actuación en razón de ser hombre o mujer: "Ellas permisivas, ellos inflexibles". 
Tabla 1. Estereotipos de género

\begin{tabular}{|l|l|}
\hline Situación 1. Estereotipos de rol & $\begin{array}{l}\text { Son proposiciones que expresan puntos de vista } \\
\text { tradicionales sobre la posición de las personas } \\
\text { en la sociedad }\end{array}$ \\
\hline Situación 2. Estereotipos de rasgo & $\begin{array}{l}\text { Se refiere al conjunto de rasgos físicos y de } \\
\text { personalidad asignados de manera estereotípica } \\
\text { para varones y mujeres }\end{array}$ \\
\hline Situación 3. Estereotipos de edad & $\begin{array}{l}\text { Son formas estereotípicas de discriminar a las } \\
\text { personas en razón de la edad }\end{array}$ \\
\hline $\begin{array}{l}\text { Situación 4. Estereotipos de género y medios de } \\
\text { comunicación }\end{array}$ & $\begin{array}{l}\text { Los medios de comunicación definen estereotipos } \\
\text { de masculinidad y de feminidad }\end{array}$ \\
\hline
\end{tabular}

\section{Estereotipos de rol}

Los siguientes relatos hacen referencia a los estereotipos en la vida profesional docente: "En las instituciones escolares existen los siguientes estereotipos: en preescolar y primaria docentes mujeres, en bachillerato hombres y mujeres, las enfermeras son mujeres, las psicólogas también y las señoras de servicios generales igual". Estos estereotipos se refieren a creencias relativas a la configuración de roles y actividades diferenciadas entre hombres y mujeres. En el relato, el rol de la mujer se presenta asociado con

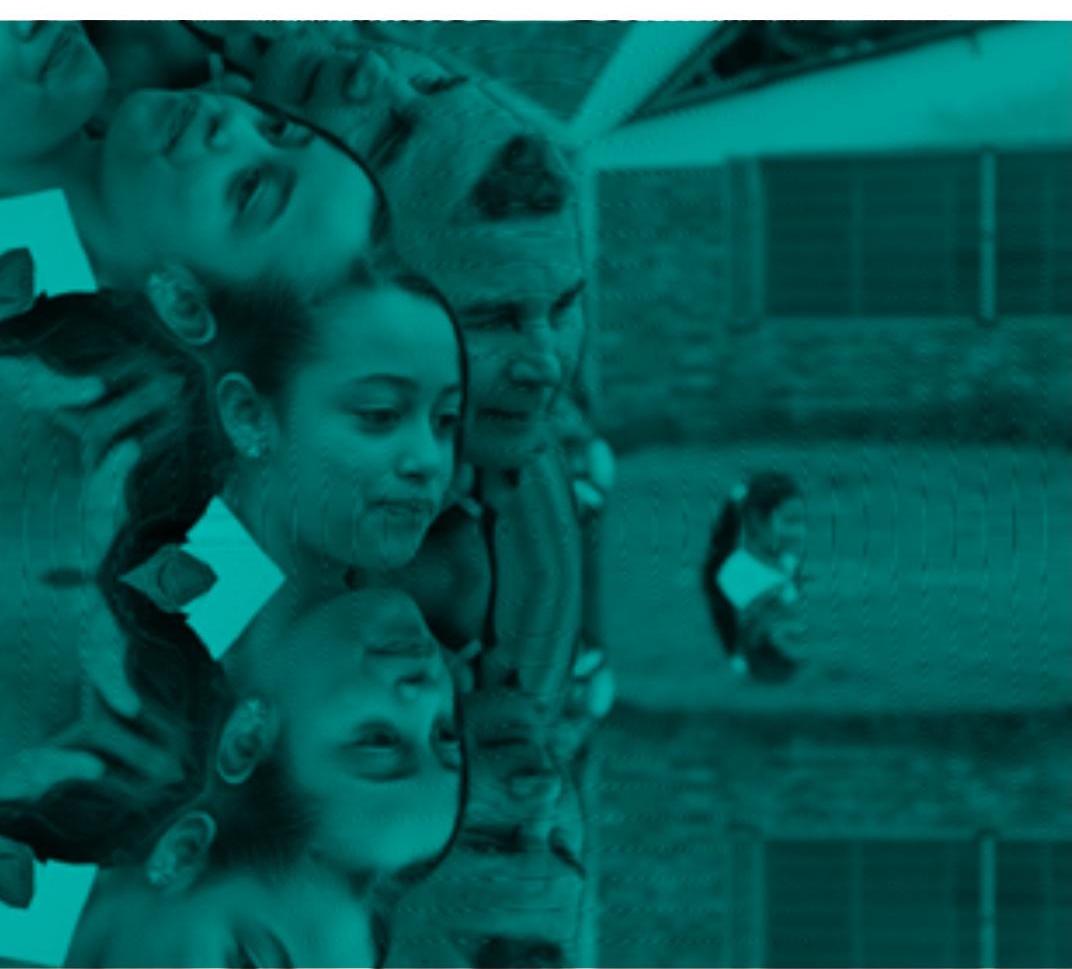

la enseñanza en preescolar y primaria, explicándolo por el papel tradicional de la mujer asociado al ejercicio del cuidado, hecho que responde a una división sexual del trabajo: "Un hombre acompaña a los alumnos de grado 11 a la cita médica para el ejército, nunca una mujer".

Por su función reproductiva, las mujeres son cuidadoras y su rol es doméstico, en oposición al papel de los hombres, que se da en la vida pública y en el ejercicio del poder. Los roles más estereotipados para las mujeres son los de cuidar niños y niñas, incluyendo el ejercicio de educarlos y cuidarlos en los centros educativos. Una docente nos confirma lo anterior: "La docencia está muy asociada con la maternidad, así que las mujeres somos profesoras y mamás de los niños". Los estereotipos de cuidado han sido asignados a las mujeres. El peso social y cultural del estereotipo lleva a que la docente asuma como algo "natural" asociar la docencia con la maternidad. Este tipo de prácticas desdibujan su labor en la docencia como sujetos que participan de una vida profesional en el ámbito de lo público, como es la educación. Se las relega a lo secundario: "El detalle (las carteleras y decoración ejemplo), o las vigilancias del comedor son para mujeres, lo demás es para varones".

En el siguiente relato una joven docente nos aclara: "En la universidad el 99\% de los estudiantes son mujeres, y cuando hay hombres estudiando una licenciatura, en este caso pedagogía infantil, se les tilda de 'maricas' o 'fracasados' que no obtuvieron su entrada a otra licenciatura, por ejemplo, a Educación Física". Aquí vemos la fuerza de los estereotipos, roles que aparecen como naturales, pues se considera que existen unas profesiones para mujeres y 
otras para varones. Se etiqueta a las mujeres para el cuidado y a los hombres para las actividades físicas; estas etiquetas se reproducen sin reflexión alguna.

Los estereotipos en el ejercicio de la docencia se han construido a través de prácticas que permean las formas de ser docente: "Los textos escolares comunican imágenes de lo femenino y lo masculino, en los libros de historia: el rol de la mujer en la historia es menospreciado". El rasgo masculino actúa como líder y amante del peligro, individualista, atlético, agresivo, con personalidad fuerte y dominante: "Es una historia contada desde la perspectiva del héroe masculino". En la historia de los acontecimientos técnicos y científicos los varones son protagonistas en la formación militar, en el ejercicio de prácticas de iniciación en los asuntos de la guerra, en el ejercicio del poder y en la ciencia. Estas formas estereotípicas binarias reproducen la división sexual del trabajo en el espacio en el que se constituyen las identidades de la profesión docente.

\section{Estereotipos de rasgo}

Los estereotipos de rasgo están compuestos por características psicológicas y de conducta, y por los rasgos físicos que se atribuyen a hombres y mujeres. Entre los estereotipos de rasgos físicos tenemos la voz aguda para la mujer y la voz grave para el hombre; como rasgos de conducta y características psicológicas, la emocionalidad ha sido típicamente asociada a lo femenino, mientras que la agresividad, a lo masculino; de ahí el título de este trabajo: "Ellas permisivas, ellos inflexibles", que evidencia los rasgos psicológicos y de conducta con los que se etiqueta a hombres y mujeres en el ejercicio docente y, en consecuencia, las conductas que se derivan de ellos como una dicotomía ente "lo duro y lo blando", "lo fuerte y lo débil". Para lo femenino, amante de los niños, tierna, comprensiva, compasiva, cariñosa, afectuosa, emotiva: "Generamos un vínculo afectivo con los estudiantes más fuerte que el de los hombres"; la docente admite que las mujeres son afectivas en oposición a los varones, sin percibir que el estereotipo de rasgo que se auto-asigna la está discriminando, pues le impide generar otro tipo de vínculo con los estudiantes, discriminando a los varones por las mismas razones.

Algunos relatos dan cuenta de la manera como se han naturalizado algunos estereotipos de rasgos físicos en el ámbito de la profesión docente: "El docente hombre les dicta clase de educación física a los varones y la docente mujer a las niñas". Todavía existen instituciones, en este caso privadas, en las que el estereotipo de rasgo físico está asociado con la fuerza física de los varones, mientras que las mujeres son vinculadas con otros rasgos; de ahí la identificación de la mujer con el trabajo diferenciado en razón de su sexo en la clase de educación física. El siguiente relato se refiere a los estereotipos de rasgo; lo "duro" y "agresivo" para la figura del hombre:

En las formaciones, porque hay que hablar con tono duro, agresivo con los estudiantes, llamados de atención en tono desafiante a estudiantes difíciles, no hay espacio para la escucha, sino para el grito y el ademán de amenaza, queriendo decir que la fuerza física, la figura del hombre, la masculinidad, sí tiene autoridad. Se sigue aceptando en el mundo del maestro el autoritarismo, la voz fuerte, el trato duro.

Se ha masculinizado lo duro, lo agresivo, la violencia, mientras se feminiza lo suave, lo blando, lo afectivo: "Cuando se trata de trabajos de dinámicas, eventos culturales, compartir, organización de eventos sociales, elaboración y organización de proyectos, les asignan la responsabilidad a las mujeres". El relato continúa para reafirmar cómo funcionan las dicotomías estereotípicas que permiten a los varones ser los que se empoderen del espacio en la profesión docente:

Ahora, cuando se trata de algún beneficio con reconocimiento económico o que implique no hacer clase, el ascenso a un cargo, que implique abrirse al espacio de la política como asuntos sindicales, consejos directivos, acomodación de horario y de carga académica, generalmente se empoderan los hombres.

Los estereotipos de género contribuyen a la feminización de la educación. No obstante, lo que se valora es el estereotipo de lo masculino; por eso los hombres están en los cargos de poder, son los que detentan la autoridad: "El magisterio es una profesión matriarcal, la mayoría somos mujeres, pero la voz de mando la tienen los hombres, casi siempre el jefe es un rector". Algunos estudios han demostrado que al hombre se le evalúa positivamente, lo que pone en desventaja a las mujeres que aspiran a los cargos directivos en una profesión feminizada en la que mandan los hombres. Los estereotipos funcionan porque están arraigados en las representaciones sociales de género y cumplen además una función ideológica en la reproducción de las mismas. En el contexto de la educación encontramos todo un andamiaje ideológico que afirma los estereotipos de género, tal como se ha manifestado en los relatos (Rodríguez, 2002).

\section{Estereotipos de edad}

El "edadismo" apunta al mantenimiento de estereotipos o actitudes prejuiciosas hacia una persona únicamente por el hecho de ser mayor. Este estereotipo ha sido señalado como la tercera gran 
forma de discriminación de nuestra sociedad, tras el racismo y el sexismo. Veamos algunos relatos: "Hay comentarios tales como: mujer malgeniada por falta de marido o por ser menopáusica, cosa que no se dice de los hombres". En una profesión social y pública como la docencia, la mujer adulta mayor es foco de discriminación por factores de biologismo. La que ya no está en edad reproductiva se la discrimina para ejercer la profesión con dignidad: "una forma frecuente de ofender a las mujeres es decirles menopáusicas, como sinónimo de vejez y de falta de atracción sexual". Aquí se cruza el estereotipo de género con el estereotipo de edad, y ambos refuerzan ideas sobre la discriminación de las docentes adultas que ejercen la enseñanza.

Aunque se valora enormemente la juventud, también se discrimina por ser joven, como lo expresó una docente: "Una leyenda o mito que existe, y es quizá una de las más fuertes, se relaciona con la edad para poder acceder al ámbito laboral, ya que se considera que si se es muy joven no hay mucha experiencia, y si se es muy mayor ya no se conectaría interpersonalmente con los educandos". Quien relata es una docente, y lo que denomina "un mito" obedece a estereotipos fundados en la edad. Aunque la experiencia es importante, es evidente la poca valoración que se le reconoce a las nuevas generaciones en el proceso de socialización docente, es necesario que las personas de edad puedan acompañar a los docentes sin mayor experiencia en vez de sentirse discriminadas.

\section{Estereotipos de género y}

\section{medios de comunicación}

Algunos relatos exponen la relación entre estereotipos de género y los medios de comunicación: "Modelos de feminidad y masculinidad en los medios: todos, la televisión, las revistas, la publicidad, asignan a la mujer el rol de madre, ama de casa, cuerpos estereotipados, productos para que la casa sea un lugar agradable”. El relato manifiesta cómo los medios de comunicación son portadores de modelos de feminidad y masculinidad. A la mujer se le asigna el rol de cuidadora de los niños o se la presenta en oficios de menor valor y remuneración, como los de la limpieza; sigue siendo la guardiana de la tradición para que el hogar sea un lugar agradable: "En general, los medios de comunicación reproducen el estereotipo de la mujer como objeto"; ser objeto se entiende contrario al de ser sujeto.

Como contraste, los relatos también ofrecen estereotipos de masculinidad: "El hombre que compra el carro para ser más influyente, o rápido con el cuerpo atlético”. Los productos que se ofrecen en el mercado están discriminados por los roles asignados de manera estereotipada a hombres y mujeres. Un carro hace a los varones influyentes, poderosos, rápidos, con cuerpos ideales, lo cual refuerza las usuales representaciones del hombre desde una visión androcéntrica: "Se diferencian los géneros y los estereotipan a través del color (azul, rosado), las marcas, las profesiones, los productos de consumo para lograr un ideal de hombre y mujer globalizado". Los medios de comunicación tienen en sus manos las imágenes de feminidad y masculinidad, y las hacen circular por medio de lo simbólico de los colores, de las marcas y valores para las profesiones.

En relación con el papel que debería tener la educación en la movilización de estos estereotipos expresados simbólicamente en los medios de comunicación, una docente nos dijo:

La escuela necesita una gran inversión en recursos para dotar a las instituciones educativas de recursos que permitan pensar otras formas de socialización de las masculinidades y las feminidades, y carece de medios como periódicos, revistas, programas de radio orientados en perspectiva de género.

Reiterativamente los docentes destacan: "La moda, a través de los medios de comunicación, impone estereotipos de masculinidad y feminidad. Si un hombre no sigue el patrón tradicional de la moda esperada, se le considera o se le tilda de maricón, y en el caso de las mujeres, de marimachos". Así, la moda a través de los medios es la que legitima los modelos de ser hombre o mujer: "El medio a través del cual se comunica la feminidad puede verse en los catálogos de prendas de vestir y cosméticos promocionados por algunas maestras y directivos docentes". Los medios de comunicación se introducen en las instituciones educativas, una obviedad en una sociedad de consumo como la nuestra; así lo confirma otro docente: "La televisión, la radio, la Internet, son los medios por los cuales circulan los modelos de feminidad y masculinidad en la escuela".

Medios de comunicación más recientes, como la Internet y los juegos de video, han irrumpido en la escuela: "los principales estereotipos de feminidad o masculinidad son aprehendidos y aprendidos de la televisión, la Internet, los juegos de video, la radio, en la cual los jóvenes escuchan música, principalmente". Los docentes confirman la relación entre medios de comunicación y estereotipos sobre las feminidades y las masculinidades, y cuestionan lo que la escuela está haciendo para contrarrestar este fenómeno: "La escuela no cuenta con medios de comunicación en los que se puedan cambiar estas formas de entender lo masculino y lo femenino". Hay una carencia para mediar ante la irrupción de los medios de comunicación en la construcción de estereotipos de 
género: "En la escuela no hay medios de comunicación a través de los cuales circulen modelos de feminidad o de masculinidad". Lo que se manifiesta es la ausencia de medios propios de la escuela: periódicos, emisoras, etc., y esto se repite: "No hay ningún medio de comunicación en el que circulen modelos de feminidad o de masculinidad en la escuela".

Un docente relaciona los medios publicitarios de empresas cosméticas con la actividad de las docentes:

La vanidad femenina se observa en la gran cantidad de dinero que mueven empresas multinacionales con la venta de cosméticos; tanto es así que un buen número de mujeres docentes obtienen ingresos adicionales, paralelos a su trabajo, vendiendo estos productos en el lugar de trabajo.

Este relato enuncia una relación entre la profesión docente y la venta de productos cosméticos, los cuales, además de ofrecer ingresos adicionales a una profesión reconocida por todos como mal remunerada, impone estereotipos como la llamada "vanidad femenina", caracterizada por el consumo de productos cosméticos.

Otro docente hace énfasis en los estereotipos de moda que impone la publicidad en el contexto de la institución educativa: "Yo ejerzo mi práctica docente en un espacio urbano, que en Bogotá está lleno de publicidad, con maniquíes y fotografías de modelos, cuyos estereotipos van creando una cultura de la belleza que los usuarios de dicha publicidad van accediendo y recreando" (P11P5). Este, como los demás relatos, presenta el papel que juegan los medios de comunicación en la configuración de estereotipos de moda; crean una cultura de la estética en las poblaciones estudiantiles sin que se evidencien otras alternativas que, desde la escuela, contribuyan a movilizar los estereotipos de género.

\section{Conclusiones}

Entre otras conclusiones, esta investigación encontró que los estereotipos de género configuran códigos de género que prescriben comportamientos diferenciados entre varones y mujeres, como la discriminación de las conductas que remitan al estereotipo femenino y, por oposición, la sobrevaloración de lo masculino. En el plano del lenguaje, a los varones se les asocia con estereotipos de lo "duro" y a las mujeres con lo "blando"; hecho que induce a que ellas sean excluidas de las esferas del poder. En cuanto a la formulación de planes de vida, las mujeres están orientadas hacia profesiones feminizadas que a su vez se relacionan con tareas del cuidado de los otros, mientras que los varones se ubican en la esfera de lo público y el poder.

Los medios masivos de comunicación han reforzado los estereotipos de género y ello hace que las mujeres sean víctimas de conductas agresivas y violentas. Una cultura para la paz debe hacer una reflexión que permita la reflexión y la transformación de tales estereotipos, mediante estrategias de comunicación alternativas en las instituciones educativas. Estas estrategias deberán aportar elementos para una lectura de los textos y contextos en los que se ejerce la experiencia docente, que no es más que el ámbito en el que se educa a niños, niñas y jóvenes. 


\section{Referencias}

Amorós, C. (2000). Feminismo y filosofía. Madrid: Síntesis.

Arfuch, L. (2005). Identidades, sujetos y subjetividades. Buenos Aires: Prometeo.

Arostegui, J. (2004). Historia Vivida. Sobre la historia del presente. Madrid: Alianza.

Bauman, Z. (2004). Identidad. Buenos Aires: Losada.

Bruner, J. (2006). Actos de significado. Más allá de la revolución cognitiva. Madrid: Alianza.

Butler, J. (2007). El género en disputa. Barcelona: Paidós.

Gadamer, H. (2006). Verdad y método. Fundamentos de una hermeneutica filosófica. Salamanca: Sígueme.

McEwan, H., y Egan, K (2005). La narrativa en la enseñanza, el aprendizaje y la investigación. Madrid: Amorrortu.

Quintero, M. (2011). Justificaciones y narraciones. Orientaciones teóricas e investigativas en la formación ética y política. Bogotá: Universidad Distrital.
Ricoeur, P. (2004). Tiempo y narración. México: Siglo XXI editores.

Ricoeur, P. (2006). La vida, un relato en busca de narrador. Agora. Papeles de Filosofia, 25 No. 2, pp. 9-22.

Ricoeur, P. (2008). Sí mismo como otro. México: Siglo XXI editores.

Rodríguez, C. (2002). De alumna a maestra: Un estudio sobre socialización docente y prácticas de enseñanza. Granada: Universidad de Granada.

Scott, J. (2000). Género e Historia. México: Fondo de Cultura Económica-Universidad Autónoma de la Ciudad de México.

Sen, A. (2008). Identidad y violencia. La ilusión del destino. Buenos Aires: Latingráfica SRL.

Vasilachis de Gialdino, I. (2006). Estrategias de investigación cualitativa. Barcelona: Gedisa.

Wollstonecraft, M. (1977). Vindicación de los derechos de la mujer. Madrid: Editorial Debate, Tribuna Feminista. 


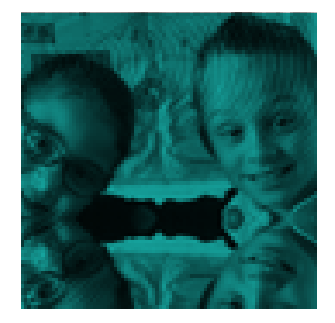




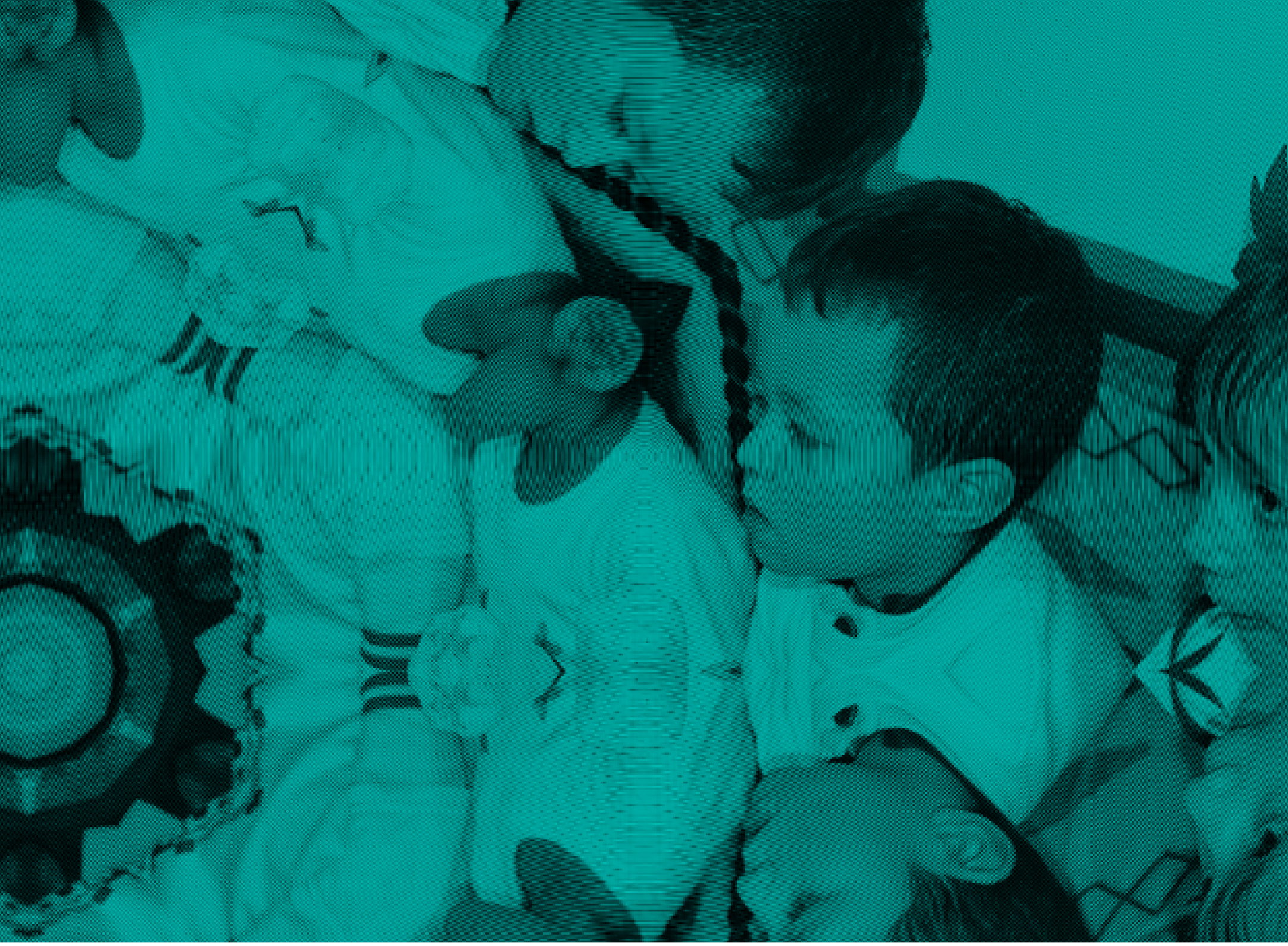

\section{Escuela de liderazgo para niñas y mujeres jóvenes en el sector educativo: una apuesta política para la construcción de paz}

Lidership school girls and young women in the education sector: a commitment policy to build peace

Escola da liderança para meninas e mulheres jovens no setor educacional: uma compromisso político para construir a paz

Guisset Stephanny Parra Ordoñez de Valdés Jessica Nathalie Corpas Figueroa 


\section{Guisset Stephanny Parra Ordoñez de Valdés 1}

Jessica Nathalie Corpas Figueroa 2
1. Magister en Estudios Culturales, Universidad de los Andes. Licenciada en Psicología y pedagogía, Universidad Pedagógica Nacional, profesora Colegio La Toscana IED; correo electrónico: stephyp57@hotmail.com

2. Trabajadora Social, Universidad Colegio Mayor de Cundinamarca. Aspirante a magister en Estudios Latinoamericanos, Universidad Nacional de Cuyo (Mendoza - Argentina); Especialista en Gerencia Social, Escuela Superior de Administración Pública, ESAP; Secretaría de Educación Distrital; correo electrónico: corpasjessica@gmail.com

Fecha de recepción: 20 de febrero de 2016 / Fecha de aceptación: 16 de septiembre de 2016

\section{Resumen}

El presente artículo expone las reflexiones realizadas durante la implementación del proceso pedagógico "Escuela de liderazgo para niñas y mujeres jóvenes", realizado con estudiantes del sector educativo oficial de Bogotá en el segundo semestre de 2015. Se busca fortalecer las ciudadanías de las mujeres a partir de la potenciación de habilidades para la participación y el liderazgo, y de la re-significación de la relación mujeres y poder. Al tiempo, se quiere promover la acción, incidencia política y la toma de decisiones de las estudiantes para la construcción de convivencias escolares pacíficas en sus colegios.

Palabras clave: Mujer, liderazgo, empoderamiento, género, participación política, convivencia pacífica.

\section{Summary}

This article presents the thoughts about the implementation of the pedagogical process "Escuela de liderazgo para niñas y mujeres jovenes" applied with Bogotá public schools students during the second half of 2015. Its goal was to uplift the women's civil responsibilities starting from their participation and leadership skills strengthening and the re-significance of the women power relation. At the same time it promoted the action and politic influence and the decision making process of the female students in the schools peaceful coexistence at their own schools.

Keywords: Woman, leadership, empowerment, gender, political participation, peaceful coexistence.

\section{Resumo}

O artigo apresenta reflexões sobre a implementação do processo de "escola da liderança para meninas e mulheres jovens "realizada com estudantes do sector de educação formal de Bogotá, no segundo semestre de 2015. O seu objectivo era fortalecer a cidadania das mulheres de o reforço das competências de participação e liderança, bem como a importância da resignificação da relação mulheres e poder. Por sua vez promoveu a ação, incidência e tomada de decisão pelas estudantes para a construção da coexistência pacífica em suas escolas.

Palavras chave: mulheres, liderança, empoderamento, genero, participação política, coexistência pacífica. 


\section{De lo político y el poder: condiciones culturales y subjetivas que determinan la participación de las mujeres en la esfera pública}

La noción de la política o de lo político es amplia, se puede relacionar con el interés o bien común, con la acción del Estado ejercida mediante la institucionalización o con el ejercicio del poder orientado a la toma de decisiones e incidencia en un ámbito específico. Por lo general se asocia lo político con la esfera pública y a ésta con lo masculino. Como sistema político vigente en Colombia, la democracia reconoce a todas las personas libres e iguales ante la ley, para el goce de sus derechos y para el ejercicio pleno de sus ciudadanías.

El Observatorio de Asuntos de Género, de la Consejería Presidencial para la Equidad de la Mujer de la República de Colombia, expresa que hay una enorme brecha en el ejercicio efectivo del poder de las mujeres con respecto a los varones, por razones históricas y culturales del acceso a los derechos civiles y políticos:

Es de resaltar que Colombia, desde que se conformó como república independiente en 1830 , ha tenido procesos electorales, pero las mujeres solo empezaron a participar de ellos en 1957: ciento veintisiete (127) años después. Esos años de desventaja, sumados a todos los elementos culturales de un país en el que la cultura machista es predominante, más las condiciones de pobreza y vulnerabilidad a las que se ven desproporcionalmente enfrentadas las mujeres, generan unas condiciones de desigualdad con barreras visibles e invisibles, para la competencia de las mujeres por el poder (OAG, 2014, p. 5).

Esto no desconoce al género, la raza o discapacidad; también las condiciones materiales de las niñas, jóvenes y mujeres en Colombia median en su acción política, el empobrecimiento y el conflicto armado con sus consecuencias (específicamente materiales) las ubican en una posición marginal respecto a varones y a mujeres de clases dominantes. Influyen en ello las múltiples opresiones que recaen sobre las mujeres en razón al género, la racialización o la orientación sexual, entre otras condiciones. El acceso al poder y a lo político está determinado por condiciones que limitan a ciertas poblaciones (mujeres, indígenas, entre otras) para hacer efectivas sus ciudadanías. Específicamente para las mujeres el poder público ha sido vetado desde antaño y, aunque hay avances, nos encontramos lejos de considerar equitativa la distribución del poder en razón al género. Según datos del OAG:
Con base en los datos del Observatorio de Igualdad de Género de la CEPAL, solo el 17.5\% de mujeres hacen parte de los gabinetes ministeriales de los países de América Latina y el Caribe en el último período presidencial. Únicamente el $22.4 \%$ de mujeres conforman el principal órgano legislativo nacional de esos países; tan solo el 19\% de mujeres son magistradas en la Corte Suprema, máximo tribunal de justicia (OAG, 2011, p. 2).

El reconocimiento de los derechos de las mujeres ha sido posible solo a partir de intensas luchas de los movimientos feministas, los cuales progresivamente han logrado posicionar en la agenda pública sus derechos civiles y políticos (derecho al voto, a la propiedad, ley de cuotas para lograr paridad en cargos públicos, entre otros), que si bien se materializan en la incorporación de mujeres a espacios de decisión, aún están lejos de lograr la paridad en las relaciones sociales y en la redistribución del poder.

El Observatorio de Asuntos de Género realizó un seguimiento a la aplicación efectiva de la Ley de Cuotas a nivel nacional y concluyó que en general se cumple la Ley, sin embargo, al desagregar los datos identificó un incumplimiento sostenido en diferentes entidades (OAG, 2011). En cuanto a la representación de las mujeres en el Congreso de la República:

La participación de las mujeres en el Congreso durante los últimos 13 años no ha superado en promedio el $12 \%$ del total de escaños ocupados. Tal situación ubica a Colombia en los últimos lugares de Latinoamérica en cuanto a la representación femenina en los Congresos nacionales (OAG, 2011, p. 12).

En cuanto al índice de mujeres en el Congreso, Colombia se ubica en el lugar 23 de 36 países en Latinoamérica, y a nivel mundial está en el puesto 90 de 136 países; pese a las leyes que promueven la paridad de género para la representación política, tal objetivo está lejos de alcanzarse. La política representativa y el poder público son escenarios en los cuales las mujeres poco a poco se han ido incorporando y por los cuales se avanza en la búsqueda de condiciones reales para su goce de derechos como ciudadanas plenas. Sin embargo, para continuar en ese camino, además de fortalecer la Ley de Cuotas y otras medidas desde la institucionalidad, es necesario reconocer que la noción de lo político y del poder son mucho más amplias que la democracia y la política representativa.

Por ello, es preciso que la cultura reconozca e incorpore los aportes de las mujeres a la sociedad, y valore su participación desde la realización de diferentes actividades para la construcción del mundo. Esto es una fuente de poder muy importante, pues permite a las niñas identificar la existencia de muchas mujeres que han incidido en la transformación social, así podrán forjar identidades 
largo de los siglos, así como el conflicto armado interno en el país, han definido las relaciones sociales, incidido en la identidad personal y colectiva, y trazado las maneras de encarar los conflictos.

$\mathrm{Al}$ respecto del conflicto armado, el Centro de Memoria Histórica afirma que "La guerra recae especialmente sobre las poblaciones empobrecidas, sobre los pueblos afrocolombianos e indígenas, se ensaña contra los opositores y disidentes, y afecta de manera particular a las mujeres, a los niños y niñas" (GMH, 2013, p. 25). Estas afectaciones particulares sobre niñas, niños y jóvenes, se hacen visibles en escenarios de la vida como la escuela, lugar en el que se identifican las múltiples expresiones de la violencia por la guerra, así como otro tipo de conflictos que emanan de la cultura. Tales cargas socioculturales se reflejan en el ejercicio de las ciudadanías, en las relaciones sociales dentro de las comunidades educativas, y en las dinámicas de convivencia escolar en las que la violencia es uno de los caminos empleados para relacionarse, obtener lo que se desea y hacer frente a los conflictos.

La experiencia del conflicto en la escuela se corresponde con las dinámicas propias que la configuran como un escenario cultural: valores, tradiciones, normas y prácticas cotidianas, hacen de la escuela un escenario de socialización con dinámica propia. Para Valenzuela (1994) el conflicto se manifiesta en la escuela como parte del relacionamiento de los seres humanos en los distintos ámbitos de la vida socio-política, ética y cultural.

Pérez (2014) hace referencia a estudios que desde el 2006 se han implementado en Bogotá para analizar la relación entre los diferentes contextos de socialización de los niños y las niñas, con sus creencias y actitudes en la convivencia escolar, de esto resalta que "a mayor nivel de violencia reportada en cada uno de estos contextos [familia, barrio, amistades] por cada encuestado, mayor probabilidad de reportes de comportamientos agresivos de su parte", destaca también que barrios o colegios muy violentos predisponen a las y los estudiantes a tener comportamientos agresivos (Pérez, 2014, p. 208).

La escuela, como uno de los principales escenarios de socialización y de consecución de aprendizajes primarios, incide directamente en la construcción de subjetividades, por ser el espacio privilegiado en el que se tejen relaciones sociales entre pares y entre generaciones. En la escuela se configuran y se validan las formas de convivencia dentro del ámbito escolar, las cuales redundan en el ejercicio de las ciudadanías y en la acción política. Así, la convivencia escolar se estructura desde una confluencia de elementos subjetivos (personales y colectivos), de prácticas legitimadas en las relaciones sociales, de expectativas, de normas y experiencia de las mismas, de intereses y de jerarquías que van moldeando la dinámica convivencial en la escuela.

Todo lo cual (conflictividad, relaciones sociales, prácticas pedagógicas, construcción de subjetividades e identidades, etc.), está atravesado por las asignaciones legitimadas por la sociedad en tanto a lo femenino y a lo masculino, es decir por el género. Es en la escuela donde se validan o transforman patrones socioculturales sobre las formas de vivir lo femenino y lo masculino, así como las formas de construir poder.

\section{Construcción de ciudadanías femeninas en la escuela}

La situación de las mujeres y niñas cobra un lugar particular en la dinámica y convivencia escolar, pues, al estar permeadas por una cultura machista, las relaciones sociales entre las personas que hacen parte de las comunidades educativas se convierten en factores para la desigualdad en razón al género en la escuela. Diferentes fuentes dan cuenta de que en la educación de Bogotá perviven valores androcéntricos que reproducen relaciones sociales y prácticas pedagógicas sexistas (IDEP, 2014; SED, 2014, Villamil, 2014). Esto se expresa en contenidos curriculares que excluyen a las mujeres de la construcción de ciencia y sociedad, en relaciones desiguales de poder en razón al género y a la edad, en situaciones de violencia sexual contra las estudiantes, en la estigmatización de niñas y jóvenes que no responden a los mandatos tradicionales sobre lo femenino.

Otros elementos que materializan el sexismo en la educación, se relacionan con los estereotipos de género (físicos, psicológicos, socioculturales) asociados a lo femenino, con marcos convivenciales sexistas que imponen el uso obligatorio de falda para las mujeres, la exclusión de espacios colectivos para la recreación como las canchas y las zonas verdes (pues de estos espacios se apropian por lo general los varones), entre otros aspectos.

Villamil (2014) explica que las estudiantes mujeres registran una mayor percepción de inseguridad en los entornos escolares, lo cual "habla del impacto de un conjunto de discursos y violencias cotidianas, que a partir de su configuración como cuerpos indefensos [mujeres] y con poca capacidad de respuesta frente a la agresión, limitan su vivencia y disfrute del espacio público" (p. 371). La autora expresa que esta percepción se correlaciona con la mayor exposición y ocurrencia de hechos de violencia sexual contra las mujeres en los colegios, lo cual perpetúa imaginarios sobre los cuerpos de las mujeres como objetualizados y de posesión masculina. 
En esa misma línea, dentro del Plan educativo de transversalización de la igualdad de género 2014-2014, se expresa que la escuela es el segundo lugar de mayor ocurrencia de hechos de violencia contra las mujeres, después de la familia, ejercida por diferentes miembros de la comunidad educativa sobre la base de relaciones de poder autoritarias y asimétricas, afectando especialmente el rango de edad entre los 14 y los 17 años. Allí se enuncia que las principales razones por las cuales las niñas y las jóvenes abandonan sus estudios son: el embarazo o la maternidad, maltrato o violencia sexual y la obligación de ocuparse de las tareas del hogar (SED, 2014, p. 43), esto da cuenta de la persistencia de tradiciones que legitiman y refuerzan el supuestamente rol natural de las mujeres para el cuidado o la maternidad.

Dichas expresiones de violencia están estrechamente relacionadas con las construcciones sociales de feminidad, privilegiadas en la escuela y en la cultura en general, y reproducidas por hombres y mujeres. Los estereotipos femeninos asociados con la debilidad, la suavidad, la delicadeza y la sumisión, son uno de los factores que favorecen la desigualdad y, en consecuencia, los ejercicios de violencia. Villamil (2014), refiriéndose a la violencia sexual en el contexto educativo, afirma:

Los miedos expresados por las mujeres sobre posibles agresiones en el camino de ida y vuelta al colegio no se pueden separar de los procesos de construcción de sus cuerpos, pensados como débiles y apropiables. Al haber sido culturalmente formadas para sentirse indefensas en el espacio público, con poca capacidad de respuesta corporal y actitudinal con respecto a situaciones de amenaza y agresión, las mujeres usualmente habitan este escenario con miedo y prevención (p. 358).

Como se ha anotado, la configuración de la feminidad, basada en adjetivos asociados con la debilidad, es una fuente de discriminación y de legitimación de la violencia hacia las mujeres, de allí la necesidad de su empoderamiento en la reconfiguración de sus identidades y autoimagen, desde la re-significación de la feminidad más allá de los estereotipos perpetuados por la cultura machista. Otro factor poco considerado, pero no menos importante, tiene que ver con los conflictos entre mujeres, asociados por lo general a formas de violencia no física, indirecta y encubierta; al no ser materialmente visibles, este tipo de confrontaciones no son consideradas como relevantes en los sistemas de mediación en la convivencia escolar.

Según Mingo (2010), el hecho de que nuestra cultura niegue a las mujeres el acceso al conflicto abierto conduce su agresión a formas no físicas, indirectas y encubiertas, pero no por ello menos lesivas y eficaces (p. 42). Sin embargo, pese a sus efectos sobre la convivencia, este es un aspecto invisibilizado en la escuela. De allí la necesidad de identificar estas formas históricamente ocultas de la violencia y promover espacios de relación y convivencia que reconozcan la diferencia como punto de partida para avanzar en la construcción de la paz.

Esto da cuenta de una naturalización de situaciones sexistas dentro de las instituciones educativas, que claramente hacen parte de la dinámica escolar, inciden en la configuración de las ciudadanías de las estudiantes, y determinan las formas de relación entre niñas, jóvenes y mujeres con el poder en la escuela. Así, el ejercicio de lo político para las mujeres pasa por reconocer las prácticas y relaciones de la vida cotidiana en la escuela, ancladas a la dominación machista, que limitan sus posibilidades para desarrollar la autonomía y para constituirse como mujeres políticas.

\section{Paz desde las mujeres: clave para la transformación en la escuela}

La paz entendida como derecho humano, como imperativo ético y forma de estar y de habitar en el mundo, se experimenta en el nivel individual, grupal y social, atraviesa todos los escenarios de la vida (familia, barrio, escuela, iglesia, etc.), y, al estar inmersa en la sociedad, se transmite a través de la cultura. Esto significa que son las personas, las instituciones y las estructuras de una sociedad las que actúan y se relacionan o no en concordancia con tradiciones, actitudes, valores y estilos de vida tendientes a una cultura de paz y de no violencia. En este contexto, hablar de paz dentro de la escuela es un gran reto, pues aunque como sociedad interpelamos permanentemente al Estado por la garantía de este derecho, nos cuesta aterrizarlo en las relaciones sociales cotidianas y en las prácticas pedagógicas presentes, por ello lo que más cuesta de la paz es construirla.

Como se expuso, las relaciones sociales están atravesadas por una cultura sexista, lo que en la escuela se materializa en relaciones de pareja caracterizadas por el control y la violencia, en la débil autoimagen/autoestima de las estudiantes al no cumplir con los estereotipos sobre lo femenino, y en experiencias de interacción entre mujeres erosionadas por el imaginario infundado de que como género somos odiosas, envidiosas y altamente dañinas. Además, algunos de los proyectos de vida de las estudiantes se relacionan directamente con la idea de ser madres, lo que responde a los mandatos culturales impuestos y a la situación de mujeres 
(jóvenes/adultas) de su entorno para quienes la vida está determinada por la maternidad, que, asumida como mandato social y divino, influye en el trazado de la vida de las estudiantes.

Todo lo anterior entra en conflicto al interior de la escuela y produce un afianzamiento de prácticas pedagógicas nocivas a la igualdad de género, que ponen en entredicho la autodeterminación de las estudiantes para la toma de decisiones, la incidencia y acción política en sus comunidades educativas. Desde este punto de vista, la dimensión de la paz como derecho, y como proceso de construcción colectiva, cobra un sentido particular en la escuela, y específicamente en las escuelas de la ciudad de Bogotá, siendo un espacio donde confluyen historias de vida de niñas, niños y jóvenes de diferentes lugares del país que experimentan la convivencia desde el reconocimiento a la diferencia.

La construcción de la paz tiene entonces que ver con la necesidad de repensar los roles de hombres y mujeres, y de generar espacios que promuevan el empoderamiento y la participación de las mujeres en los escenarios públicos, como una manera de reducir la brecha entre géneros y avanzar en la cimentación de una cultura de paz. Por ello, interesa reflexionar sobre la relación entre escuela, género y paz, a la luz de la experiencia de la Escuela de Liderazgo para niñas y mujeres jóvenes en colegios, como base para avanzar hacia la convivencia escolar pacífica, la incidencia política de

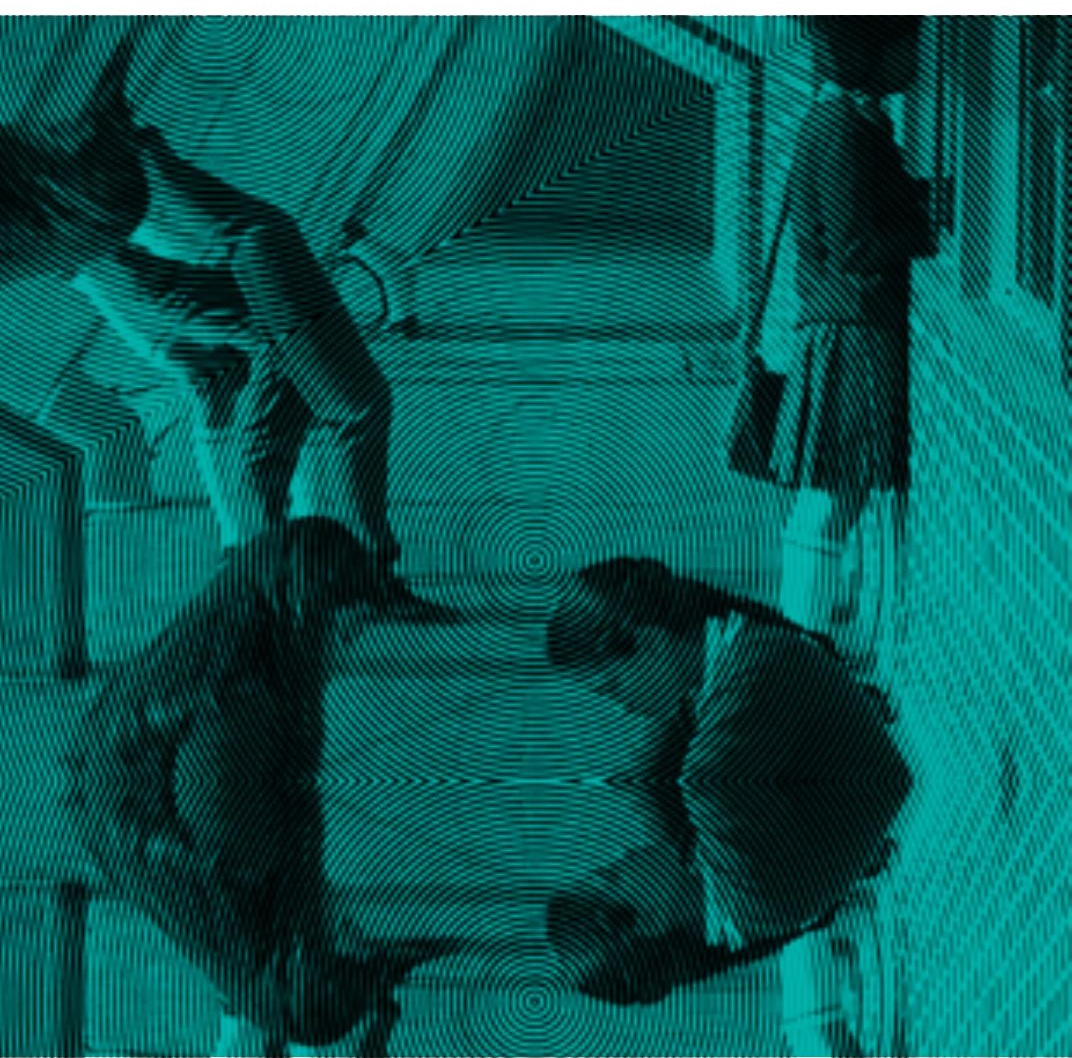

las estudiantes en sus comunidades educativas y la construcción de ciudadanías activas de la mujer en la escuela.

\section{Repensar las ciudadanías en la escuela: Experiencia de la Escuela de liderazgo para niñas y mujeres jóvenes}

La Escuela de liderazgo surgió como un espacio de formación para niñas y mujeres jóvenes que tomó como referente la experiencia de Escuela de Formación Política, impulsada por la Secretaría Distrital de la Mujer, durante los años 2014 y 2015, dirigida a mujeres adultas y diversas. Nuestra escuela buscó promover en las instituciones educativas un espacio equivalente, en el cual las niñas y las jóvenes tuvieran herramientas para participar y ejercer liderazgos en sus comunidades educativas, que a su vez fuesen la base para fortalecer sus ciudadanías como mujeres de derechos.

Este espacio de formación, se consolidó como un escenario propio de las niñas y las jóvenes para construir, re-significar y aprender formas diversas de experimentar la condición de lo femenino, como plataforma para involucrarse activamente en diferentes formas de participación en el colegio a partir del fortalecimiento de las habilidades necesarias para incidir en la toma de decisiones, en la búsqueda de relaciones asertivas y en una convivencia escolar pacífica.

Por diferentes razones la Escuela de Liderazgo estuvo dirigida exclusivamente a estudiantes niñas y jóvenes: 1) La necesidad de crear un clima de confianza que les permitiese expresarse sin temor a ser juzgadas o señaladas por sus compañeros varones; 2) Por la necesidad de crear un espacio para que ellas formularan sus inquietudes como mujeres y discutieran sobre lo cotidiano como base de lo político; 3) Para fortalecer habilidades que tradicionalmente no se han asociado a lo femenino, entre otras, argumentación, debate, confrontación; 4) Para crear vínculos de solidaridad entre mujeres y desmontar el mito de que no hay relaciones armoniosas entre nosotras.

El objetivo fue contribuir en la promoción y el fortalecimiento de los liderazgos de las niñas y mujeres jóvenes en las instituciones educativas del Distrito Capital, a través del desarrollo de una Escuela de Liderazgo que proporcione procesos formativos y de reconocimiento con enfoque de género y de derechos, haciendo énfasis en la incidencia política, tanto en el sistema formal de participación escolar (por ejemplo el gobierno escolar), como en otros 
procesos de la dinámica escolar: artístico, académico, recreativo, cultural, ambiental, etc.

Se tomaron como referencia algunos diagnósticos y documentos sobre la participación de las mujeres en la escuela y, a partir de allí, se definieron unos contenidos estratégicos para avanzar en el fortalecimiento del potencial personal de las estudiantes. Esto fue leído a la luz de las limitaciones de los espacios de socialización de las mujeres para la actividad e incidencia política. Los contenidos estratégicos fueron desarrollados así: conceptos básicos sobre géne-

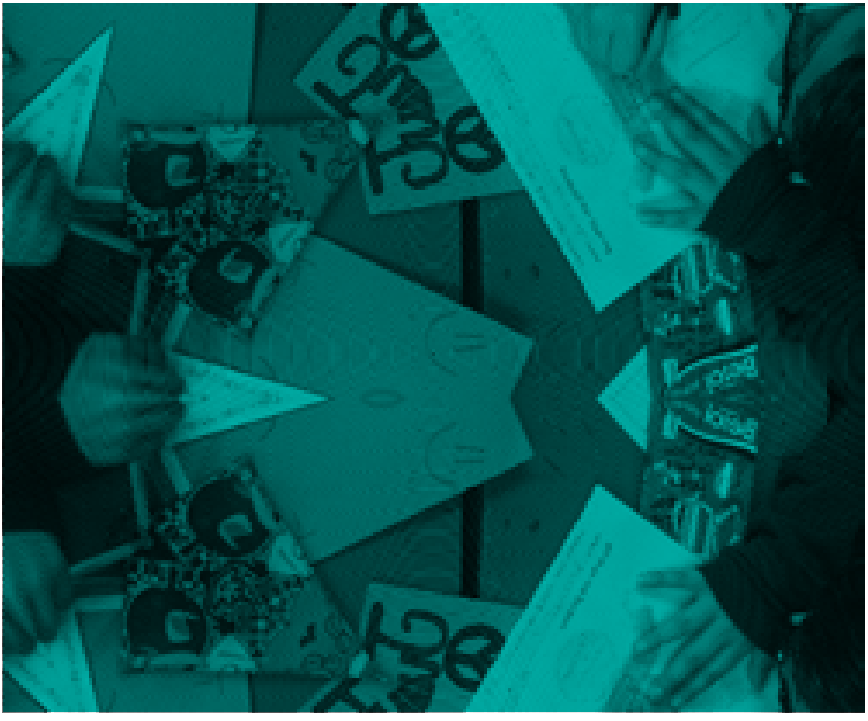

ro; Derechos Humanos de las niñas, las jóvenes y las mujeres; una vida libre de violencias para las mujeres; empoderamiento y autonomía de las mujeres; cultura y ciudadanías para la paz, y participación política de las niñas y las jóvenes.

La Escuela de liderazgo, se puso en marcha en el segundo semestre de 2015 con estudiantes de los colegios Juana Escobar (San Cristóbal), Gerardo Paredes y Nueva Colombia (Suba), contó con la participación de 80 estudiantes de grados octavo a once, con edades entre 13 a 19 años. La Escuela entró a fortalecer procesos dentro de colegios, por lo cual su implementación se articuló con proyectos transversales o semilleros de género, lo cual le dio un carácter de mayor envergadura en las instituciones.

Las actividades se realizaron en contra-jornada escolar, con encuentros semanales, de cuatro horas cada uno, en los cuales se desarrollaron elementos centrales que facilitaron identificar las principales inquietudes de las niñas y las jóvenes sobre su condición como mujeres y su rol político en la sociedad. Como resultado de la puesta en marcha de la Escuela de Liderazgo, las estudiantes realizaron proyectos socioculturales fundamentados a partir de la identificación de situaciones problemáticas presentes en los colegios, sobre su situación en la participación y toma de decisiones en las comunidades educativas.

Estos proyectos socioculturales se cristalizaron en piezas audiovisuales, performances y representaciones teatrales que fueron producidas en su totalidad por las estudiantes alrededor de los siguientes temas: subvaloración de las mujeres para las matemáticas en el aula; violencia simbólica ejercida contra las mujeres; roles y estereotipos de género en la familia y la escuela; sororidad (solidaridad entre mujeres y reconstrucción de relaciones entre ellas); embarazo adolescente y proyecto de vida; derechos sexuales y derechos reproductivos, y convivencia pacífica desde las diversidades en la escuela.

\section{Hallazgos y propuestas por la paz en la escuela desde el poder femenino}

Durante el desarrollo del proceso de la Escuela de Liderazgo encontramos elementos que dan cuenta de las particularidades de las ciudadanías de las niñas y las jóvenes para la acción política y el liderazgo, que a su vez reflejan las formas de interacción social en la escuela y en la convivencia escolar. Las estudiantes tenían algunas nociones sobre el género y su incidencia en las relaciones sociales; sin embargo, estaban cargadas de prejuicios fundamentados en ideas erróneas como que los feminismos son equiparables al machismo, o que con la igualdad de género se ha victimizado a las mujeres y atacado a los hombres, o que las mujeres que trabajamos por la igualdad de género odiamos a los varones, o que las mujeres somos las culpables de mantener el sistema patriarcal.

Estos imaginarios son el reflejo de la cultura, puntualmente de la cultura escolar, pues al estar naturalizados dificultan un manejo acorde con la realidad y, por supuesto, el desmonte de relaciones desiguales de poder en razón al género. Al finalizar el proceso se evidenciaron diferentes elementos de género en las producciones artísticas de las estudiantes, apropiados de forma coherente con su experiencia vital, y transmitidos al colegio en lenguajes claros y consistentes. Para que la convivencia escolar sea pacífica debe incorporar análisis sobre el sexismo e involucrar a hombres y mujeres (estudiantes, docentes, directivas, madres y padres, etc.) en la construcción de nuevas formas de vivir lo femenino y lo masculino, alentando las diversidades y una cultura para la paz libre de violencias contra las mujeres. 
Encontramos un desconocimiento, por parte las estudiantes, de los Derechos Humanos de las mujeres, específicamente en la diferencia de los derechos de varones y de mujeres. Así como la no incorporación de los acontecimientos y luchas históricas mediante las cuales se han conseguido derechos para las mujeres. Pese a esto, ellas reconocen diferentes formas de vulneración a estos derechos en espacios como la familia y la escuela, lo cual les permitió vislumbrar que la existencia de las mujeres está a travesada por diferentes tipos de violencia machista que influyen en su acceso al poder, a la política y al liderazgo.

Al respecto de la violencia contra las mujeres, la mayoría de estudiantes reconocieron haber sido víctimas de ésta al menos una vez en su vida. Durante el desarrollo de las actividades, ellas hicieron notar la presencia constante de la violencia simbólica de género en la música y en las prácticas culturales tradicionales, tanto de la escuela como del hogar. Llamaron la atención sobre la presión social y la violencia que se ejerce en razón de los estereotipos de género, y la estigmatización que viven día a día por no encajar en las formas socialmente aceptadas de ser mujer, destacando, desde la estética (gorda, cabello corto, etc.), hasta las actividades realizadas en la cotidianidad (jugar fútbol o videojuegos, etc.). Además resaltaron la constante de violencia psicológica e incluso física, que se vive y es aceptada socialmente, en las relaciones de pareja.

Algunas de las violencias reconocidas por las estudiantes son: la física (golpes, empujones, pellizcos), la sexual (tocamientos, violaciones, relaciones sexuales no consentidas con la pareja, acoso sexual), la psicológica (menosprecio, humillaciones), entre otras. Las jóvenes también plantearon estrategias de prevención y acción frente a la vulneración de estos derechos en la escuela, como perder el miedo y difundir la situación, utilizar medios de comunicación en el colegio para prevenir sobre la violencia contra las mujeres y protegerse entre amigas.

Las estudiantes identifican en la escuela un territorio en el que se presentan violencias contra ellas, y un escenario que posibilita transformaciones a nivel sociocultural. Por ello, muchas de sus intervenciones se enfocaron en estos temas y en visibilizar la situación de las mujeres, como formas de instar a las comunidades educativas a incorporar su experiencia en los procesos de resolución de conflictos y en la promoción de convivencias pacíficas desde un enfoque de género y de derechos femeninos. En cuanto a la participación política de las estudiantes, se reconoció que las habilidades necesarias para la acción política, como la enunciación asertiva de ideas y emociones, la conjugación de la expresión verbal y no verbal, y la fluidez para manifestarse en público, estaban poco incorporadas y desarrolladas por las estudiantes en sus relaciones sociales y en el trabajo específico de la Escuela de Liderazgo.

Llamó la atención que durante la realización de las actividades (tanto en lo formal como en lo lúdico) a las jóvenes se les dificultó hacer uso de la palabra en público, dar a conocer sus opiniones, argumentar y debatir; parecía una constante que prefirieran quedarse calladas incluso cuando estaban en desacuerdo o convencidas de sus propios argumentos. La timidez estuvo presente en el primer momento de discusión entre las compañeras, ruborizarse, taparse la cara y la boca para hablar, esconderse detrás de otra o enojarse, fueron manifestaciones de esta situación.

No obstante, la producción creativa de las estudiantes fue una constante y pudo ser incluso una manera de contrarrestar las dificultades de expresión oral; de manera individual, pero ante todo grupal, volcaron su inventiva en el diseño de piezas comunicativas, en las cuales exteriorizaron sus experiencias, argumentos, opiniones y emociones. El trabajo creativo siempre fue un dinamizador de ideas y propuestas. Así, una de las principales estrategias de participación política de las estudiantes se materializó a través de la expresión artística como mecanismo de denuncia y de re-significación de su rol como mujeres. El teatro, la danza y las artes plásticas fueron las principales expresiones que dieron muestra de su posicionamiento político en el espacio escolar.

En cuanto a la re-significación de las relaciones entre mujeres, se resalta que al inicio de las actividades las estudiantes mostraron apatía y desinterés por trabajar en grupos con personas diferentes a las de su círculo de amistades. Sin embargo, la dinámica de la Escuela de Liderazgo y las metodologías empleadas facilitaron un clima de acercamiento y encuentro entre las jóvenes, incluso entre las que existían relaciones poco asertivas. Con el transcurrir de las sesiones de trabajo las estudiantes fueron reconociendo las simetrías y asimetrías de su propia experiencia con respecto a las de otras estudiantes; esto permitió avanzar en posturas de respeto y curiosidad por la historia de vida de las otras, con sus problemáticas y formas de resolverlas. El ejercicio de reconocimiento de las particularidades individuales, y la puesta en común dentro de la Escuela de Liderazgo, permitió que las relaciones entre mujeres (por lo menos en esos grupos) se repensaran a la luz de trayectorias comunes.

Acorde al subtítulo de este apartado, este proceso pedagógico nos mostró diferentes aspectos a tomar en cuenta para ampliar las posibilidades reales de las mujeres en la toma de decisiones e 
incidencia dentro de sus comunidades educativas. Donde el poder femenino redunde en las relaciones sociales de los planteles a partir de una cultura para la paz que incorpore los derechos de las mujeres y el enfoque de género como claves de la convivencia escolar. 


\section{Referencias}

Contreras, J. (2003). El conflicto armado en Colombia. Revista de Derecho Universidad del Norte.

IDEP-SED. (2014). Informe final de convenio interadministrativo 3198. Bogotá: IDEP.

Grupo de Memoria Histórica. (2013). Informe general, Grupo de memoria histórica. ¡Basta Ya! Colombia: memorias de guerra y dignidad. Bogotá: Imprenta Nacional.

Medina Gutiérrez, F. (2009). El conflicto armado en Colombia: Nuevas tendencias, viejos sufrimientos. Misión Jurídica. Revista de Derecho y Ciencias Sociales. Universidad Nacional de Colombia, Bogotá.

Mingo, Aracelli. (2010-Enero). Ojos que no ven...Violencia escolar y género. Revista Scielo, Vol. 32, No.130. México.

Observatorio de Asuntos de Género (OAG). (2011-Octubre). Boletin 13. La participación politica de las mujeres en Colombia: avances, retos y análisis sobre la presencia y acceso de las mujeres a los espacios de decisión en el país. Bogotá: Consejería presidencial para la equidad de la mujer.

Observatorio de Asuntos de Género (OAG). (2014-Octubre). Boletin 18. Avances en la participación politica de las mujeres en Colombia. Bogotá: Consejería presidencial para la equidad de la mujer.
Pérez Salazar, B. (2014). Maltrato entre pares en ámbitos escolares. Clima escolar y victimización en Bogotá 2013. Encuesta de convivencia escolar (pp. 207-254). Bogotá: Secretaría de Educación.

Secretaría de Educación del Distrito (SED). (2014). Plan Educativo de Transversalización de la Igualdad de Género. Bogotá: SED.

Valenzuela, Pedro. (1994). La estructura del conflicto y su resolución. Democracia y Conflicto en la escuela. Documento preparado como material de lectura para los talleres sobre resolución de conflictos y democracia, organizado por el Instituto para el Desarrollo de la Democracia Luis Carlos Galán, el Ministerio de Educación y la Organización de Estados Americanos.

Villamil Peñaranda, M. (2014). Género y escenario educativo bogotano: una aproximación a los resultados de la encuesta de clima escolar, 2013. Clima escolar y victimización en Bogotá, 2013 Encuesta de convivencia escolar (pp. 343-373). Bogotá: Secretaría de Educación. 


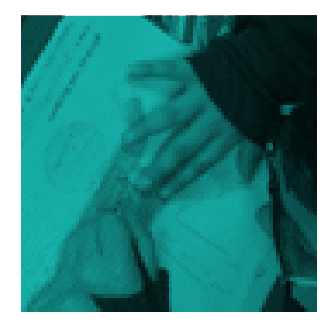




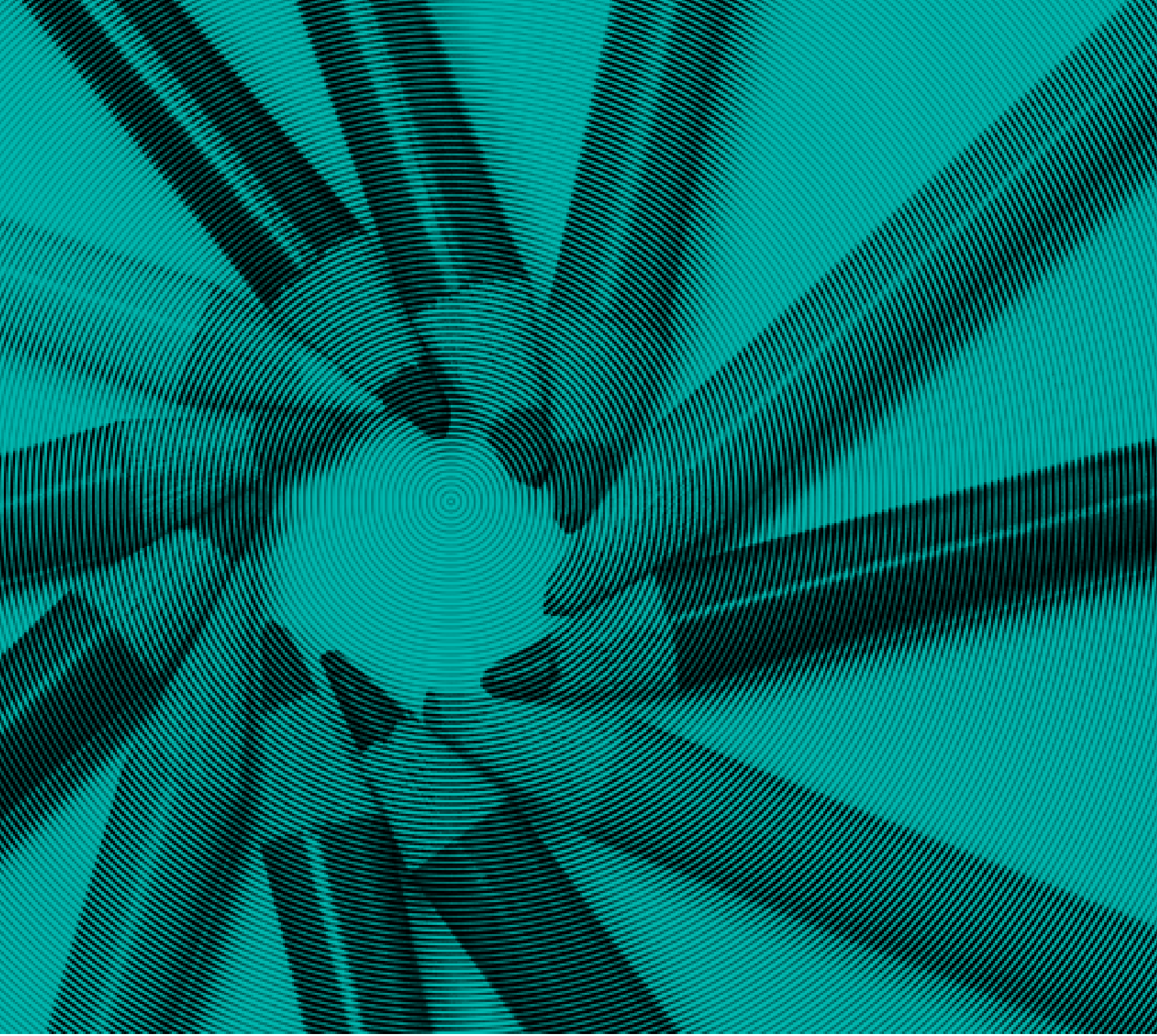

La lectura en voz alta de cuentos, un camino
para cambiar la percepción de agresividad

Reading tales aloud, a way to change the aggressiveness perception

A leitura em voz alta de histórias, uma maneira de mudar a percepção de agressão

Liliana Turriago Rincón Carolina González Herrera Nelsy Peña Guerrero 


\section{Liliana Turriago Rincón 1 \\ Carolina González Herrera 2 \\ Nelsy Peña Guerrero ${ }^{3}$}

1. Licenciada en Básica con énfasis en Lengua Castellana, Fundación Universitaria Monserrate. Candidata a Magíster en Pedagogía, Universidad de la Sabana; correo electrónico: lilispaty@, yahoo.com

2. Licenciada en Pedagogía Infantil, Universidad Libre de Colombia. Candidata a Magíster en Pedagogía, Universidad de la Sabana; correo electrónico: karitoo9@yahoo.es

3. Licenciada en Educación Básica, Universidad Pedagógica y Tecnológica de Colombia. Magister en Pedagogía, Universidad de la Sabana; correo electrónico: nelsypin060@gmail.com

Fecha de recepción: Febrero 23 de 2016 / Fecha de aceptación: 16 de septiembre de 2016

\section{Resumen}

El presente artículo se deriva de una investigación realizada para obtener el título de Maestría en Pedagogía de la Universidad de la Sabana, orientada por la docente Nelsy Peña Guerrero. Se presentan algunos resultados que dejan ver la influencia de la aplicación de una Secuencia Didáctica, que incluyó la lectura en voz alta de cuentos, en el cambio de la percepción de agresividad en los estudiantes del grado 503 de la Institución Educativa Distrital Carlos Albán Holguín, a partir de la relación del contenido de la lectura con las situaciones de agresividad experimentadas.

\section{Palabras clave: Agresividad,} lectura en voz alta, cuento, escucha activa, asertividad.

\section{Summary}

The present article is derived from a research developed to get the pedagogic magister degree from the Universidad de la Sabana, guided by the teacher Nelsy Peña Guerrero. This article presents some results that shows the incidence of an application of a didactic sequence with activities such as the reading aloud of tales, and the cooperative learning in the perception change of the students' aggressiveness of level 503 of the school Distrital Carlos Albán Holguín sede A.

\section{Keywords: Aggressiveness,} reading-aloud, Tale, Active listening and assertiveness.

\section{Resumo}

Este artigo deriva de uma pesquisa realizada para o título de mestrado em educação pela Universidade de La Sabana, guiada pelo ensino Nelsy Peña Guerrero. Ele apresenta alguns resultados que mostram o impacto da aplicação de uma seqüência didática que incluiu a leitura em voz alta das histórias em mudar a percepção de agressão em 503 estudantes da classe do Distrito Educational Institution Alban Carlos Holguin a partir de a proporção do teor das situações de agressão experimentado.

Palavras chave: Agressividade, leitura em voz alta, conto, escuta ativa e assertividade. 


\section{Introducción}

En la actualidad la agresividad es uno de los temas que genera mayor preocupación, debido a su incidencia en las relaciones de convivencia dentro del ámbito educativo. Dicha inquietud hoy requiere de atención inmediata, es necesario identificar sus características para brindar alternativas que propicien espacios escolares armónicos y en paz, en los que sea posible consolidar la formación de ciudadanos capaces de vivir juntos, de respetar y coexistir con la diferencia.

La Institución Educativa Distrital Carlos Albán Holguín no es ajena a esta problemática. Al observar las relaciones cotidianas entre estudiantes se hallaron frecuentes comportamientos agresivos, con el agravante de que en la mayoría de los casos los protagonistas de este tipo de conducta la consideran un acto "normal" dentro del trato con sus pares. Un claro ejemplo de ello se da en espacios libres como el descanso, en los cuales se dan casos de escolares que acuden a la agresión física y verbal como forma de relacionarse con el grupo. Al preguntar por sus actos se encuentran respuestas como: "estamos jugando" o "profe pero si no estamos haciendo nada"; los estudiantes no son conscientes de lo que es una agresión o si son víctimas o victimarios, tienen una percepción equivocada de la agresividad.

Los anteriores eventos llevaron a las investigadoras a reflexionar sobre la importancia de que los estudiantes reconozcan este tipo de conductas, y desde allí surge la Secuencia Didáctica "Leer para convivir en armonía”, que incluyó la lectura en voz alta de cuentos y se enfocó en cambiar la percepción de agresividad del grupo intervenido. Para dar solidez a la secuencia y fundamentar el proceso de investigación se abordaron aspectos como: la agresión en el aula de clase; la lectura reconocida como práctica social; la importancia de la lectura en voz alta para la construcción de la convivencia y la paz; y el cuento como estrategia para identificar la agresión.

\section{La agresividad en las aulas de clase}

$\mathrm{El}$ ingreso de los estudiantes al ámbito escolar tiene gran incidencia en el desarrollo de sus habilidades sociales y en la posición social frente a sus pares; justamente uno de los aspectos que aturde la socialización en la escuela es el de las agresiones escolares, que pueden ser definidas como acciones deliberadas y puntuales mediante las cuales algunos miembros de las comunidades educativas buscan hacer daño a otros (Chaux, 2012, p. 17). Igualmente, los espacios escolares no son ajenos a la agresividad, las aulas de clase se han convertido en lugares propicios para replicar o producir conductas agresivas en las que los victimarios buscan dañar a sus víctimas, agrediéndolas física o verbalmente sin enfrentar ninguna consecuencia; algunos tienen comportamientos agresivos con sus pares o acudientes y consideran que actúan "bien”, sin reconocer la intensidad y frecuencia de sus agresiones, con lo cual se convierten en situaciones "normales" del contexto escolar.

Es importante observar la habilidad social de los niños y jóvenes para enfrentar diversas situaciones, considerando que quienes son agresivos tienden a percepciones, decisiones e interpretaciones que aumentan su probabilidad de actuar de esa forma (Trianes, Muñoz y Jiménez, 2007). Los docentes deben abordar esta problemática de una manera eficaz, de tal forma que contribuyan a transformar las percepciones sobre la agresión. Es importante que los afectados identifiquen el significado, lo comprendan y lo vean en sus acciones y en las de otros, para que puedan cambiar su percepción de sí mismos. Después de esto, es necesario promover prácticas continuas que contribuyan a disminuir los comportamientos agresivos y lograr una sana convivencia en los espacios escolares.

\section{La lectura entendida como una práctica social para la ciudadanía}

Establecer la lectura como alternativa para desarrollar la ciudadanía implica reconocerla como práctica social y cultural que vincula a los estudiantes, convirtiéndolos en lectores activos, capaces de construirse como sujetos sociales. Así lo vislumbran los Lineamientos Curriculares del Ministerio de Educación (1998) para lengua castellana:

En una orientación de corte significativo y semiótico, tendríamos que entender el acto de leer como un proceso de interacción entre un sujeto portador de saberes culturales, intereses deseos, gustos [...] y un texto como el soporte portador de un significado, de una perspectiva cultural, política, ideológica y estética particular, y que postula un modelo de lector; elementos inscritos en un contexto: una situación de la comunicación en la que se juegan intereses, intencionalidades, el poder; en la que está presente la ideología y las valoraciones culturales de un grupo social determinado. El acto de leer es concebido como un proceso significativo y semiótico cultural e 
históricamente situado, complejo, que va más allá de la búsqueda del significado y que en última instancia configura al sujeto lector (p.27).

Se puede decir que las prácticas de lectura transforman al estudiante y le brindan una ruta para lograr su integración, como ciudadano, a prácticas y ambientes que contribuyen socialmente al desarrollo de un grupo o comunidad desde la mirada individual y colectiva.

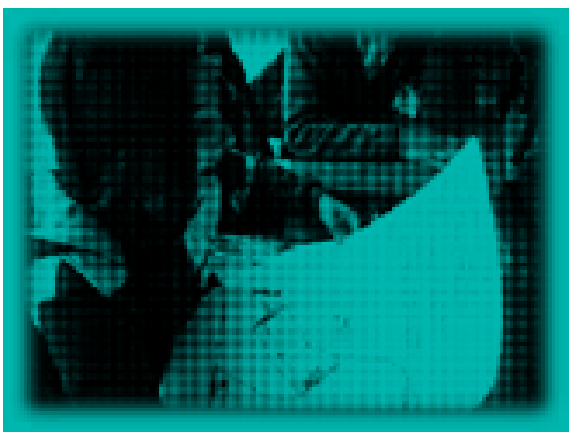

Imagen 1. Lectura en voz alta "Irina y el espíritu del bosque" Nota. Tomada durante el ejercicio
En este sentido, la lectura es una habilidad que se desarrolla con la práctica (Trelease, 2004), y solo se fortalece si se emplea como lo que es: un hábito social inmerso en lo cotidiano que, desde allí, marca significativamente la vida en sociedad; tal definición lleva a la necesidad de estimular prácticas de lectura en los niños, permitiendo que vivan esa experiencia de la mejor manera. Es importante comprender que para que la lectura participe en las prácticas sociales, en la propuesta socio-cultural deja de ser una técnica individual para ser una práctica social vinculada a unas instituciones, modelada por unos valores y un orden preestablecido (Cassany, 2009, pp. 20-21). Al leer el alumno comprende un sentido, adopta un rol, construye una imagen y participa en una organización de la comunidad. Se requiere mucho más que el conocimiento lingüístico de los signos o un proceso cognitivo.

Todo lo anterior se resume en tener una mirada del proceso de lectura que vaya más allá de la decodificación de un texto, para verlo como un proceso de significación inmerso en las prácticas sociales que transforma al sujeto lector. En tal sentido, la lectura permite generar espacios de ciudadanía, los cuales son necesarios para una interacción acertada entre los aprendices, como sujetos sociales, frente a un contexto determinado.

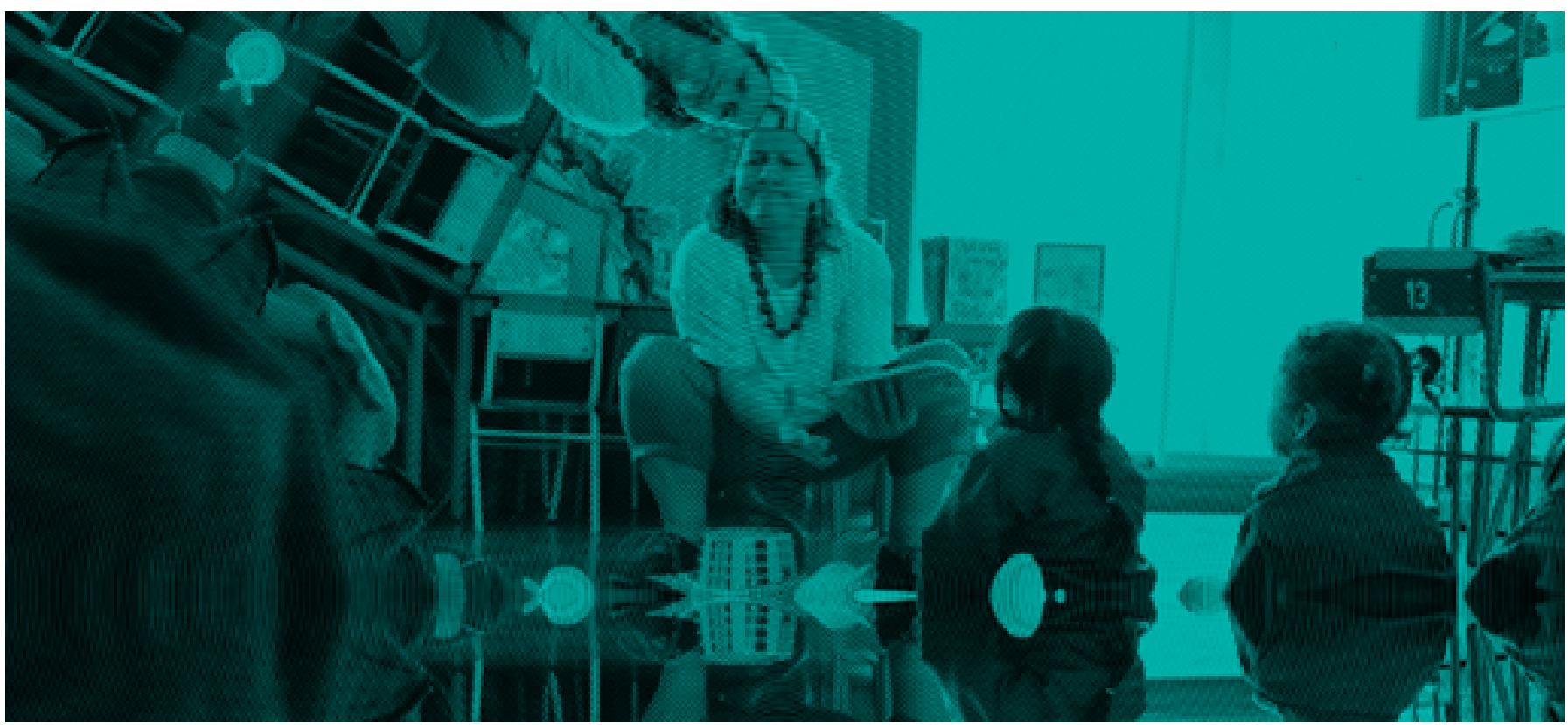

Imagen del proyecto Club de lectura Apapaches, del Colegio Gabriel Betancourt Mejía. Docente Blanca Lilia Medina. 


\section{La importancia de la lectura en voz alta en la construcción de la convivencia y la paz}

Dentro de las modalidades de lectura señaladas por Pérez y Roa (2010) para el ciclo uno, se encuentra la lectura en voz alta, la cual puede ser llevada a cabo por el docente, un lector invitado o los mismos estudiantes. Esta modalidad cuenta con muchas ventajas para el trabajo en el aula, en la medida en que permite al niño ingresar al mundo de los libros y al disfrute de textos escritos. La lectura en voz alta es una experiencia que contribuye significativamente en la formación como lector y actor social: "al leer en voz alta se transmite no solo el contenido lingüístico del texto, la voz de quien lee transmite emoción, asombro y otros sentimientos que el texto genera" (Pérez y Roa, 2010).

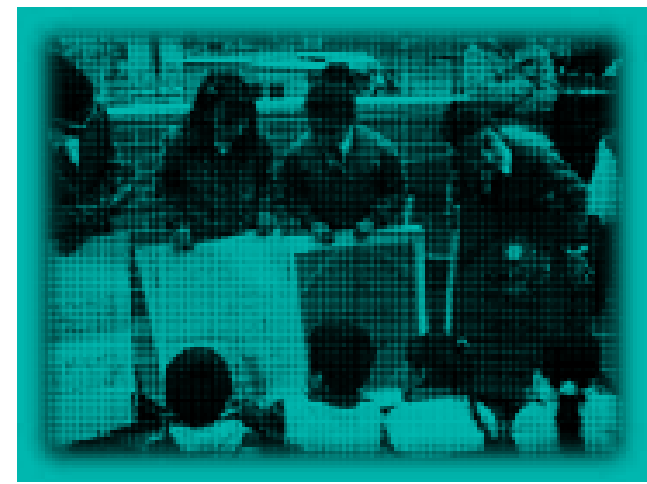

Imagen 2. Lectura en voz alta de cuento-álbum a niños de primeros grados Nota. Tomada durante el ejercicio

Leer a los estudiantes contribuye a estrechar el vínculo afectivo, es una actividad conjunta y deliciosa que afianza los lazos emocionales de una forma divertida y relajada, ayuda al desarrollo del lenguaje, amplía vocabulario, orienta a los oyentes hacia otra perspectiva del mundo y les permite ver a quien lee como un modelo ciudadano, capaz de comunicarles lo que otro quiso transmitir en un texto escrito. Este tipo de lectura ofrece un modelo de lector que brinda amplios beneficios: "leemos a los niños por las mismas razones que les hablamos: para tranquilizarlos, para entretenerlos, para crear lazos; para informarles o explicarles algo, para despertar su curiosidad e inspirarlos” (Trelease, 2004).

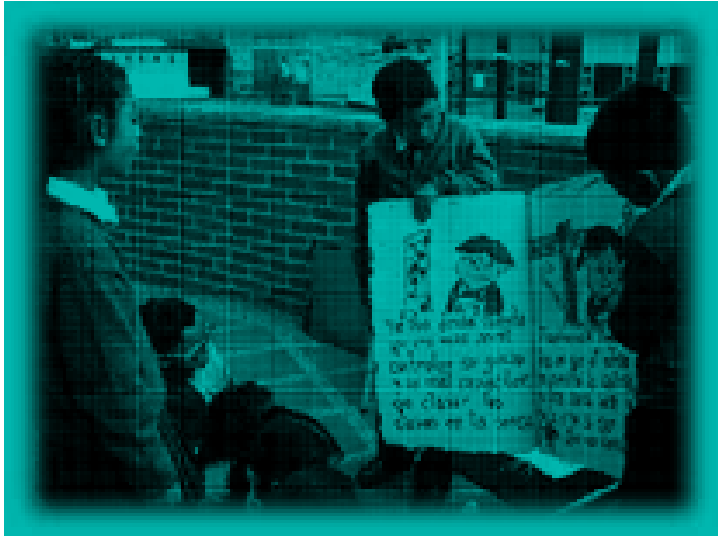

Imagen 3. Lectura en vOz alta de cuento-álbum a niños de primeros grados Nota. Tomada durante el ejercicio

Como práctica cotidiana la lectura en voz alta mejora la capacidad del estudiante para expresarse; mediante la escucha de distintas estructuras gramaticales y sintácticas propicia espacios de ciudadanía que se hacen evidentes en el respeto por el otro, en la interacción en grupo, en el acto de escuchar para opinar frente a los demás y en dar aportes y consejos al lector. Por tanto, bajo las condiciones adecuadas, los estudiantes pronto aprenden que otros de la clase también pueden tener conocimiento y que éste se puede compartir (Bruner, 2000, p. 70). La lectura es una práctica social que permite al alumno compartir y expresar lo que piensa ante un público determinado, convirtiéndole en ciudadano activo que hace visible y posible la convivencia pacífica.

Leer es la oportunidad de "reconocernos en las experiencias de otros. Es la posibilidad de conocer otras personas, otros lugares, otras maneras de vivir con las que podemos sentirnos identificados" (Marín, 2013, p. 25), perspectiva que se debe adoptar en aula de clase, pues allí se convive con personas que piensan diferente, tienen otros intereses y ofrecen situaciones diversas que requieren de soluciones adecuadas. Por tanto, es importante poner en práctica la lectura en voz alta, especialmente la lectura de cuentos, pues con ella es posible que lectores y oyentes reconozcan situaciones que les son familiares y que, al verse reflejados, se sientan motivados a evitarlas y transformarlas si son negativas, o a apoyarlas y mantenerlas si son positivas. 


\section{El cuento como estrategia para la identificación de la agresión}

El trabajo literario con cuentos para fortalecer habilidades comunicativas es un gran aliado a la hora de trabajar el lenguaje y formar en la sana convivencia durante los procesos de enseñanza y aprendizaje generados en el ámbito educativo. Este tipo de texto narrativo presenta diversidad de situaciones reales o imaginarias que casi siempre se relacionan con conductas humanas y que, de una u otra manera, se pueden reflexionar en el aula; tal es el caso de las situaciones de agresividad: "el cuento es una narración de acontecimientos (psíquicos o físicos) interrelacionados, en un conflicto y su resolución, que nos hacen meditar en un implícito mensaje sobre el modo de ser del hombre" (Kayser, 1976, p. 489).

Teniendo en cuenta lo anterior, el cuento es una alternativa para conocer y reflexionar sobre diferentes circunstancias reales e imaginarias, que en algún momento se pueden vivir. Por lo general, en la trama de este tipo de textos se hacen evidentes acciones agresivas, estas sirven como ejemplo de modelos que no se deben reproducir en la cotidianidad de las aulas y en el contexto social y familiar en donde se mueven los estudiantes.

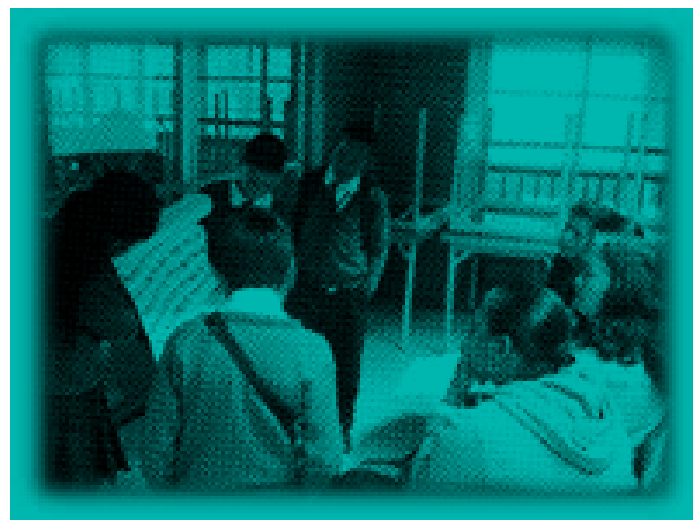

Imagen 4. Práctica de lectura en voz alta de cuentos de los niños a padres de familia

$\mathrm{Al}$ encontrarse con una narración en la que el contenido se asimila con su vida diaria, el niño entra en diálogo con el texto y, orientado por el maestro, realiza una reflexión dinámica que lo lleva a identificar situaciones y a establecer relaciones con hechos en los que se ha visto involucrado en algún momento y de los cuales tiene recuerdos positivos o negativos. Como se dijo, los cuentos incluyen actos agresivos que pueden ser identificados y solucionados mediante un trabajo práctico en el aula. Esta práctica se convierte en un camino que vale la pena recorrer en la formación para la convivencia, hasta desarrollar en el estudiante la habilidad para reconocer situaciones agresivas reales y la capacidad de resolverlas o evitarlas.

\section{Metodología}

La investigación se enmarca en un enfoque cualitativo, ya que busca describir, comprender e interpretar los fenómenos a través de las percepciones y significados producidos por la experiencia de los alumnos, esto se hizo evidente en cada una de las fases. El diseño metodológico parte de la Investigación-Acción-Participativa (IAP), una herramienta que permite crear vínculos de reflexión-diálogo-acción-aprendizaje entre las personas y los agentes externos interesados en promover acciones para el desarrollo sociopolítico de los grupos marginados.

Esto se evidencia con la implementación de la secuencia didáctica "Leer para convivir en armonía", en la que se abrieron espacios de diálogo y reflexión desde la práctica de la lectura en voz alta de cuentos, para que los alumnos hicieran parte de acciones que permitieron un cambio de la percepción respecto a la agresividad. Los instrumentos utilizados para recoger la información fueron: encuesta a estudiantes; encuesta a padres de familia; prueba de entrada; matriz de sistematización de actividades y el observador del estudiante.

\section{Algunos resultados del proceso de investigación}

A continuación se presenta el análisis de algunos resultados obtenidos a la luz de los referentes teóricos, en ellos es posible ver la incidencia de la aplicación de la Secuencia Didáctica, que incluyó la práctica de lectura en voz alta de cuentos, contrastada con los datos obtenidos al inicio de la investigación. Este análisis tiene en cuenta las categorías previas, sustentadas en los aportes de autores que han abordado los elementos teóricos que constituyen el tema de investigación. En primer lugar se presenta la categoría Agresividad, constituida por las sub-categorías agresión física, verbal y relacional; su análisis expone el cambio de percepción en los estudiantes sobre la agresividad, a partir de la lectura 
en voz alta de cuentos, y el avance respecto a la identificación de los tipos de agresión.

En segundo lugar está la categoría Lectura de cuentos, constituida por las sub-categorías de relación contenido-experiencia e identificación de la enseñanza. Ella es el eje central de la secuencia didáctica planteada y deja ver la forma en que, a través de la lectura de cuentos seleccionados, los estudiantes cambian su percepción de agresión y la manera en la que relacionan situaciones de agresividad de su vida con el contenido de los cuentos. Además de ello, los estudiantes derivan del relato una enseñanza relacionada con el uso de competencias comunicativas como la escucha activa y la asertividad, para así hacer evidente la necesidad de plantear acciones que permitan restablecer el derecho de quien ha sido agredido.

\section{Agresividad}

La agresión es "toda acción que tiene la intención de hacer daño" (Chaux, 2012, p. 39), pero no se trata solamente de ello, ésta tiene distintos niveles, por ejemplo, la agresión hostil: "aquella que tiene la intención de infligir daño o lesionar a la víctima, sin que el agresor obtenga ninguna recompensa o ventaja" (Trianes, Muñoz y Jiménez, 2007, p. 81), como acto, la agresión se expresa de distintas formas, no es solo física, sino que puede tener, al menos, cuatro manifestaciones claras:

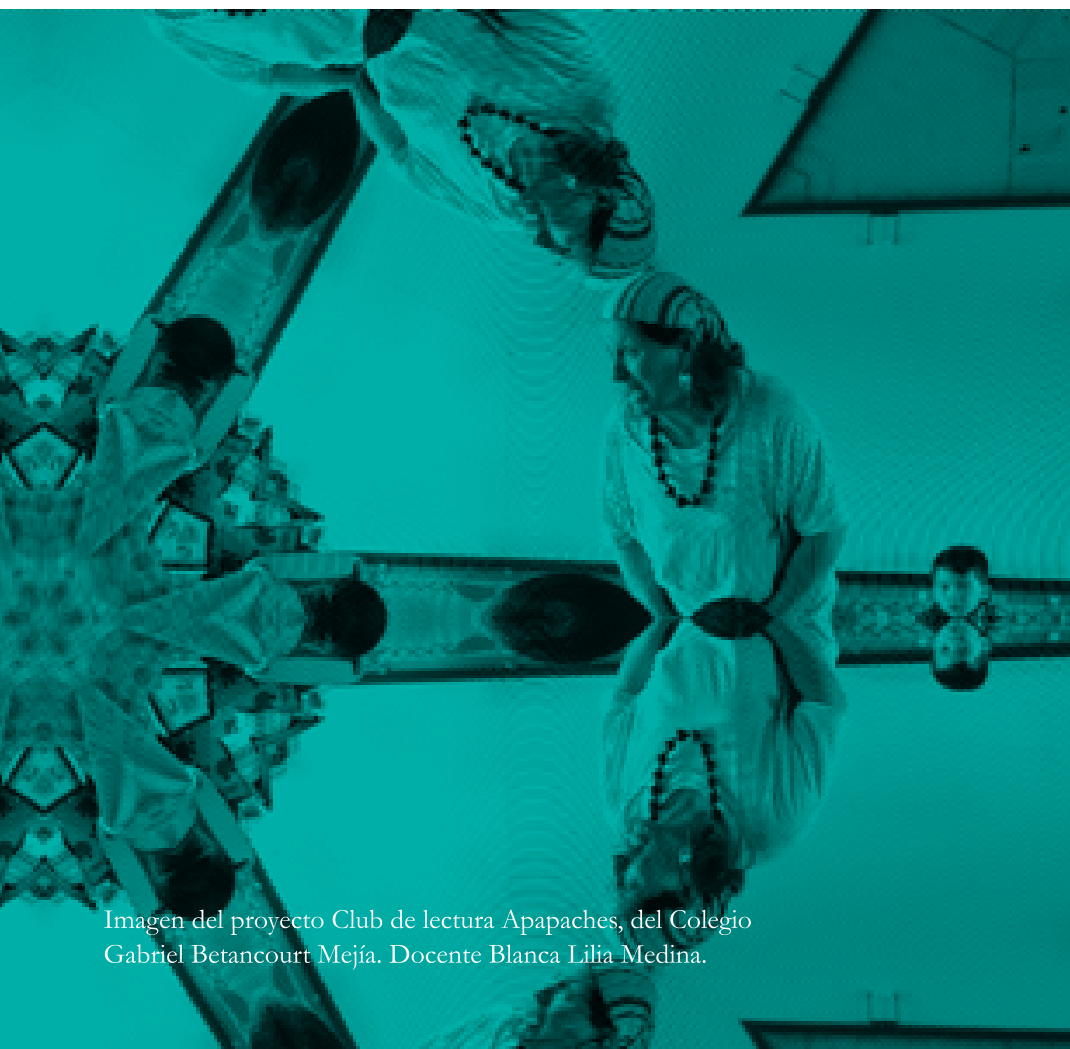

- Agresión física: Aquella que busca hacer daño físico a otros o a sus pertenencias, por ejemplo, con patadas, puños, cachetadas, mordiscos, golpes con objetos, rompiendo sus pertenencias, etc.

- Agresión verbal: Se manifiesta mediante daño a otros con las palabras, por ejemplo, con insultos o burlas que les hacen sentir mal.

- Agresión relacional: Se dirigen al intento de afectar negativamente las relaciones de otra persona, por ejemplo, excluyéndola de los grupos, esparciendo rumores o contando un secreto que le hace quedar mal frente a su grupo.

- Agresión indirecta: Busca dañar a una persona de manera encubierta, sin que se dé cuenta de quien lo hizo (Chaux, 2012, p. 40).

Dentro y fuera del país la agresividad escolar es evidente en muchas instituciones escolares; en el contexto educativo es uno de los factores que afectan a diario a niños y niñas, por lo que es indispensable asumir el reto de brindarles herramientas que les permitan contrarrestarla. El grupo de estudiantes del grado 503 de Colegio Carlos Albán Holguín, Sede A, Jornada Mañana, veía las situaciones de agresividad como un juego, caracterizaban el comportamiento del agresor y del agredido como algo normal, una forma de relacionarse entre pares, sin reconocerse como víctimas o victimarios.

Los resultados obtenidos en la encuesta a estudiantes y en la prueba de entrada permitieron ver lo normalizado de la agresión; por ejemplo, las respuestas a la pregunta ¿Alguna vez se te has sentido agredido en el colegio?, en las que 16 estudiantes manifestaron no haber sido agredidos en el colegio, contrastan con la información de las anotaciones del observador del alumno, en las que se encontraron registros que sustentaban casos de agresión que no se reconocían como hecho violento. Tal información, comparada con los datos del formato de sistematización de la secuencia, del diario de campo, las anotaciones del observador del estudiante después de aplicada la secuencia pedagógica y la información de la prueba de salida, permite ver la forma en que los estudiantes cambian su percepción de la agresión.

Esto se hace evidente en la tercera sesión, cuando los estudiantes hicieron la lectura del cuento "Irina y el espíritu del bosque", analizaron su contenido y reconocieron que hay agresiones clasificándolas según su tipo: "Verbal, porque la hija del herrero hablaba muy mal de los cuentos de Irina y ella contaba sus aventuras porque se sentía sola"; "Verbal: la hija del herrero culpó a Irina de mentirosa"; "Verbal: porque el herrero le dijo que no 
los creyera estúpidos y que dejara sus cuenticos sin sentido" (Sesión 5). Otro ejemplo se dio durante la quinta sesión, cuando con la lectura del cuento "Un extraño en mi colegio", afirmaron: "Es una agresión Verbal porque lo rechazaron, se burlaron y no lo aceptaron"; "Los niños no lo aceptaron así y él se volvió grosero, es (agresión) verbal y relacional"; "La agresión fue verbal y relacional porque le decían groserías y lo apartaban" (Sesión 5).

$\mathrm{Al}$ reconocer la agresividad física, verbal y relacional con la lectura de los cuentos de la secuencia

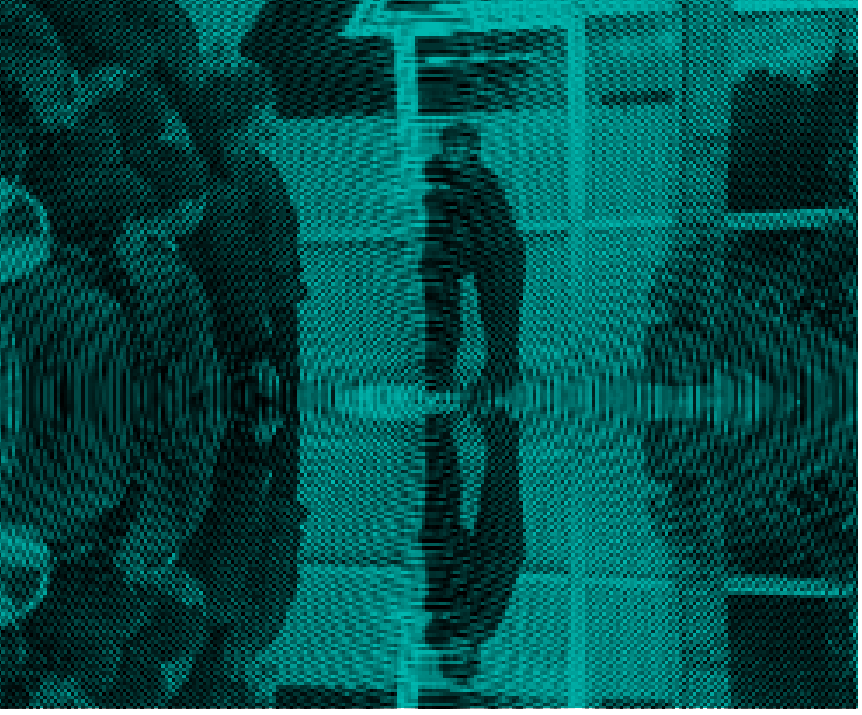

lectura cuenta con muchas ventajas para el trabajo en el aula, pues permite al niño ingresar en el mundo de los libros y en el disfrute de textos escritos, además de facilitar la participación de cualquier miembro de la comunidad educativa y favorecer competencias ciudadanas como la escucha activa (Pérez y Roa, 2010, p.40).

La estrategia puso a disposición de los alumnos diferentes textos que les permitieron contar con distintas miradas de una situación que muchas veces hace parte de la realidad cotidiana. Cada ejercicio fue analizado y ese proceso didáctica, los estudiantes cambiaron su idea sobre la agresión, aprendieron a identificar sus diferentes formas y a evitarlas durante las actividades escolares y de relación con sus pares. Los datos extraídos de los registros del observador del alumno, consignados después de la aplicación de la propuesta, permiten ver que los estudiantes reseñados por algún comportamiento agresivo aceptan y declaran haber agredido física o verbalmente a sus compañeros, además se pueden encontrar formas en que intentarán restituir el derecho a sus pares. Ahora los niños identifican la agresión física y verbal, y aunque algunos no reconocen aún la relacional, tienen claro que el rechazo del otro es también una agresión.

Fue posible un proceso efectivo de transformación en la percepción de agresividad en los estudiantes, quienes expresaron la necesidad de enfatizar y comprender la importancia de restaurar los derechos del agredido, mediante: la sanción social, la reparación del daño y la restauración de la comunicación y la confianza. Al tiempo, expresaron preocupación por evitar la agresión con sus compañeros; durante los juegos toman distancia de acciones en las que observan la agresión como medio de diversión: "Eso no es un juego, eso es agresión, yo no juego a eso".

\section{Lectura de cuentos en voz alta: Relación contenido-experiencia e identificación de la enseñanza}

La lectura en voz alta de cuentos es un camino que promueve la participación social, se convierte en un ejercicio dinámico y atractivo en el que todos y todas pueden participar. Esta modalidad de reflexivo les permitió tener claro lo que pueden hacer cuando ocurra algo parecido, de tal forma que puedan obrar adecuadamente; se buscó dar herramientas para que piensen antes de actuar y que así eviten posibles actos agresivos en la resolución de los problemas. Para que la lectura de cuentos en voz alta tuviera eco fue necesario identificar el gusto inicial por la lectura y, para hacerlo, se indagó sobre el interés por los libros, si se disfrutaba de la lectura y si ésta era reconocida como actividad importante en el proceso de formación, en la encuesta aplicada a padres y a estudiantes.

Las respuestas de la encuesta demostraron pocos hábitos de lectura, aproximadamente el $27 \%$ de los estudiantes aseguró practicarla en su tiempo libre, contra un $73 \%$ que no lo hacía. Por su parte, $52 \%$ de los padres afirmó desarrollar el hábito de leer en casa con sus hijos, y el $48 \%$ manifestó lo contrario; aquellos que ven la lectura como algo importante, destacan su utilidad en cuanto a que ayuda a mejorar ortografía y a que permite a sus hijos acceder a nuevos espacios académicos, sociales y profesionales, descubrir nuevos saberes y oportunidades de progreso en la relación con sus pares.

A través de la práctica de lectura de cuentos en voz alta se puede entablar un diálogo entre el autor, el lector y los oyentes. Ese diálogo hace visible el pensamiento de tres actores y se escuchan sus voces sin demeritar el planteamiento de ninguno de ellos. Es $\tan$ importante lo que el autor quiso trasmitir con su narración, como lo que los oyentes pueden reflexionar luego de su lectura. Reconocer su valor formativo fue el punto de partida para fortalecer en los estudiantes del grado 503 la lectura de cuentos, de tal 
manera que su práctica se prestara como instrumento de reflexión sobre las diferentes situaciones de agresividad en el entorno escolar. Para hacer viable este propósito, y después de analizar los datos de las encuestas y la prueba de entrada, se seleccionaron cuidadosamente los textos narrativos, de tal forma que entusiasmaran a los estudiantes y que su contenido ofreciera episodios con formas implícitas o explícitas de agresión.

Con la aplicación de la propuesta se observó que para el grupo fue emocionante encontrar textos que narraban situaciones ligadas a su realidad. En los cuentos leídos en voz alta los estudiantes identificaron las agresiones y encontraron posibles soluciones. El hecho de que la solución no fuera explícita hizo que se movilizaran y buscaran posibles soluciones como equipo. En el transcurso de cada sesión, y de acuerdo al texto, los estudiantes relacionaron los episodios narrados con situaciones de agresividad que les involucraban como actores o testigos, luego anotaron la enseñanza del relato y sus opiniones en el formato de tipos de agresión, posibles soluciones y restauración del derecho. En cada una de las sesiones el grupo tuvo que establecer relaciones entre contenido, experiencia y conceptos abordados con el apoyo de las maestras.

Se puede observar un aumento en la capacidad de establecer relaciones entre texto y experiencia, en las expresiones dadas durante las sesiones; por ejemplo, en la tercera sesión, luego de leer el cuento, uno de los participantes reconoció el tipo de agresión presentada en el cuento, lo comparó con su vida e identificó que también había sido agredido; al referirse a los tipos de agresión en la lectura, dijo: "Fue verbal porque el herrero le dijo que no los creyera estúpidos y que dejara sus cuenticos sin sentido"; en cuanto a la relación con su vida, afirmó: "Estúpido es un palabra grosera, algunos niños nos dicen así en el descanso, unos niños de mi curso la dicen, se la dicen a las niñas"; expresión que refleja cómo identificó la palabra "estúpidos" con un tipo de agresión verbal.

Por su parte, en la cuarta sesión María identificó el tipo de agresión afirmando: "La conclusión es que la agresión es física porque le pisó la cola a Coco-Coco, cocodrilo, y lo lastimó”, estableció una relación con vida cotidiana diciendo: "nosotros también hacemos así, a veces le hacemos zancadillas a nuestros compañeros cuando pasan por nuestro lado o los pisamos cuando pasamos, y eso no se debe hacer porque los podemos lastimar, si alguien lo hace debe pedir disculpas y no volverlo a hacer". Así, los estudiantes son capaces de establecer relaciones con el concepto trabajado sobre agresión fisca.

La lectura en voz alta llevó a los estudiantes a apropiarse de los conceptos trabajados, el transcurso de las sesiones mejoró su capacidad para relacionar los episodios de agresión en la lectura con las nociones abordadas y las situaciones del ambiente escolar. Como valor agregado, se apropiaron de las normas básicas a practicar para tener éxito en las prácticas de lectura en voz alta; fortalecieron su capacidad de expresarse en público y de captar la atención de quien escucha. Así mismo, mostraron serenidad y tranquilidad, tuvieron en cuenta el tono de voz y la clara pronunciación de las palabras. En cada una de las sesiones leyeron con ritmo y entonación apropiados, según la intención del texto y los signos de puntuación. Como oyentes fueron respetuosos: “es importante que escuche a mi compañero y que todos podamos participar"; "Todos podemos dar ideas". Los aportes y sugerencias se hicieron con respeto, evidenciando el interés por evitar cualquier tipo de agresión.

\section{Conclusiones}

Cambiar la percepción sobre la agresividad fue una meta ambiciosa, pero a pesar de los obstáculos, los resultados muestran que se alcanzó el objetivo de la implementación de la secuencia didáctica. El grupo de estudiantes logró apropiarse conceptualmente del significado de la agresión, comprenderlo y verlo en sus propias acciones y en las de otros. Es importante reconocer que los cuentos funcionan como un instrumento potencial que permite a los estudiantes establecer relaciones entre contenido y situaciones de vida. El lector puede pensarse y verse en los episodios narrados y, a partir de allí, reconocer sus problemáticas, analizarlas y plantear soluciones que le permitan contrarrestarlas.

De esta manera se confirma que el proceso de lectura va más allá de la decodificación de un texto, es un acto de significación inmerso en las prácticas sociales e incluye aspectos semióticos y culturales. Con las prácticas de lectura, especialmente con la lectura en voz alta de cuentos, se crean espacios de ciudadanía que son necesarios para una interacción acertada entre los miembros de una comunidad. La agresividad es un problema en las aulas, los maestros, como garantes de los derechos de los niños en las instituciones educativas, están llamados a implementar estrategias que permitan abordar este hecho y contrarrestarlo. Por lo tanto, deben promover prácticas pedagógicas que vayan más allá de lo conceptual y permitan asumir el problema de forma dinámica e interactiva, para que el estudiante se sienta motivado y no solo cambie sus percepciones, sino su comportamiento. 


\section{Referencias}

Bruner, J. (2000). La educación, puerta de la cultura. Capitulo 2. Madrid: Aprendizaje Visor.

Cassany. (2009). Para ser letrados, voces y miradas sobre la lectura. Barcelona: Paidós educador.

Chaux, E. (2012). Educación, convivencia y agresión escolar. Bogotá: Taurus.

Kayser, W. (1976). Interpretación y análisis de la obra literaria. Madrid: Gredos.

Marín, D. (2013). Leer para comprender, escribir para transformar: palabras que abren nuevos caminos en la escuela. Bogotá: Ministerio de Educación Nacional.

Ministerio de Educación Nacional (MEN). (1998). Lineamientos curriculares. Obtenido en Mayo de 2015, desde http://www.mineducacion.gov. co/1759/articles-339975_recurso_6.pdf
Ministerio de Educación Nacional (MEN). (2004). Estándares básicos de competencias ciudadanas: formar para la ciudadanía... jSí es posible! Lo que necesitamos saber y saber hacer. Bogotá: MEN.

Pérez, A. y Roa, C. (2010). Referentes para la didáctica para el Lenguaje en el primer ciclo. Bogotá: Secretaría de Educación Distrital. Proyecto Editorial CERLARC.

Quiroga, H. (1928). La retórica del cuento. Idilio y otros cuentos. Buenos Aires: Losada.

Trelease, J. (2007). Manual de la lectura en voz. alta. Bogotá: Fundalectura.

Trianes, Muñóz y Jiménez. (2007). Las relaciones sociales en la infancia y en la adolescencia y sus problemas. Madrid: Editorial Pirámide. 



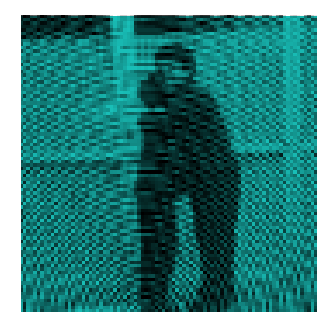


Ingrid Rivas Buitrago 1
1. Becaria de la Secretaría de Educación del Distrito, Fondo para la Formación Avanzada para Docentes en el Doctorado Educación y Sociedad, Universidad de La Salle. Maestría en Ciencias, Nova Southeastern University, Fort Lauderdale, Florida; correo electrónico: ingridrivasb@gmail.com
Fecha de recepción: 18 de abril de 2016 / Fecha de aceptación: 16 de septiembre de 2016

\section{Resumen}

El actual documento es parte del trabajo adelantado para la investigación "Educación ética para la convivencia escolar pacífica. Estudio de caso en los Megacolegios de la UPZ 87 de la Localidad siete de Bosa, Bogotá", en el marco del Doctorado en Educación y Sociedad de la Universidad de La Salle. Se elabora una revisión de documentos que han abordado la problemática de la violencia escolar en las instituciones educativas de Colombia, particularmente la violencia escolar en la ciudad de Bogotá, destacando los avances de los últimos años en la materia.

\section{Palabras clave: Educación,} educación moral, educación para la paz, entorno educativo, ética.

\section{Summary}

The current document is part of the advance work for doctoral research; "Ethics for School Education Peaceful Coexistence. Case study in the UPZ Megacolegios 87 Location seven Bosa, Bogotá ", under the Doctorate in Education and Society at the University of La Salle. In this, a review of documents that have addressed the problem of school violence in educational institutions in Colombia and especially is made, school violence sight for the city of Bogotá, highlighting the progress in this area in recent years.

Keywords: Education, moral education, peace education, environmental education, ethics.

\section{Resumo}

O presente documento é parte do trabalho adiantado para pesquisa de doutorado; "Ética para a educação escolar Convivência. Estudo de caso na UPZ Megacolegios 87 Localização sete Bosa, Bogotá ", sob o Doutorado em Educação e Sociedade na Universidade de La Salle. Neste, uma análise dos documentos que têm abordado o problema da violência escolar nas instituições de ensino na Colômbia e, especialmente, é feita, a violência vista escola para a cidade de Bogotá, salientando os progressos nesta área nos últimos anos.

\section{Palavras chave: Educação,} educação moral, educação para a paz, educação ambiental, ética. 


\section{Introducción}

En el ámbito de la investigación social, desde la década de los noventa va en aumento la preocupación por la creciente y cada vez más complicada situación de conflicto entre menores, y la manera como se ha materializado en los entornos escolares, lo que ha llevado a que se adelanten tareas encaminadas a profundizar, no solo en el conocimiento de esta problemática, sino en la promoción de acciones y actividades que colaboren en el ejercicio de reducir los índices de violencia que genera dentro y fuera de las aulas.

Considerando lo pertinente que resulta indagar y ofrecer soluciones a esta problemática, el actual documento busca realizar un acercamiento, similar al de Valencia (2004), al acervo de trabajos que se han producido sobre el fenómeno, reconociendo particularmente aquellos que han profundizado en el reconocimiento de la ética como parte esencial de la formación del sujeto, y de su trascendencia en la formación de escenarios de respeto propio y del otro; junto con una construcción de la dimensión valorativa de su entorno social, que permita la sana convivencia y la promoción de valores para la formación ciudadana.

El documento ha sido estructurado con base en la formulación del estado del arte realizado para la investigación doctoral "Educación ética para la convivencia escolar pacífica. Estudio de caso en los Megacolegios de la UPZ 87 de la localidad siete de Bosa, Bogotá", por lo que se trabajan documentos relacionados con la ética y la convivencia, aunque también se ha decidido indagar sobre la relación de estas categorías con una educación para la paz, en el marco del actual proceso nacional que busca llegar a un acuerdo para el fin del conflicto, por lo que la revisión se extiende hasta los trabajos realizados en este ámbito.

Se sigue una ruta expositiva, por lo que inicialmente se presentarán trabajos regionales de América Latina en los que se observó la problemática de la violencia escolar, pasando, en un segundo momento, al panorama colombiano, donde se revelan los alcances y resultados de investigaciones alineadas con dicha problemática, para en un tercer momento llegar a las investigaciones de Bogotá, y finalmente presentar las conclusiones para alimentar el debate respecto a los temas trabajados.

\section{El deterioro de la convivencia escolar en la región}

Un primer ejercicio a realizar en la revisión de documentos internacionales que den cuenta del fenómeno de la violencia escolar, consiste en detenerse a tratar la producción documental hecha por organismos internacionales, puesto que marca el referente y propone las recomendaciones a seguir, que en muchos casos se discuten y se incluyen en el diseño de las políticas públicas y en situaciones específicas. Así, debe señalarse que en 2006 fue presentado ante la Asamblea General de las Naciones Unidas, el estudio mundial sobre la violencia contra los niños, el cual evidencia la sistemática violación de sus derechos en entornos como la familia, las instituciones educativas y las comunidades, de allí que el informe exponga una serie de desafíos que deben enfrentar los Estados y la sociedad civil para la construcción de tejido social desde la escuela, en procura de mejorar las relaciones de convivencia, no solo en el aula, sino en otros entornos sociales.

En este marco, organizaciones como UNICEF han realizado estudios orientados a conocer la situación de niños y adolescentes en cuanto al fenómeno de la violencia escolar, tal como el informe Violencia escolar en América Latina y el Caribe superficie y fondo (2011), el cual cuenta con un amplio marco referencial y la lectura de numerosos trabajos de organismos nacionales e internacionales, sobre los aspectos relacionados con la caracterización de la convivencia escolar y sus puntos de discusión, de allí que este organismo diseñara una de las propuestas más fuertes relacionadas con la promoción de estrategias para mejorar la convivencia escolar, el Programa para la Gestión del Conflicto Escolar Hermes (2009).

Román y Murillo (2011) realizan un estudio similar con instituciones de educación primaria; su análisis se centra en la violencia escolar y su incidencia en el desempeño de los estudiantes, a partir de la revisión de datos del Segundo Estudio Regional Comparativo y Explicativo (SERCE), de la Organización de las Naciones Unidas para la Educación, la Ciencia y la Cultura (UNESCO), realizado con estudiantes de 16 países latinoamericanos, y que para el caso colombiano reconoce una alta presencia de episodios violentos entre compañeros de clase, que hace necesario intervenir con propuestas pertinentes que den alguna solución al problema de las falencias en términos de convivencia escolar.

La ruta metodológica del estudio comparado es también usada por Sime y Tincopa (2004), para formular un estado del arte sobre ética, ciudadanía y paz en la educación de cinco países de América Latina (Brasil, Colombia, Chile, México y Perú), concluyendo que 
si bien en todos los países se nota un ejercicio por generar una construcción teórica y práctica respecto a la ética, la ciudadanía y la paz en la educación dentro de los diseños curriculares de los centros de aprendizaje de educación básica, éste ha sido más exitoso, en términos de alcance, para aquellos países en que la enseñanza de la ética se ha acompañado de la reflexión alrededor de temas de educación en Derechos Humanos, educación ciudadana, convivencia y democracia, entre otros.

Esta es una posición apreciativa que se encuentra igualmente compartida en los trabajos de Dueñas y Magendzo (1994); Peluchonneau y Romagnoli (1994); el Programa de Promoción de la Reforma Educativa para América Latina, PREAL (2003 y 2004), y Hoyos (2000), en los cuales se reconoce la necesidad de establecer en los primeros años de vida escolar y, por ende, en la escuela, una instancia socializadora secundaria que sirva en la construcción de una valoración positiva intersubjetiva sobre la participación y la tolerancia, para facilitar el logro de sociedades más democráticas.

Por su parte, Schmelkes (2006) trabaja el tema de interculturalidad y educación desde el marco referencial de la inclusión de los pueblos indígenas, y propone que la enseñanza de la ética en la educación básica es una condición necesaria para la formación de un esquema de valores que permita desarrollar la convivencia, el respeto del otro, el reconocimiento y la promoción de los
Derechos Humanos, por lo que resulta clave el diálogo con quienes diseñan e imparten los contenidos de formación cívica y ética.

De esta manera ha sido posible agrupar un primer grupo de trabajos que recogen los postulados de diferentes estudios internacionales o regionales, y que comparten el hecho de convocar a los entes gubernamentales e institucionales educativos, a avanzar en la generación de estrategias que permitan mejorar los violentos panoramas de convivencia escolar en las instituciones educativas de la región y de Colombia; considerando que esta es una condición de deterioro social que imposibilita la formación de capacidades ciudadanas, en el marco de los Estados democráticos que propugnan los proyectos de nación para estos países.

\section{Formación ética para la convivencia escolar pacífica: su aporte a la construcción de la paz}

A nivel nacional son varias las líneas de trabajo desarrolladas en relación a la investigación en ética, convivencia escolar y educación para la paz, destacando estudios investigativos como el de González, Niño, Ortiz, Posada, Rey y Solórzano (2012), sobre los rasgos característicos de las prácticas educativas destacadas en el

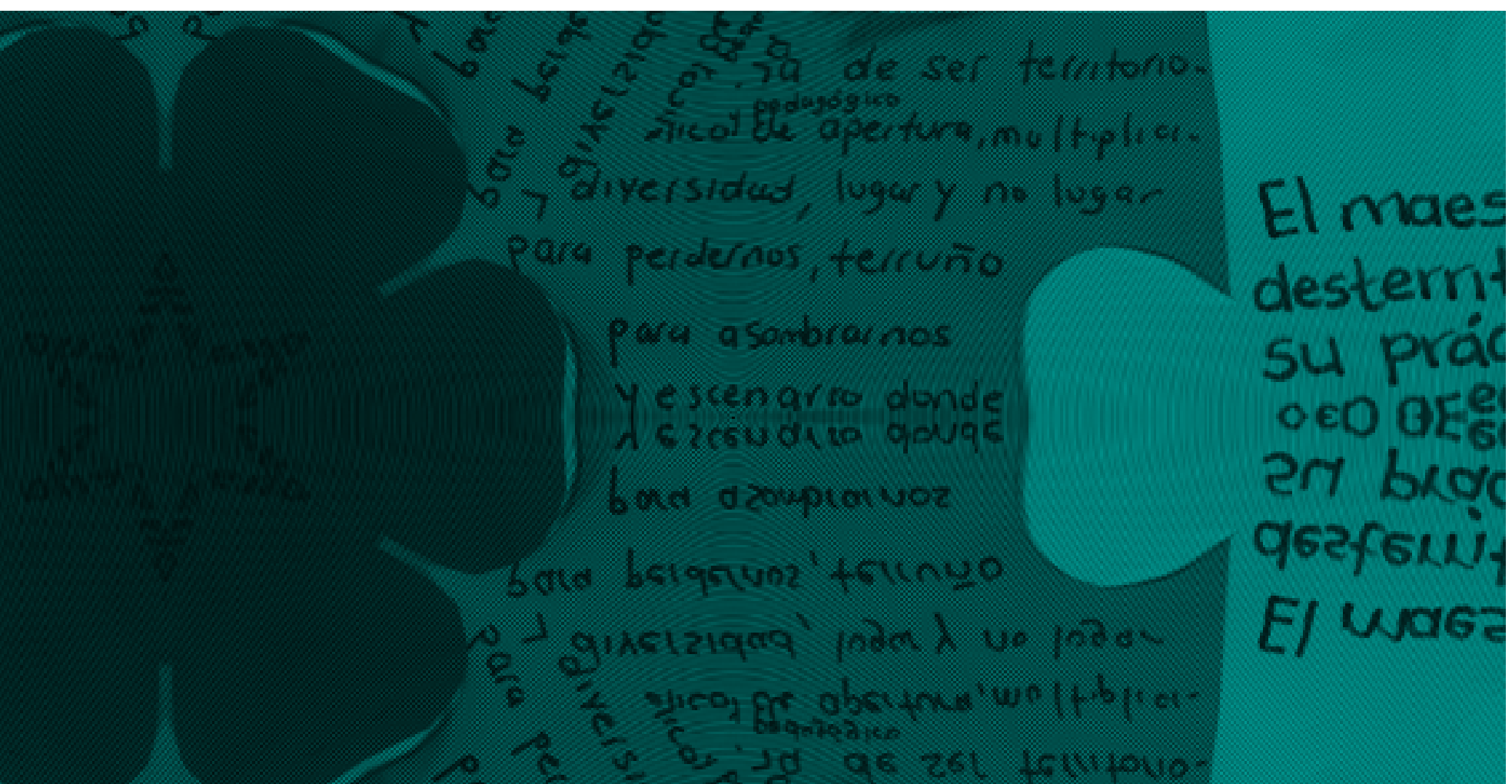


área de ética y valores humanos, cuyo propósito fue el de caracterizar "las prácticas de enseñanza de los y las maestras en las áreas mencionadas, a partir del análisis documental de los textos enviados por los educadores colombianos, durante 12 años, al Premio Compartir al maestro (entre 1999-2011)" (p. 16).

Se destaca como conclusión en el estudio de González, et al. (2012), una reflexión que también es compartida por Hoyos (2000) en el sentido de reconocer al área de Educación Ética y Valores Humanos en la escuela, como un espacio eminentemente interdisciplinar, transversal y complejo del que no se puede derivar una pedagogía y didáctica específicas, sino que debe atender a la conjugación de múltiples estrategias y prácticas de enseñanza y aprendizaje, dentro y fuera del ámbito escolar, para la construcción de democracia y formación en valores y Derechos Humanos.

González, et al. (2002), identifican que aquellos docentes que se destacan impartiendo la asignatura de Educación Ética y Valores Humanos, son los que se preocupan por "hacer reflexiones relacionadas con una educación moral, potenciando las capacidades de argumentación moral de las personas, como uno de los elementos centrales para el ejercicio de la autonomía y la solidaridad entre los integrantes de una sociedad" (p. 48), y que los docentes más destacados de Colombia, reconocidos por el Premio Compartir al Maestro, se caracterizan por asumir la asignatura de Educación Ética y Valores Humanos como espacio que debe ser trabajado de manera dedicada desde la escuela, para formar convivencia dentro y fuera de ella.

Aunque desde una perspectiva más normativa, la tesis doctoral de Robledo (2012) también se ubica en la ruta de la formación en valores; se trata de un texto que indaga por las condiciones para brindar una educación para la autonomía en la educación formal colombiana, acudiendo a un análisis de la legislación y de la cultura nacional para plantear, como parte de las conclusiones, que antes que una formación significativa respecto a la ética y a los valores, lo que tiende a verse en la escuela es una tarea repetitiva que hace parte de un contenido curricular y complica el ejercicio de una formación ética para la convivencia escolar pacífica.

La Fundación Compartir es también copartícipe de una investigación de 2015, cuyo objeto consistió en revisar la manera como la asignatura de Educación Ética y Valores Humanos se relaciona significativamente con la educación para la democracia y con la educación para la paz y los Derechos Humanos, planteando al respecto que la educación ética debe ser un eje fundamental de la formación escolar, teniendo en cuenta que en la actualidad el país se encuentra en un período de transición de fin del conflicto armado, lo cual hace pertinente el aprendizaje significativo de esta área en el ambiente educativo, de manera que sea canal para el desarrollo de la autonomía, la resolución de conflictos en el aula y el logro de una convivencia pacífica en las instituciones escolares.

Otro trabajo que se refiere a la constante violencia en los centros educativos colombianos es el de Salguero (2004), quien tomando como centro de su investigación al Centro Cultural y Educativo Español "Reyes Católicos", elabora la tesis doctoral en la cual presenta un análisis del contexto de la violencia en el país, especialmente a su materialización en los centros educativos, comparándola con la experiencia educativa del autor en territorio español, de allí surge un modelo de educación institucionalizada en torno a un tipo de cultura de paz que, desde la interdisciplinariedad, construya una pedagogía de la convivencia capaz de superar los episodios de constante violencia en los centros educativos.

Aunque estos elementos han sido también abordados en documentos del Ministerio de Educación Nacional (s.f.), en la Formulación de los lineamientos curriculares de la Educación Ética y Valores Humanos, se considera que las ideas allí planteadas permanecen en abstracto, puesto que se quedan en trazar el fortalecimiento de la autoestima, la toma de conciencia y el respeto por la integridad del ser humano, y a pesar de que estos parámetros son referentes ciertos para la construcción del sujeto desde la infancia, se requiere de una mayor claridad para materializar dichas condiciones en la formación ética escolar, y lo más importante, para que incidan en la vida en sociedad y amplíen el sentido democrático y participativo del escolar. Nancy Palacios (2013) comparte esta apreciación.

A pesar de lo anterior, el Ministerio de Educación Nacional (2004) estableció el Programa Nacional de Competencias Ciudadanas, sobre el que Jiménez, Lleras y Nieto (2010), realizan un análisis, preguntando por la incidencia y aplicación del programa, encontrando que aunque el plan aboga por la mejora de la convivencia en los colegios, y que de allí se desprenden estrategias como Aulas de Paz, caracterizadas en textos como el de Chaux (2012), hace falta ensanchar la acción institucional encaminada a tareas como la capacitación docente y la mejora de los procesos, que eviten la pérdida de calidad del programa en su esfera de ampliación a todo el territorio nacional.

Sin embargo, pese a lo anterior, no debe desconocerse que para los últimos años este aspecto ha sido profundizado en la investigación institucional, llevando a que el Ministerio acuda a investigadores expertos en el tema para desarrollarlo en documentos como el realizado por Suárez (2011), en el que se introducen conceptos de manejo de la ética tomando como referente distintos aspectos 
puntuales de la vida del infante, dejando como mensaje final la necesidad de construir desde distintas concepciones valores que integren el desarrollo del menor, para que asuma como propias las responsabilidades de su tiempo.

El Ministerio de Educación Nacional (2011) también realizó un texto para lograr la institucionalización del Programa de Competencias Ciudadanas -PCC, en el cual se indica que la ética escolar es un área fundamental en la formación ciudadana de niños y jóvenes, pues permite invitarlos al desarrollo de competencias ciudadanas y es una herramienta para desarrollar habilidades y competencias consecuentes con la construcción de convivencia, la participación democrática y el respeto desde la promoción de la pluriculturalidad, compartiendo así la posición del trabajo de Montoya (2007).

El estudio presenta otra arista, relacionada con el fenómeno escolar del bullying, considerándole una manifestación de la violencia escolar que, para el caso colombiano, también ha sido abordada en trabajos como los de Echeverri, Gutiérrez, Ramírez y Morales (2014); Cruz (2014); Andrade, Bonilla y Valencia (2011); o Forero (2011), y con un enfoque más conceptual en Benites (2012), Díaz (2003 y 2005) y Horna (2012), los cuales establecen una condicionalidad de instrumentalización de la violencia escolar a partir del bullying, que, en ocasiones, al ser tolerada por distintos actores de las instituciones educativas, debilita las posibilidades para lograr mejoras en las condiciones de reducción de la violencia juvenil y en convivencia escolar de las instituciones del país.

Las investigaciones presentadas exponen la forma en que los estudios sobre educación ven en la ética un aspecto fundamental a desarrollarse en el ámbito escolar, teniendo en cuenta que es ella la que da los fundamentos morales al comportamiento del ser humano y la que, en última instancia, le proporciona el sentido de ser a la educación, en la medida que su labor es humanizar a sus actores, docentes, padres de familia y estudiantes, lo cual permite reconocer el fenómeno social de la convivencia escolar como un escenario en el que directamente influye la educación en ética y en valores.

\section{Una mejor convivencia escolar de niños y jóvenes en la ciudad}

Los trabajos referenciados tienen una visión mediada desde el actor institucional, pero, apartándose de esta perspectiva pueden encontrase trabajos como el de Chaux $(2001,2011)$ y Chaux y
Velásquez (2008), que ven la violencia escolar desde el actor propio del conflicto, desde los menores. Para ello consultan directamente a niños y adolescentes de Bogotá, especialmente a aquellos en condiciones socioeconómicas de pobreza o pobreza extrema, intentando retratar la realidad de un sector importante de la ciudad (Chaux, 2001, 2011 y 2012); sus estudios son también el soporte teórico de investigaciones como la de Aponte, Pineda y Romero (2015), sobre la violencia en una IED de la localidad de San Cristóbal, en la que, como sucede en la investigación de Chaux (2001), el factor emocional es determinante de la agresividad escolar.

Chaux (2001) trabaja a partir de una entrevista a 56 menores entre los 8 y los 14 años de edad, conjugada con la recolección de 128 historias que tratan sobre conflictos y la solución que se les dio entre amigos o compañeros de clase, evidenciando que, comparado con los países desarrollados, en nuestro país se da un mayor uso de la violencia como mecanismo para solucionar las situaciones de conflicto. En términos generales, ante una situación real de conflicto, los menores prefieren acudir a la violencia, sea física o verbal, en lugar del diálogo. Se establece que este tipo de reacciones son resultado de la construcción de imaginarios que se forma el menor sobre el conflicto, y de las emociones propias o contextuales de la situación.

Bajo el mismo enfoque, Cepeda, Pacheco, García y Piraquive (2008) realizaron un trabajo que les permitió determinar las características y niveles de acoso escolar en los colegios públicos de la Localidad de Ciudad Bolívar, a partir de una muestra de 3226 estudiantes de educación básica y media que fueron encuestados para consultar los niveles de bullying; se encontraron altos niveles de estudiantes rechazados o humillados por sus compañeros, sin que la condición de acoso estuviera determinada directamente por su nivel socioeconómico.

Los recientes documentos bien podrían ser el contraste de una tesis que resulta interesante en relación con el tipo de investigación que desarrolla y el escenario de conflicto que retrata; el trabajo de Maestría en Educación de Rodríguez (2005), que plasma la violencia escolar primaria (con escolares de segundo grado) en un colegio de estrato alto de la ciudad de Bogotá. La autora establece que con la intervención pedagógica llevada a cabo para el desarrollo del estudio, le fue posible construir habilidades en los estudiantes que permitieron que, con el paso de los meses, los conflictos resueltos en primera instancia de manera violenta, fueran tratados desde soluciones más dialogadas, como parte de unas destrezas interiorizadas por los alumnos que combinaban el manejo de emociones, el perdón y la reconciliación. 
Hay también textos que estudian la violencia escolar en la ciudad a partir de las relaciones entre la escuela y las barras bravas (Ávila, Buitrago y Ortiz, 2015; García y Cañón, 2007) o la violencia escolar desde el barrio con una perspectiva de género (García y Torres, 2007; Torres, 2011), o desde el contexto familiar y de barrio (García, 2008; García y Guerrero, 2011; García, Guerrero y Ortiz, 2012), para, en el último caso, establecer la estrecha relación entre los entornos y el comportamiento escolar y viceversa; un trabajo más interdisciplinario es el de Chaux, Velásquez, Melgarejo y Ramírez (2007), el cual infiere que pertenecer a una familia no violenta no implica el no desarrollo de agresividad en el entorno escolar o del barrio, lo cual puede depender del mismo nivel de violencia que se reproduzca en ellos.

Otra línea de documentos distritales va de la mano con lo gubernamental y, en este caso, no se puede desconocer el avance de los últimos años, especialmente durante la administración 2012-2015 que, a través de la Secretaría de Educación Distrital, diseñó una política pública para la convivencia escolar, intentando recoger parte de los programas y proyectos que ya habían sido discutidos en administraciones anteriores, y los resultados de las encuestas de clima y violencia escolar para los colegios de la ciudad, elaboradas entre 2006 y 2013 (SED, 2013b).

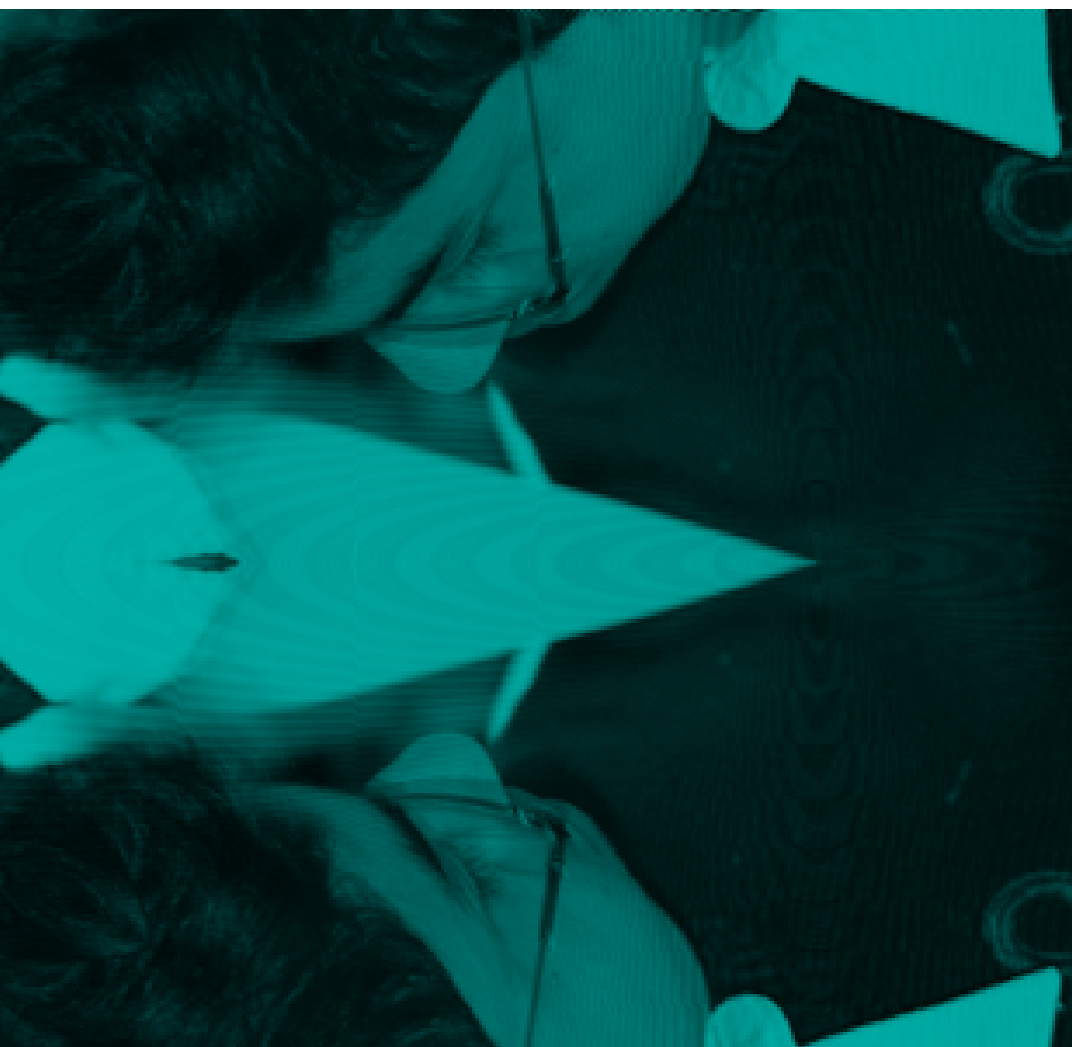

La política establece que aunque los avances de anteriores administraciones, plasmados en textos como el del Observatorio de Convivencia y Seguridad Ciudadana (2006), fueron parte de una formulación de programas relacionados con la convivencia en las instituciones educativas, no desarrollaron unos lineamientos claros que trazaran la ruta a seguir para la implementación de los planes y programas de convivencia en los colegios; además expresaban una dispersión en la operacionalización de los programas, que conducía a una desarticulación de la iniciativa (SED, 2013). A ello se suma el hecho de que a pesar de que las Instituciones Educativas Distritales (IED) venían avanzando en ejercicios propios de fortalecimiento de los escenarios de convivencia escolar, a través de actividades internas con programas de gestión no violenta de los conflictos, gobiernos escolares, entre otras, al momento de interconectarlos con los programas diseñados por la administración educativa distrital, las directivas de las instituciones no los tomaban como parte fundamental de la formación escolar (SED, 2014b).

Es por eso que en el marco del Plan Sectorial de Educación 2014 se estableció "la consolidación de la Educación para la Ciudadanía y la Convivencia como elemento fundamental en la garantía del derecho a una educación de calidad en el Distrito Capital" (SED, 2014b, p. 6), para lo cual se instituyó una estructura pedagógica, técnica y financiera, que diera paso a lo que hoy es el Proyecto para la Educación para la Ciudadanía y la Convivencia-PECC, definiendo las actuales líneas de trabajo aplicables a iniciativas como: Planes Integrales de Educación para la Ciudadanía y la Convivencia -PIECC-; Iniciativas Ciudadanas de Transformación -INCITAR-; Gestión del Conocimiento; y Respuesta Integral de Orientación Escolar -RIO-, consideradas en el texto como el marco operativo del Proyecto, puntos de concreción de lo que se define como Lineamiento Pedagógico de la Educación para la Ciudadanía y la Convivencia (SED, 2014b).

Puede en tanto reconocerse un avance académico e institucional en lo que respecta a la mejora de las relaciones de convivencia en las instituciones educativas para el caso de la ciudad de Bogotá, no obstante, se considera que se debe profundizar en el debate y formulación de nuevos planes curriculares, donde temas como la formación ética y la formación en valores adquieran relevancia y sean considerados ámbitos de formación transversal en la educación de los menores, con estrategias innovadoras, incluyentes y participativas, que sean discutidas y consensuadas con todos los actores de la escuela y con especial participación de los estudiantes. 


\section{Conclusiones}

La aproximación a los trabajos internacionales, nacionales y locales, expuestos a lo largo del este texto, da cuenta de un amplio acervo de títulos gubernamentales, institucionales y académicos que exponen el estado presente de la convivencia escolar en las instituciones educativas del país, especialmente de la ciudad de Bogotá, convirtiéndose, tal vez, en insumos para avanzar en la generación de estrategias que permitan mejorar la convivencia en las instituciones educativas, reconocien-

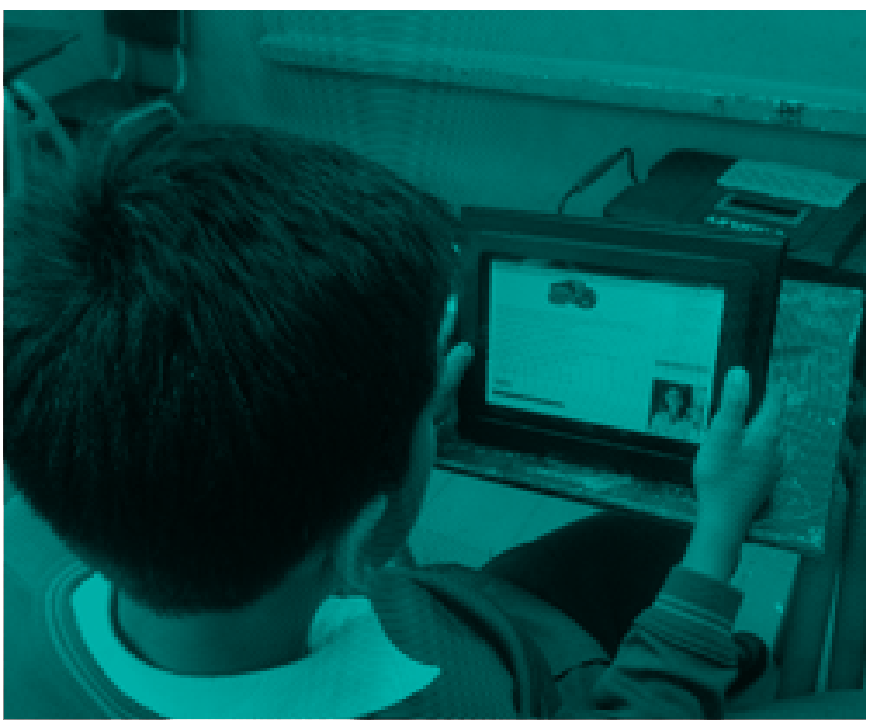

que les permitan un cambio significativo en la manera como, desde la infancia y la adolescencia, se construye ciudadanía y se forman valores y capacidades encaminadas a la convivencia, no solo en la escuela, sino en cada uno de los ámbitos sociales.

Para el caso de Bogotá, el cúmulo de aportes que se han dado desde el ámbito académico e institucional, permite reconocer avances fuertes en la materia, aunque se debe seguir trabajando para lograr que, en efecto, la convivencia en los colegios se vea mejorada por la implementación do en la ética y la formación en valores un aspecto clave para el logro de tal fin.

Esto, reconociendo también el escenario actual de construcción de paz en el país, para el que se considera debe hacerse altamente partícipes a las instituciones educativas, que deben además asumir la tarea de desarrollar en los escolares, a partir de múltiples estrategias, las capacidades cognitivas, comunicativas y argumentativas de acciones que persuadan a los estudiantes a tener mejores tratos entre ellos, y que a su vez posibiliten un ambiente saludable en materia de convivencia que se traslade a otros escenarios de la vida social de los escolares, sugiriendo para ello prácticas pedagógicas basadas en el reconocimiento de la ética como base para la formación de las capacidades ciudadanas. 


\section{Bibliografía}

Andrade, J., Bonilla, L., y Valencia, Z. (2011). La agresividad escolar o bullying: una mirada desde tres enfoques psicológicos. Pensando Psicologia, 7(12), pp. 135-149.

Aponte, A., Pineda, L., y Romero, V. (2015). Evaluación de conductas hostigadoras que afectan la convivencia escolar en niños de quinto de primaria. Revista Evaluación e Intervención Psicológica, 1(1), pp. 34-44.

Ávila, B., Buitrago, J., y Ortiz, A. (2015). La influencia de la pertenencia a barras bravas en la convivencia escolar de tres instituciones educativas distritales. Una mirada desde la escuela. Tesis de Maestría. Chía: Universidad de la Sabana, Facultad de Educación.

Benites, L. (2012). La convivencia escolar: una estrategia de intervención en bullying. En ALFEPSI. Bullying y convivencia en la escuela: aspectos conceptuales, aplicativos y de investigación. Lima: ALFENSI.

Cepeda, E., Pacheco, P., García, L., y Piraquive, C. (2008). Acoso escolar a estudiantes de educación básica y media. Revista Salud Pública, 10(4), pp. 517-528.

Chaux, E. (2001). Peer conflicts in a violent environment: strategies, emotions, reconciliations, and third parties in conflicts among Colombian children and early adolescents. Tesis doctoral. Harvard University.

Chaux, E. (2011). Múltiples perspectivas sobre un problema complejo: comentarios sobre cinco investigaciones en violencia escolar. Psykhe, 20(2), pp. 79-86.

Chaux, E. (2012). Educación, convivencia y agresión escolar. Bogotá: Universidad de los Andes, Taurus.

Chaux, E., y Velásquez, A. M. (2008). Violencia en los colegios de Bogotá: contraste internacional y algunas recomendaciones. Revista Colombiana de Educación, 55, pp. 14-37.

Chaux, E., Velásquez, A. M., Melgarejo, N., y Ramírez A. (2007). Victimización escolar en Bogotá: prevalencia y factores asociados. Informe elaborado para la Secretaría Distrital de Gobierno. Sistema Unificado de Información sobre Violencia y Delincuencia-SUIVD. Bogotá: Universidad de los Andes.
Cruz, E. (2014). Hipótesis sobre el matoneo escolar o bullying: a propósito del caso colombiano. Intersticios. Revista sociológica de pensamiento crítico, 8(1), pp. 149-156.

Díaz, M. J. (2003). Diez condiciones básicas para prevenir la violencia desde la adolescencia. Revista de estudios de juventud: Aspectos psicosociales de la violencia juvenil (62), pp. 21-36.

Díaz, M. J. (2005). Por qué se produce la violencia escolar y cómo prevenirla. Revista Iberoamericana de Educación (37), pp. 17-47.

Dueñas, C., y Magendzo, A. (1994). La construcción de una nueva práctica educativa. México: Comisión Nacional de Derechos Humanos.

Echeverri, A., Gutiérrez, R., Ramírez, C., y Morales, S. (2014). Hacia una construcción del concepto violencias escolares. Revista Colombiana de Ciencias Sociales, 5(1), pp. 122-138.

Forero, O. F. (2011). La violencia escolar como régimen de visibilidad. Magis. Revista Internacional de Investigación en Educación, 4(8), pp. 399-413.

García, B. (2008). Familia, escuela y barrio: un contexto para la comprensión de la violencia escolar. Revista Colombiana de Educación (55), pp. 108-124.

García, B., y Cañón, L. (2007). Estudio de caso sobre el fenómeno de barras bravas: una mirada desde la escuela. Típica, Boletín Electrónico de Salud Escolar, 3(2).

García, B., y Guerrero, J. (2011). Nuevas concepciones de autoridad y cambios en las relaciones de violencia en la familia y la escuela. Magis. Revista Internacional de Investigación en Educación, 4(8), pp. 297-318.

García, B., Guerrero, J., y Ortiz, B. (2012). La violencia escolar en Bogotá desde la mirada de las familias. Bogotá: Universidad Distrital Francisco José de Caldas.

García, B., y Torres, C. (2007). La violencia femenina en el ámbito escolar. Un estudio de caso en una institución educativa distrital de Bogotá. Típica, Boletín Electrónico de Salud Escolar, 3(2). 
González, J. A., Niño, D. M., Ortiz, M. I., Posada, J. I., Rey, N. E., y Solórzano, J. C. (2012). Rasgos característicos de las prácticas educativas destacadas en el área de ética y valores humanos doce años del Premio Compartir al Maestro. Obtenido desde https://repository.javeriana.edu.co/handle/10554/12374

Horna, V. (2012). Un estudio cualitativo sobre convivencia escolar: el bullying desde la perspectiva de las víctimas. En ALFEPSI. Bullying y convivencia en la escuela: aspectos conceptuales, aplicativos y de investigación. Lima: ALFEPSI.

Hoyos, G. (2000). Formación ética, valores y democracia. Estados del Arte de la Investigación en Educación y Pedagogia en Colombia. Obtenido desde http:/ / www.academia.edu/3547329/FORMACION_\%C3\%89TICA_VALORES_Y_DEMOCRACIA_Guillermo_Hoyos_V\%C3\%A1squez_Profesor_Universidad_Nacional_de_Colombia

Jiménez, M., Lleras, J., y Nieto. A. M. (2010). La paz nace en las aulas: evaluación del programa de reducción de la violencia en Colombia. Educación y educadores, 13(3), pp. 347-359.

Ministerio de Educación Nacional (MEN). (s.f.). Lineamientos Curriculares- Educación Ética y Valores Humanos. Bogotá: MEN. Obtenido el 8 de Febrero de 2014 desde http://www.mineducacion.gov.co/1621/articles-89869_archivo_pdf7.pdf

Ministerio de Educación Nacional (MEN). (2004). Estándares básicos de competencias ciudadanas. Formar para la ciudadanía... jSí es posible! Lo que necesitamos saber y saber hacer. Bogotá: MEN.

Ministerio de Educación Nacional (MEN). (2011). Orientaciones para la institucionalización de las competencias ciudadanas: cartilla 1 Brújula. Programa de Competencias Ciudadanas. Bogotá: MEN.

Montoya, I. (2007). Acercamiento al desarrollo del pensamiento crítico, un reto para la educación actual. Revista Virtual Universidad Católica del Norte, 1(21).

Observatorio de Convivencia y Seguridad Ciudadana. (2006). Convivencia y seguridad en ámbitos escolares de Bogotá D. C. Bogotá: Subsecretaría de Asuntos para la Convivencia y Seguridad Ciudadana.

Palacios, N. (2013). Transformación y crisis de la escuela: algunas reflexiones sobre el caso colombiano. Revista Historia de la Educación Latinoamericana, 15(21), pp. 335-375.
Peluchonneau, P., y Romagnoli, C. (1994). Convivencia social: perspectivas y proposiciones de experiencias nacionales y extranjeras para educar la convivencia social en la escuela. Santiago de Chile: CPU, Corporación de Promoción Universitaria.

Programa de Promoción de la Reforma Educativa para América Latina (PREAL). (2003). Buenas prácticas para mejorar la educación en América Latina. Santiago de Chile: PREAL.

Programa de Promoción de la Reforma Educativa para América Latina (PREAL). (2004). Construcción de la profesión docente en América Latina: tendencias, temas y debates. Santiago de Chile: PREAL.

Rodríguez, C. (2005). Manejo de emociones, conflictos, perdón y reconciliación: Análisis del proceso de desarrollo en niños y niñas de un colegio privado de Bogotá. Tesis de Maestría. Bogotá: Universidad de Los Andes, Facultad de Educación.

Román, M., y Murillo. J. (2011). América Latina: violencia entre estudiantes y desempeño escolar. Revista CEPAL, No. 104, pp. 37-54.

Salguero, J. M. (2004). Educar para la paz: el caso de un país dominado por la violencia: Colombia. Tesis doctoral. Madrid: Universidad Complutense de Madrid.

Schmelkes, S. (2006). La interculturalidad en la educación básica. Ponencia presentada en la Segunda Reunión del Comité Intergubernamental del Proyecto Regional de Educación para América Latina y el Caribe (PRELAC), Santiago de Chile, 11.

Secretaría de Educación Distrital (SED). (2013a). PIECC General: Planes integrales de Educación para la Ciudadania y la Convivencia. Bogotá: Secretaría de Educación Distrital.

Secretaría de Educación Distrital (SED). (2013b). Clima escolar y victimización en Bogotá, 2013: encuesta de convivencia escolar. Bogotá: Secretaría de Educación Distrital.

Secretaría de Educación Distrital (SED). (2014a). Documento marco: Educación para la Ciudadanía y la Convivencia. Bogotá: Secretaría de Educación Distrital.

Secretaría de Educación Distrital (SED). (2014b). Lineamiento pedagógico: Educación para la Ciudadanía y la Convivencia. Bogotá: Secretaría de Educación Distrital. 
Secretaría de Educación Distrital (SED). (2014c). Currículo para la excelencia académica y la formación integral: orientaciones para el área de Educación para la Ciudadanía y la Convivencia. Bogotá: Secretaría de Educación Distrital.

Secretaría Distrital de Integración de Social (SDIS). (s.f.). Localidad de Bosa: documento preliminar de narrativa. UPZ 87 Tintal Sur. Bogotá: Secretaría Distrital de Integración de Social.

Sime, L., y Tincopa, L. (2004). Estado de arte sobre ética, ciudadanía y paz en la educación en cinco países de América Latina. En FLAPE, Ética, ciudadania y paz en la educación. Estudios, análisis y propuestas. Lima: Foro Educativo.

Suárez, R. (2011). Ética y Valores Humanos. Bogotá: Ministerio de Educación Nacional.
Torres, C. (2011). Pandillismo y violencia escolar femenina en el barrio y su proyección a la escuela. Magis. Revista Internacional de Investigación en Educación, 4(8), pp. 383-398.

UNICEF. (2009). El Programa para la Gestión del Conflicto Escolar Hermes: Bogotá, Cundinamarca (Colombia). Panamá: UNICEF, Oficina Regional para América Latina y el Caribe.

UNICEF. (2011). Violencia escolar en América Latina y el Caribe, superficie y fondo. Panamá: UNICEF, Oficina Regional para América Latina y el Caribe.

Valencia, F. (2004). Conflicto y violencia escolar en Colombia: lectura breve de algunos materiales escritos. Revista cientifica Guillermo de Ockham, 7(1), pp. 29-41. 


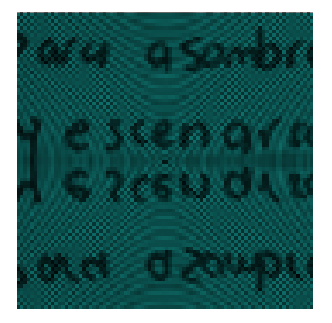




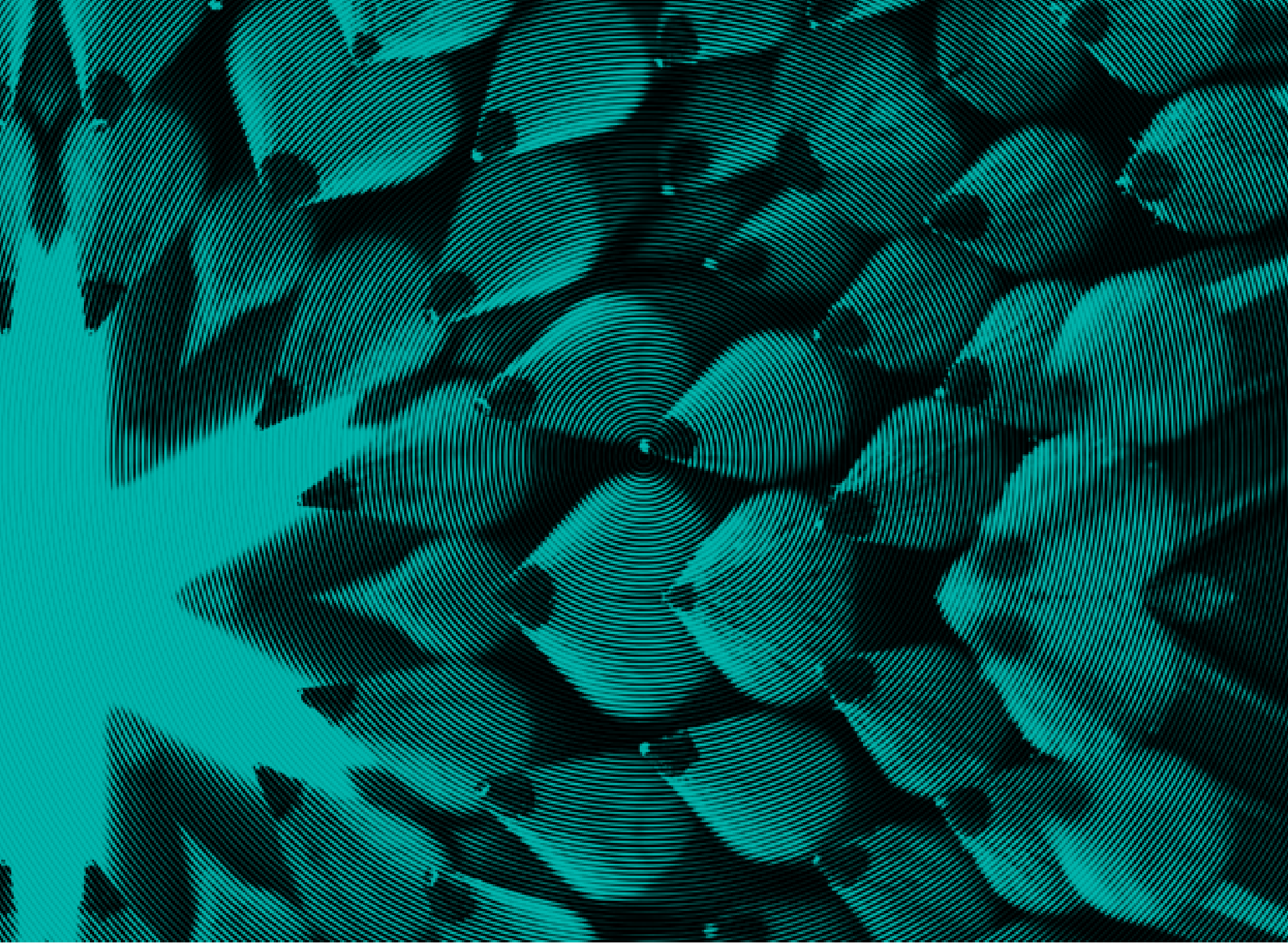

Giro Lingüístico hacia la paz

Linguistic Turn to peace Retorno linguístico para a paz Olga Yolanda Rojas Torres 
Olga Yolanda Rojas Torres 1
1. Profesora de Pedagogía de los lenguajes en la Universidad Nacional de Colombia; candidata a doctora en Semiótica por la Universidad de Córdoba, Argentina. Magíster en Educación de la Universidad Externado de Colombia; correo electrónico: oyrojast@unal.edu.co
Fecha de recepción: 26 de febrero de 2016 / Fecha de aceptación: 16 de septiembre de 2016

\section{Resumen}

En este artículo se insiste en la pertinencia de hacer el giro lingüístico en la enseñanza de la lengua española. La razón para optar por esta perspectiva es que, ubicados en el estudio del habla coloquial en oposición a la lengua ideal, podemos construir tejidos sociales más comprensivos. Con este propósito se explica el concepto de Giro Lingüístico, se reflexiona sobre la paz en tanto comunicación, y se aportan cinco ejemplos de proyectos de aula diseñados por estudiantes de español del Departamento de lingüística de la Universidad Nacional de Colombia.

Palabras clave: Giro Lingüístico, proyecto de aula, comunicación, español, enseñanza-aprendizaje.

\section{Summary}

This essay stresses the relevance of making the linguistic turn in teaching the Spanish language. The reason for choosing this perspective is because once we study colloquial speech, as opposed to the ideal language, we can build more comprehensive social relations. concept of linguistic turn, also the idea of peace as related to communication, and five examples of school classroom projects, which were designed by students of Spanish at the Universidad Nacional de Colombia.

Keywords: Linguistic turn, classroom project, communication, Spanish, teaching-learning. On this purpose we present the

\section{Resumo}

Este ensaio salienta a importância de fazer a virada linguística no ensino da língua espanhola. A razão para a escolha desta perspectiva situa-se na hipótese de que o estudo da fala coloquial, em oposição à linguagem ideal pode construir tecido social abrangente. Para este efeito se explica o conceito de virada linguística, além disso se reflete sobre a paz tanto em quanto comunicação, e se apresentam cinco exemplos de projetos de aula concebidos por estudantes do departamento de linguística na Universidade Nacional da Colômbia.

Palavras chave: Virada linguística, projeto de aula, comunicação, Espanhol, ensino-aprendizagem. 
La paz nace en nuestras voces. En las escuelas colombianas la asignatura de Español puede proponerse el objetivo de estudiar el habla ordinaria sobre el supuesto de que la convivencia mejora si reflexionamos sobre el efecto de sentido producido por el uso de la lengua. Otro escenario, el que aún se privilegia en las aulas, presenta al español como lengua ideal. Esta opción se toma para mantener a la asignatura concentrada en conocimientos lingüísticos confiables y comprobados; pero no abriga la convivencia en su centro. Retomaremos en este ensayo la discusión del Giro Lingüístico sobre la verdad en la lengua ideal, y los efectos de sentido en el habla cotidiana. Con este propósito, ahondaremos en algunos presupuestos que dan forma a estas dos posturas; además, aportaremos, sucintamente, algunas pautas centrales en las propuestas de proyecto pedagógico que están realizando los estudiantes de la carrera de Español y filología clásica de la Universidad Nacional, junto con alumnos de Lingüística y de otras disciplinas interesados en la educación.

\section{Describir el habla, comprendernos}

Preguntémonos, junto a los filósofos del lenguaje Wittgenstein, Austin y Searl, o al hermeneuta Rorty, entre otros, si "lo real" habita la palabra, es decir, si decimos la verdad o si, en cambio, producimos efectos de sentido. Aunque claro, ¿para qué plantearnos preguntas filosóficas o hermenéuticas si necesitamos pensar la práctica en el aula? Está bien. Entonces, como docentes, preguntémonos si podemos y debemos estudiar la lengua ideal o el habla ordinaria con nuestros estudiantes. ¿Qué ganamos con esta pregunta? Ganamos una necesidad: la necesidad de tomar posición; y la posición que optemos no es puramente filosófica, es también de convivencia.

Esto quiere decir que si optamos por enseñar a nuestros $40 \mathrm{o}$ cientos de estudiantes que la lengua contiene y expresa una verdad delimitada, o que la grafía es una impresión exacta de nuestras ideas, estaremos diciéndoles simultáneamente que la tarea de un estudiante es la de memorizar significados, estructuras, superestructuras y autores, en lugar de provocarlos a reconocer que ganan nuevos significados en cada contexto de uso las palabras, y que escuchar detenidamente a nuestro interlocutor es la única manera de comprenderlo. No hay un diccionario, ni una gramática que me revele el sentir de "aquel" con quien converso... o discuto. Somos los dos en nuestra interacción quienes creamos realidad. El mundo no está incrustado en las palabras, son nuestras palabras, aquí y ahora, dioses creadores de realidades de las que somos responsables.
De modo que, si optamos por estudiar el habla ordinaria, necesitaremos convertir nuestras aulas en laboratorios, en museos interactivos de la comunicación. La metodología más propicia no será ya la memorización sino la descripción. Necesitaremos identificar situaciones conversacionales: un discurso político, una charla familiar, una discusión de pareja, un juego en el patio de recreo, un encuentro deportivo, un poema desesperado, una caricatura, una pintura, una pauta de publicidad... Entonces, la tarea será prestar atención aguda al rol del emisor, a su relación con el destinatario, al contexto o situación de conversación y a sus reglas, a las intenciones comunicativas que circulan, a las estrategias discursivas con que se hace exitosa la intención, a las evocaciones con que gana sentido el texto, a los universos de sentido que se privilegian, a lo que no se dice, a las normas de interacción que se transgreden, etc. Luego la reconstrucción compleja del sentido revelado obligará a adoptar la metodología de comité editorial que, con sus discusiones y sus aportes desviantes, será el escenario que provoque la semiosis, los nuevos sentidos y nuevas intertextualidades.

\section{Paz es comunicación}

La paz nace con la palabra "nosotros"; un nosotros amplio, inclusivo. Un Yo y un Tú que se escuchan, que hablan desde su interior; eso es la paz. Entonces, una salida discursiva a la guerra es la de acercar al Yo y al Tú. Esto implica repensar al otro de la relación, también repensar al sí mismo como sujeto del acto relacional. En cambio, la construcción del Yo y del Tú de la comunicación, en tanto héroes y villanos, es una de las representaciones propias de la guerra. Es decir, un Yo muy distante, moralmente distante del Tú, es una construcción en el centro del pensamiento de la violencia. Ya lo señala el comunicador Jesús Martín-Barbero:

El diálogo se teje sobre un fondo de pronombres personales que forman la textura de la intersubjetividad. En la corriente más dinámica de la lingüística, como la de E. Benveniste (1971, p. 67) el análisis lingüístico se encuentra con la hermenéutica de M. Bubber y sobre todo de E. Levinas. Mientras para el análisis el lenguaje es un sistema de signos, para el que habla el lenguaje es una mediación simbólica: "masa de signos dispuestos en el mundo para ejercer en él nuestra interrogación” (Bubber, 1968, p. 29). La dialéctica habita las proto-palabras-yo-tú como ejes en torno al cual se realiza el encuentro y la posesión, la convivencia y la organización (Martín-Barbero, 2003, p. 34). 
Un acto comunicativo en el que el Yo se revela y presenta sus configuraciones puede ser peligroso si el otro no está dispuesto a escucharlas, a reconocer su validez. Así mismo, un acto de habla para la convivencia es aquel en el que se reconoce al otro, al Tú, como otro Yo que necesita de mi palabra para completarse. Un Tú que se sabe escuchado en las preguntas, en las dudas, en los acuerdos, entra en ese nosotros que es la paz.

La paz es una cualidad de la vida en sociedad. Esta cualidad tiene todo que ver con la posibilidad de la inclusión. Incluir, a su vez, supone un reconocimiento de uno y del otro como sujetos de derecho. Además, el concepto de paz como inclusión reclama el reconocimiento de la normativa. Este reconocimiento puede ser entendido en primera instancia como un acatamiento estricto de la norma; sin embargo, lo más clave para pasar de un escenario de confrontaciones sociales a uno de paz es la permanente revisión de las normas de convivencia explícitas e implícitas. Es necesario examinar la normativa, o lo que llamaremos las reglas de juego sociales, porque justamente ellas han sido viciadas por los intereses del conflicto, o, más directamente, por el desequilibrio entre el reconocimiento de derechos desmedidos a unos ciudadanos, y la privación de los derechos a una facción importante de la población.

Debido a que aquello que decimos construye realidades, se hace vital reflexionar sobre el efecto de sentido de aquello que comunicamos. Es decir, cuando hablamos nos construimos como sujetos sociales, creamos la distancia o el vínculo con el otro, y también creamos una imagen del mundo que referimos. La relación entre la escuela y la sociedad como espacio de negociación de los derechos es natural, siendo la escuela la primera institución extra-familiar en que participan los ciudadanos infantes o adultos.

Convertir los problemas en objetos de estudio es una manera como la complejidad de los derechos sociales llega a la escuela. Los problemas personales y locales son el material perfecto para comprender qué es ser ciudadano; observar la realidad de sus micro y macro-relatos, la función de las categorías lingüísticas como lupas de observación, y las múltiples formas de comunicación como expresiones para la catarsis, la creatividad, y la reconstrucción de los símbolos sociales. La comunicación no resuelve todos los problemas de convivencia que comprometen a la esfera legislativa y a la equidad económico-social, entre otros, pero la comprensión de los mecanismos comunicativos, y la subsiguiente reformulación de las estrategias comunicativas, son aportes invaluables que pueden hacer la escuela y la clase de lengua a la sociedad.

Las marcas de violencia que se han tatuado en la piel de los latinoamericanos desde la Colonia, circulan entretejidas en las expresiones verbales de nuestro español y en los modos de relación que validamos. Es por eso que es una necesidad profunda observar nuestra lengua, preguntarle qué discriminaciones la habitan y cómo lo hacen, e incluso responderle con opciones creativas, liberadoras y vivificantes. En fin, la escuela puede enseñar a sus estudiantes cuáles son los básicos del sentido de la vida; estando este sentido, muy personal, sin duda, asociado casi siempre a qué necesitamos como sujetos individuales y como sujetos colectivos.

\section{Un aula para la paz}

Los escenarios que los docentes podemos diseñar tienen que ver con actividades en las que se haga protagonista un aspecto, tema o problema de la vida cotidiana. Este tema puede ser estudiado a través de categorías y teorías del habla como las tipologías textuales, los roles sociales, los marcos de cognición, las representaciones, y muchos otros. Con el propósito de ejemplificar los problemas sociales en el aula son clave las fuentes textuales con información sobre el uso cotidiano del habla: producciones literarias canónicas y no canónicas; y material mediático. Por supuesto, el propósito es fortalecer las competencias comunicativas, entonces, el diseño de las actividades que componen el proyecto de aula estarán orientadas a fortalecer las habilidades comunicativas: lectura, escritura y oralidad.

En la experiencia que hemos avanzado en la Universidad Nacional de Colombia cada estudiante, o grupo de estudiantes, publica un borrador de su proyecto en la página issuu.com/signos; también se publican estos y otros ejercicios en la comunidad "Enseñar a aprender" de Google+. Allí se encuentran reunidos y disponibles borradores de proyectos que cada semestre cumplen con las características del compromiso colectivo frente a la paz. Ejemplo de ellos son los proyectos que sintetizamos aquí.

\section{El animal como prójimo}

Miguel Ángel Fuerte (2015) creó un proyecto pedagógico para conversar en el aula acerca de la manera como se convive con el "otro", y para hacerlo elige a un "otro" muy distinto al "uno", y muy querido: los animales. La tarea final que propone a sus futuros estudiantes es el diseño de un póster en el que participe el lenguaje explicativo. Dentro de las actividades están: la lectura de textos explicativos sobre la vida de los animales; una clase sobre lo que es un texto explicativo; la formulación de descripciones; seriaciones y la presentación de relaciones causales en torno a la vida de animales rurales y urbanos, concluyendo con un análisis de imágenes, sus contenidos icónicos y referenciales. 
Como resultado de este proyecto los niños han explorado su propia relación con "el otro", y han fortalecido sus habilidades con la producción de textos explicativos.

Si bien, y como lo presentan Calsamiglia y Tusón (1999), la explicación centra su interés en la presentación de una información que amplía la enciclopedia de quien la recibe, como fenómeno discursivo "consiste en hacer saber, hacer comprender y aclarar, lo cual presupone un conocimiento que, en principio, no se pone en cuestión sino que se toma como punto de partida" (Calsamiglia y Tusón, 1999, p. 308). Este conocimiento que no se pone en duda, apoyado en gráficos, en descripciones, en relaciones lógicas y secuenciales, responde también a las particularidades de esa "enciclopedia" que el hablante construye. En todo caso, lo interesante de la propuesta de Miguel Ángel es que, con la excusa de organizar textos explicativos, lleva a los estudiantes a pensar, a conocer, a acercarse con curiosidad a unos seres distintos de los que se aprende por contraste, por ordenación y por los lazos afectivos que se establecen con ellos.

\section{Sala académica: el reto de habitar la escuela}

Weendy Orjuela (2015) armó un proyecto de aula pensando en la manera como se vive el paso de la escuela al hogar y del hogar a la escuela, en donde aparece la tensión entre lo público y lo íntimo. El objetivo es el de identificar significados, sentidos y variaciones en los roles sociales cuando se pasa de la escuela al hogar. El proyecto está pensado para estudiantes de primaria. La tarea final propuesta es la escenificación de un reto que enfrenta la familia. Dentro de las actividades del proyecto están el análisis de la superestructura de un cuento, el análisis de fotografías y la planeación de tomas fotográficas; también se analizan y construyen personajes; para pensar los personajes se hacen reflexiones sobre sus acciones, sus intenciones o la función discursiva de sus enunciados en algunos diálogos. Al final, los estudiantes han explorado aquello que se entiende por narración, pero también han pensado en los roles familiares.

Weendy propone una apropiación del concepto de "rol" desde la perspectiva de Bernstein (1989), para quien las relaciones de poder, propias de esferas como la familiar y la escolar, dan lugar a actividades de control:

Un rol social es una constelación de significados aprendidos y compartidos por medio de la cual los individuos son capaces de entrar en formas estables, consistentes y públicamente reconocidas de interacción con otros. Por tanto, un rol social puede ser considerado como una compleja actividad codificante que controla, tanto la creación y organización de significados

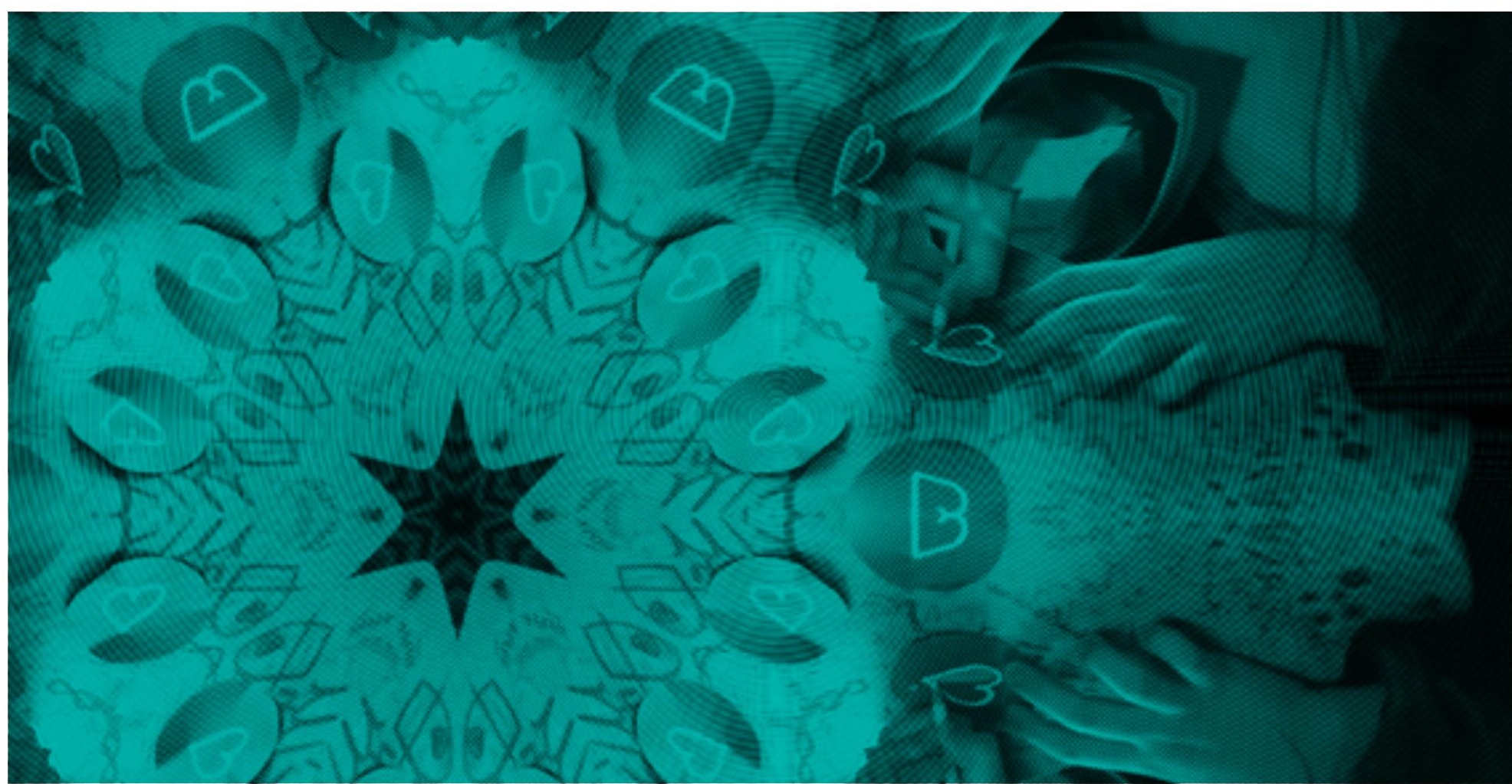


específicos como las condiciones para su transmisión y recepción (Bernstein, 1989, p. 151).

La manera como el estudiante o hijo se mimetiza, a partir de la adopción de actitudes propias del rol que se le ha asignado, revela que el sujeto tiene aptitudes que van más allá de lo admitido o promovido por las esferas de control, pero que el sujeto se adaptará reduciendo o redefiniendo su potencial con arreglo a las determinaciones sociales del contexto. Es decir, a través de las actividades, presentadas por Weendy, los estudiantes podrán

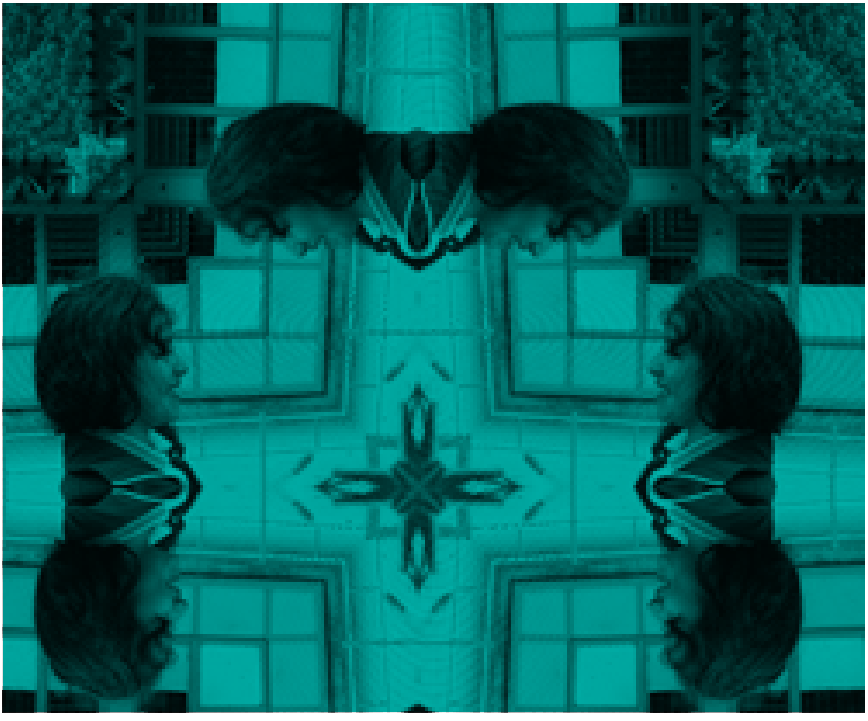

con quienes leerá a Dickens y la historia de famosos ciclistas colombianos, se desenmascararán las mímesis por las que han pasado tiempo y personajes, para constituir héroes de la ternura y la franqueza bajo el abrigo del desamparo y la escasez.

\section{La mitología del hombre y la mujer en los mass media}

El estudiante Juan Muñoz (2014) presenta un proyecto pedagógico para reflexionar sobre las representaciones de lo femenino en los medios de comunicaconstruir unas meta-representaciones de su papel mientras, dentro del rol mismo de alumnos, siguen las pautas de la docente y se observan en tanto sujetos institucionalizados.

\section{Más que garabatos}

La estudiante Yuly Orjuela (2015) diseñó un proyecto de aula para reflexionar acerca de la vida en estado de pobreza y los retos que impone. El eje lingüístico es la tipología textual de la narración, y su objetivo fue fortalecer las habilidades narrativas mientras se reconocen las motivaciones y retos de la pobreza. Como tarea final se propuso a los estudiantes la presentación oral o escrita de un relato e incluyó actividades como: el análisis de las superestructuras textuales de cuentos y biografías; tomando a protagonistas de obras literarias y televisivas como el Chavo del 8, propuso la identificación de personajes y sus cualidades; además, planteó ejercicios para desarrollar la habilidad narrativa a partir del uso de fragmentos inspiradores. Como resultado, hubo una mejora en cuanto a la habilidad para narrar, y una apropiación colectiva de formas expresivas y perspectivas sobre la pobreza: sus retos, aprendizajes y salidas.

Ricoeur (2006) nos dice: "La narración es el guardián del tiempo" (p. 991); "el mundo de la ficción entra en contrapunto con el mundo histórico” (p. 817). Entonces narrar la experiencia vital de la pobreza es en sí una invitación a redefinirla, a presentarla como se le vive, como se le siente con los énfasis y matices que la hacen historia personal; así como con los acentos que la hacen drama universal. Para los estudiantes que tendrá Yuly, ción. En este proyecto pedagógico son fundamentales el concepto de "mito", de Roland Barthes, así como los ejemplos que presentan un tratamiento despreciativo y reductor de la imagen de la mujer en los medios. El objetivo es fomentar la reflexión sobre las mitologías de "hombre" y "mujer" en los medios. Como tarea final se espera que los estudiantes produzcan un texto analítico-interpretativo en el que reconstruyan sus discusiones sobre el tema. Incluye actividades como el estudio del concepto de "mito" de Barthes, el análisis de publicidad en la que se mitifican los roles femenino y masculino, y de fragmentos del diálogo en un documental, así como de los elementos visuales con los que se construyen las representaciones.

Juan explica en un video a sus futuros estudiantes que, para Barthes, el concepto de mito tiene que ver con una dialéctica entre forma y significado:

El mito es un valor, su sanción no consiste en ser verdadero: nada le impide ser una coartada perpetua, le basta que su significado tenga dos caras para disponer siempre de un más allá: el sentido siempre se encuentra en su lugar para presentar la forma; la forma está siempre allí para distanciar el sentido. Y jamás existe contradicción, conflicto, estallido entre el sentido y la forma: jamás se encuentran en el mismo punto (Barthes, 1970, p. 216).

El mito se refiere a una impregnación de sentido sufrida por la forma y viceversa. Este fenómeno hace que la conciencia imaginante, de donde proviene el sentido, haga carne en la palabra para que en adelante ella contenga al mito, a la creación colectiva. Entonces, con esta propuesta para estudiar las mitologías del 
hombre y la mujer en los mass media, los estudiantes asisten al develamiento del juego mimético. En las actividades se reconoce cómo aquello que los medios llaman "hombre" o "mujer" no es un sentido "verdadero", sino un mito, una forma significativa que se ha incubado en la forma lingüística. Entonces tales conceptos son contextuales, hechos a conveniencia y, por tanto, discutibles.

\section{Libre desarrollo de la personalidad}

El estudiante David Hidrobo (2014) propone discutir en clase el derecho al libre desarrollo de la personalidad; con esto en mente diseña un proyecto para estudiar las representaciones mentales o marcos de cognición desde los cuales se concibe lo apropiado y lo inapropiado en el desarrollo de la personalidad. Como tarea final sugiere a sus futuros estudiantes el montaje de una danza-teatro en la que cada uno se construya como un personaje particular que entrará en relación vivencial y espacial con otros distintos. Estudian algunas estrategias de manipulación a través de la comunicación y se promueven discusiones sobre la identidad y el concepto de representación. Al final del proyecto los estudiantes han explorado formas expresivas de la identidad y han estudiado el concepto de "marco cognitivo".

Cuando Lakoff discute las distancias irreconciliables entre la perspectiva de mundo de demócratas y republicanos, nos

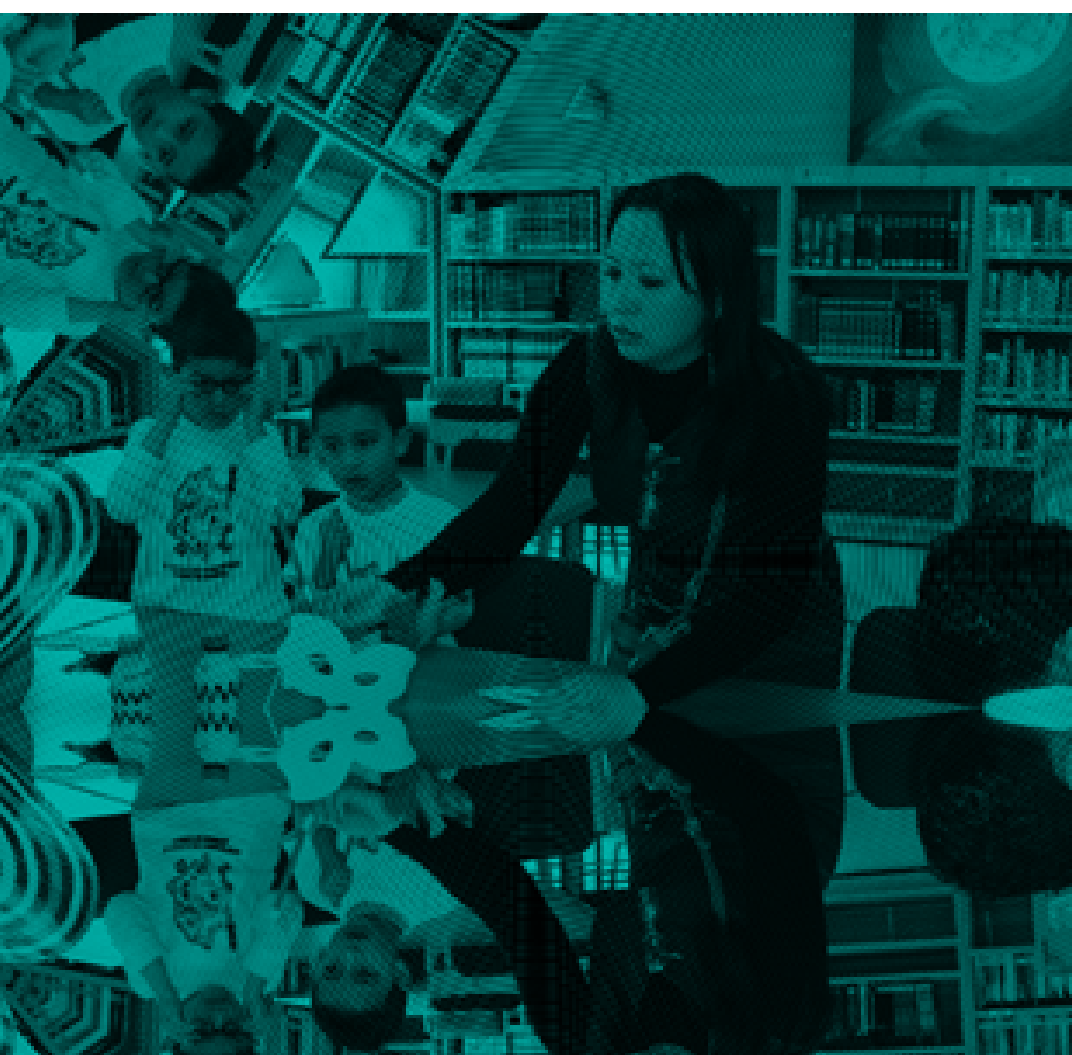

permite ver cómo el pensamiento lógico se mueve dentro de marcos, dentro de formas de pensar:

Enmarcar tiene que ver con el pensamiento, con comprender en el nivel profundo, con los circuitos que tienen fuertes sinapsis que persisten en el cerebro, con ordenar comprensiones inconscientes, automáticas, lugares comunes, en otras palabras, con organizar el sentido común (Lakoff, 2014, p. 82).

La automatización de ciertas formas de entender y representar ideas como la de "identidad", no señala que haya unas maneras correctas o incorrectas de construir la propia identidad, sino que el modo como la concebimos se instala en el pensamiento, haciendo sinapsis con otros valores que aparecen relacionados de manera "lógica" con éste, pero que se afincan con otros valores por efecto de repetición y de entramados cohesivos, antes que por razones que contengan verdad.

Así, el ejercicio dancístico, pictórico y discursivo, presentado por David, plantea a los estudiantes la posibilidad de comprender la manera como se ordena el pensamiento, e incluso les permite elaborar meta-comprensiones tendientes a redefiniciones más personales, más vinculadas con su sentir profundo que con la automatización del sentido.

Muchos otros proyectos diseñados por los estudiantes revelan maneras de pensar la vida, las exclusiones, la naturaleza, las formas de producción, el otro, las familias, el género, la violencia en la pareja, en la familia, en la escuela; otros, diseñados por los estudiantes de Español y filología clásica, sugieren otras maneras de aprender español, conectando las categorías lingüísticas con la vida en sociedad.

\section{Conclusiones}

Todo lo presentado hace parte de una experiencia pedagógica que ha dado lugar a la discusión sobre la importancia de hacer el Giro Lingüístico en el aula de clase; con ella encontramos que de la dicotomía entre yo y tú podemos pasar a un nosotros que nos permita convivir en paz. Ese nosotros surge en cuanto hacemos plurales las perspectivas y damos cabida a puntos de vista diversos sobre la vida. Encontramos y corroboramos a cada paso que las teorías del habla: análisis del discurso, pragmática, psicología cognitiva, sociolingüística y semiótica, entre otras, aportan categorías de análisis que permiten entender los efectos de sentido que se construyen con la palabra. Es decir, construimos mundos con la palabra, ajustados a reglas de juego, pero redefinibles y rediseñables. 
En el aula de clase es posible construir hábitos y escenarios para la discusión de las estrategias comunicativas y sus efectos de realidad en los entornos de la comunicación. Estos escenarios pueden ser altamente creativos, dialógicos y reflexivos, y dan lugar también a un fortalecimiento de las competencias comunicativas. 


\section{Referencias}

Austin, J. (2010). Cómo hacer cosas con palabras. Madrid: Paidós.

Barthes, R. (1970). Mitologías. México: Siglo XXI.

Benveniste, E. (1971). Problemes de linguistique général. París: Gallimard.

Bernstein, B. (1989). Clases, códigos y control. Madrid: Akal.

Bubber, M. (1968). La vie en dialogue. París: Aubier-Montage.

Calsamiglia, H., y Tusón, A. (1999). Las cosas del decir. Manual de análisis del discurso. Barcelona: Ariel.

Hart, R. (2005). Conversación con Roger Hart. Comprensiones sobre ciudadanía: veintitrés expertos internacionales conversan sobre cómo construir ciudadanía y aprender a entenderse. Bogotá: MEN-Magisterio.
Lakoff, G. (2014). Don't think of an elephant! Know your values and frame your debate. Vermont: Chelsea.

Levinas, E. (1968). Totalité et infini. La Haya: Martinus Nijhoff.

Martín-Barbero, J. (2003). La educación desde la comunicación. Bogotá: Norma.

Ricœur, P. (2006). Narración. El tiempo narrado III. México: Siglo XXI.

Rorty, R. (1990). El Giro Lingüístico. Barcelona: Paidós.

Searl, J. (1999). Speech acts. USA: Cambridge.

Wittgenstein, L. (2007). Los cuadernos azul y marrón. Madrid: Tecnos. 


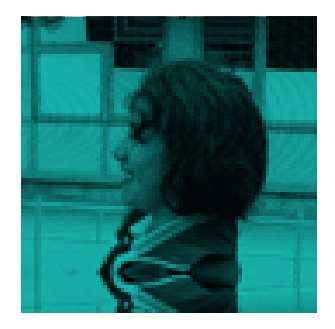




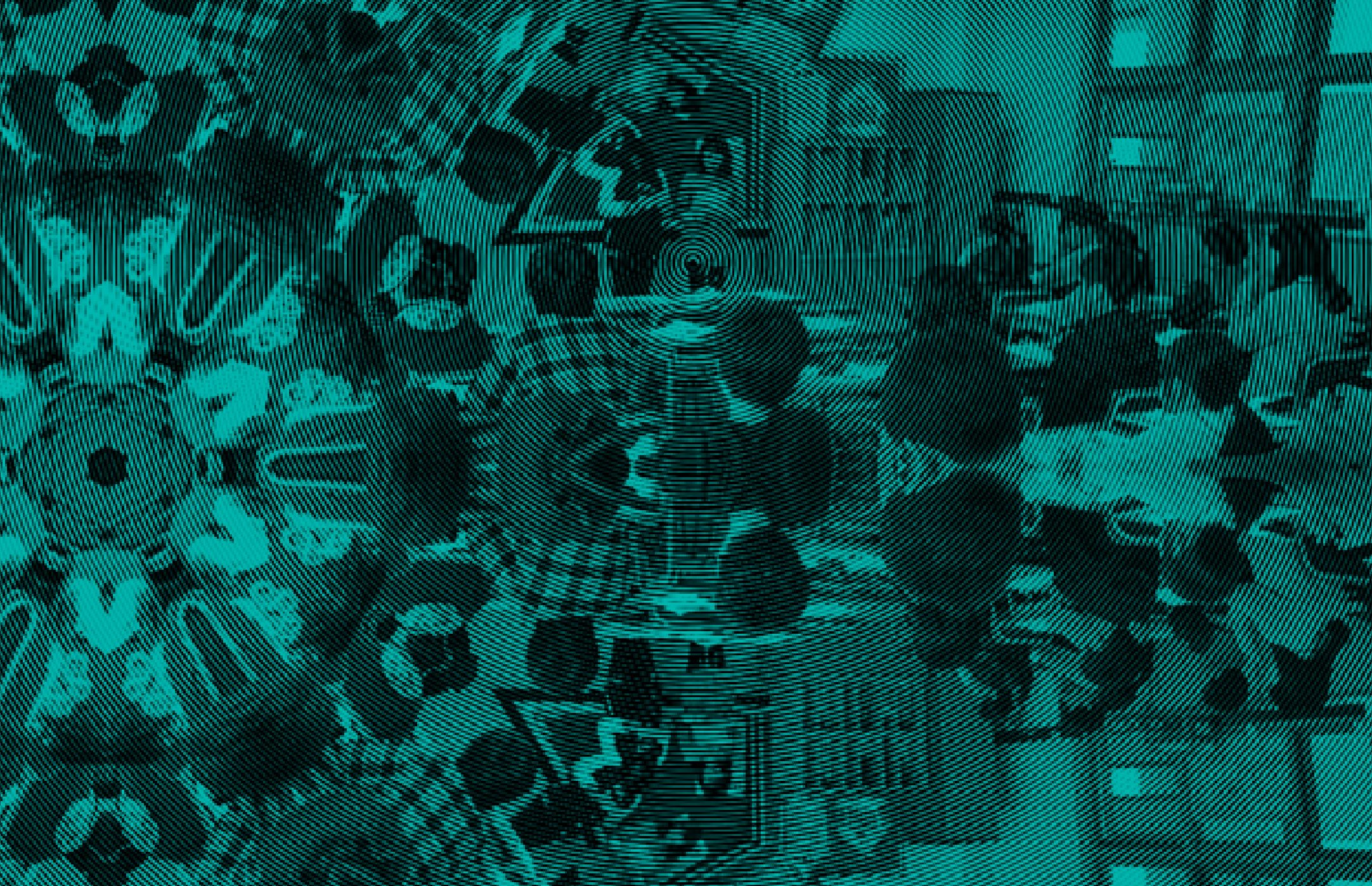

La configuración espacial del
colegio Nelson Mandela IED

The spatial configuration Nelson Mandela IED school

A configuração espacial escola Nelson Mandela IED John Alexander Aranzazu Portilla 
John Alexander Aranzazu Portilla 1
1. Maestrante en Educación, Universidad Nacional de Colombia; Licenciado en Ciencias Sociales, Universidad Pedagógica Nacional; Docente de la Secretaría de Educación Distrital, Colegio Nelson Mandela. Integrante Nodo de Ciudadanía y Educación para la Paz, Red Distrital de Docentes Investigadores; correo electrónico: aranzazujhon@gmail.com

Investigación de tesis de grado, Maestría en Educación, Universidad Nacional de Colombia. Director: José Guillermo Ortiz.

Fecha de recepción: 25 de febrero de 2016 / Fecha de aceptación: 16 de septiembre de 2016

\section{Resumen}

El espacio no solo es ocupado y formado por cosas u objetos, ante todo es vivido y percibido por quienes lo habitan. En el caso de la escuela, las percepciones y prácticas espaciales de los estudiantes develan contradicciones frente a las concepciones dominantes que organizan la vida institucional y desde donde se promueven situaciones de vulnerabilidad, discriminación o exclusión socioespacial, las cuales requieren ser resueltas en el marco de una educación para la paz, bien sea a partir de los marcos legales, los procesos de convivencia o las prácticas pedagógicas.

\section{Palabras clave: Espacio social,} educación, participación estudiantil, vida escolar.

\section{Summary}

Space is not only busy and made up things or objects above all is experienced and perceived by those who live there. In the case of the school, perceptions and spatial practices of students reveal contradictions against the dominant conceptions organized institutional life and where situations of vulnerability, discrimination or socio-spatial exclusion are promoted, which need to be resolved in the framework of a peace education, either from the legal frameworks, processes coexistence or pedagogical practices.

\section{Keywords: Social space,} education, student engagement, school life.

\section{Resumo}

O espaço não só é ocupado e fez-se coisas ou objetos, acima de tudo é experimentado e percebido por aqueles que vivem lá. No caso da escola, percepções e práticas espaciais de alunos revelam contradições contra as concepções dominantes organizados vida institucional e em que situações de vulnerabilidade, discriminação ou exclusão sócio-espacial são promovidos, que precisam de ser resolvidas no âmbito de uma educação para a paz, quer junto dos quadros jurídicos, processos coexistência ou práticas pedagógicas.

Palavras chave: Espaço social educação, envolvimento dos alunos, a vida escolar. 


\section{Introducción}

La escuela, eje fundamental del sistema educativo, se ha concebido como escenario para la formación integral del ser humano ${ }^{2}$, sin embargo, las prácticas cotidianas que allí tienen lugar pueden configurar espacios excluyentes, generadores de violencia y poco democráticos, debido a las restricciones, resistencias o imposiciones construidas en su interior o desde agentes externos a ella. Aún cuando sea pensada para la formación, el bienestar y desarrollo de los estudiantes, no siempre es ideada por ellos, hecho fundamental en tanto que sus experiencias, motivaciones y prácticas cotidianas, al ser parte de su zona de desarrollo próximo, constituyen un punto de anclaje para construir nociones científicas, y son fuente de conocimiento para orientar el énfasis y sentido de un proyecto educativo institucional.

El presente artículo quiere exponer la importancia, para la construcción del espacio escolar, de las percepciones, sentimientos y experiencias de quienes le habitan; intenta pensar desde la experiencia del estudiantado esos otros modos de ser y habitar la escuela, los cuales no siempre se articulan a las prácticas formales de control -horarios, reglamentos, organización institucional-, ni a las concepciones hegemónicas que imponen un orden en la escuela, y configuran una serie de relaciones que determinan espacios particulares, susceptibles de ser transformadas. Para hacerlo, se realiza una triple aproximación al espacio escolar, desde lo concebido, percibido y vivido.

En este sentido, se intenta resolver las siguientes preguntas: ¿Cómo asumir la complejidad que caracteriza la configuración del espacio escolar?; ¿es posible incorporar a los estudiantes al estudio de dichos espacios y desde allí aportar a la formación ciudadana? Se espera determinar la configuración de espacios isotópicos y heterotópicos que permiten el surgimiento de situaciones, particulares y colectivas, de discriminación o exclusión socio-espacial que afectan la vida escolar y pueden ser transformadas socialmente.

2 El Artículo 67 de la Constitución Política de Colombia de 1991, reconoce la responsabilidad del Estado por cumplir con los fines sociales de la educación y "velar por la mejor formación moral, intelectual y física de los educandos", así como "garantizar el adecuado cubrimiento del servicio y asegurar a los menores las condiciones necesarias para su acceso y permanencia en el sistema educativo". Por su parte el Artículo 1 de la Ley 115 General de Educación en Colombia, señala que ésta "es un proceso permanente, personal, cultural y social, que se fundamenta en una concepción integral de la persona humana, de su dignidad, de sus derechos y de sus deberes".

\section{Metodología}

Debido a la naturaleza del estudio, la metodología aplicada se enmarca en el enfoque cualitativo, pues se refiere a la forma en que se articula, funciona y se constituye el espacio interno de una institución, teniendo en cuenta las relaciones de interacción que establecen los estudiantes; este enfoque permite distintos tipos de comprensión: por un lado, descriptiva, ya que indaga sobre qué pasó realmente, en términos de comportamientos o eventos observables, al transitar la institución de lo privado a lo público; por otro, interpretativa, porque busca establecer sentidos relevantes que los estudiantes atribuyen a las acciones mediante las cuales se configura el espacio escolar; y también analítica, porque diferencia y establece las relaciones implícitas en la configuración del espacio a partir de múltiples fuentes. El análisis busca examinar por separado las partes que constituyen el espacio escolar, intentando conocer las relaciones entre cada una de ellas con la intención de reconstruir el significado global.

El enfoque cualitativo permite emplear la cartografía social e instrumentos de recolección de datos integrados: observación participante con registros visuales, entrevistas semi-estructuradas, encuestas a estudiantes de diferentes grados, talleres con grupos focales y análisis documental. El estudio de caso seleccionado corresponde al colegio Nelson Mandela, Institución Educativa Distrital localizada en el sector sur-occidental de la ciudad de Bogotá, la localidad de Kennedy, que cuenta con los niveles de preescolar, básica y media en las jornadas mañana y tarde; actualmente hay 2049 estudiantes matriculados. El marco inicial de referencia se sintetiza un objetivo general: "Determinar cómo inciden las prácticas, percepciones y concepciones espaciales de las y los estudiantes de básica secundaria, del colegio Nelson Mandela, en la configuración del espacio escolar". Así, de acuerdo con esto, las categorías y sub-categorías de análisis, son:

1. Espacio percibido.

1.1 Infraestructura física.

1.2 Ubicación y formas.

2. Espacio concebido.

2.1 Imaginarios y representaciones.

2.2 Formas de control y administración.

3. Espacio vivido.

3.1 Prácticas y experiencias.

3.2 Transgresiones.

3.3 Relaciones de género y edad. 
Los datos se organizan mediante diversos procedimientos, como: codificación, inducción analítica, incidentes críticos, mapas cognitivos y clasificación. Las variables y las respuestas de las encuestas se agrupan en diagramas, mientras que las transcripciones de las entrevistas se tabulan y analizan mediante un proceso de categorización inductiva de datos, en tres categorías claves que se corresponden con las dimensiones del espacio escolar.

La metodología para el análisis de las representaciones e imaginarios de los estudiantes, busca identificar y hacer emerger elementos constitutivos de la representación y el núcleo central de las mismas. A partir del uso de un término introductor (o de una serie de términos), los estudiantes producen espontáneamente expresiones o adjetivos que muestran su perspectiva y su sentido de vida en la cotidianidad de su espacio escolar, enseguida, se sitúa y analiza el sistema de categorías utilizado por los sujetos, de tal manera que permita delimitar el contenido mismo de la representación; luego se extraen los elementos organizadores de ese contenido: frecuencia del ítem en la población y su rango de aparición en la asociación, que se representa a través de asteriscos.

La información de los talleres se cruza con los datos obtenidos de las encuestas, las entrevistas, los registros visuales y los documentos oficiales. Las características de las fuentes e instrumentos como las entrevistas hacen necesario el uso de estrategias hermenéuticas que permitan procesar la información. Este estudio no representa la opinión total del cuerpo de estudiantes del Colegio Nelson Mandela, sino que ilustra algunas posiciones ante las experiencias, relaciones y prácticas espaciales en la institución. Aunque la muestra es parcial, se puede decir que se trata de visiones reales de estudiantes, en las que se expresan sus dificultades, desacuerdos y necesidades.

\section{El espacio social: conceptualización y su aplicación al caso escolar}

La idea del espacio como construcción social ha sido sustentada por diversos autores, uno de los más citados es Lefebvre, quien advierte que no existe un solo espacio social, sino varios de ellos, pues hay múltiples prácticas en su interior dispuestas a desbordarse con posibilidades alternativas; Al tiempo, Lefebvre (1991) señala que dichos espacios tienen, como elementos centrales: su naturaleza relacional; la multi-escalaridad como escala social de afectación; la condición de permanente construcción; y su realidad unitaria. Reconocer esta multiplicidad de dimensiones implica ver la posibilidad de relaciones sociales y, por tanto, la existencia de una serie de tensiones y contradicciones entre quienes habitan.

Lefebvre (1991) también propone una triada conceptual para el análisis espacial, que surge de la coexistencia del espacio físico y mental en el espacio social. Así, el espacio contiene esos múltiples entrecruzamientos en lugares asignados, que toman forma en una trialéctica espacial:

- Espacio percibido: corresponde al espacio físico, materialmente perceptible, en él los objetos son fácilmente catalogables en mapas por medio de representaciones cartesianas; esta espacialidad materializada se explica a través de descripciones precisas de lugares específicos, supone el uso del espacio, el empleo de lo que contiene y revela la forma en que los espacios son apropiados.

- Espacio concebido: atañe al espacio mental, los imaginarios relacionados con la cultura y la sociedad por medio de símbolos, signos, códigos y otros elementos que no son percibidos materialmente; está vinculado a conocimientos convenidos. Es la construcción hegemónica de los grupos dominantes, lo pensado desde el saber en tanto poder, a partir del cual se imponen el orden y el control sobre el espacio a través de los discursos. Es el espacio dominante en el sentido que controla poderosamente la manera en que pensamos, analizamos, explicamos y practicamos la espacialidad humana.

- El espacio vivido: concierne a las experiencias, representa la manera como se vive y habita el espacio, así como las prácticas que se configuran; junto con el espacio concebido, constituye el espacio socialmente construido, es posible abordarlo desde la cartografía social o participativa.

Así, las percepciones, concepciones y prácticas espaciales de los estudiantes configuran heterotopías en la escuela, las cuales surgen de los ordenamientos dominantes marcados por situaciones particulares y colectivas de vulnerabilidad, discriminación o exclusión socio-espacial que afectan la vida escolar. 


\section{Resultados}

\section{El espacio percibido y concebido del colegio Nelson Mandela}

El colegio Nelson Mandela se localiza en el sector occidental de la Localidad de Kennedy y hace parte de la UPZ 3 83, Las Margaritas, la cual contó hasta el año 2013 con la Institución Educativa Compartir Tintal, en convenio con la Fundación Compartir, es decir, funcionaba como una institución de naturaleza jurídica privada. Sin embargo, a partir de la compra del colegio el 21 de Enero de 2014 por parte de la Secretaría de Educación Distrital (SED), la institución pasó al sector oficial e hizo parte, transitoriamente, de la Institución Educativa Eduardo Umaña Luna (EUL) de la UPZ Patio Bonito, que le acogió como sede B; esta situación ocasionó una serie de traumatismos administrativos, inconformismos en la toma de decisiones y resistencias en la comunidad que se expresan en comentarios negativos y en una percepción desfavorable de la educación pública.

Durante los últimos tres años la matrícula se ha incrementado hasta los 2049 estudiantes en 2016, por lo que las instalaciones físicas de la institución han llegado al límite de capacidad, ocasionando restricciones en el uso de los espacios y una organización particular. Precisamente en relación con el espacio físico de una institución educativa, el Ministerio de Educación (MEN) exigió el cumplimiento de la Norma Técnica Colombiana (NTC) 45954, que establece los requisitos especiales de accesibilidad, capacidad física de las aulas para atender a los estudiantes, circulaciones interiores, corredores, rampas y escaleras. Sin embargo, el cumplimiento de esta norma, es decir, del discurso declarado o espacio concebido, se contrapone a las condiciones cotidianas del colegio, pues, por jornada, cerca de mil personas conviven diariamente.

Al comparar el área del lote donde está construido el colegio con lo dispuesto en la NTC 4595, y con el total de estudiantes matriculados para 2015, se puede encontrar una baja correspondencia entre lo declarado y lo vivido. Mientras la NTC 4595 define un área mínima del lote urbano de $4,7 \mathrm{~m}^{2}$ por estudiante, para una matrícula de 1680 estudiantes en educación general que correspondería a $1786 m^{2}$ (NTC 4595, 1999, p. 13); el colegio Nelson Mandela, con 1823 estudiantes matriculados, tendría que contar con un área total de $8568 \mathrm{~m}^{2}$, sin embargo, apenas tiene un área de $3500 \mathrm{~m}^{2}$.

3 UPZ (Unidades de Planeamiento Zonal). En Bogotá hay un total 112 UPZ, 92 reglamentadas mediante Decreto; 10 a través de otros instrumentos y otras 10 con reglamentación pendiente.

4 Norma Técnica Colombiana. (NTC 4595). (1999). Ingeniería Civily arquitectura. Planeamiento y diseño de instalaciones y ambientes escolares.

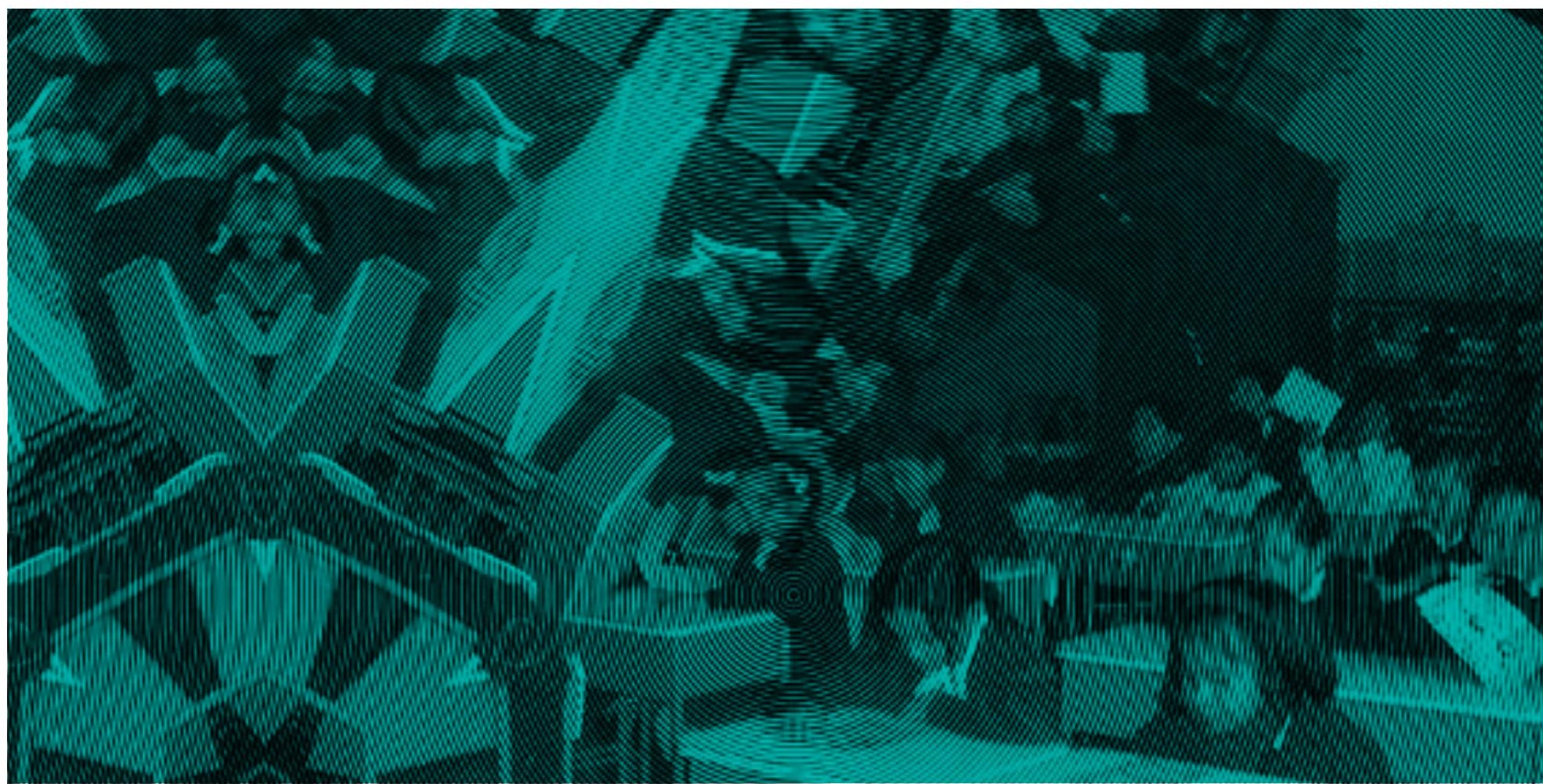


Ahora bien, considerando que los 1823 estudiantes no permanecen durante toda la jornada académica en el espacio del colegio, sino que están distribuidos por jornada (923 JM y 903 JT), en un área de $3500 \mathrm{~m}^{2}$, tendrían que haber matriculados tan solo 745 estudiantes por jornada, es decir, el área física del colegio ni siquiera cumple con el espacio mínimo requerido en el caso de que la norma se aplicase únicamente al número de estudiantes por jornada, pues excede en 178 en la mañana y en 158 en la tarde, esto se traduce en condiciones de hacinamiento dentro de los salones, en el patio e incluso en los baños, pues por cada 85 estudiantes hay disponible un sanitario, por lo cual estos son representados como topofobias dentro de la institución.

Así, un primer conflicto espacial entre el espacio concebido por la NTC y el espacio percibido, tiene que ver con el espacio vital que necesita un estudiante. Se aprecian contradicciones entre lo declarado en una norma técnica que concibe de un modo el espacio, y lo vivido en él por los estudiantes, quienes en talleres vivenciales, realizados en sexto, séptimo y décimo grado, manifiestan su desagrado por la disposición del espacio físico, aunque su respuesta varía con la edad, el género ${ }^{5} \mathrm{y}$, ante todo, el lugar donde reciben clases, pues quienes pertenecen a cursos numerosos expresaron con más detalle su desagrado por el tamaño de los salones, la biblioteca, el patio y la cooperativa; paradójicamente, los espacios que perciben como agradables y amplios, o no pertenecen al colegio, como la zona verde, o se les da un uso distinto, como la "sala de audiovisuales", que funciona como salón de danzas.

El conocimiento de las zonas de aceptación o rechazo de los diferentes espacios físicos del colegio, como resultado de las sensaciones percibidas, es un instrumento que facilita la toma de decisiones y la planeación para atender las demandas requeridas. Las zonas de aceptación se definen de acuerdo con los lugares que se identifican y perciben como agradables, limpios, tranquilos o amplios, mientras las zonas de rechazo se identifican con calificativos como pequeño, sucio o inseguro. Al tiempo, la encuesta virtual permitió concluir que la mayoría de alumnos estudia en este colegio debido a que está cerca de su casa ${ }^{6}$.

5 El concepto género entendido desde la posición de Herraz (2006), como una construcción "como mujeres y hombres a partir de nuestra biología, por supuesto, pero en interrelación con un medio socio-cultural que la va moldeando y modificando, y del que adquirimos pautas de comportamiento que interiorizamos desde muy temprano" (Citado en SED, 2015, p. 54).

6 El instrumento se aplicó entre el 9 de marzo y el 11 de abril de 2014, recogió 27 preguntas de las planteadas en la encuesta de Clima Escolar y Victimización para estudiantes de $6^{\circ}$ a $11^{\circ}$ grado, hecha en Bogotá en 2013; encuesta

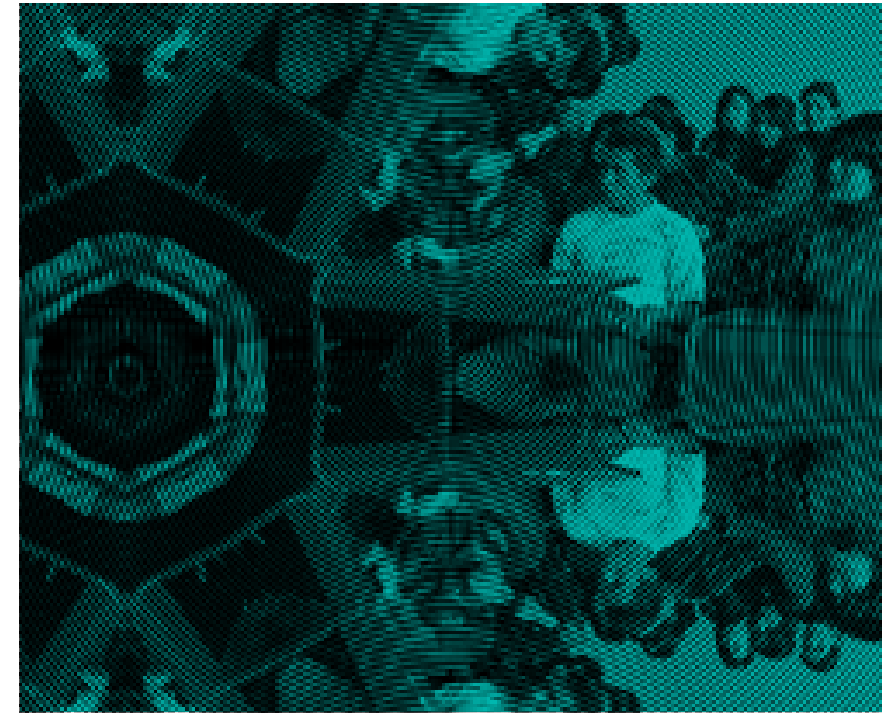

\section{El espacio relacional: representaciones} de relaciones sociales y de lugares

Aunque el espacio físico percibido desde los diseños urbanísticos, y las políticas de planificación, impone un tipo de organización que facilita un acercamiento y localización del colegio en la ciudad, de hecho su planta física, completamente rectilínea, parece diseñada para cumplir con el principio de "clausura" (Foucault, 1976); existe una separación y distribución en la que se asigna un lugar a cada cosa, individuo o acción. Además, la ubicación del colegio puede entenderse mejor desde la construcción social de su territorio, en donde ocurren relaciones de implicación social a diferente escala; es decir, las formas en cómo es afectado el colegio por lo que sucede a su alrededor, las prácticas sociales y el tipo de relaciones que tienen lugar en la escuela, resultan del contexto inmediato donde se encuentra.

Para conocer más detalladamente el territorio del colegio se realizó un taller de cartografía social, buscando captar la diversidad de representaciones sociales y de construcción del espacio, viendo así las distintas lógicas que coexisten en él. De acuerdo con la representación elaborada por los distintos actores escolares, en principio las relaciones en este territorio se caracterizan por ser

proporcionada por el equipo de acompañamiento a los Planes Integrales de Educación para la Ciudadanía y la Convivencia, PIECC, como insumo y herramienta metodológica para los trabajos institucionales. Fueron153 los estudiantes que respondieron, de los cuales 42 eran de grado $6^{\circ}, 58$ de grado $7^{\circ}$ y 38 de grado $10^{\circ}$, cursos que constituyen los grupos focales. Del total de 137 respuestas de estos tres grados, 73 son de niñas y 64 de niños. 
excluyentes, en tanto que, con excepción del sector educativo, no hay presencia Distrital para atender las necesidades identificadas; paradójicamente, en lugar de que este sector sea aceptado o reconocido, su presencia provoca resistencias en la comunidad, debido a que ofrece la "amenaza" de que se comiencen a ofertar masivamente cupos a personas de barrios cercanos; la urbanización se protege de dichos barrios con muros y cercas eléctricas, estableciendo fronteras territoriales e ilusiones de superioridad entre el propio territorio del colegio y el de quienes no viven en la UPZ.

Las relaciones sociales determinadas por la configuración espacial del territorio son fragmentadas y politizadas, lo cual se refleja en la ausencia de una junta de acción local y en la desarticulación entre la urbanización y los barrios de la UPZ a la que pertenece. También existen relaciones distantes en cuanto a ofertas culturales, recreativas o de atención hospitalaria, que están ubicadas en lugares retirados de las viviendas; es necesario que desde la institución educativa se configure una única entidad pública en la zona que favorezca una mayor justicia espacial en términos de acceso a sitios de interés cultural, deportivo o académico, a través de actividades institucionales, con redes de trabajo o salidas pedagógicas, que permitan acceder a nuevos horizontes y sirvan como factor protector. La ausencia de entidades distritales ha dado lugar a relaciones de apropiación; por ejemplo con las casas, que terminan por suplir necesidades comerciales o el encerramiento de los conjuntos, la apropiación del espacio también se expresa

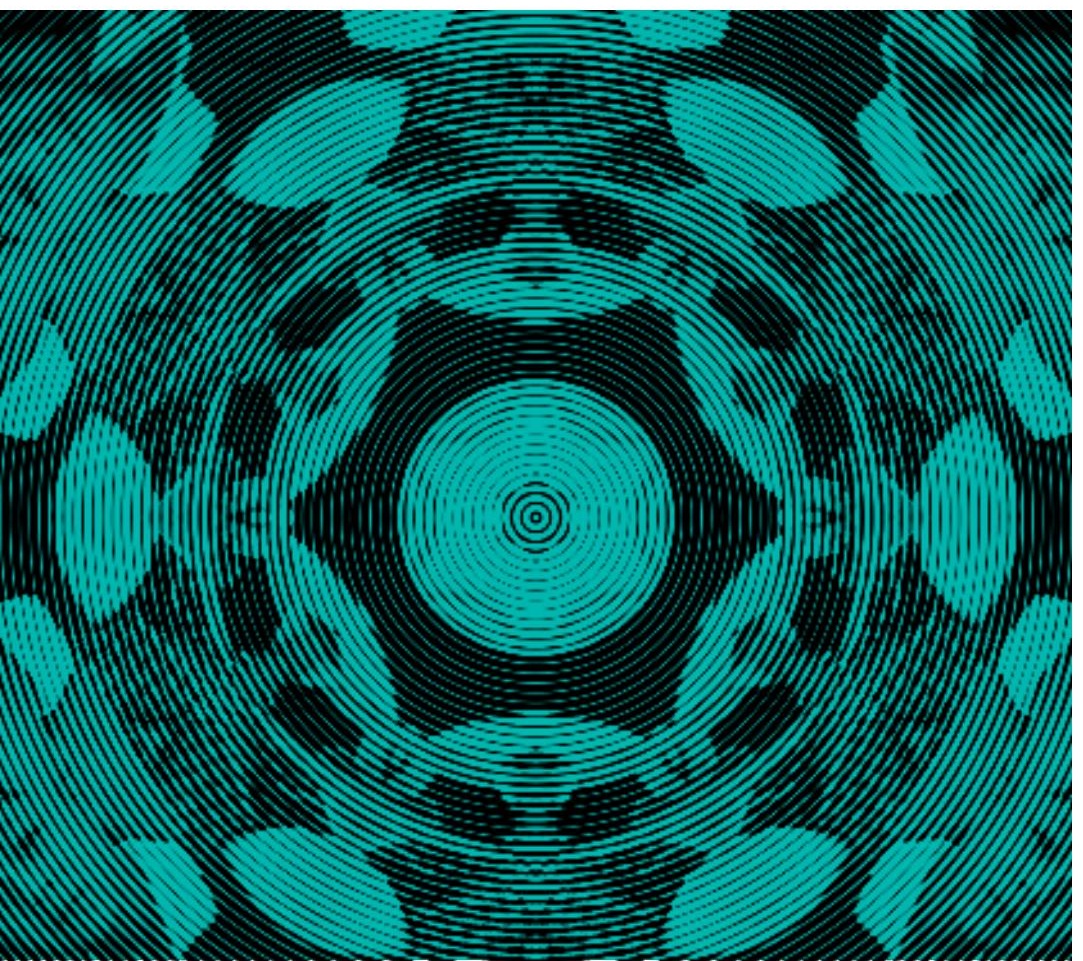

en el cuidado de parques públicos, aunque falta un manejo adecuado en la disposición de residuos.

\section{Heterotopías y prácticas espaciales}

Hasta el momento se ha descrito el espacio del colegio desde la forma en que es percibido y concebido, iniciando por la ubicación y aspectos físicos que lo caracterizan, así como a partir de las representaciones producidas por políticas institucionales y grupos hegemónicos que imponen una organización y un uso determinado (isotopías) que genera fobias y filiaciones en los estudiantes. No obstante, existen otros espacios o heterotopías, los cuales están articulados a las prácticas espaciales de los estudiantes, son las otras formas de ser y habitar el colegio, desde el espacio del cuerpo, hasta las rutinas y movimientos que se realizan por el territorio, y las transgresiones, resultado de tensiones en espacios isotópicos.

En este sentido, al leer el espacio escolar, y en él el espacio del cuerpo, es necesario considerar las implicaciones que tienen las acciones del colegio a través del uso de uniforme, la ordenación de grupos o las formaciones generales (en los espacios de descanso y los corredores), para los niños y niñas; así como preguntarse por las maneras pertinentes y transgresoras de recrear las normas que producen sentido del lugar y de relación social. Una de las heterotopías es justamente el salón, allí se yuxtaponen identidades, inconformidades, relaciones de proximidad o distancia, filiaciones y fobias que se expresan en la misma disposición y ubicación del cuerpo en el espacio.

Así, por ejemplo, en un ejercicio realizado se solicitó a los estudiantes dibujar su salón de clases, la tendencia general fue representar linealmente la disposición de los pupitres frente al profesor(a), omitiendo dibujar su propio cuerpo y el de sus compañeros, además se pudo notar la ausencia de sujetos en el aula; se evidencia una producción espacial restringida al trabajo individual o a la interacción vertical entre profesores y estudiantes, espacio que parece repetirse en distintas clases conforme lo expresan algunas opiniones de las entrevistas grupales. El aula es percibida como una caja cerrada y solitaria, como si vivieran en una especie de vacío.

Esto lleva a pensar que las prácticas y acciones de los sujetos (estudiantes, profesores) dan forma al salón de clases y al colegio, por ello lo corporal puede también ser visto en términos de transformación, transgresión o construcción de redes y relaciones que permiten o limitan la circulación de ideas, conceptos o valoraciones. Al interpretar los datos de las observaciones de clases, las entrevistas realizadas y, por supuesto, desde la reflexión sobre la propia práctica pedagógica, es posible diferenciar algunos hábitos 
espaciales en los salones, que son cerrados y unidireccionales, y que se articulan con el poder del profesor en el salón y su imagen como poseedor del conocimiento; impone los ritmos de trabajo e indica cuando comenzar y terminar las actividades (reproduciendo así un espacio unidireccional, maestro/estudiante o guía/ estudiante), así como el seguimiento ordenado de instrucciones que lleva a los estudiantes a realizar acciones limitadas, a escuchar, mirar y, en ocasiones, tomar apuntes.

El tipo de espacialidad menos usual fue el de interacción entre grupos y profesor, en el que la imagen descentrada del conocimiento permite llegar a acuerdos, realizar un trabajo colaborativo, dialógico e inter-grupal en la construcción de sentidos, y que el profesor haga un seguimiento diferenciado de los estudiantes. La construcción de este tipo de espacialidad no está limitada al tiempo de clase, ni necesariamente debe darse en el salón para realizar y dar continuidad a los ejercicios, ya que pueden enmarcarse en el desarrollo de centros de interés de la pedagogía por proyectos y de la pedagogía problémica, o de estrategias de aprendizaje activo que promuevan un espacio abierto en el aula y una práctica de aprendizaje multidireccional, en la que se produce el aprendizaje profesor-alumno, alumno-profesor, estudiante-estudiante, entorno-estudiante; de hecho, se reiteró la demanda por realizar más trabajos de grupo y actividades prácticas que involucren a los alumnos en el desarrollo de proyectos colaborativos en espacios abiertos. En este sentido, es clara la importancia de producir otras espacialidades en el salón de clases.

\section{Prácticas espaciales multi-escalares}

Como es natural, aunque lo visiten mucho, la vida de los estudiantes no está restringida al colegio, y éste a su vez no es un sistema cerrado, aislado completamente del contexto social, por eso es necesario conocer las relaciones multi-escalares de los estudiantes, pues la reflexión sobre los vínculos con el entorno potencia la capacidad de análisis y argumentación. Así, para documentar cómo viven los cuerpos la experiencia del movimiento en el espacio y su espacio-temporalidad, se partió de las representaciones gráficas llamadas espacio-gramas. Una de las hipótesis para realizar el ejercicio fue que existe una actividad espacial diferencial en términos de género, edad y condición social, en tanto que las prácticas espaciales de los estudiantes están orientadas por el contexto donde viven, tradiciones, ideologías y nivel económico, así como por afectos y familia.

Algunas diferencias vistas en las prácticas espaciales son el tiempo dedicado por los actores a la actividad física y el tipo de lugares que visitan para realizar prácticas deportivas; los hombres acostumbran jugar fútbol en canchas del barrio o pertenecen a escuelas deportivas, mientras que las mujeres no señalaron ninguna práctica deportiva particular, solo reseñaron visitas a parques, por lo que se infiere que es poco el tiempo dedicado al deporte. La poca movilidad espacial reflejada en los espacio-gramas implica mayores niveles de sedentarismo y de permanencia frente a pantallas (televisión, ordenador, videojuegos, Internet, telefonía móvil). Es necesario favorecer estrategias que involucren actividades físicas en el colegio, el juego como experiencia lúdica y los campeonatos que permitan la participación de todas y todos, no solo de quienes practican fútbol; la familia debe promover traslados a sitios distantes de sus casas, mediante tareas que impliquen un acompañamiento de los adultos por lugares de interés de la ciudad.

Las actividades de ocio situadas en el entorno inmediato fueron los elementos comunes en la práctica espacial de los estudiantes de sexto, séptimo y décimo grado, particularmente en los centros comerciales, donde asisten a funciones de cine, estos fueron los puntos centrales de atracción. Los espacio-gramas también reflejaron la disociación entre los espacios de vida o residencia, de trabajo, de ocio y de consumo mercantil, debido a la especialización residencial del territorio de la UPZ las Margaritas, que lleva a una sensación de que todo está lejos; la dirección de los movimientos se hace en los barrios limítrofes, donde se encuentran actividades comerciales.

\section{Conclusiones}

Las prácticas espaciales de las y los estudiantes son de escaso movimiento, tienen modos de vida y recorridos rutinarios cuasi fijos en el espacio, situadas en el consumo comercial, la permanencia en el espacio del barrio y la localidad; en muchos casos el colegio no fue representado, siendo paradójicamente el espacio en donde pasan gran parte de su tiempo. Poco aparece la espacialidad del trabajar de los padres y del estudiar en otros escenarios. Aquellas actividades que implican una movilización espacial amplia consisten en visitar a familiares que viven en otros barrios o, anualmente, a quienes están en otros municipios o ciudades del país.

La mayoría de estudiantes reconocen como poco práctico el aprendizaje de las clases, pues se concentran en la teoría y eso lleva a la desmotivación y apatía. Hay una correspondencia entre la percepción del cuerpo como espacio y las vivencias del cuerpo en el área del colegio, dado que los aprendizajes centrados en las posibilidades de movimiento, la expresión de emociones, el 
juego y la actividad física, son los que resultan más agradables. Es necesario reivindicar el colegio como un escenario para inspirar a pensar a las nuevas generaciones en clave de ciudadanía crítica con autonomía, de manera pluralista y rigurosa y desde la empatía, democráticamente responsables, como un espacio para el disfrute a partir de actividades artísticas y físicas transversales a las disciplinas fundamentales.

De los tres grados analizados, las niñas de séptimo fueron el grupo etario y de género que más percibe sexismo en el colegio; esto se relaciona con en el uso de espacios, el trato entre alumnos y la posibilidad de participar en actividades deportivas; al tiempo, son el grupo de mejor desempeño académico y de mayor participación en los espacios de representación. El espacio escolar está involucrado en generar y mantener diferentes procesos de desigualdad, injusticia y sexismo. La paz en el escenario escolar implica el tratamiento de los conflictos por la vía del diálogo, el debate democrático a través del pluralismo y el debate argumentado, que reconoce en el otro un sujeto de derechos. Es fundamental involucrar a los estudiantes en la construcción del Proyecto Educativo Institucional, articulando en él un enfoque diferencial que permita restablecer los derechos de los estudiantes, la participación con equidad y el poder de decisión.

La mayoría de estudiantes reconoce que existe intimidación en el colegio, motivada en parte por la ilusión de superioridad de algunos grados sobre otros, el machismo y el desempeño académico. Es necesario por tanto construir mejores relaciones entre estudiantes, no solo al interior del aula, sino entre los distintos grados, a través de la configuración de espacios comunes de aprendizaje que superen la organización segmentada que impone la institución sobre el espacio y los estudiantes, pues reproduce formas de exclusión y violencia que se expresa en: la indiferencia de los estudiantes al interactuar con pares de otros grados; el uso de lugares del colegio y de espacios abiertos por parte de los hombres de cursos superiores; el disciplinamiento del cuerpo, regulado por el uso estricto del uniforme; la circulación por espacios del colegio; y el desconocimiento del tipo de relaciones entre estudiantes y áreas de conocimiento.

Las prácticas espaciales han dado lugar a una disposición particular de los individuos en el lugar, configurando un espacio escolar en donde se impone un orden sobre el deber ser de cada miembro de la comunidad; el deber ser del estudiantado es el de la regulación constante de su comportamiento, lo cual limita sus posibilidades de participación con decisión en los órganos colegiados y su capacidad creativa, de cooperación y motivación personal en varias de las clases. 


\section{Referencias}

Delgado, O., Murcia, D., y Díaz, H. (1999). Geografía escolar: discursos dominantes y discursos alternativos. Bogotá: Universidad Nacional de Colombia-Programa de Fortalecimiento de la Capacidad Científica en la Educación Básica y Media.

Delgado, O. (2003). Debates sobre el espacio en la geografía contemporánea. Bogotá: Unibiblos.

Foucault, M. (1976). Vigilar y castigar. Nacimiento de la prisión. Argentina: Siglo Veintiuno.

Harvey, D. (1998). La condición de la posmodernidad. Investigación sobre los origenes del cambio cultural. Madrid: Amorrortu.

Harvey, D. (2013). Ciudades rebeldes. Del derecho de la ciudad a la revolución urbana. Madrid: Akal.

Herrera, J. D. (2013). Pensar la educación, hacer investigación. Bogotá: Universidad de la Salle. Facultad de Ciencias de la Educación.

Institución Educativa Compartir Tintal. (2013). Manual de convivencia y reglamento escolar. Bogotá: Institución Educativa Compartir Tintal.

Jodelet, D. (1985). La Representación social: fenómenos, conceptos y teoría. En Moscovici, S. (1985). Psicología social II. Pensamiento y vida social (pp.469-493). Buenos Aires: Paidós.

Lefebvre, H. (1991). La producción del espacio. Anthropos Difusión: Económica, 49. París.

Massey, D. (1995). A place in the world? Places, cultures and globalization. The Open University. Oxford UK.: Oxford University Press.
Massey, D. (2008). Ciudades mundiales. Caracas: Centro Simón Bolívar-Fundación Editorial el perro y la rana.

Massey, D. (2008, julio-diciembre). Hay que traer el espacio a la vida. Signo y pensamiento, No. 53, Vol. XXVII.

Norma Técnica Colombiana (NTC 4595). (1999). Ingeniería civil y arquitectura. Planeamiento y diseño de instalaciones y ambientes escolares. Bogotá: NTC.

Restrepo, D. (1998). Eslabones y precipicios entre participación y democracia. Curso de extensión Desarrollo Local y Gestión Ambiental. Bogotá: Universidad Nacional de Colombia, Instituto de Estudios Ambientales (IDEA).

República de Colombia. (1994). Ley 115, febrero 8 de 1994. Por la cual se expide la Ley General de Educación. Bogotá: Imprenta Nacional.

República de Colombia. (1997). Constitución Política. Bogotá: Legis.

Restrepo, G. (2004). Ciudad/Nación/Mundo. Escuela y formación en conciudadania democrática. Informe final de investigación presentado por Corporación Comunicar a la Secretaría de Educación Distrital. Bogotá: SED.

Secretaría de Educación Distrital (SED). (2015). Plan educativo de transversalización de la igualdad de género 2014-2023. Bogotá: SED.

Tuan, Yi-Fu. (2007). Topofilia. Madrid: Melusina. 



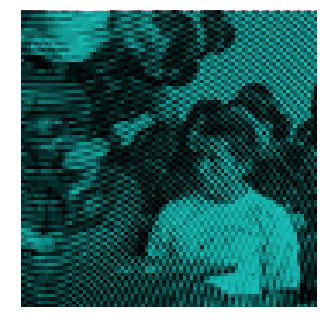


Ricardo Alfonso Soler Rubio 1 Guillermo Alfonso Viasús Quintero 2
1. Sociólogo, Universidad Nacional de Colombia; correo electrónico: rasolerr@unal.edu.co

2. Estudiante de Lingüística, Universidad Nacional de Colombia; correo electrónico: gaviasusq@unal.edu.co
Fecha de recepción: 18 de abril de 2016 / Fecha de aceptación: 16 de septiembre de 2016

\section{Resumen}

Este artículo presenta los resultados del proyecto de investigación "Parchemos: Creando paz desde la comunicación en la escuela y el barrio", desarrollado en el marco de la Beca de InvestigaciónAcción en Cultura Democrática Guillermo Hoyos Vásquez, en su versión 2015. El proyecto buscó fortalecer las prácticas ciudadanas en el contexto escolar del grado noveno de la Institución Educativa Distrital Eduardo Umaña Luna, para favorecer la construcción de paz y cultura democrática desde la comunicación como apuesta política, potenciando estos procesos desde las artes musicales y visuales.

Palabras clave: Educación para la paz, cultura democrática, comunicación, cultura escolar.

\section{Summary}

This article presents the results of the research project called "Parchemos: creando paz desde la comunicación en la escuela y en el barrio" framed in the fellowship of Action Research in Democratic Culture Guillermo Hoyos Vásquez, on its 2015 version. The project aimed to strengthen the civic practices at school context of the ninth grade from the District Educative Institution Eduardo Umaña Luna, in search of peace construction and democratic culture using communication as a political stake, improving these processes from musical and visual arts.

Keywords: Peace Education, Democratic Culture, Communication, School Culture.

\section{Resumo}

Este artigo apresenta os resultados do projeto de pesquisa "Parchemos: creando paz desde la comunicación en la escuela y en el barrio" desenvolvido no âmbito da Bolsa de Pesquisa de investigação-ação em Cultura Democrática Guillermo Hoyos Vásquez, na sua versão 2015. O projeto procurou fortalecer as práticas cidadãs no contexto escolar do nono grado da Instituição Educativa Distrital Eduardo Umaña Luna, em prol da construção da paz e de cultura democrática desde a comunicação como aposta política, potencializando estes processos desde as artes musicais e visuais.

Palavras chave: Educação para a paz, Cultura democrática, Comunicação, Cultura escolar 


\section{Introducción}

En el contexto colombiano, el campo educativo se ha venido consolidando como un objeto constante de intervenciones e investigaciones por parte de distintos agentes nacionales e internacionales, en donde transitan o incluso se imponen discursos y acciones específicas sobre los sujetos implicados en el proceso educativo: proyectos gubernamentales para hacer más competentes y efica$\operatorname{ces}^{3}$ a la administración educativa y al personal docente; jornadas ampliadas; contratación de corporaciones para mejorar el desempeño en las pruebas estandarizadas a nivel nacional e internacional; e incluso maximizar económicamente los recursos para abarcar una mayor cantidad de población con el fin de mejorar indicadores.

Sin embargo, la posibilidad de incidir en la cotidianidad de los procesos educativos, reconociendo realmente a los niños, niñas y jóvenes como sujetos (no solamente de derecho, sino en plena capacidad de construir, crear y compartir sentidos de vida), se ve reducida a simples proyectos de corta duración, o a la voluntad pedagógica y política de escasos docentes aún con vitalidad para generar procesos alternativos de formación que no se reduzcan a mejorar el desempeño de sus estudiantes en las pruebas estandarizadas, sino que procuren generar espacios de creación de sentido o de mentalidades críticas.

En este sentido, es importante la posibilidad de compartir y de visibilizar algunas voces desde perspectivas no tan nuevas, para posicionar al interior, no solo de los centros académicos, sino de la reflexión docente y el debate público, la necesidad de seguir replanteando los procesos educativos, pero reconociendo a estos sujetos históricamente infantilizados como voces y experiencias capaces de dar cuenta del estado actual de la institución escolar: su crisis como ente productor de saberes, y de sujetos "mayores de edad", que sigue imponiéndose como dispositivo disciplinario (Sáenz, 2010), conduciendo sistemáticamente las subjetividades hacia la reproducción de un orden macro social cargado de prejuicios y con poca consciencia de la actual situación económica y ambiental, y a la imposibilidad de pensar proyectos de vida que produzcan bienestar colectivo en los territorios que habitamos.

3 En el Decreto 1055 de 2011 del MEN, Artículo 6, se hacen explícitas las estrategias para promover el reconocimiento a la gestión, las cuales se fundamentan en aumentar los niveles de permanencia y calidad. El indicador de calidad: "Se calcula como la relación entre el número de estudiantes con mejores resultados a partir del percentil 75 en los resultados de español y matemáticas en las pruebas SABER PRO del año n, sobre el número de estudiantes que presentan las pruebas SABER PRO del año n".
El proyecto que aquí presentamos tuvo como propósito fortalecer las prácticas ciudadanas en el contexto local, pretendiendo mejorar en el entorno escolar las posibilidades de construcción de paz y de cultura democrática, desde la comunicación como apuesta política que permite manifestar el sentir y pensar de los estudiantes, potenciando estos procesos desde las artes musicales y visuales.

El proyecto de investigación fue financiado en el marco de la Beca de Investigación-Acción en Cultura Democrática Guillermo Hoyos Vásquez, promovida por la Secretaría Distrital de Cultura, Recreación y Deporte en conjunto con el Instituto de Estudios Sociales y Culturales "Pensar", de la Pontificia Universidad Javeriana, y el Instituto Goethe de Bogotá. El Colegio Eduardo Umaña Luna IED se encuentra ubicado en el barrio Dindalito (UPZ 82 -Patio Bonito) de la localidad de Kennedy.

El Colegio abarca los niveles educativos desde preescolar hasta educación media, con la posibilidad para el estudiantado de últimos años de recibir formación técnica en convenio con el SENA. La población estudiantil proviene en su mayoría de las UPZ aledañas a la institución como Corabastos, Britalia, Tintal, entre otras, y está compuesta por poblaciones de diversas trayectorias y orígenes geográficos y culturales. La localidad de Kennedy, en particular las UPZ 80 y 82, ha sido contemplada y estigmatizada como zona de alto riesgo y de intervención prioritaria, en procesos como la "Estrategia Integral de priorización y focalización 75/100 de Bogotá D.C.” (Alcaldía de Bogotá, 2013)

El colegio se ve influenciado por las dinámicas poblacionales, sociales, económicas y políticas propias de su contexto. De acuerdo con la SED y el Hospital de Kennedy (2010), en el territorio de Kennedy se cuentan cerca de 48.760 jóvenes de diferentes edades que conviven con problemáticas estructurales de la ciudad como la inseguridad, casos de violencia (física, emocional, sexual, agresión familiar, de género), tráfico de sustancias psicoactivas, amenazas de "limpieza social" por parte de bandas paramilitares, que estigmatizan a los jóvenes y a sus formas de vida, llegando incluso a causar varias muertes en la localidad, y casos de maltrato infantil y violencia contra las mujeres.

A pesar de que estas situaciones afectan a la ciudad en general, el diagnóstico deja claro el hecho de que la población de infancia y juventud es una de las más afectadas en la UPZ de Patio Bonito. El documento también contempla otros problemas relacionados con lo vulnerables que pueden ser los procesos de constitución de las identidades juveniles, debido a la influencia de grupos como barras bravas y "tribus urbanas", hecho que: 
Puede considerarse a la vez un mecanismo de respuesta a dificultades o situaciones conflictivas, donde la violencia es un patrón de conducta cotidiano en la comunidad. Si bien algunos jóvenes construyen su identidad dentro de confrontaciones ideológicas, asimetrías de poder, condiciones de pobreza o incomprensión, presentes al interior de familias o diversos ámbitos de la vida, otros promueven la organización y redes juveniles como mecanismo para la superación de sus necesidades y problemáticas (SED y Hospital de Kennedy, 2010, p. 140).

Así, la población joven del sector es estigmatizada por la población adulta, que desconoce y desvaloriza sus prácticas sociales y manifestaciones culturales, desencadenando problemas en red, ya que ellas tienden a ser reprimidas (por ejemplo, el grafiti) y anuladas en el contexto del territorio, impidiendo su reconocimiento como expresiones de interlocutores válidos en las discusiones y propuestas de transformación social local:

Si bien es cierto algunos jóvenes construyen su identidad en el marco de confrontaciones ideológicas, y relaciones de poder, la consolidación de parches y redes sociales con intereses comunes, les ha permitido encontrar una forma de equilibrio que en algunos casos favorece el desarrollo del territorio (SED y Hospital de Kennedy, 2010, p. 135).

\section{Metodología}

El análisis aquí presentado corresponde a una investigación cualitativa enmarcada en un diseño de etnografía educativa (Goetz y Lecompte, 1998), realizado en cuatro etapas: planeación, trabajo en campo, recolección de datos y análisis. El trabajo en campo consistió en el desarrollo de una serie de talleres temáticos dentro y fuera el aula con 3 grupos de grado noveno, de 2 jornadas escolares de la IED Eduardo Umaña Luna (EUL), contando cada curso con un promedio de 40 estudiantes. Estos talleres teóricos y prácticos generaron espacios participativos y de reflexión en torno a los temas que se buscaba problematizar: identidad, género, medios de comunicación, paz/conflicto, comunicación, democracia y lo político y la otredad; espacios en los que los/as estudiantes pudieron expresar a través de la música, el dibujo y el grafiti sus reflexiones personales y colectivas.

Dentro de las estrategias de recolección de la información se contemplaron posibilidades como la observación participante y no participante, entrevistas con las/os estudiantes y la realización periódica de grupos focales. Adicional a este proceso, los investigadores se preocuparon por extender una mirada etnográfica sobre el espacio del aula y las relaciones, tensiones y colaboraciones entre estudiantes y entre estudiantes y talleristas, complementándola con la información entregada por los/as estudiantes a través de dibujos, mapas y escritos cortos.

El proyecto tuvo una duración total de 4 meses, en los que se contó con la participación de una artista plástica, un músico percusionista y los miembros del grupo de investigación, dos sociólogos egresados y uno en formación, un estudiante de lingüística y una estudiante de Licenciatura en Educación Básica con énfasis en Ciencias Sociales.

\section{Resultados}

La reflexión guiada en los talleres de sensibilización buscó que las y los estudiantes no solo se acercaran a aspectos que buscaban complejizar la mirada sobre los actos comunicativos y las implicaciones éticas, políticas, históricas, individuales, emocionales y colectivas que éstos tenían en sus cotidianidades; sino que también tuvieran la posibilidad de participar de procesos de creación, reflexión y diálogo a partir del arte, como un espacio no solamente estético, sino dialógico y esencialmente comunicativo.

Con ello se buscaba promover en ellos y ellas una resignificación de sus prácticas comunicativas y proponer otras nuevas, entendiéndolas como sustento para la producción y reproducción de relaciones sociales y culturales. Los talleres en sí mismos tenían la intención de que durante el proceso los estudiantes se concienciaran de las prácticas y discursos culturalmente sedimentados y reproducidos en su colegio, y de cómo ellos y ellas podían incidir en esos discursos para controvertirlos y transformarlos.

Ejemplo de lo anterior fue el trabajo sobre los temas de identidad y género, que tuvo como sustento la idea de que la identidad no es un constructo estático, sino una construcción permanente que cambia con el tiempo (Hall, 2010) y que tiene la potencia de producir y reproducir estereotipos sociales sobre la alteridad étnica, de género, racial, etc. Las temáticas se abordaron desde una perspectiva de lo político como una acción personal que tiene incidencia en el entorno, desde los medios de comunicación como productores de discursos hegemónicos que circulan diariamente en nuestra sociedad, y desde lo conflictivo del encuentro de identidades diferentes en espacios de interacción en la ciudad.

Las preguntas y comentarios de los/as estudiantes, y las conexiones que hacían entre sus experiencias personales, el trabajo de los talleristas y los materiales de apoyo audiovisual de los talleres, les dieron herramientas para desnaturalizar las representaciones 
y las características que consideraban "esenciales" de las "otras" personas con quienes convivían diariamente en los espacios del colegio y del barrio.

Las reflexiones suscitadas por este tema se abordaron desde una propuesta de taller de apreciación musical que, a través de ejercicios básicos de escucha y de uso individual y colectivo de instrumentos musicales, buscó que los/as jóvenes se reconocieran como sujetos activos de su entorno, y que a través de las herramientas, que se les brindaron desde la didáctica musical, exploraran formas de comunicación que no necesariamente estuvieran mediadas por palabras. Se propuso que habilidades como la disposición a escuchar y a hacer silencio, o a apelar a la sensibilidad y al cuerpo para comunicar, construyen desde formas diferentes de comunicación (ya no exclusivamente uno a uno), al producir interdependencias directamente con el cuerpo propio, la otredad y con el entorno.

Lo anterior se relacionó con reflexiones sobre cómo sus formas de habitar y decidir sobre los espacios eran también maneras de hacer política y de participar activamente en lo que tiene que ver con la ciudadanía, entendiéndola como un elemento movilizador y transformador en sus relaciones de convivencia en el colegio y fuera de él, y no como la acción de ser mayor de edad y votar o tener cédula, como la entendían al inicio del proyecto. Todo esto, no en el marco de una sociedad ideal sin tensiones ni problemas, sino abordando constantemente los conflictos y desencuentros que se producen en el espacio de la ciudad.

El proyecto enlazó las reflexiones sobre identidad con los conflictos y las diferentes formas de violencia cotidiana a las que los/ as estudiantes están constantemente expuestos y que afectan sus vidas diarias (acoso callejero, racismo cotidiano, matoneo escolar, entre otros). Indagamos por las formas en que resolvían sus conflictos personales y grupales, lejos de las imágenes estereotipadas del conflicto como una problemática que se resuelve a través del diálogo, o como fenómeno opuesto a la paz, destacando el potencial del conflicto como espacio de transformación y de encuentro con la alteridad que puede tener posturas diferentes a las propias. En este sentido, las chicas y chicos reconocieron que el conflicto no necesariamente es la manifestación de algo que debe ser rechazado o negado, sino que significa una oportunidad de confrontación y cambio de posturas o condiciones.

A través de una discusión sobre la coyuntura actual del conflicto colombiano y los diálogos de paz, es importante rescatar algunos aportes de los alumnos, como la problematización de la paz en tanto concepto vacío que remite a una supuesta tranquilidad producida por la ausencia de conflictos, pero que desconoce la necesidad de ciertas condiciones, como mejoras en la calidad de vida de la gente y un control político sobre las élites históricamente

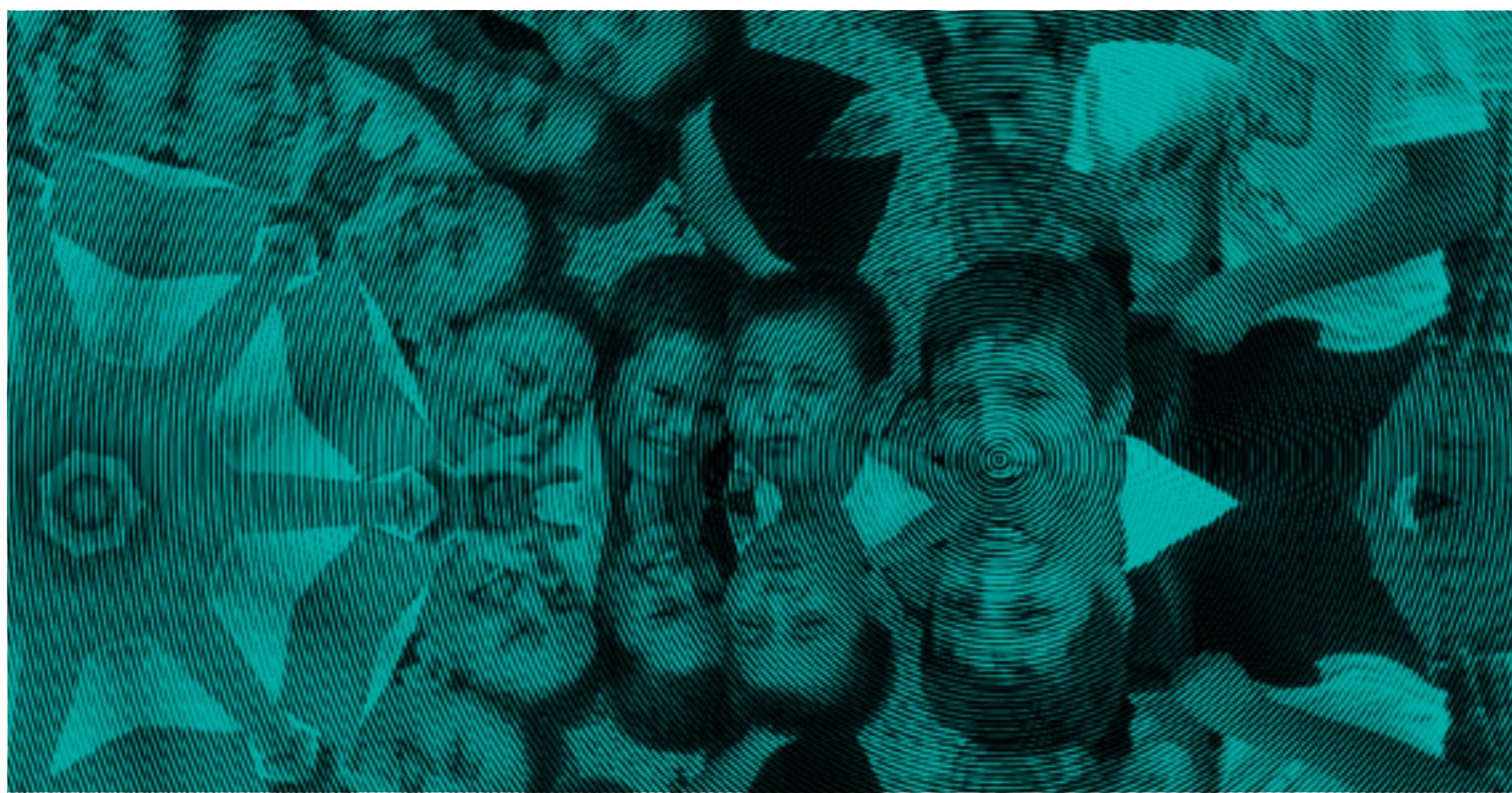


aficandas en el poder. Lo anterior también se analizó a nivel personal, dadas las experiencias que cada uno de los/as estudiantes tenían y las estrategias que usaban para transitar por situaciones de conflicto. Percibir al conflicto más allá de las valoraciones negativas sobre él, llevó a considerar que los disensos y las diferencias son constantes en las relaciones interpersonales.

En conjunto con los participantes se realizaron varias discusiones en torno a materiales audiovisuales que mostraban los discursos de los medios de comunicación, cuestionando constantemente que transmitir un mensaje fuera un proceso ideal, aséptico y racional, ya que esta percepción desconoce las dinámicas contextuales que modifican por completo la recepción y la producción de mensajes y significados. Se buscó que el estudiantado también dilucidara las intenciones detrás de los mensajes comunicados, que tenían una naturaleza fundamentalmente política, en la medida en que presentaban una representación de la realidad que promovía prácticas y prejuicios que llegaban a afectar la forma de conocer a la alteridad.

En este sentido, consideramos interesante reconocer que, en la actualidad, la escuela como institución de saber se encuentra en disputa con las nuevas formas de socialización y formación a las que se exponen los/as estudiantes, como los medios de comunicación (Reguillo Cruz, 2000, p. 7), debido a que la información aparentemente neutral que se presenta en distintos formatos, y de fácil acceso, genera nociones sobre una realidad que no necesariamente les atañe en la cotidianidad, y producen imágenes de lugares y culturas con las que no se tiene contacto directo; sin embargo el receptor se sujeta a ellas por la inmediatez de lo visual y lo narrado, percibiéndolas como una única verdad.

Trabajamos en la creación de un mural (instalado por el colegio en la sección de preescolar) que reflejaba los aprendizajes de los/ es estudiantes durante la investigación; participaron activamente en todo el proceso, que incluyó el dibujo y corte de plantillas, la preparación de la superficie y la pintura en aerosol del mural. Este ejercicio despertó su curiosidad y buena disposición, llevándoles a manifestar su agrado por el espacio para la elaboración práctica y creativa, pues les permitió expresarse libremente; criticaron que no tenían muchos espacios para actividades similares. También fue significativo el hecho de que fue posible re-significar prácticas artísticas como el grafiti y el muralismo, y sus aportes a la reflexión sobre la intervención del espacio público de la ciudad, convirtiéndose no solo en una forma de hacer arte, sino de comunicar y hacer visible la opinión personal.

Buscamos que el taller sirviera para mostrar que desde sus formas de relacionarse, percibirse y comunicarse con los sujetos de

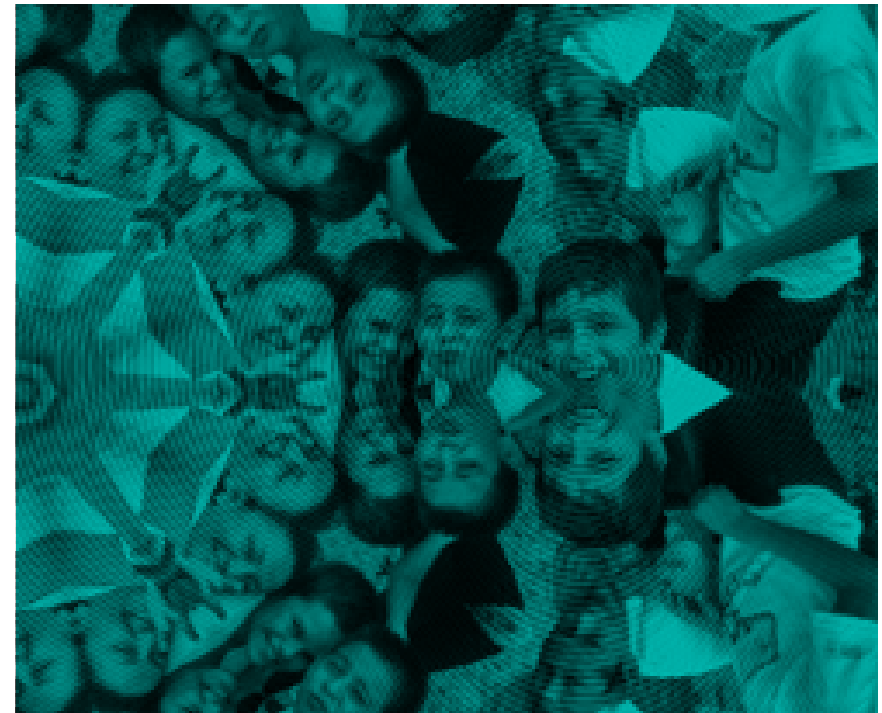

su cotidianidad, las/os estudiantes tenían un rol central en la construcción de ciudadanías capaces de proponer y generar cambios en sus entornos locales, replanteando y resignificando la idea de ciudadanía desde la acción comunicativa, lo cual pasa por la indagación de:

Las reglas explícitas y ocultas que regulan los comportamientos, las historias y los mitos que configuran y dan sentido a las tradiciones e identidades, así como a los valores y las expectativas que desde fuera presionan la vida de la escuela y del aula (Pérez-Gómez, 2005, p. 162).

Es en los puntos de encuentro entre dichas reglas y el conjunto de saberes y poderes que regulan al aula y a la escuela, donde tienen lugar las posibilidades de potenciar procesos que fomenten la transformación y la producción cultural, entendida como:

El uso creativo de los discursos, los significados, los materiales, las prácticas y los procesos de grupo, para explorar, comprender y ocupar creativamente posiciones particulares en los conjuntos de posibilidades materiales que, en general, se hallan disponibles (Willis, 1993).

El ámbito de la producción cultural (en este caso, el que se desarrolla en la escuela) siempre está abierto a la creación, pero también en tensión permanente con las manifestaciones anteriores de cultura y con la tendencia que tiene ésta de reproducirse. La visión resignificada de la constitución de las prácticas comunicativas como expresiones del lenguaje y de la cultura individual y colectiva, permite concebir formas amplias de producción de las posibilidades de la comunicación, las cuales pasan por diferentes tipos de narrativas como la escritura, la oralidad, el arte, lo audiovisual y lo pictórico, entre otras. 
En este sentido, pensar la comunicación como acto político, y de paso cuestionar a las y los estudiantes sobre los lenguajes usados tradicionalmente en los procesos educativos, posibilita trascender la escritura y la lectura en sus formas elementales, para abrirle campo a lenguajes menos cristalizantes de la realidad social y subjetiva, abriendo paso a la creatividad y a la ambigüedad de producción de sentidos y significados. Esta posibilidad de subjetivación, a través de nuevos lenguajes al interior del aula, implica entonces hacer un mayor esfuerzo para decodificar la información adquirida (tanto para estudiantes como para docentes), lo cual requiere de promover la empatía o la sensibilidad (sensorial, de investigar), y también potenciar la capacidad de construirse subjetivamente en relación con otredades, para poder consensuar significados, sentidos e intenciones en los actos educativos y comunicativos.

\section{Conclusiones}

Luego de un corto semestre donde compartimos con las y los estudiantes a través de varios talleres de sensibilización y artísticos, y donde intentamos establecer un precedente para posicionar el debate sobre cultura democrática a través de la comunicación, creemos que nuestras herramientas de investigación pueden quedarse cortas para exponer algunos indicadores fiables de transformaciones subjetivas o culturales de largo alcance, tanto de los y las estudiantes como de nosotros mismos, mucho más considerando

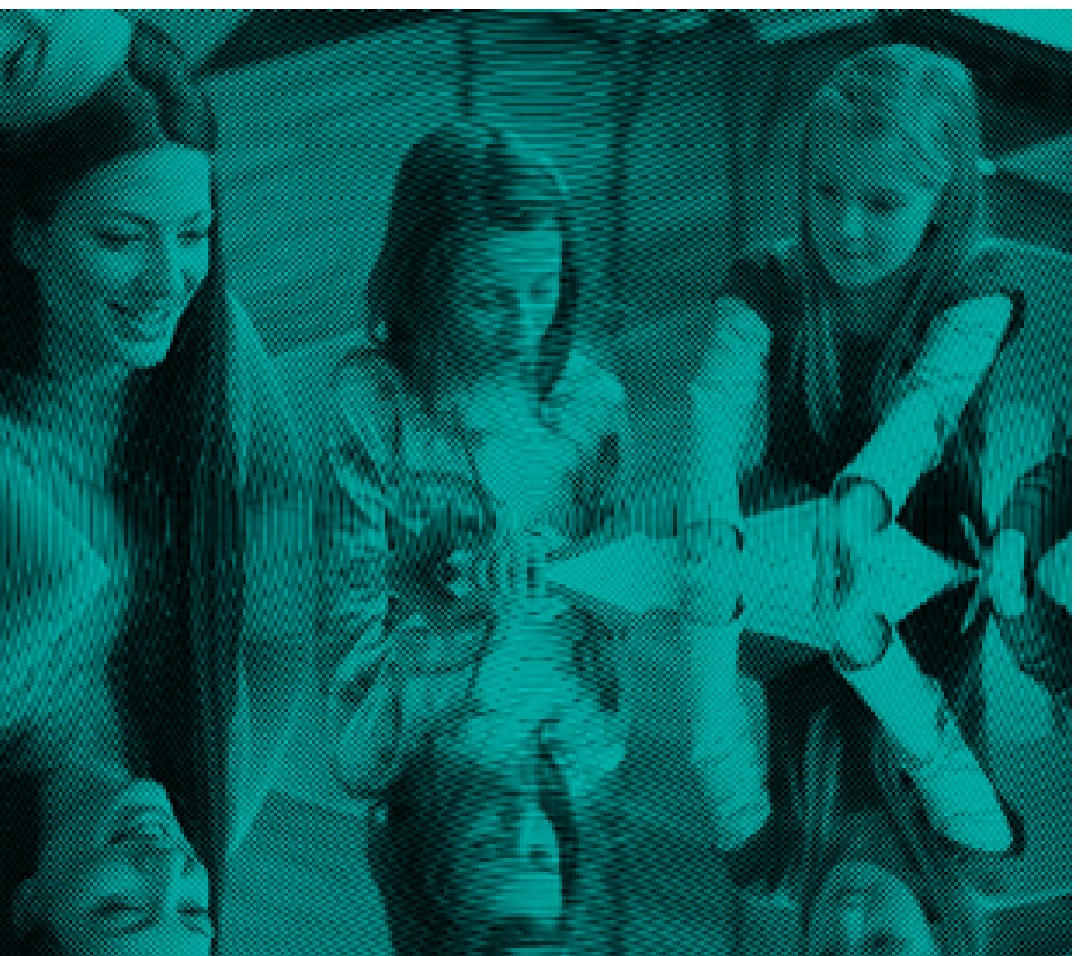

que intentábamos dar cuenta de un estado de cosas mientras buscábamos producir cambios en él; aún así tratamos de recoger aquí unos resultados que tienen más bien la forma de aprendizajes mutuos, pues reconocemos el carácter situado y limitado del proceso como la posibilidad de seguir desarrollando preguntas y acciones siempre inacabadas que movilicen nuevas posibilidades de acción, sentido y reflexión sobre la condición humana individual y colectiva.

Antes que nada, debemos decir que a partir de lo visto en el espacio escolar, los y las estudiantes vienen con unos referentes culturales, sedimentados histórica y biográficamente, que son constantemente actualizados, como se evidencia en el uso de ejercicios que buscan generar desplazamientos de las certezas o del "sentido común" en temas como la identidad de género, o en intentar construir colectivamente el término de política; estos referentes no solo permean fuertemente su habitus, sino que dan forma a sus propias identidades y definen sus formas de ser y de producir relacionamientos.

Así que cuando proponemos la tarea de producir cambios culturales a partir de una serie de actos alejados del programa curricular, sabemos que es un trabajo bastante limitado porque es preciso fomentar desde las instituciones escolares y académicas procesos sistemáticos de largo aliento, en donde se trasciendan de las visiones instrumentalistas y gerenciales de la educación pública como indicador de bienestar por su cobertura, y en donde se empiecen a pensar procesos situados con maestras y maestros interesados en fomentar procesos de construcción de subjetividades diferentes, sensibles y reflexivas de sí mismas y de su entorno, pero principalmente con ganas y posibilidades de crear alternativas para actuar, comunicarse, agenciar cambios y transformar su entorno, transformándose a sí mismas.

Llevar a cabo este proyecto se convirtió en un reto para cada uno de nosotros, pues nos enfrentamos a un escenario que, si bien no era nuevo, nos exigía estar en constante reflexión acerca de nuestro quehacer en el aula. Encontrarse en un espacio con jóvenes que durante la construcción de su historia han apelado a discursos y prácticas que no están precisamente relacionados con el ejercicio reflexivo de la cultura ciudadana, pues les resulta un discurso más impuesto que vinculado a sus realidades cotidianas, nos llevó a propiciar las confrontaciones respecto al modo en el que cada uno de ellos vivían y asumían su papel como ciudadanos.

Arriesgarnos a trabajar temas como el género o la producción de la identidad a partir de visiones dualistas cargadas de prejuicios, la vida personal como escenario político, entre otros, implicó 
un constante proceso de reflexión y de construcción colectiva de significados, además debimos re-pensarnos las prácticas pedagógicas, es decir, el cómo lograr que el aula se posicionara como lugar de producción de significados relevantes y contextualizados para los chicos y chicas, y ver que, al mismo tiempo, de allí surgiera la posibilidad de incentivar nuevas formas de reconocimiento de la otredad y de la diferencia. Este reto no se hubiese logrado sin la continua evaluación y reflexión sobre el desarrollo de cada uno de los talleres y de las metodologías utilizadas, que pretendían propiciar espacios reflexivos y creativos para cada uno de las y los estudiantes.

Consideramos que el proceso de confrontación vivido durante el diseño y la ejecución de los talleres logró poner sobre la mesa los discursos, prácticas y roles que estaban imbricados en el acervo cultural de los chicos y chicas, lo cual nos y les brindó herramientas para poner en duda el sistema simbólico de representaciones culturalmente sedimentado, no solo dejando la reflexión en términos discursivos, sino buscando trascenderla para empezar a generar prácticas comunicativas desde los sentires y pensares de los chicos y chicas sobre los espacios en que habitan, como sus barrios y la institución escolar.

Otro de los retos fue articular todo el andamiaje teórico/discursivo sobre el que se basó este proyecto, con las vivencias y prácticas cotidianas de cada uno de los/as estudiantes. Era claro que este proceso no podría llevarse a cabo siguiendo la lógica tradicional de las escuelas con clases magistrales y evaluaciones; por el contrario, nos enfocamos en que cada uno de los talleres de sensibilización tuviera como eje central la experiencia de los chicos y las chicas en su territorio, con su familia y en los diferentes espacios en los que se relacionan, para desde allí empezar a tejer los nuevos lazos entre teoría y práctica a partir de actividades, juegos y herramientas multimediales y textuales.

Hoy podemos ver reflejados nuestros esfuerzos en un pequeño cambio alrededor de la percepción y entendimiento de la serie de conceptos sobre los cuales centramos el trabajo de los talleres artísticos y de sensibilización, sobre todo en categorías fundamentales como la de democracia, la cual pasó, de ser una palabra sin significado inteligible para los estudiantes o con poca relevancia, a un término que no solo hacía referencia a su definición como la construcción colectiva de las decisiones, sino a uno que también tuvo la oportunidad de experimentarse en ejercicios como la creación del mural o de la muestra musical, y los trabajos grupales desarrollados a lo largo de todo el proyecto.
La política y lo político ${ }^{4}$ también se hicieron presentes en el proceso de re-significación de los estudiantes, quienes lograron superar su visión abstracta, instalada en su sentido común como la esfera pública, y rechazada por asociarse a los gobernantes "malos" o "corruptos", para empezar a considerar el hecho de que la política y lo político se juegan cada día en todas las esferas de la vida cotidiana y que, por ende, todos/as tenemos diferentes niveles de incidencia en ellas, cuestión fundamental en el camino hacia la construcción de una cultura escolar más democrática.

Por eso, conscientes de que podemos desanimarnos al encontrar frecuentemente la cara reproductora y conservadora de la máquina escolar y de caer en cualquier tipo de pesimismo estructuralista, que constantemente acecha el quehacer pedagógico, decidimos siempre partir de aquella premisa del pedagogo Paulo Freire de que en la educación no hay espacio para el pesimismo, sino que debe ser una práctica de y para la esperanza.

En este sentido, uno de los aprendizajes compartidos, y una potencia enorme que encontramos, es que en el contexto de una ciudad y de un país que se empiezan a cuestionar sobre la promoción de nuevas subjetividades pensando estratégicamente en culturas de paz, resulta enormemente interesante trabajar a través de "nuevos" lenguajes en los procesos educativos, como las artes en sus diversas modalidades, no solo usándolos como herramientas de transmisión de información, sino como productores de estéticas y subjetividades que vienen cargadas de sentido, de saberes, de trayectorias y mensajes que se omiten por el peso del legado histórico de la educación escolarizada como proceso instrumental e "iluminador".

El potencial de las artes como medios comunicativos inherentemente políticos y cargados de subjetividad, devela un debate importante para la pedagogía contemporánea, en donde se hace necesario pensar en procesos educativos constantes, que movilicen transformaciones subjetivas y debiliten el legado histórico-colonial de la escuela como proceso de imponer verdades, para dar paso a la ambivalencia de significados como camino para visibilizar otras historias y posibilidades de mundo, diversificando las voces y reconociendo a la otredad como elemento que permite ampliar saberes y experiencias.

Este proyecto fue una apuesta política que partió de reconocer que la escuela es y seguirá siendo un espacio preciso para llevar

4 Aludiendo a la distinción que hace la politóloga Chantal Mouffe, en donde la política se refiere a las instituciones de gobierno y lo político a las relaciones de poder existentes en los relacionamientos sociales. 
a cabo procesos pedagógicos reflexivos, pues creemos que solo haciendo sistemáticas las prácticas que movilicen diversos cuestionamientos en los estudiantes -pero a su vez motivándoles a comunicar sus percepciones e ideas-, es como se puede apuntar de manera efectiva y no impositiva a transformaciones, resignificaciones y producciones culturales que no solamente habiliten a las juventudes a participar de maneras creativas y novedosas en la sociedad civil, sino que permitan volver a enfocar el rol de la escuela como espacio para potenciar la vida en sus múltiples formas, en aras de desestabilizar su funcionamiento histórico como institución disciplinaria y normalizante, que reproduce órdenes racistas, sexistas y clasistas en las formas de relacionamiento con y en el mundo. 


\section{Bibliografía}

Alcaldía Mayor de Bogotá. (2013). Estrategia Integral de priorización y focalización 75/100 de Bogotá D.C. Política pública Distrital de Convivencia y Seguridad Ciudadana: Plan Integral de Convivencia y Seguridad Ciudadana PICSC 2013-2023. Bogotá: Alcaldía Mayor de Bogotá.

Goetz, J., y Lecompte, M. (1998). Etnografía y diseño cualitativo en investigación educativa. Madrid: Morata.

Hall, S. (2010). Sin garantías: trayectorias y problemáticas en estudios culturales. Bogotá: Instituto de estudios sociales y culturales Pensar, Universidad Javeriana, Instituto de Estudios Peruanos, Universidad Andina Simón Bolívar, sede Ecuador.

Ministerio de Educación Nacional (MEN). (2011). Decreto 1055 de 2011, Artículo 6. Bogotá: MEN.

Pérez-Gómez, A. (2005). La cultura escolar en la sociedad neoliberal. Madrid: Morata.
Reguillo Cruz, R. (2000). Emergencia de culturas juveniles. Estrategias del desencanto. Buenos Aires: Norma.

Sáenz Obregón, J. (2010). Gobierno de los pobres, culturas y saber pedagógico. Algunas líneas de fuerza emergentes en la configuración del dispositivo escolarizador público en Colombia. Revista Colombiana de Educación, No. 67, Bogotá: Universidad Pedagógica Nacional, pp. 201-226.

Secretaría Distrital de Salud, y Hospital de Kennedy. (2010). Diagnóstico local con participación social. Localidad de Kennedy. Bogotá: Alcaldía Mayor de Bogotá.

Willis, P. (1993). Producción cultural no es lo mismo que reproducción cultural, que no es lo mismo que reproducción social, que tampoco es lo mismo que reproducción. En Velasco, H. M., García, J. F., Díaz, A. (Eds.). Lecturas antropológicas para educadores. El ámbito de la antropología de la educación y de la etnografía escolar. Madrid: Trotta, pp. 389-429. 



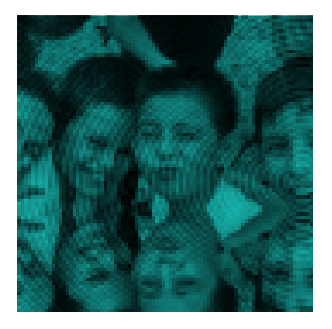




\section{Nidya Soraya Páez Martínez 1 \\ Ruth Milena Páez Martínez 2}

1. Magister en Educación de la Pontifica Universidad Javeriana, docente de primaria en colegios estatales del Distrito Capital de Bogotá, Colombia; correo electrónico: nisopama@yahoo.es

2. Doctora en Educación de la Universidad Pedagógica Nacional de Colombia. Docente investigadora de la Universidad de La Salle; correo electrónico: rmpaez@unisalle.edu.co
Fecha de recepción: 23 de mayo de 2016 / Fecha de aceptación: 16 de septiembre de 2016

\section{Resumen}

Como mediación pedagógica el yoga en la escuela contribuye a disminuir la violencia escolar. Esta conclusión se deriva de la experiencia pedagógica "Yoga, educación y vida", que fue realizada entre los años 2008 y 2012 en el Colegio Técnico Distrital República de Guatemala de Bogotá, y de su combinación con la investigación titulada Interacción sin violencia. En ambos casos se concluyó que el uso de unos mecanismos pedagógicos en el aula que potencien, como el yoga, no solo la exterioridad, sino la interioridad de los niños, permite potenciar la interacción sin violencia en el ámbito escolar y resulta de utilidad para el maestro que comparte su experiencia con ellos.

Palabras clave: Yoga, escuela, niños, violencia escolar.

\section{Summary}

Yoga at school as pedagogical mediation helps to reduce school violence. This conclusion is derived from the pedagogical experience "Yoga, education and life" which was conducted between 2008 and 2012 in the Colegio Técnico Distrital República de Guatemala in Bogotá and the research entitled "Interaction without violence". In both cases it was concluded that to enhance the interaction without violence in schools, the use of a pedagogical devices in the classroom that enhance not interiority of children, such as yoga, useful for teacher which shares a long time with them.

Keywords: Yoga, school, kids, school violence. only the externality but also the

\section{Resumo}

loga na escola, mediação pedagógica ajuda a reduzir a violência escolar. Esta conclusão é derivada da experiência pedagógica "Yoga, educação e vida", que foi realizado entre 2008 e 2012 no Colegio Técnico Distrital República de Guatemala e da pesquisa "Interação sem violência". Em ambos os casos concluiu-se que para melhorar a interação sem violência nas escolas, o uso de um dispositivo pedagógicas em sala de aula que melhoram não só a externalidade, mas também a interioridade das crianças, tais como yoga, útil para o professor que compartilha um longo tempo com eles.

Palavras chave: loga, escola, miúdos, violência escolar. 
El yoga en la escuela, abordado como mediación pedagógica, contribuye a disminuir la violencia escolar. Esta conclusión se deriva de los resultados de la investigación titulada Interacción sin violencia, desarrollada en el Colegio Campestre Monteverde IED ${ }^{3}$ (Páez, 2009, pp. 989-1007) y de la experiencia pedagógica "Yoga, educación y vida", que fue realizada en el Colegio República de Guatemala de Bogotá IED ${ }^{4}$, las cuales se llevaron a cabo en contextos de similares características y cuya combinación permitió ver la transferencia del conocimiento.

Por un lado, la pertinencia de la investigación se enmarca en la necesidad de reconocer la violencia escolar como un fenómeno cada vez más frecuente que afecta las dinámicas de la escuela y revela una problemática de fondo, casi siempre vinculada con los sistemas que le permean (familia, medios de comunicación y de información, etc.). La violencia escolar sigue siendo una constante en los colegios dentro y fuera del país, tanto, que se han creado observatorios de violencia escolar en varias regiones ${ }^{5}$, y Bogotá y sus colegios no escapan a esta situación, de ahí que se haya creado el Observatorio de convivencia escolar (Alcaldía Mayor de Bogotá, 2010).

La investigación que se reporta en "Cuerpo reconocido: Formación para la interacción sin violencia en la escuela” (Páez, 2009), plantea que uno de los principales motivos que originan dicha interacción en los niños es la ausencia de reconocimiento del propio cuerpo y de la palabra: los modos de interacción violenta de los niños con sus pares se experimentan por el cuerpo y se manifiestan sobre su idea de cuerpo; tales modos se concentran en la interacción espacial, la interacción no verbal intencional y en el comportamiento verbal. Cuando los niños reconocen su cuerpo como referente central de su relación consigo mismos y con los otros, tienen más posibilidades de disminuir o abandonar la interacción violenta en la escuela.

3 Desarrollada entre los años 2004 y 2006 con los docentes Nubia Velásquez, María del Carmen Bravo, Daniel Moyano y Ruth Milena Páez como investigadora principal.

4 La experiencia fue gestada y dirigida por Nidya Soraya Páez, siendo docente de primaria en la misma institución, entre los años 2010-2012.

5 Entre ellos: el Observatorio Internacional de Violencia Escolar (OIVE, s.f.); el Observatorio europeo de la violencia escolar (Ortega y Blaya, 2006.); el Observatorio de violencia escolar en México (Gómez, Zurita y López, 2013); el Observatorio argentino de violencia en las escuelas (Ministerio de Educación y Deportes, s.f.), y el Observatorio sobre la violencia y convivencia en la escuela de Perú (s.f.).
Por otro lado, la importancia de la experiencia pedagógica tiene que ver con dos asuntos, el primero de ellos es que escasean propuestas con fines pedagógicos enmarcadas en el ámbito escolar dentro de la bibliografía vigente de yoga para niños. En Colombia, el libro Yoga para niños (Villegas y Kent, 2007) presenta las distintas posiciones de yoga en forma de secuencias didácticas, cada una de las cuales trabaja diferentes valores y está acompañada de imágenes ilustrativas; por lo demás, no se hallan artículos científicos ni libros sobre el tema que cumplan con los criterios editoriales de rigor, algunos carecen de autores, año o editorial; su "respaldo" es un centro de yoga y la nominación "yoga para niños" se hace fuera de la escuela. Estos textos parecen tomar insumos de fuentes a las que no siempre dan los créditos, y ponen en circulación materiales tipo "manual" o "guía".

En el fondo de esta situación y de los fragmentos con pretensiones de "yoga para niños", subyacen, de uno u otro modo, los aportes de la francesa Micheline Flak, quien realizó en París (1973) la primera experiencia práctica de yoga en el aula con el fin de mejorar el rendimiento de sus alumnos, y quien en 1978 fundó el RYE (Recherche sur le yoga dans l'éducation), que se extendió a países europeos y latinoamericanos y aún sigue vigente. El propósito del RYE fue desarrollar un método práctico donde se aplicaran los principios básicos del yoga, que pudiese integrarse al aula escolar e incidiera sobre la enseñanza y el aprendizaje; esto se fue nutriendo de nuevas pretensiones como potenciar en los niños el entusiasmo por aprender, estimular su cerebro, favorecer la confianza en sí mismos y su bienestar. El conjunto de estas ideas se concreta en buena medida en el libro de Flak y Coulon Niños que triunfan. El yoga en la escuela (1985).

En segundo lugar, la importancia de esta experiencia pedagógica parte de la necesidad de construir una propuesta práctica de yoga con niños situados en una institución escolar bogotana. Si la experiencia reportada por Flak había dado buenos resultados, ¿por qué no abrir el espacio en el Colegio Distrital República de Guatemala desde sus particularidades contextuales y poblacionales?; ¿de qué forma el yoga podría favorecer el desarrollo integral de un grupo de niños de primaria desde el aula de clase?; ¿podría una "técnica" de práctica personal como el yoga disminuir la interacción violenta de ese grupo de niños en este colegio? Estos interrogantes fueron el inicio de un proceso de conocimiento y aprendizaje para la docente líder de la experiencia, en su propia práctica y en su relación con un grupo de 70 niños que se convirtieron en sujeto de observación e interacción con otros sujetos y con los objetos. 
Partiendo de lo anterior, se concretó la siguiente situación problema: los niños de segundo y tercero primaria de la institución escolar manifiestan actitudes y expresiones, verbales y no verbales, de violencia que afectan la dinámica de las clases e interfieren con la concentración y atención de las mismas; además no están respondiendo a los llamados de atención habituales y ni la motivación ni la "represión" parecen importarles. Entonces: ¿De qué manera el yoga puede contribuir en la disminución de la interacción violenta de los niños de $2^{\circ}$ y $3^{\circ}$ primaria en el aula de clases del Colegio Técnico Distrital República de Guatemala? Desde aquí:

- Se entendió que la violencia intrafamiliar, la ausencia de padre o madre, el uso inadecuado de la autoridad y la carencia de normas en casa, al lado de condiciones socioeconómicas desfavorables, influyen en el comportamiento "inadecuado" ${ }^{\text {" de }}$ los menores: agresividad y mal trato con los otros.

- Se reconoció al niño como sujeto, no solo externo, aunque las manifestaciones de su presencia sean más visibles de este modo, sino como un ser interior que se relaciona con los otros de acuerdo con esa misma interioridad, entendiendo que es más bien esa armonía o desarmonía de adentro lo que le motiva e induce a actuar.

- Se identificó que la escuela ha descuidado esta formación interior que contribuye a resolver los conflictos internos que agobian al niño y le impiden vivir bien (habrá que estudiar qué ha pasado con el papel de la familia), los mismos que generan la exteriorización de unas acciones caracterizadas como violentas, como expresión de auxilio, un "¡necesito ayuda!", ante el cual los maestros solemos estar sordos.

Teniendo en cuenta esto, la inclusión del yoga en el ámbito escolar resulta ser una posibilidad de trabajo pedagógico muy pertinente, con mayor razón en contextos vulnerables, pues vuelca la mirada sobre el interior de los niños como nicho potente de su acción externa. Por supuesto, esto no exime a la familia ni a otros entes responsables de la educación de los menores de cumplir con sus funciones, pero sí resulta ser una mediación favorable y cercana para el docente, quien se las tiene que ver durante su cotidianidad escolar con situaciones de violencia escolar.

6 El término "inadecuado" hace referencia a esa interacción entre niños que se visualiza como agresión verbal, física o gestual en la escuela.

\section{Referentes conceptuales}

\section{Pedagógicos}

La investigación se soportó en los lineamientos curriculares de educación ética y valores humanos, de educación física y de educación artística (Ministerio de Educación Nacional, 1998, 2002a, 2002b). En el caso de los componentes para una educación ética y en valores humanos, se rescatan dos de esos lineamientos: La conciencia, confianza y valoración de sí mismo, en la cual "Se requiere proponer actividades y relaciones que permitan al alumno un reconocimiento, una toma de conciencia de su individualidad y de sus relaciones con los otros" (1998, p. 73); y la autorregulación, es decir: "El autocontrol y la autorregulación son procesos largos y complejos, es importante la identificación de elementos del medio que ejercen un control y ayudan a la regulación de los individuos"; al tiempo, es "necesaria la identificación de los mecanismos que en cada institución pueden facilitar el paso de un control externo a una regulación propia” (1998, p. 74).

Para los lineamientos del área de educación física la atención se centró en el cuerpo y su relación con los objetos y el mundo social. Dentro de la estructura propuesta para el plan de estudios, en el desarrollo físico y motriz para los niños se enuncian el reconocimiento del cuerpo, la relación dinámica entre movimiento corporal y objetos, y la identificación de capacidades corporales y de su sentido (2002a, p. 128); no obstante, queda sin mencionarse el trabajo con el cuerpo para el logro de la introspección, del silencio interior. Por último, para el caso de los lineamientos de educación artística se contempla la gestualidad corporal como forma expresiva y efecto del desarrollo perceptivo, o sea, el cuerpo en la danza comunica a otros; se espera un despertar de la sensibilidad, desarrollo visual y auditivo, un cuerpo lúdico como expresión del arte (2002b, p. 189) que supla el vacío que ha dejado de lado el cuerpo como vuelta a la vida interior.

\section{Epistemológicos}

El acercamiento a la comprensión del yoga para niños escolares implicó comprender y ubicar una perspectiva en cuatro conceptos.

Yoga. El yoga no es una religión ni una moda para los desocupados o ciertas clases sociales, es una técnica para aprender a vivir, con muchos beneficios para quienes lo practican ${ }^{7}$. Es una técnica de relajación que apoya la formación integral, pues le permite al

7 Los resultados del estudio científico publicado: "Beneficios sobre la calidad de vida en personas que practican Sahaja Yoga. Estudio descriptivo en base a 
niño conocerse, pacificarse, des-estresarse, condiciones que estimulan su crecimiento y desarrollo. Se asume el yoga como una actividad que posibilita el desarrollo de las capacidades físicas, socio-afectivas e intelectuales, facilitando y propiciando en forma integral el proceso educativo.

No solo se trata de un espacio de tranquilidad, sino que además persigue explorar en el niño una serie de elementos que contribuyan de manera positiva en su desempeño académico y en el ambiente escolar (Flak y Coulon, 2001). Es una técnica para mejorar la convivencia escolar y la salud emocional y física de estudiantes y docentes, que apunta al interior del niño, a su propio ser, a la reflexión desde su yo interno sin presiones ni represión, e invita sutilmente a buscar la paz, a mejorar continuamente. Por supuesto, cuando hay esa paz interior, se exterioriza más amor y comprensión, que violencia o agresión.

Cuerpo. Es tanto elemento material de una persona como construcción cultural, exterioridad e interioridad: "El cuerpo realiza una cierta comprensión de la realidad (...) de conocimiento experiencial, antes de pasar por la mediación de las operaciones racionales", pero cuando pierde ese contacto vital con la realidad entonces:

resultados de encuesta auto-administrada" de Brenda Núñez, es un ejemplo de los buenos efectos del yoga.
Cae en la dispersión, en el desfallecimiento y en la enfermedad. De hecho, la corporeidad del hombre se expresa sobre todo a través de la energía vital o bioenergía del sentir; y los procesos somáticos y psíquicos son determinados por la acción de esta bioenergía" (Babolín, 2005, p. 66).

Se asimiló el cuerpo como evidencia material de una presencia humana a través de la cual se comprende el mundo gracias a las múltiples relaciones que posibilita con los demás, consigo mismo y con las cosas. En su forma verbal o no verbal, explícita o tácita, la violencia escolar está atravesada por el cuerpo:

La interacción violenta entre los niños y niñas escolares tiene un referente importante, y es la idea de cuerpo que ellos y ellas tienen. Esta interacción se manifiesta especialmente en la interacción espacial, en la interacción no verbal (intencional) y en el comportamiento verbal que muestran (Páez, 2009, p. 993).

Interacción violenta. Se denomina así a las acciones y relaciones donde las personas actúan imponiendo la fuerza, de manera obstinada, sin recurrir al diálogo ni a otras mediaciones. Aunque la interacción violenta de los niños puede relacionarse con la violencia externa a la escuela, se da principalmente por la ausencia de reconocimiento del cuerpo y de la palabra entre los pequeños y, por ende, por la impotencia para explicar aquello que evitaría un golpe o una ofensa (Páez, 2009). Esta interacción se asume como un uso deliberado y visible de los gestos corporales, de la fuerza

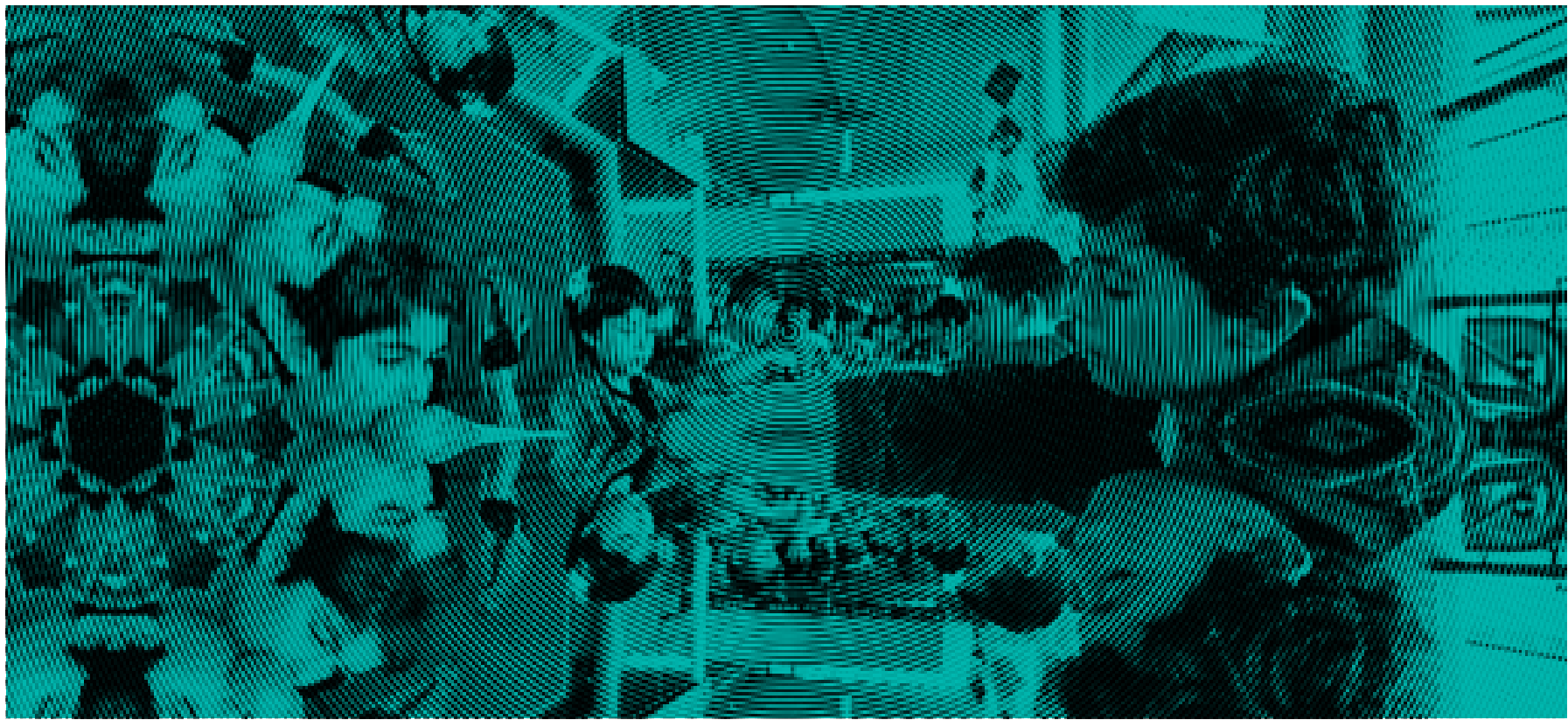


física o del cuerpo y/o del lenguaje verbal, que causa algún daño físico o psicológico en un compañero, que suele relacionarse con lo no visible, o la causa de dicha violencia (dureza, angustia, desprotección, inseguridad).

El niño como sujeto. El niño, como sujeto de la educación, representa para el educador un doble aspecto: "es nuevo en un mundo que le es extraño, y está en proceso de transformación", por ello es preciso pensar la educación como una tarea de "protección, de cuidado y de preservación de las posibilidades de nuevo comienzo que cada recién llegado contiene" (Bárcena, citado en Páez, 2009). Con el apoyo del maestro es posible conseguir un auto-reconocimiento de los niños, una situación que aminore sus temores e interacción violenta. El niño, como alguien a quien se le reconoce en su totalidad, se halla en un estado de formación más sensible que el de los adultos debido a su condición joven y abierta a lo nuevo. Para los menores, el yoga se constituye en una medicación protectora y de cuidado con experiencia novedosa con ellos.

\section{Metodología}

El método empleado en la investigación fue etnográfico, atendiendo a una perspectiva abductiva que permitió una interpretación más integral a partir de cuatro diarios de campo, fuentes bibliográficas, reflexiones de los investigadores y experiencia docente. Los niños involucrados fueron 90 . Se logró reconocer que sus modos de interacción violenta se experimentan por el cuerpo, que la comprensión de la experiencia de sí y del otro se da por el cuerpo, y que la experiencia del juego en niños y niñas es una posibilidad de formación en la interacción sin "violencia".

Para desarrollar el objetivo de la experiencia pedagógica Yoga, educación y vida, que consiste en favorecer la formación interna del niño, su reflexión y autoconocimiento, a través de la técnica del yoga como mecanismo pedagógico, para disminuir las relaciones violentas de los niños y mejorar la convivencia escolar, la metodología empleada fue el proyecto de aula. A partir de un proceso de indagación descriptivo-experimental se hizo una recolección de información acerca de la realidad en un grupo de 35 niños de segundo y tercero primaria del Colegio Técnico Distrital República de Guatemala.

Las condiciones básicas para su realización fueron: un docente que asuma el papel dinamizador en el proceso, constante, con una disciplina de trabajo y un propósito claro en cada sesión; un espacio físico apto (iluminado, aseado, ventilado); unos recursos (sonido, música, vestuario, colchonetas); y una estructura flexible

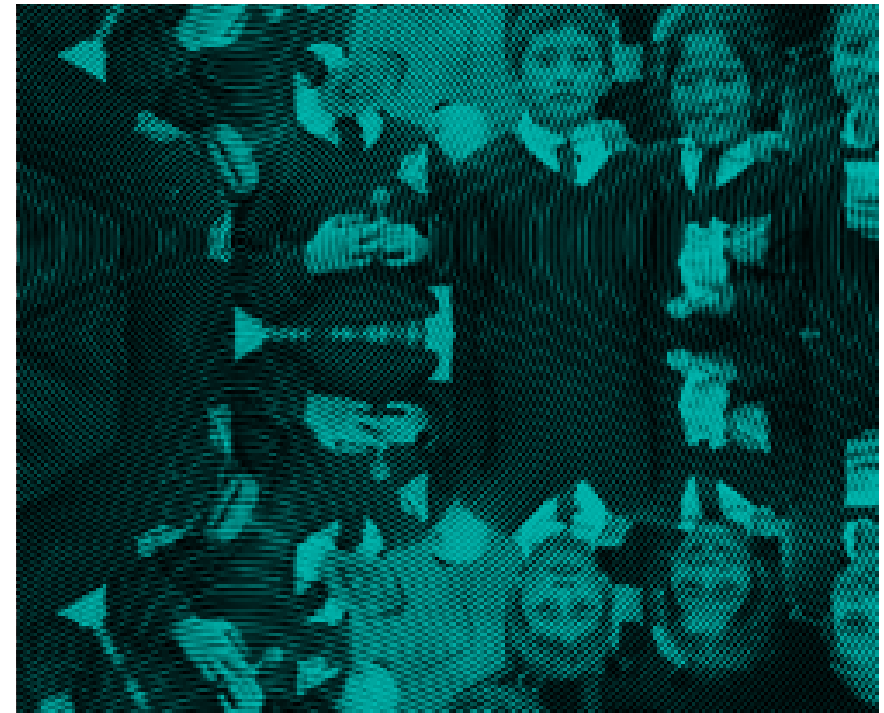

y organizada en fases. La proyección de la investigación, junto con la experiencia pedagógica como tal, permitieron concretar cuatro fases que fueron validadas con el grupo de 35 niños:

Fase exploratoria. Transcurrió durante el año 2010; se pretendió explorar nuevas formas de llegar a los niños para mejorar la "disciplina" del salón, luego de haber agotado otros recursos que funcionaban poco $^{8}$. En esta fase se empezaron a perfilar las posibles causas de ese comportamiento en los niños, el cual impedía el desarrollo normal de las clases, llegando a ratificar la necesidad de formalizar una propuesta poco convencional pero más adecuada a las necesidades reales del curso $2^{\circ}$ primaria y de la comunidad en general.

En ese año se hicieron las primeras prácticas de yoga para experimentar, ver qué reacción tendrían los niños de $2^{\circ}$ frente a una rutina diferente de ejercicios físicos, y probar si la violencia puede tener respuestas internas a partir de la propia corporalidad y no solo externas. Las sesiones se trabajaron de acuerdo a las necesidades del curso, sin una planeación estricta, obedeciendo a los momentos de mayor dificultad en la interacción de los niños y a la disponibilidad de los recursos. Se empezaron a ver los efectos

8 Tales como: llamadas de atención, verbales o escritas; anotaciones en el observador del alumno; citación y diálogo con los padres; seguimiento en protocolos de convivencia; remisión a coordinación y a comités de convivencia; sanciones; e incluso desescolarización en algunos casos. Estas técnicas ya no son significativas, en especial para aquellos niños que más necesitan ayuda, porque sus actitudes son demasiado "negativas" y agresivas, y muchas veces responden con más violencia ante estos correctivos. 
y así dejó de ser una actividad complementaria para convertirse en un proyecto de aula dentro del currículo escolar.

Fase de diseño y ejecución. Se trabajó en el año 2011 y giró alrededor de la recolección y procesamiento de la información, estudio de probabilidades y recursos, y montaje de la propuesta. Esto se hizo con la mayor sutileza posible, por tratar de vincular en el aula una técnica producto de una filosofía hindú, desconocida para muchos, con algunos tabúes de por medio y para una comunidad en la que hay una gran diversidad de convicciones religiosas y arraigo a las mismas.

De acuerdo con la mayor necesidad identificada en el curso, se buscaron la secuencia y las posturas de yoga más indicadas. La docente ajustó cuatro componentes básicos en todas las sesiones: oración, respiración, secuencia de ejercicios y relajación. De modo general, se trabajaron valores, movimientos, respiración y conocimiento del cuerpo, atendiendo los propios ritmos, pues en estas sesiones de yoga no hay mejores ni peores, ni notas, no se compite con el otro sino que se aprende y se progresa individualmente, con la presencia del grupo. La atención de la docente se centró especialmente en ocho niños con problemas de agresión constante, "hiperactividad" o comportamiento disruptivo en el aula, con el fin de hacer un mayor acompañamiento, observación y seguimiento (Tabla 1).

\section{Tabla 1. Ejemplo en síntesis de un registro de observación y seguimiento a los niños con interacción violenta}

\begin{tabular}{|c|c|c|c|c|c|c|}
\hline \multicolumn{7}{|c|}{ Registro de observación y seguimiento } \\
\hline Niño ${ }^{1}$ & $\begin{array}{c}\text { Sesión } 1 . \\
\text { Observación }\end{array}$ & $\begin{array}{c}\text { Sesión } 2 . \\
\text { Observación }\end{array}$ & $\begin{array}{l}\text { Sesión } 3 . \\
\text { Observación }\end{array}$ & $\begin{array}{l}\text { Sesión } 4 . \\
\text { Observación }\end{array}$ & $\begin{array}{l}\text { Sesión 5. Palabra } \\
\text { del niño con la que } \\
\text { relaciona el yoga }\end{array}$ & $\begin{array}{c}\text { Sesión 6. Gesto } \\
\text { particular }\end{array}$ \\
\hline Felipe & $\begin{array}{l}\text { Estuvo inquieto, } \\
\text { mirando al resto } \\
\text { de los niños, } \\
\text { se movió todo } \\
\text { el tiempo, se } \\
\text { le dificultó el } \\
\text { aquietamiento }\end{array}$ & $\begin{array}{l}\text { Al principio estuvo } \\
\text { pendiente de los } \\
\text { demás; poco a poco } \\
\text { se dejó llevar por la } \\
\text { música y entró en } \\
\text { "sintonía" con la } \\
\text { clase }\end{array}$ & \multirow{3}{*}{ 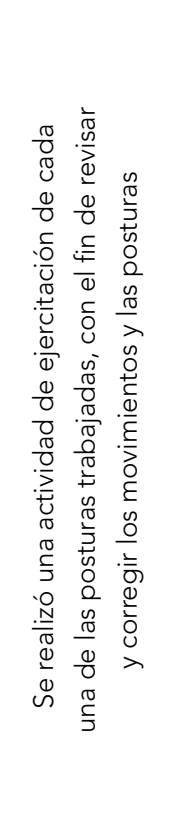 } & $\begin{array}{l}\text { Concentrado y muy } \\
\text { relajado }\end{array}$ & $\begin{array}{c}\text { "Paz" } \\
\text { "Felicidad" }\end{array}$ & Introspectivo \\
\hline Estefanía & $\begin{array}{l}\text { Su actitud fue } \\
\text { de ayudar a los } \\
\text { demás a hacer } \\
\text { los ejercicios y } \\
\text { de explicar los } \\
\text { movimientos }\end{array}$ & $\begin{array}{c}\text { Realiza } \\
\text { adecuadamente las } \\
\text { posturas, no se deja } \\
\text { interrumpir por ruidos } \\
\text { externos }\end{array}$ & & $\begin{array}{l}\text { Al finalizar la } \\
\text { meditación se } \\
\text { encontraba con } \\
\text { lágrimas en sus } \\
\text { ojos, pero en una } \\
\text { actitud más bien } \\
\text { de descanso }\end{array}$ & $\begin{array}{l}\text { "Descanso" } \\
\text { "Libertad" }\end{array}$ & $\begin{array}{l}\text { En actitud de } \\
\text { concentración, } \\
\text { en profundidad }\end{array}$ \\
\hline Fredy & $\begin{array}{l}\text { Concentrado, } \\
\text { dispuesto a } \\
\text { desarrollar } \\
\text { los ejercicios } \\
\text { sugeridos }\end{array}$ & $\begin{array}{c}\text { Su rostro permanece } \\
\text { relajado; parece } \\
\text { alegre }\end{array}$ & & $\begin{array}{l}\text { Parecía impaciente } \\
\text { y un poco tenso (su } \\
\text { ceño fruncido) }\end{array}$ & $\begin{array}{c}\text { "Moverse" } \\
\text { "Tener fe en uno } \\
\text { mismo" }\end{array}$ & Despreocupado \\
\hline
\end{tabular}




\begin{tabular}{|c|c|c|c|c|c|c|}
\hline \multicolumn{7}{|c|}{ Registro de observación y seguimiento } \\
\hline Leonardo & $\begin{array}{l}\text { Se movió mucho } \\
\text { durante la } \\
\text { sesión, buscando } \\
\text { quién lo estaría } \\
\text { mirando. } \\
\text { Interrumpió } \\
\text { con diferentes } \\
\text { comentarios }\end{array}$ & $\begin{array}{l}\text { Se quejó todo el } \\
\text { tiempo: "Me duele } \\
\text { aquí", "otra vez no", } \\
\text { "me cansé, ya no } \\
\text { más" }\end{array}$ & \multirow{5}{*}{ 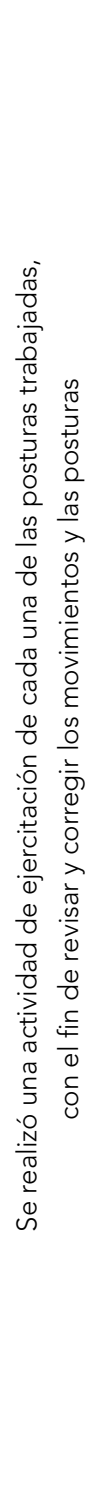 } & $\begin{array}{c}\text { Realizó la } \\
\text { secuencia en forma } \\
\text { correcta. Se le vio } \\
\text { muy sereno }\end{array}$ & Tranquilo & Casi dormía \\
\hline Brayan & $\begin{array}{l}\text { Se esforzó } \\
\text { bastante por } \\
\text { imitar los } \\
\text { movimientos. } \\
\text { Se notó gran } \\
\text { tensión en su } \\
\text { cuerpo }\end{array}$ & $\begin{array}{l}\text { Algo inquieto y con } \\
\text { varios momentos de } \\
\text { desconcentración }\end{array}$ & & $\begin{array}{l}\text { Se le ve muy } \\
\text { interesado, } \\
\text { se ubica en la } \\
\text { primera fila. Hoy } \\
\text { permaneció muy } \\
\text { atento y silencioso }\end{array}$ & & Relajado \\
\hline Edison & $\begin{array}{l}\text { Se observó } \\
\text { silencioso e } \\
\text { incómodo con } \\
\text { las posturas; } \\
\text { manifestó haber } \\
\text { sentido dolor }\end{array}$ & $\begin{array}{l}\text { Atento a las } \\
\text { indicaciones, } \\
\text { sin embargo se } \\
\text { preocupa mucho } \\
\text { por ejecutar bien los } \\
\text { movimientos, lo que } \\
\text { le hace cansarse }\end{array}$ & & $\begin{array}{l}\text { Le cuesta un poco } \\
\text { relajar el cuerpo. } \\
\text { Estuvo tranquilo } \\
\text { durante la sesión }\end{array}$ & "Tranquilo de paz" & $\begin{array}{l}\text { Relajado } \\
\text { Sonriente }\end{array}$ \\
\hline David & $\begin{array}{l}\text { Se le dificultó } \\
\text { ubicarse y } \\
\text { respirar. En la } \\
\text { parte final estuvo } \\
\text { tranquilo }\end{array}$ & $\begin{array}{l}\text { El primer momento } \\
\text { en que pude ver al } \\
\text { niño aquietado y en } \\
\text { silencio. Buen trabajo }\end{array}$ & & $\begin{array}{l}\text { Permaneció en } \\
\text { silencio durante } \\
\text { la meditación. } \\
\text { Ocasionalmente } \\
\text { abrió los ojos para } \\
\text { mirar a los demás }\end{array}$ & $\begin{array}{c}\text { "Armonía"; "Nadie } \\
\text { me molesta" }\end{array}$ & Silencioso \\
\hline Yeimy & & $\begin{array}{l}\text { Quiere relajarse, sin } \\
\text { embargo, se molesta } \\
\text { pues algunos ruidos } \\
\text { de los demás no la } \\
\text { dejan trabajar }\end{array}$ & & $\begin{array}{l}\text { Permaneció } \\
\text { sonriente, su } \\
\text { respiración muy } \\
\text { profunda y lenta, } \\
\text { casi llevada al } \\
\text { suspiro }\end{array}$ & $\begin{array}{l}\text { "Paciente" } \\
\text { "Feliz" }\end{array}$ & Sonriente \\
\hline
\end{tabular}

1. Los nombres de los niños se han cambiado.

Fuente: Páez, Nidya. Informe final del proyecto de aula, 2012

La docente encontró también que las secuencias de yoga propuestas por Villegas y Kent (2007) resultaban interesantes para los niños y para ella, pues se entrelazan fluidamente y apuntaban al desarrollo de valores y acciones específicas, por eso desarrolló: 
- Secuencia de la nobleza. Ayuda a calmar el sistema nervioso central; mientras se alarga y estira la columna, se fortalecen los músculos de las piernas; ayuda a despertar la nobleza que todos llevamos dentro y bajar la cabeza ante el corazón (algunas posturas: montaña, pinza, muñeca de trapo).

- Secuencia purificadora. Sirve para limpiar y purificar las toxinas que se acumulan y producen estrés, preocupaciones y tensión emocional; permite al cuerpo sentirse más ligero (posturas: mariposa, variación de la mariposa, mariposa de alas abiertas, mariposa relajada y pretzel).

- Secuencia del honor. Fortalece y activa los centros energéticos de todo el cuerpo, eleva la autoestima, el buen humor, la seguridad, la confianza y el aprecio por todas las cosas (posturas: montaña, estiramiento de cauchos, saludo al sol, pinza, corredor, plancha, cobra, perro, corredor, pinza, saludo, namasté).

- Secuencia de la armonía. Ideal para el equilibrio, fortalece los brazos y los muslos, ayuda a centrar el cuerpo y la mente y en la armonía y el balance de los dos hemisferios del cerebro (posturas: montaña en puntas de pies, árbol, media luna, mesa-plancha, montaña).

- Secuencia del té. De apertura, abre los sentidos, promueve la concentración, despereza el cuerpo, calienta la columna y los brazos, despierta la mente (postura: focalización de sentidos, himno de gratitud, meditación de la taza de té, círculos positivos, gato, bebé).

- Secuencia del héroe. Renueva las energías, ayuda a liberar sentimientos negativos; busca que se aprenda a derrotar el miedo a través del coraje, el valor y la decisión (posturas: toro fuerte, triángulo, el gran héroe, variación del gran héroe).

Fase de evaluación. Se entiende como retroalimentación (semestre 1 de 2012). A medida que se realizan las secuencias de yoga se hacen los registros de avances o dificultades que puedan presentar los niños, o las sesiones como tal. No se evalúa para juzgar, sino para ver en qué forma se aporta al objetivo de la sesión y al general, para conocer el grado de satisfacción de los niños y sus padres. La encuesta, entrevista, exposición y observación directa fueron instrumentos de evaluación.

\section{Resultados}

\section{Para la población beneficiada}

- Frente a otras actividades pedagógicas el momento del yoga fue uno de los preferidos por los niños porque no necesitan competir con sus compañeros, el yoga no está mediado por la calificación, se sienten libres y felices.

- Para los niños más agresivos o con mal comportamiento escolar es más difícil iniciarse en el yoga, les cuesta mucho silenciarse y aquietarse, pero son los más interesados en participar de la clase $y$, al cabo de unas seis sesiones, consiguieron mayor concentración.

- El contacto de los pies con el suelo y la colchoneta dio a los niños cierta sensación de libertad que les fascinó, condición que despertó mayor conciencia sobre el propio cuerpo, notándose una preocupación por estar limpios y aseados.

- El yoga impactó en otros aspectos de la vida de los niños, contribuyendo al desarrollo de la concentración, al pensamiento creativo y la memoria; al aumento del control sobre los procesos de pensamiento; la tranquilidad creciente y la capacidad para superar el estrés; fomentó la auto-comprensión, la auto- aceptación y el autoestima.

- A pesar de sus propias creencias religiosas, la acogida por parte de los padres fue positiva, y llegaron a expresarse en frases como: "ayuda al estímulo propio", "crea buenos hábitos", "ayuda a la concentración, comportamiento y buenos modales", "mi hija demuestra mucho interés por la clase, se siente feliz"; "mi hijo llega a la casa a enseñarnos yoga".

- En el grupo de los ocho 8 niños identificados con interacción violenta se observó una disminución significativa de la misma; algunos más rápidamente, pero todos mostraron progreso con respecto a cómo iniciaron. De todas maneras, el resultado no es inmediato, se necesita constancia y disciplina para ver todos los beneficios.

\section{En lo pedagógico}

A nivel pedagógico se hicieron tres aportes: el primero en el ámbito académico, con la inclusión de una programación de yoga para niños dentro del currículo escolar, lo que significó que se le entendiera como parte del trabajo pedagógico y no como una actividad anexa (tiene un espacio en el horario escolar). Dentro del plan curricular docente se estableció el yoga con un propósito, una metodología y un seguimiento. El segundo en el campo convivencial, por el desarrollo de una alternativa distinta que favoreció la transformación de unas prácticas escolares, sin recurrir a la presión, y donde el niño fue sintiendo la necesidad de estar en un ambiente armónico, lejos del ruido y la agresión. Con el yoga se consiguió poco a poco más tranquilidad, más quietud e interacción pacífica, lo que repercutió positivamente en la convivencia con los 
otros. El tercero, en el ámbito biológico, pues con esta experiencia se logró aumentar la capacidad física, desarrollar la flexibilidad, el equilibrio y la postura corporal, entre otros. También se creó mayor conciencia y conocimiento del cuerpo humano.

\section{En lo metodológico y didáctico}

A nivel metodológico se logró configurar una estrategia para reducir la violencia del niño con un trabajo desde su interioridad. A través del reconocimiento de su ser interior y físico, el niño fue consciente de su propio comportamiento gracias a la auto-reflexión y la autocorrección. Esto contrasta con estrategias desgastadas y con poca evolución, donde docentes y directivos suelen emplear técnicas externas como el señalamiento de errores, el uso de imperativos orales para dar órdenes, el uso de "protocolos de convivencia", y todo el seguimiento que se hace a los casos de violencia como reza en los manuales de convivencia.

\section{A nivel de la comunidad}

Por un lado, se dejan sentadas las bases para que la institución escolar aborde el problema de la interacción violenta, no solo desde lo externo, como lo ha venido haciendo, sino desde lo interno (referido al sí mismo, a las emociones, dolores, facultades y espiritualidad). Siempre será posible que, desde la educación, la comunidad escolar sea más pacífica, receptiva y abierta al conocimiento; estudiantes e hijos más serenos, centrados y saludables, contribuirán en la construcción social sin violencia.

Por otra parte, se dio la posibilidad de romper los esquemas tradicionales para afectar directamente el plan de estudios y la verdadera formación integral, implementando así una propuesta que encaja, por ejemplo, con la organización por ciclos escolares que inició en el 2009 en la ciudad de Bogotá. El yoga para niños no es una propuesta aislada o añadida, sino que puede desarrollarse desde dentro del colegio: es una maestra de aula quien lleva a cabo la labor, no una persona externa que carece de vínculos afectivos y que no cuenta con un conocimiento de las características de cada niño.

A nivel del docente, la experiencia con la técnica del yoga puede permitirle más serenidad, concentración y beneficios para su cuerpo y su espíritu. Bien es sabido que los maestros tienden a estresarse, lo que afecta su salud y su estado emocional. Si ellos están bien, sus alumnos también podrán estarlo. El sentirse más conectados con ellos mismos y con sus estudiantes ayudará significativamente a mejorar el ambiente escolar.

\section{Dificultades}

Al comienzo del proyecto de aula fue difícil enfrentar la carencia de colchonetas propias y para uso más frecuente, así como de un lugar acondicionado para esta actividad. La brecha entre lo administrativo y lo académico hizo que la docente dinamizadora interrumpiera la secuencia estructurada luego de dos años, debido a que se le asignó la dirección de un curso distinto al que tenía. Sería interesante considerar el componente cuantitativo en experiencias como esta, de modo que se puedan obtener resultados desde otro lenguaje.

En conclusión, el proceso educativo es interno, pero el comportamiento es externo y afecta las inclinaciones internas (Ponce, 2001). La interacción violenta escolar no puede verse solo desde lo exterior de las acciones y discursos de sus protagonistas; sin duda, el trabajo con la interioridad a través del yoga aporta enormemente en la disminución de dicha interacción. Desde el ámbito escolar hemos de considerar en serio que:

Cuando el ser humano cuando llega al mundo, no está terminado. La educación tiene por objetivo desarrollar sus potencialidades para llevarlo a la comprensión de su lugar en la tierra y de sus vínculos con el universo. La escuela no tiene por finalidad hacer de nosotros profesionales solamente, sino personas en evolución a lo largo de la vida (Flak, 1985). 


\section{Referencias}

Alcaldía Mayor de Bogotá. (2010). Acuerdo 434 de 2010: observatorio de convivencia escolar. Obtenido desde http://www.alcaldiabogota.gov.co/sisjur/normas/Norma1.jsp?i=3 9291

Babolín, S. (2005). Producción de sentido. Bogotá: Universidad Pedagógica Nacional, Ediciones San Pablo.

Flak, M., y Coulon, J. (1985). Niños que triunfan. El yoga en la escuela. Barcelona: Cuatro Vientos.

Gómez, N., Zurita, U., y López, S. (2013). La violencia escolar en México. México: Cal y Arena Ediciones.

Ministerio de Educación de Colombia. (1998). Lineamientos curriculares educación ética y valores humanos. Bogotá: Cooperativa Editorial Magisterio.

Ministerio de Educación de Colombia. (2002a). Lineamientos curriculares educación física, recreación y deporte. Bogotá: Cooperativa Editorial Magisterio.

Ministerio de Educación de Colombia. (2002b). Lineamientos curriculares educación artística. Bogotá: Cooperativa Editorial Magisterio.

Ministerio de Educación y Deportes. (s.f.). Observatorio argentino de violencia en las escuelas. Presentación. Obtenido desde http://www.me.gov.ar/ construccion/observatorio.html
Nuñez, B. (s.f.). Beneficios sobre la calidad de vida en personas que practican Sahaja Yoga. Estudio descriptivo en base a resultados de encuesta auto-administrada. Revista médica electrónica Portalesmedicos.com. Obtenido desde: http://www.revista-portalesmedicos.com/revista-medica/ beneficios-calidad-de-vida-sahaja-yoga/

Observatorio Internacional de Violencia Escolar (OIVE) (s.f.). Presentación. Obtenido desde http://www.ijvs.org/5-6346-Presentacion.php

Observatorio sobre la violencia y convivencia en la escuela. (s.f.). Inicio. Obtenido desde http://www.observatorioperu.com/

Ortega, R., y Blaya, C. (2006). El observatorio europeo de la violencia escolar. En Cuadernos de pedagogía, 359, 56-59.

Páez, N. (2012). Informe final del proyecto de aula: Yoga, educación y vida. Bogotá: Colegio República de Guatemala. Manuscrito no publicado.

Páez, R. (2009). Cuerpo reconocido: formación para la interacción sin violencia en la escuela primaria. Revista Latinoamericana de Ciencias Sociales, Niñezy Juventud, 7 (2), 989-1007.

Ponce, G. (2001). Introyoga. Santiago: Editorial Trineo.

Villegas, M., y Kent, J. (2007). Oomm. Yoga para niños. Bogotá: Villegas Editores. 


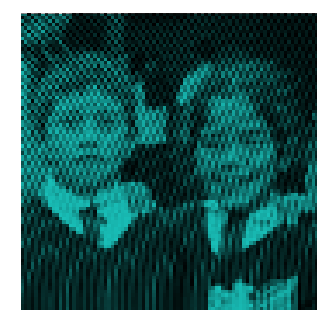




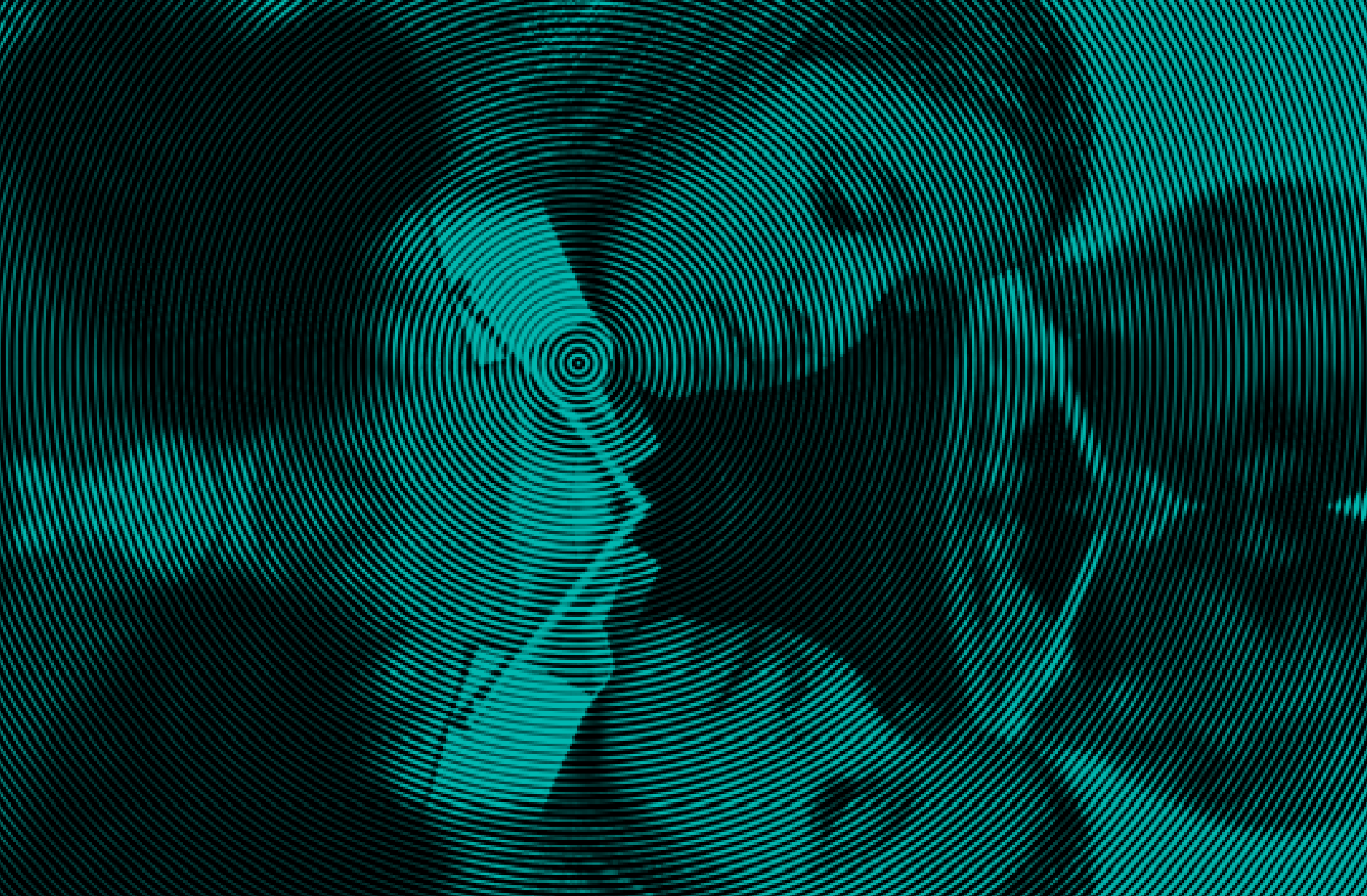

\section{Los aprendizajes no intencionados en la complejidad del ambiente escolar: asunto emergente y posibilitador de acciones para la paz}

Not-intentional learning in the complexity of school environment: An emerging matter and actions' facilitator towards peacebuilding

As aprendizagens não intencionadas na complexidade do ambiente escolar: Assunto emergente e possibilidade nas ações para a paz

James Frank Becerra Martínez Oscar Leonardo Cárdenas Forero María Anais Moncada Rodríguez Edith Constanza Negrete Soler Ángela Prieto Acuña Sonia Milena Uribe Garzón 
James Frank Becerra Martínez 1

Oscar Leonardo Cárdenas Forero 2

María Anais Moncada Rodríguez 3

Edith Constanza Negrete Soler 4 Ángela Prieto Acuña 5

Sonia Milena Uribe Garzón 6
1. Colegio Simón Rodríguez IED; Especialista en Pedagogía, Universidad Pedagógica Nacional; Correo electrónico: jafra8@hotmail.com

2. Colegio Entre Nubes S. O.; Magister en Desarrollo Educativo y Social, Universidad Pedagógica Nacional; Correo electrónico: osle1972@gmail.com

3. Colegio Gustavo Restrepo IED; Especialista en Multimedia para la Docencia, Universidad Cooperativa de Colombia; correo electrónico: anais.moncada@gmail.com

4. Colegio Inem Francisco de Paula Santander; Magíster en Enseñanza de las Ciencias Exactas y Naturales, Universidad Nacional de Colombia; correo electrónico: negretesoler@gmail.com

5. Colegio Antonio Baraya; Magister en Educación con Énfasis en Valores y Desarrollo Humano, Universidad Externado De Colombia; correo electrónico: angeis72@yahoo.es

6. Colegio Entre Nubes Sur Oriental; Especialista en Psicología Educativa, Universidad de la Sabana; correo electrónico:sonia.smug80@gmail.com

Maestros en Colectivo

Fecha de recepción: 18 de abril de 2016 / Fecha de aceptación: 16 de septiembre de 2016

\section{Resumen}

En las interacciones del ambiente escolar existen ciertos aprendizajes que no surgen necesariamente de los contenidos curriculares, actividades académicas o intenciones pedagógicas del maestro, sino que involucran formas de lenguaje, comportamientos, actitudes y expresiones no explícitas en esas gestiones, pero visibles en las dinámicas de convivencia de los estudiantes. Estas particulares formas de relacionarse suceden sin la mediación directa de la institución escolar, convirtiéndose en aprendizajes que revisten de gran importancia porque son marcadores de las relaciones de convivencia, potenciadores o inhibidores de los aprendizajes escolares y de los actos de paz en la escuela. Son ellos el punto de partida para el presente artículo.

Palabras clave: Aprendizajes no intencionados, ambiente escolar, interacciones, educación para la convivencia y la paz.

\section{Summary}

There are some interactions, some learning in the school environment that do not appear in relation with curriculum content, academic activities or teacher's pedagogical intentions, but also involve types of languages, behaviors, attitudes and expressions that are not explicit in these activities, but they become visible in the convivial dynamics of the students. These particular ways of relating happen without the direct mediation of the school, becoming learnings that line of great importance in extent that it seems that they are the market of convivial relations, enhancers or inhibitors of the school learning's and the actions to build peace at school.

Keywords: Not-intentional learning, school environment, interactions, peace and coexistence education.

\section{Resumo}

Nas interações que acontecem no ambient escolar, existem certos aprendizados que não necessariamente surgem em relação com os conteúdo currículares, atividades acadêmicas ou as intenções pedagógicas do professor; mas envolvem formas de linguagem, comportamentos, atitudes e expressões que não se encontram explícites nessas atividades, porém se tornam visíveis nas dinâmica de convívencia dos estudantes. Estes modos particulares de relacionarse acontecem sem a mediação directa da instituiçãs, de grande importância na medida em que aparentemente são eles marcadores das relações de convívio, potencializadores ou inibidores da aprendizagem escolar e do ação para a construção da paz na escola.

Palavras chave: Aprendizagens não intencionadas, ambiente escolar, interações, educação para a convivência e paz. 


\section{Presentación}

Una de las intenciones es exponer algunas reflexiones adelantadas por el grupo Maestros en colectivo ${ }^{7}$ alrededor de cómo, en el estudio de las dinámicas, interacciones y tendencias que caracterizan al ambiente escolar, entendido como ese entramado sistémico de actores, actividades y contextos que continuamente se enreda y deshila en el vaivén del tiempo y el espacio de los escenarios escolares, aparecen una serie de aprendizajes no intencionados por los maestros que, en gran medida, determinan, contribuyen y condicionan las maneras de ser sujeto, de relacionarse con los otros y de asumir los conocimientos escolares, y que en ocasiones permanecen dispersos e imperceptibles en el acontecer escolar y en el aula misma, pero que, contrario a ello, se deben considerar para adelantar procesos de formación subjetiva, acciones de paz y relaciones de convivencia distintas, acordes con los requerimientos contemporáneos.

Algunos aprendizajes suelen escapar no solo a las prácticas de enseñanza, sino a la rigurosidad del sistema, y afloran en cualquier momento por efecto de las interacciones que se suscitan entre los agentes escolares, manifestándose como simples preguntas o comportamientos individuales o colectivos que develan que a veces lo enseñado por el maestro trasciende a otros aprendizajes, no intencionales, pero que de igual manera influyen en la formación y en los modos de relación subjetiva.

Estos aprendizajes "no intencionados" (al escaparse la mayoría de veces del protocolo institucional y de la planeación de aula) revisten gran importancia, pues al parecer trascienden hasta la formación convivencial de los estudiantes y ponen en evidencia aquello que con más facilidad se aprende y, ante todo, lo que cautiva los intereses, la construcción de conocimientos y el desarrollo de habilidades y comportamientos en ellos. Entre esos aprendizajes no intencionados aparecen, por ejemplo, situaciones en las que los maestros buscan enseñar a resolver pacíficamente conflictos $y$, sin darse cuenta, lo hacen con acciones inconsistentes en las que se percibe agresión y empleo de la violencia, manifestándoles a los niños que los conflictos son un asunto relacionado con la agresión.

Es importante destacar que el quehacer en la escuela se basa principalmente en prácticas, acciones e intenciones de corte didáctico,

7 Colectivo de maestros de diferentes áreas e instituciones públicas que adelanta estudios e investigaciones alrededor de los Ambientes de Aprendizaje en el Aula, constituido por: María Gilma Acosta Rodríguez, Cristina Behrentz Pfalz, Juan José Garzón. pedagógico y metodológico, pero, sin embargo, en algunas situaciones los objetivos formulados de modo oficial y visible son trascendidos por un entramado de relaciones, saberes, costumbres, conocimientos, imaginarios, sentimientos, emociones, vivencias y conductas que permean el proceso educativo, tanto en su ambiente de mediación cultural como en las otras formas de construir ciudadanía, por la complejidad de las interacciones entre los actores escolares, viéndose afectados y condicionados hacia la incursión de ciertos aprendizajes no intencionados.

Lo anterior implica que, simultáneo a la apropiación y producción de saberes académicos, y en la formación para la convivencia, se desarrollan procesos conjuntos y articulados de socialización con los estudiantes que van más allá de lo que los maestros estructuran en las actividades de enseñanza en el aula, y les dinamizan desde actitudes que fortalecen las dinámicas de convivencia (los conflictos, las tensiones de carácter tribal, religioso, de género, racial, entre otras) desconocidas o no percibidas por el profesorado, olvidando aquello que acontece en relación con la experiencia de principios éticos y estéticos manifiestos en formas de ser, de actuar y de comprender el mundo por parte de los estudiantes, $\mathrm{y}$ que generan experiencias convivenciales colectivas que traspasan lo académico y trascienden en su formación personal.

Esta situación permite ver que al interior de la escuela se posibilitan una serie de aprendizajes vividos como comportamientos, actitudes, acciones, lenguajes y gestos que, a pesar de no ser intencionales para el docente en sus prácticas de enseñanza, intervienen en el proceso de formación académica y ciudadana de los estudiantes. Antes que ocultos, ese conjunto de aprendizajes e influencias hace parte de la cultura escolar, de la convivencia y de las interacciones de los actores escolares que, por alguna razón, pasan desapercibidos y no son reconocidos por no considerarles equivalentes a las actuaciones netamente académicas.

Sin embargo, ese conjunto de aprendizajes circula en las relaciones entre los sujetos y hacen parte de sus códigos, modos de comunicación, de producción de saberes, de interrelación y de construcción de identidad; asuntos fundamentales en la formación política, democrática, ciudadana y para la paz, que de no hacerse evidentes pueden formar subjetividades ajenas a las intenciones de la escuela y, por supuesto, a las apuestas contemporáneas de una sociedad pacífica, respetuosa, democrática y que reconoce la diversidad y la diferencia.

Reconocer estos otros aprendizajes no es sencillo, pero es necesario para dar cuenta de la complejidad de las relaciones subjetivas y, en especial, para aportar elementos de reflexión a la construcción 
de la paz desde la escuela, pues a pesar de estar latentes en su cotidianeidad, en las mentalidades e imaginarios de maestros y estudiantes, y de asumir la forma de ciertas rutinas, paradigmas y prácticas dogmáticas en el aula, condicionando la formación subjetiva y la manera de convivir y relacionarse con los otros, suelen no considerarse al momento de formular alternativas para estudiar las dinámicas convivenciales en la escuela. Si no se cuenta con estrategias para rastrear estos aprendizajes no intencionados, se considerarán solo un asunto de las dinámicas escolares, desconociendo que su reconocimiento es un acto de paz.

En este sentido, una de las estrategias para aproximarse al reconocimiento de los aprendizajes no intencionados, involucra considerar una serie de preguntas: ¿Qué es lo que realmente aprenden los estudiantes?; ¿por qué se aprende?; ¿para qué aprenden eso que aprenden?; ¿cómo es que la estructura biológica y emocional condiciona en determinado momento el aprender?; ¿qué impulsa o motiva a aprender?; ¿el aprendizaje existe en relación directa con el objeto de estudio, o está afectado por el contexto del educando?; ¿cómo aporta la escuela a los procesos de ciudadanía, en el reconocimiento y el respeto por el otro?

Cada una de estas preguntas permitirá a los maestros acercarse a la identificación de estos aprendizajes. Es más, ya en la escena escolar, por ejemplo las formas de organización de los estudiantes para abordar un objeto de estudio, los signos de regulación, actitudes, intereses y disposiciones frente al otro, al igual que las formas de lenguaje pluri-significativo, valores y patrones construidos individual y colectivamente, permiten percibir algunas respuestas a lo planteado que requieren de atención para ver este reconocimiento como un acto que aporta a la paz en el marco de la escuela.

\section{Los aprendizajes, un asunto también emocional}

A menudo, cuando se plantea la necesidad de reflexionar sobre el aprendizaje de los educandos, los maestros suelen hacer afirmaciones a partir de propuestas surgidas de algunas corrientes psicológicas que lo consideran como la captación de algo que es independiente a los sujetos. Sin embargo, pocos se han detenido a examinar que el aprendizaje es un proceso condicionado a la naturaleza y constitución biológica y emocional que poseen como seres vivos.

En este sentido, los sujetos son sistemas determinados con una estructura, y lo que pasa en determinado instante depende de dicha estructura en ese instante (Maturana, 1997), así, el aprendizaje no solo está sujeto al deseo y a la voluntad por saber, sino a aquello que como sistemas biológicos y emocionales nos afecta en determinado momento de la vida, por lo tanto, las personas son sistemas con una estructura de cambio continuo que se afecta y se transforma cotidianamente desde sus miradas y vivencias.

Como se observa, la emoción se convierte en un determinante del aprendizaje, el cual está condicionado por los estados anímicos de los niños y jóvenes, su interés y motivaciones internas y externas o su voluntad y deseo por saber y aprender. Son los estudiantes quienes, dependiendo de esa estructura en constante cambio, determinan qué contenidos culturales han de aprender, desde los puramente académicos, hasta los que son determinantes para desenvolverse en situaciones convivenciales, retadoras, conflictivas y de incertidumbre.

Lo que el estudiante aprende depende de él, de su emoción, de la relación que establezca con los otros y de su deseo, entonces, esta acción es mediada por su estructura interna y no solamente por aquello que procura el maestro para estimularla. Por lo tanto, el aprendizaje es condicionado por la actitud que se asume frente al estudio de algún fenómeno, por esa relación entre el objeto de estudio y la disposición interior.

Curiosamente en ciertas ocasiones los estudiantes no aprenden lo que determinan los propósitos e intenciones pedagógicas, sino aquello que impulsa la emoción o la relación que establecen con el otro, o particularmente lo que desean aprender, quizás "ese asunto" de alguna asignatura escolar que deben memorizar por un momento para luego reproducirlo como para "pasar". Aprenderán aquello que consideren relevante y necesario para sobrevivir con éxito en la escuela, no lo que venga exigido por las peculiaridades de la cultura escolar (Pérez, 1996).

En definitiva, el aprendizaje es totalmente opuesto a captar algo externo, depende de los estudiantes, de si estudian o abordan y posibilitan el conocimiento para solucionar situaciones problema y tomar decisiones. ¿Cómo determinar entonces, si un estudiante sabe o no sabe acerca de algo, si justo en el momento de la actividad escolar su estructura biológica y emocional no está dispuesta y en actitud de aprendizaje?; ¿realmente los estudiantes "no saben"?, ¿’ es que lo que el docente desea enseñar no es de su interés y por eso es innecesario?

Cada uno de estos interrogantes se convierte en punto de partida durante la discusión sobre qué es lo que verdaderamente se quiere que aprendan los educandos, en especial, cuando se enfrentan a una prueba de evaluación de su proceso de aprendizaje o de aquello que 
se cree que aprendieron. $\mathrm{Al}$ respecto, consideremos que lo se hace es escuchar al otro y decidir si éste sabe o no, en tanto satisfaga ciertas nociones respecto de lo que se escucha (Maturana, 1997).

En este sentido, conocer es una adscripción que uno le hace al otro cuando su conducta satisface el criterio de validez que se le da a lo que escucha. Lo cual implica que el aprendizaje es un fenómeno de transformación estructural en la convivencia, no solo de manera congruente se transforma al otro en su estructura, sino en relación con el medio, su historia y su postura, en cuanto a lo que le es benéfico de ello y lo que posiblemente esté en capacidad de obtener. Es por esto que los organismos no se adaptan al medio, sino que en interacción constante se transforman recíprocamente (Maturana, 1997).

Si el aprendizaje depende de cada sujeto, de sus necesidades, intereses, emociones y de aquello que en un momento determinado afecta su estructura biológica y emocional: ¿Es importante que el docente procure que aquello que desea enseñar llame la atención del sujeto, para lograr lo que Maturana denomina el cambio estructural de las personas en la convivencia?; ¿qué es aquello que aprenden los estudiantes y por qué aprenden?; ¿lo qué aprenden apunta a la dialéctica de construcción de conocimiento, o a la repetición de contenidos curriculares? Cuando dentro de sus criterios de evaluación un docente afirma que el estudiante no sabe: ¿A qué hace referencia?; ‘a que no memorizó y divulgó un concepto?; ¿a que no quiso hacer nada en su clase?; ¿a que a pesar de que lo intentó, no logró los niveles esperados? o ¿a que su interés y actitud no estuvieron centrados en la temática abordada por el docente?

Cuando se interroga a los estudiantes acerca de lo que aprenden en la escuela, extrañamente hacen referencia a conceptos de las áreas de conocimiento, pero: ¿es eso lo que realmente aprendieron?; ¿sirve acaso para sus vidas?, o tal vez no mencionan -o no logran divulgar porque no son conscientes de ello- lo que realmente aprenden de la escuela para su desempeño personal y social, y para la construcción de una sociedad democrática, plural y para la paz.

Cuando un niño o un joven ingresa a la escuela no es el mismo sujeto que termina el año escolar, no es el mismo después del descanso, de una clase o de una salida pedagógica, luego de ello es eso que aprende y que logra en la interacción, es el cambio en la estructura de su organismo como ser vivo lo que le invita a seguir transformándose y creando nuevos mundos y formas de relación para emprender acciones de paz. El aprendizaje es un fenómeno de transformación en la convivencia; el tipo de convivencia que se dé en los ambientes de aprendizaje, en el aula y en la escuela misma, favorece ciertas tendencias, comportamientos, procesos de ciudadanía y, por lo tanto, las actitudes y formación para la paz.

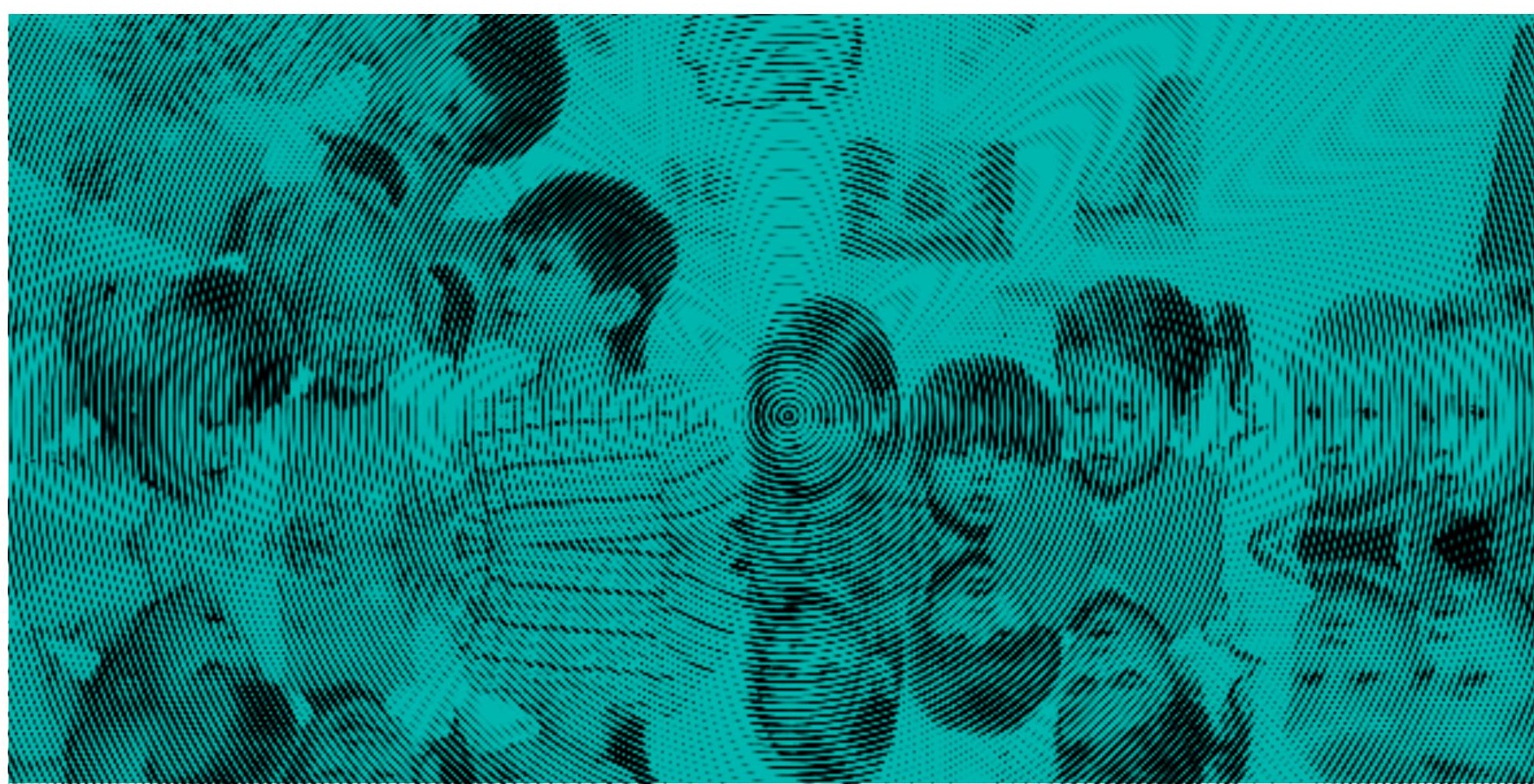




\section{Reconociendo los otros aprendizajes}

Volviendo a los planteamientos iniciales, mediante los discursos y prácticas explícitas e implícitas de los profesores, y de los demás miembros que conviven en la escuela, se logran ciertos aprendizajes, comportamientos, significados e imaginarios en los estudiantes, de los cuales no son plenamente conscientes pero que, sin embargo, hacen parte de la cultura escolar, de la convivencia y de la formación de los sujetos que constituirán una sociedad más equitativa, democrática, plural y pacífica.

En cada actividad escolar, izadas de bandera, festivales, foros, ferias, salidas pedagógicas, juegos, en los descansos, etc., se viven reglas y patrones comunicados explícita o implícitamente que, al no ser entendidos, llevan a los alumnos al riesgo de enfrentar sanciones, afectando no solo la forma de vincularse con el otro, sino las relaciones de convivencia que se establecen al interior de la institución y que transcienden a las esferas privadas y públicas.

De este modo, aquellos estudiantes que ingresan por primera vez a una institución escolar, por lo general se ven comprometidos a leer, validar, confrontar y asumir ciertos roles, comportamientos, lenguajes, pautas y aprendizajes para lograr su permanencia, reconocimiento $y$, ante todo, su validación como personas que pertenecen a un grupo particular; deben entender los discursos de sus profesores, escoger las respuestas y preguntas pertinentes, apropiadas, aceptables, participar en clase cuando el momento lo exija; de esta forma pueden acomodarse en el contexto del aula de clase, encajando, no corriendo el riesgo del rechazo, de la exclusión o la estigmatización

Mediante las interacciones, en especial las no verbales, con los adultos y, por tanto, con el profesorado, cualquier niño o niña comprende que si presta atención, y se preocupa por atender a lo que los demás realizan, puede ser el centro de interés de un adulto (Torres, 1996). Esto significa que si la escuela en su conjunto educa, los maestros lo hacen con sus actos, con ellos se convierten en modelos para seguir o para rechazar, pues algunos solo despiertan apatía y desinterés, y es en esta dinámica relacional que el aprendizaje se determina, en virtud de la emoción y del agrado por el docente o los mismos compañeros de curso; pensemos en ese curso al cual nos desagrada ir por los comportamientos de los estudiantes, eso es lo que invita a aprender.

No solo se educa con el discurso, también con la expresión, la vitalidad o desgano que se imprime a lo que se hace, con los gestos y actitudes. Inconscientemente el docente establece normas

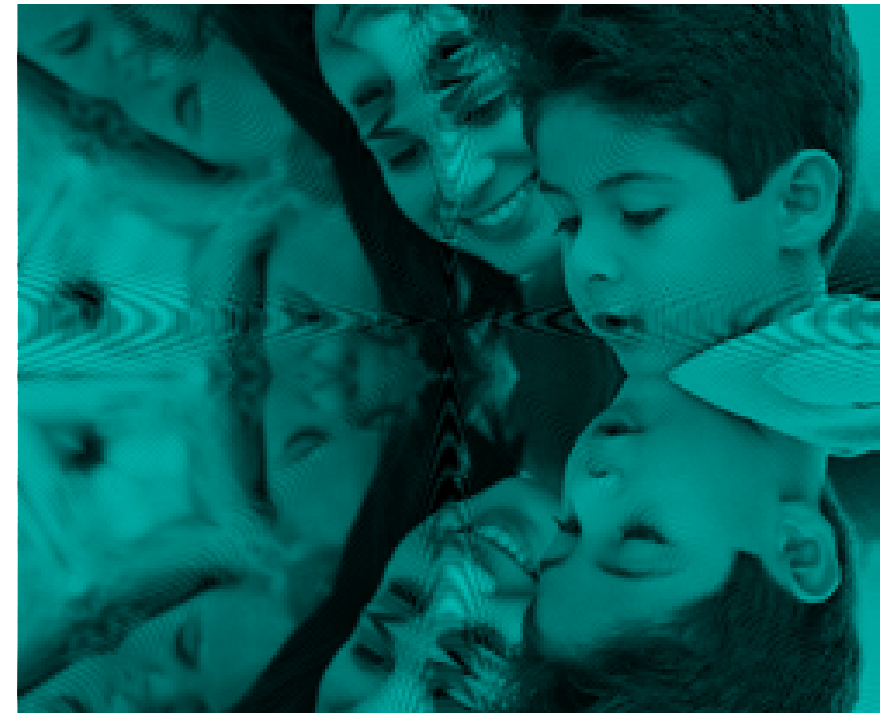

y patrones de comportamiento y son los estudiantes los primeros en evidenciar esa coherencia entre su discurso (teoría) y su actuación cotidiana (práctica). Es mediante la interacción social que se produce a diario la forma como se van construyendo los significados de los objetos y de las situaciones en las aulas, las subjetividades y las habilidades, conocimientos, valores, comportamientos, actitudes de convivencia y destrezas privilegiadas por la sociedad (Torres, 1996).

Sin embargo, aún persisten prácticas escolares que confirman formas particulares de relación con los niños, niñas y jóvenes, maneras de interacción que están condicionadas por la idea de un docente poseedor del conocimiento y unos estudiantes que necesitan aprender mediante la enseñanza de una serie de contenidos propios de las áreas. Ante esta situación queda la inquietud sobre los aprendizajes no intencionales del docente que fueron adquiridos por los alumnos.

Además de esos aprendizajes intencionales, relacionados con las asignaturas escolares, en los que los estudiantes construyen sus formas particulares de representar el conocimiento, de comprender y relacionarse con el mundo, hay otros que son inherentes a la convivencia y a la socialización humana, en los que se aprenden actitudes, normas, comportamientos, lenguajes y gestos que condicionan su interacción con nosotros (maestros y/o directivos) y con el entorno, escolar y extra-escolar.

Estos otros aprendizajes, pedagógicamente hacen parte de la cultura escolar y, en ocasiones, generan en los estudiantes actitudes que los definen como sujetos con capacidades excesivamente 


\section{Referencias}

Apple, M. (1995). Educación y poder. Barcelona: Paidós.

Cazden, C. (1991). La interacción entre iguales: procesos cognoscitivos. El discurso en el aula. El lenguaje de la enseñanza y el aprendizaje. Barcelona: Paidós.

Maestros en Colectivo. (2006). Ambientes de aprendizaje en el aula. Bogotá: IDEP.

Maturana, H., y Varela, F. (1997). El sentido de lo humano. Chile: Dolmen.

Ministerio de Educación Nacional (MEN). (1998). Lineamientos curriculares en Educación Ética y Valores Humanos. Bogotá: MEN.
Pérez, Á. (1996). La cultura escolar en la sociedad neoliberal. Málaga: Morata.

Segura, D. (2002). La enseñanza de las ciencias en Colombia. Revista Innovación y Ciencia, Vol. X. No. 3-4. Bogotá.

Suárez, R. (1994). Educación y sociedad. La educación. Bogotá: Trillas.

Torres, J. (1996). El curriculo oculto. Madrid: Morata.

Trilla, J. (1993). La escuela y el medio. Una reconstrucción sobre el contorno de la institución escolar. Barcelona: Ariel. 



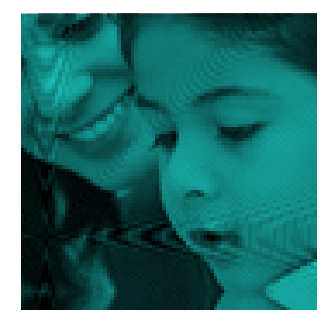




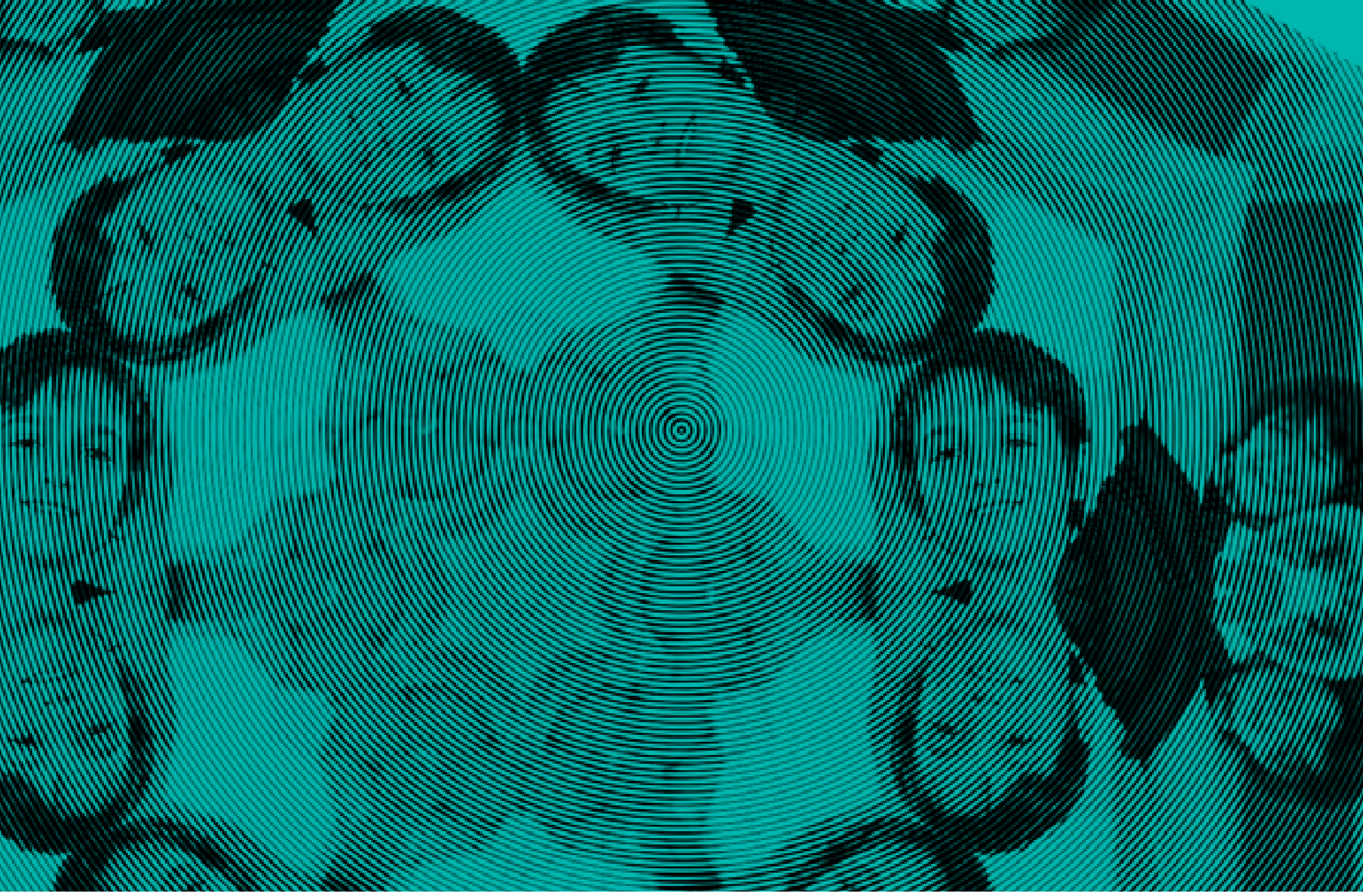

\section{Tras bambalinas. Un momento para la reflexión. Importancia de la recuperación de la memoria histórica y las masacres en Colombia a través del teatro}

Behind the scenes. A time for reflection. Importance of recovery of historical memory and massacres in Colombia through theater

Nos bastidores. Um tempo de reflexão. Importância da recuperação da memória histórica e massacres na Colômbia através do teatro 
Angélica María Valencia Murillo 1
1. Licenciada en Lingüística y Literatura de la Universidad Distrital Francisco José de Caldas; estudiante de la Maestría de Comunicación, Desarrollo y Cambio Social, Facultad de Comunicación social para la paz, Universidad Santo Tomás, inscrita en la línea de Comunicación, gobierno y ciudadanía. Docente de Lengua Castellana en el Colegio Veinte de Julio IED, Bogotá; Correo electrónico: angelicavalencia@usantotomas.edu.co
Fecha de recepción: 30 de marzo de 2016 / Fecha de aceptación: 16 de septiembre de 2016

\section{Resumen}

Esta reflexión es una propuesta que evidencia el papel formador de la escuela desde el teatro, entendido éste como expresión artística importante que fomenta procesos de recuperación de la memoria histórica de nuestro país, a partir de las representaciones artísticas y culturales sobre las masacres perpetradas desde comienzos del siglo XX hasta hoy. Se trata de una apuesta para vincular ciudadanos y ciudadanas que comprendan, denuncien y actúen frente a la violencia de nuestro país.

Palabras clave: Escuela, familia, teatro, memoria histórica, violencia.

\section{Summary}

This Reflection is a proposal that demonstrates the formative role of the school from the theater as an art form that promotes vital processes of recovery of historical memory of our country, from the artistic and cultural representations that exist on the massacres which have been perpetrated since the early twentieth century to today. Also it's a gamble to link citizens to understand, speak out and act against the phenomenon of violence in which our country is submerged.

Keywords: School, family, theater, historical memory and violence.

\section{Resumo}

Esta reflexão é uma proposta que demonstra o papel formativo da escola do teatro como uma forma de arte que promove processos vitais da recuperação da memória histórica do nosso país, a partir das representações artísticas e culturais que existem nos massacres que tenham sido perpetrados desde o início do século XX até hoje. Também é uma aposta para vincular os cidadãos de compreender, falar e agir contra o fenômeno da violência em que o nosso país está submerso.

Palavras chave: Escola, família, teatro, memória histórica e da violência. 
"El teatro es un arte que es capaz de representar lo que la sociedad tiene oculto. Permítanos hacerlo porque es una necesidad social demostrar, como lo estamos haciendo, con muchos otros y otras, que otro mundo mejor es posible".

Santiago García
Desde antes de nacer el ser humano está en constante interacción con su entorno, percibe diferentes estímulos y transmite sus sensaciones a su primogénito o primogénita, creándose así el primer vínculo comunicacional. En este intercambio de interacciones se configuran los múltiples lenguajes que cobran sentido en el momento del entendimiento, la comprensión y la interpretación que tiene uno del otro. En el camino para llegar al nacimiento continúa la carrera de conocer las nuevas y variadas maneras de acercamiento, no solo con el ser humano con quien se conecta a través del cordón umbilical, sino con varias personas que dejan a su disposición referentes importantes que conllevan aprendizajes.

En el nacimiento, dichos aprendizajes del ser humano van a depender de la interacción con el otro, de los constantes intercambios de experiencias con los sujetos y objetos de su entorno. En ese recorrido se comienzan a vivir colores, sabores, tamaños, texturas, entre otras experiencias importantes y trascendentales en la formación de quien empieza una nueva etapa de su vida. El punto de partida de este ser que comienza a integrarse a la sociedad va a depender en gran medida de la educación, teniendo en cuenta que:

El interés común de la familia y la escuela es el desarrollo de los niños y adolescentes. Y hablamos de desarrollo de manera expresa porque, si bien en la escuela el aprendizaje pareciera ser el asunto más importante, mientras en la familia lo son el afecto y la socialización, ambos le apuntan a ese proceso complejo y dinámico de crecimiento, cambio y avance continuo que caracteriza los seres humanos y que es crucial en el ciclo de vida de la niñez y la adolescencia (Isaza, 2012, p. 23).

Es así como estos contextos (familia/escuela) se convierten en eje fundamental de apropiación de relaciones de afecto para el progreso social, emocional, de pensamiento y acciones del ser humano; es decir, el desarrollo valorado en su complejidad de acuerdo con las demandas y capacidades de su edad. Dicho desarrollo debe tener en cuenta que la educación necesita de procesos que, si bien se vienen desplegando desde el vientre materno, fuera de este se interiorizan aún más en la comunicación con el otro, desde el diálogo y el compromiso que involucra su avance intelectual, cultural, artístico, político, etc.
Sin embargo, no se puede desconocer que todo campo en que se presente la comunicación debe ser aprehendido en el medio; este medio debe estar condicionado por la educación como eje principal de intercambio de experiencias que seguirán fomentando el gusto que los seres humanos tarde o temprano sienten por algo o algún sujeto u objeto en particular, que conlleva a estructurar planes, misiones, argumentos, ideas, y a generar una transformación del diario vivir, de hábitos, de costumbres, de memorias.

En este punto es importante resaltar que la memoria, como campo de recuerdos, de evocaciones, de imágenes relacionales con eventos, lugares, entre otros fenómenos que marcan las experiencias, es un recurso humano al alcance del momento y en algunos casos del lugar, puesto que se convierte en fuente esencial y de alimento para continuar o no en un estado quizá de lucidez, quizá de locura.

$\mathrm{Al}$ relacionar familia, escuela -educación- y memoria, surge una preocupación importante que lleva a analizar las orientaciones académicas y de formación en memoria histórica que hoy en día se trabajan en diferentes instituciones educativas de Colombia. En este sentido, el teatro y la educación en memoria histórica juegan un papel fundamental en los procesos de socialización, interpretación, argumentación y crítica de cada proceso escolar y extraescolar, que también incita a un trabajo de una memoria colectiva, una memoria llena de incidencias, permanencias y situaciones no vividas pero sí recordadas por un individuo que genera grupo, comunidad, localidad, región y país.

Trabajar sobre memoria histórica no es fácil y requiere que se replanteen momentos álgidos de la historia, instantes que puedan introducir a identificar sucesos que desencadenen la preocupación y la necesidad de querer saber más sobre dichos acontecimientos, que generen nuevas perspectivas de trabajo donde se deje de lado la indiferencia, la apatía, la falta de información veraz sobre las verdaderas formas en que acontecieron los hechos.

Es complejo desarrollar una serie de teorías que aplicadas al contexto educativo evidencien aprendizajes significativos, puesto que se requiere de bases conceptuales que lleven a la construcción de un tipo de conocimiento que no se quede solo en el campo de 
la identificación, sino que también apunte a la apropiación y participación ciudadana y fomente el cambio en la manera de pensar y reflexionar en torno a lo que sucede en Colombia. Para concebir esa sociedad con conciencia ciudadana se necesita conocer y reconocer, en la escuela, el impacto y la gravedad de las mútliples masacres perpetradas en el país, que han dejado huella no solo en el cuerpo, sino en el alma de quienes la viven.

En este sentido, Molano (2010) hace alusión a una exposición realizada en la Universidad Nacional en 2008 que recordaba los 80 años de la Masacre de las Bananeras, entendiéndola como un acto significativo de lucha por mantener la memoria de las masacres y la forma como éstas han hecho parte de un proceso de décadas, además de explicar la forma en que han sido determinadas por razones políticas, sociales y económicas:

[...] es un retazo poco claro [la masacre] del panorama de la historia social colombiana. Se inscribe en las luchas obrero-campesinas de principios del siglo XX en Colombia y se relaciona con el fortalecimiento del capitalismo a nivel mundial bajo la figura del establecimiento de industrias internacionales [para este caso particular, la empresa norteamericana United Fruit Company] que se dedica-

ban a la explotación agrícola de extensas zonas en Hispanoamérica.

Oropéndola-Arte \& Conflicto es un esfuerzo conjunto entre el Centro Nacional de Memoria Histórica, Verdad Abierta y la Fundación Ideas para la Paz, que se constituye como un portal Web que busca documentar, reunir y recuperar iniciativas artísticas de víctimas del conflicto armado y trabajos de artistas colombianos que, desde 1990 hasta la actualidad, han reflexionado sobre la violencia en el país. Este proceso de conflictos de la sociedad y todas sus instituciones precisa de un posicionamiento proactivo en la escuela, una mirada puesta en el compromiso por el sostenimiento de los valores éticos, que contribuya a construir una educación en la que el conocimiento sea un capital estratégico y valioso para el desarrollo de sujetos autónomos, con capacidad para la toma de decisiones, y a favorecer un sentido de vida personal y comunitario (Libertad y Zappino, 2012).

Abordar todo tipo de elementos de memoria histórica en Colombia sería un mega-proyecto ambicioso y enriquecedor; no obstante, la finalidad en este proceso de recolección de memoria histórica se centra en las distintas formas de trabajo de grupos culturales y artísticos que han presentado sus propuestas desde mediados del siglo XX hasta nuestros días, en torno a la concientización social sobre algunas masacres en el país, puesto que tales grupos tienen una voz de conciencia y protesta; Mélich y Duch (2005) lo plantean desde el aspecto de:
Seres históricos que tienen la libertad de acción para decidir y elegir [...], así que en esta tensión de lo histórico se busca hasta encontrar "puntos de apoyo" para sostener las experiencias positivas de lo conocido y saltar, de la confianza que nos dan las costumbres, a revisar lo conflictivo para decidir el cambio a partir de las situaciones nuevas o desconocidas. Sin desechar todo lo heredado, pues lo pasado es conveniente para dar comienzo a lo nuevo, que se proyecta en acciones mejoradas (p. 56).

El teatro, como una de las ramas del arte, será la base fundamental para desarrollar la memoria histórica, pues es en él los seres históricos recobran vida, resignificando sus experiencias; Cuervo (2011) comenta:

$\mathrm{El}$ arte promueve formas de pensar, emocionar, sentir y asumir el cuerpo, que transgreden, afectan, acontecen, nuestro pensamiento racionalizador, domesticado, dual, enajenado, excluyente, marcado por la unicidad-mismicidad y territorializado en la cultura patriarcal -de la guerra-. Las execrables acciones de supresión de lo humano: guerra, torturas, genocidios y todas las formas necrofilias, hacen señalar nuestra inhumana condición (p. 63).

De esta manera, el arte recobra significado a partir de los diferentes vínculos que establece con la historia; desde los sucesos que quedan plasmados en pinturas, esculturas, canciones, hasta pasar por la danza, el teatro y la música, entre otras manifestaciones que recrean realidades de la existencia humana. Al hablar de memoria y realidad Ordoñez (2011) dice:

Las interpretaciones de la realidad a través del arte son exquisitas y esa sensibilidad se tiene que potenciar, hecho que se puede propiciar desde la educación, desde la pedagogía de la liberación, de la autonomía, del pensamiento crítico y la representación de aquellas vivencias que marcan un hito para la propia historia existencia del ser, la historia del campo vivencial en donde se sumerge. No podemos perdernos en la historia dejando pasar lo que está sucediendo ahora, de las creaciones que nos son contemporáneas y que por lo mismo están muchísimo más cerca de la sensibilidad y de los referentes del alumnado (p. 81).

Desde diversos postulados que se hacen en educación, se debe entender el arte como la dimensión de exploración de las sensibilidades, de las emociones, de las representaciones que se interiorizan y luego se sumergen en un ciclo comunicacional con el otro. Tener en cuenta la formación artística en todos los ámbitos de crecimiento y desarrollo del ser humano es fundamental, puesto que dispone el alma y magnifica virtudes, diversifica defectos y otorga la capacidad de convivir en sociedad con la aceptación de sí mismo y del otro. Parafraseando a Vygotski, el arte puede llegar 
a transformar al individuo y las relaciones entre éste y la sociedad, gracias a que sus obras son piezas únicas, capaces de transmitir intensamente (1991).

$\mathrm{Al}$ tener en cuenta el teatro como una de las formas vivenciales del arte, se puede decir que, desde el aspecto social, sirve para relacionarnos con los demás en un sentido extenso: como los demás, y como lo otro que es digno de un respeto que el arte crea, defiende, apropia y critica. Así, desde el arte el papel del teatro centra su mirada en la comunicación creativa y en la recolección dialógica e histórica, puesto que en su largo proceso de consolidación aquello que hoy llamamos arte, sea escritura, sonido, movimiento, pintura o figura tridimensional, todo ha sido, en cada momento y para los pueblos que lo han visto nacer y desarrollarse, el más preciado legado de su creatividad, la memoria de sus hombres, la huella de identidad a la que difícilmente se renuncia sin correr el riesgo de desdibujarse (Ordoñez, 2011).

De tal suerte, en el teatro se propician conglomerados de historias, de figuras representativas que son palabra y, en la palabra, memoria; como dijo Aristóteles (1981): "el teatro, como arte, tiene una finalidad estética. Su función última sería, como planteaba, producir la catarsis (o liberación) de sentimientos y emociones (1981, p. 34); o bien, como planteaba Brecht (1998): "Construir un espacio para la diversión consciente" (p. 110). Aunque en algunos casos para el campo educativo se tiende a exagerar y omitir una de sus características importantes:

Se olvida con frecuencia que el teatro ha sido utilizado recurrentemente como un medio eficaz para difundir ideas, defender tesis o aleccionar grupos sociales. Durante la conquista y colonización de América, por ejemplo, el arte escénico jugó un papel importante en el adoctrinamiento y evangelización de los indígenas. En contraparte, las posibilidades didácticas fueron ampliamente utilizadas para exponer las ideas socialistas, tanto por Brecht y Picator, como por el nuevo teatro colombiano y latinoamericano (Pardo, 2011, p. 53).

Es este tipo de aspecto el que se quiere resaltar a partir de la visualización y representación del teatro, como manifestación artística de situaciones álgidas de nuestra historia, en particular de nuestro contexto colombiano, que pretende marcar la diferencia de la NO indiferencia, del rescate de las conciencias sociales; para este caso, de la recolección y recreación de la memoria histórica.

Para ser más cercanos al contexto colombiano y su interrelación con la memoria histórica y el teatro, es importante resaltar las palabras de un célebre dramaturgo que se ha caracterizado por evidenciar distintas posibilidades de conciencia social en este país, Santiago García (2012), quien afirma:

Nosotros, los hombres y mujeres de teatro colombiano, sabemos que es posible hablar de lo que nos duele y de lo que nos alegra y

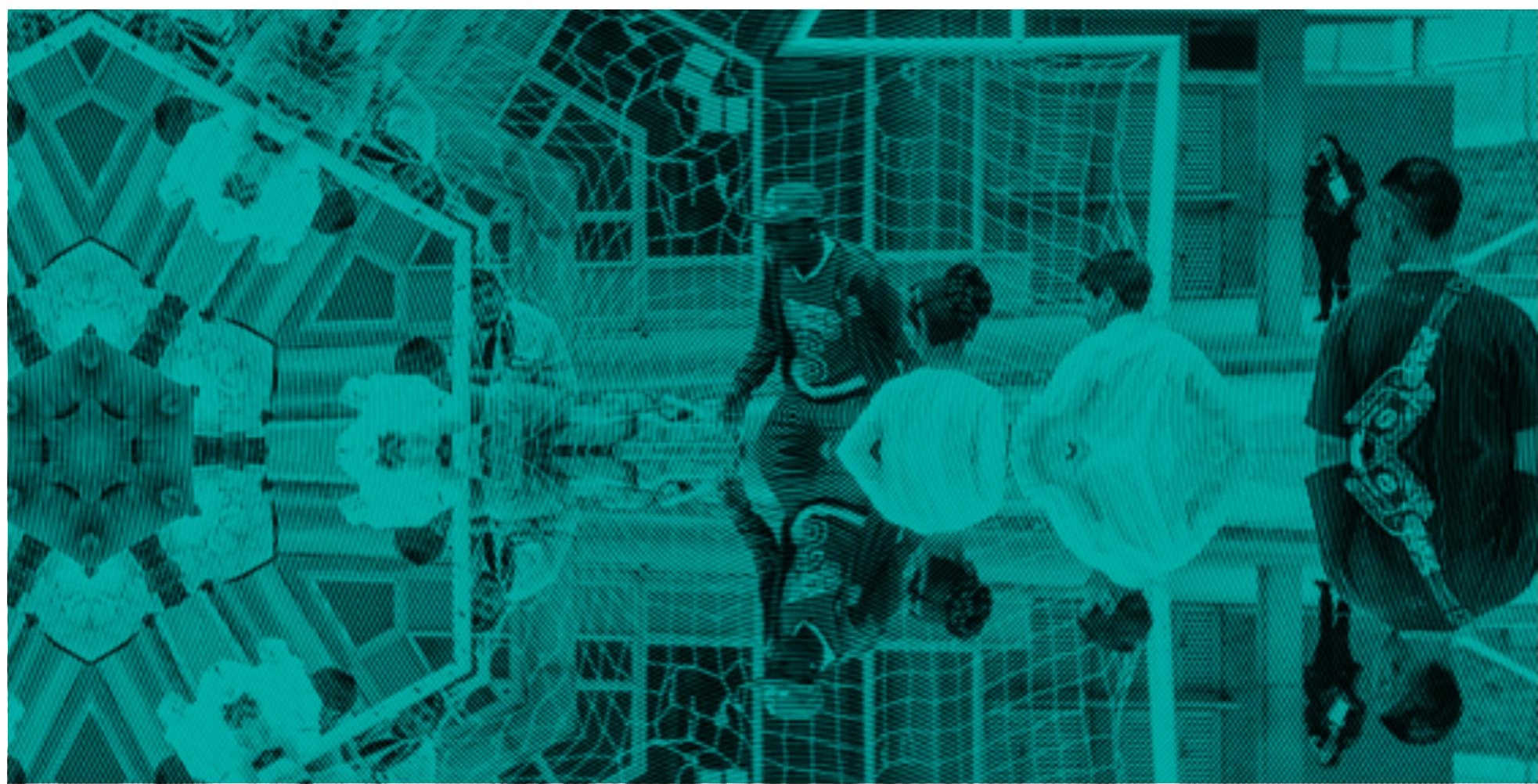


que también se puede, como en la escena, entender los conflictos. Lo sabemos porque hemos conformado grupos y públicos, hemos sabido convivir entre diferentes y hemos tramitado las divergencias en la creación, un lugar sagrado y misterioso que permite recrear la vida y por lo tanto contribuir a transformarla.

Desde esta perspectiva, el espacio de teatro ha generado procesos de trabajo y reconocimiento sobre quiénes somos, de dónde vienen nuestros conflictos, cuál es nuestro papel como ciudadanos en esta sociedad y cuáles son las transformaciones vivenciales y cotidianas que se quieren en nuestro propio contexto. Como dice García (2012):

El teatro es un arte que es capaz de representar lo que la sociedad tiene oculto. Permítanos hacerlo porque es una necesidad social demostrar, como lo estamos haciendo, con muchos otros y otras, que otro mundo mejor es posible. Los hombres y mujeres se hicieron verdaderamente humanos cuando empezaron a celebrar la vida y a conservar la memoria. Cuando entendieron que vivir era ir más allá de buscar comida y abrigo. Y cuando comprendieron que se hacían mejores personas si celebraban lo bueno de la existencia y compartían la memoria.

Somos parte de un momento histórico, de una corriente de niños, jóvenes, adultos y viejos que deben cambiar las situaciones que se viven a nivel político, económico y cultural; pero, ¿̇en qué instante empiezan estas palabras a pertenecer a un grupo, a un colectivo de personas comprometidas con su familia, colegio, barrio, ciudad o país? Estas palabras no se pueden quedar solo en ideas sueltas, panfletos que desarrollan argumentos válidos pero impensables para realizar, las palabras deben trascender a la acción, deben narrar sucesos que han sido resultados de grandes cambios, de revoluciones; la palabra cobra vida en la importancia del relato, del relato que es representación y de la representación que se convierte en transformación.

Es entonces cuando nace la necesidad de narrar y con ella el arte de representar. Un arte que tiene el don especial e irreductible de la presencia humana. Ese don está en el teatro y hace que unas personas arriesguen su vida narrando con su cuerpo y con su vOz ante otras para desentrañar los misterios de la existencia humana (García, 2012).

Experimentar la memoria a partir de la tradición oral, del relato que cobra vida en el recuerdo, en la evocación, en la tensión entre el pasado y el presente, hace que cada ser partícipe de este proceso experimente emociones, conmociones y sentimientos que lo confronten con su propia humanidad y la del otro, con su realidad y la de los demás.

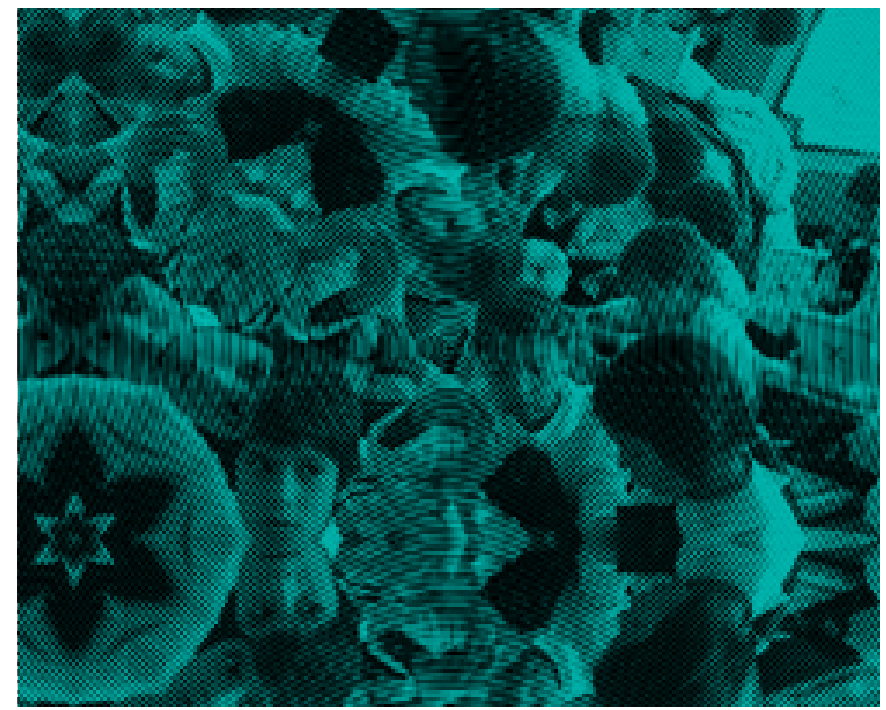

¿Cómo discernir en una práctica teatral la presencia de la memoria? ¿Acaso los procesos de memoria, la activación de los recuerdos y reminiscencias no están siempre en el accionar humano? La memoria es parte de nuestra vida, nos define, nos ayuda a clasificar, catalogar, emitir juicios de valor, actuar, etc. Es decir, que no podemos desconocer que la memoria siempre está presente, porque no es algo externo a nosotros, vivimos y actuamos con ella todo el tiempo. Y esta presencia de la memoria adquiere relevancia en las relaciones sociales, ya que sin memoria no puede haber acuerdo o convención posible entre las personas, no puede haber vínculo (Candau, 2002, p.75).

Siguiendo con la relación familia educación y memoria ${ }^{2}$, si partimos de la idea de que la memoria está siempre presente en las relaciones sociales, esto significa que también atañe a cualquier práctica humana, incluido el teatro. De ahí cobra validez la idea de que con el teatro se produce una repetición de situaciones cotidianas que están en la memoria de los protagonistas y de los espectadores, para relacionar al teatro con la memoria. En este sentido, el teatro funcionaría como un "simulacro del proceso cultural e histórico mismo", lo que permitiría a la sociedad tener registros de sus propias acciones. Es decir, sería como un depósito cultural que está sujeto a cambios y transformaciones, en la medida en

2 En este caso la familia continúa en el proceso educativo, como agente que acompaña estos procesos y tiene el importante rol de establecer vínculos de colaboración y participación creativa en las distintas etapas de su hijo o hija. 
que depende de los recuerdos, mutables en contextos y situaciones históricas diferentes (Carlson 2009).

Concebir una educación que propicie manifestaciones artísticas como el teatro, que fomenta la recolección y re-creación de la memoria histórica, hace a este tipo de formación un diálogo que crea, libera y conciencia; como afirma Freire (1972):

El diálogo es un requisito existencial cuyo fundamento es el amor por el mundo y por los hombres, y está basado en la reflexión y la acción de los sujetos implicados. El diálogo es un acto de creación que puede ser utilizado por un sujeto como un instrumento para conquistar al otro, sin que ello represente la subordinación de un sujeto a otro (p. 65).

Así, la práctica educativa dialógica propuesta por Freire (1972), favorece el desarrollo de prácticas educativas que tienen el propósito de superar el ciclo dominante de la educación bancaria, para llegar a una educación donde el proceso educativo se centra en el grupo de acción de los sujetos capaces de interactuar y de comunicarse en permanente colaboración. Siguiendo a este autor en Pedagogía de la Autonomía. Saberes necesarios para la práctica educativa, es vital resaltar que las relaciones educación, teatro y memoria, imprimen un carácter especial a la forma de trabajar y establecer conocimientos viables y accesibles para los y las estudiantes como sujetos históricos.
Saber de la Historia como posibilidad y no como determinación. El mundo no es, el mundo está siendo. Mi papel en el mundo como subjetividad curiosa, inteligente, interferidora, con que dialécticamente me relaciono, no es solo de quien constata lo que ocurre, sino también el de quien interviene como sujeto de ocurrencias. No soy solo objeto de la Historia, sino que soy igualmente su sujeto. En el mundo de la historia, de la cultura, de la política, compruebo, no para adaptarme, sino para cambiar (Freire, 1997, p. 75).

Es evidente que en el campo educativo las transformaciones se tienen que propiciar a partir de la participación activa y consciente de los principales agentes, a quienes se quiere orientar y no adoctrinar; sin embargo, estas transformaciones de y desde su entorno son posibles a partir del reconocimiento de la memoria histórica de su país, de su región, de su ciudad, de su colegio, de su familia, teniendo en cuenta las interacciones en el aprendizaje con el otro como ser comunicacional que ve su pasado y presente en el arte, y en especial en el teatro, como fuente y herramienta de inspiración y expiración de sus sentimientos y representaciones de sus propios saberes con relación a su contexto, a su localidad, a su ciudad, a su región, a su país. 


\section{Referencias}

Aristóteles. (1981). Poética. Madrid: Gredos.

Boal, Augusto. (1974). Teatro del Oprimido. Obtenido desde http://ebiblioteca.org/?/ver/83431

Brecht, B. (1998). El pequeño Organón. Revista Conjunto. La Habana, p. 110.

Candau, J. (2002). Antropología de la memoria. Buenos Aires: Ediciones Nueva Visión.

Carlson, M. (2009). El teatro como máquina de la memoria. Los fantasmas de la escena. Buenos Aires: Ediciones Arte del Sur.

Cuervo Mondragón, I. (2011). Cuerpo con Sentido: Hacia una pedagogía poética. Revista Internacional Magisterio. Educación y Pedagogía (49).

Freire, P. (1997). Pedagogía de la Autonomía - Saberes necesarios para la práctica educativa. México: Siglo XXI.

Freire, P. (1972). Pedagogia del Oprimido. Buenos Aires: Siglo XXI, Argentina Editores.

García, S. (s.f.). Palabras del Maestro Santiago García, dramaturgo y director, fundador del Teatro la Candelaria en el Día Internacional del Teatro, al ser acreditado por la Unesco como Embajador Mundial del Teatro. Le Monde Diplomatique Colombia. Obtenido desde http://www.eldiplo.info
Isaza, L. (2012). La relación Familia-Escuela. Revista Internacional. Educación y Pedagogía Magisterio (55).

Libertad, M. I., y Zappino, L. (2012). Familia-Escuela: un binomio inseparable cuando se habla de educación hoy. Revista Internacional Magisterio. Educación y Pedagogía (55).

Mélich, J., y Duch, L. (2005). Escenarios de la corporeidad. Madrid: Trotta.

Molano. (2010). La memoria de las masacres como alternativa para construir cultura politica en Colombia. Trabajo presentado en el Seminario Educación, Cultura Política y Proyecto de Nación en América Latina: Aproximaciones Históricas. Buenos Aires. Argentina.

Ordoñez Castro, S. P. (2011). El arte como hermenéutica social y cultural. Entrevista con Richard Huerta. Revista Internacional Magisterio. Educación y Pedagogía (49).

Pardo, J. M. (2011, Marzo-Abril). El teatro en el escenario pedagógico. Revista Internacional Magisterio. Educación y Pedagogía, (49), p. 53.

Revista Arcadia. Santiago García: Embajador mundial del Teatro. (2012-Marzo 8). Obtenido desde http://www.revistaarcadia.com

Vygotski, L. (1991). Zona de desarrollo Próximo. Madrid: Gredos. 



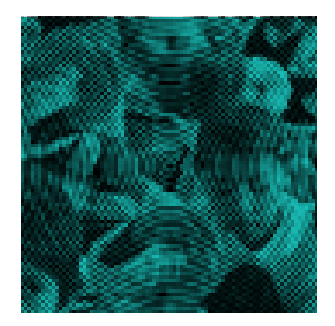




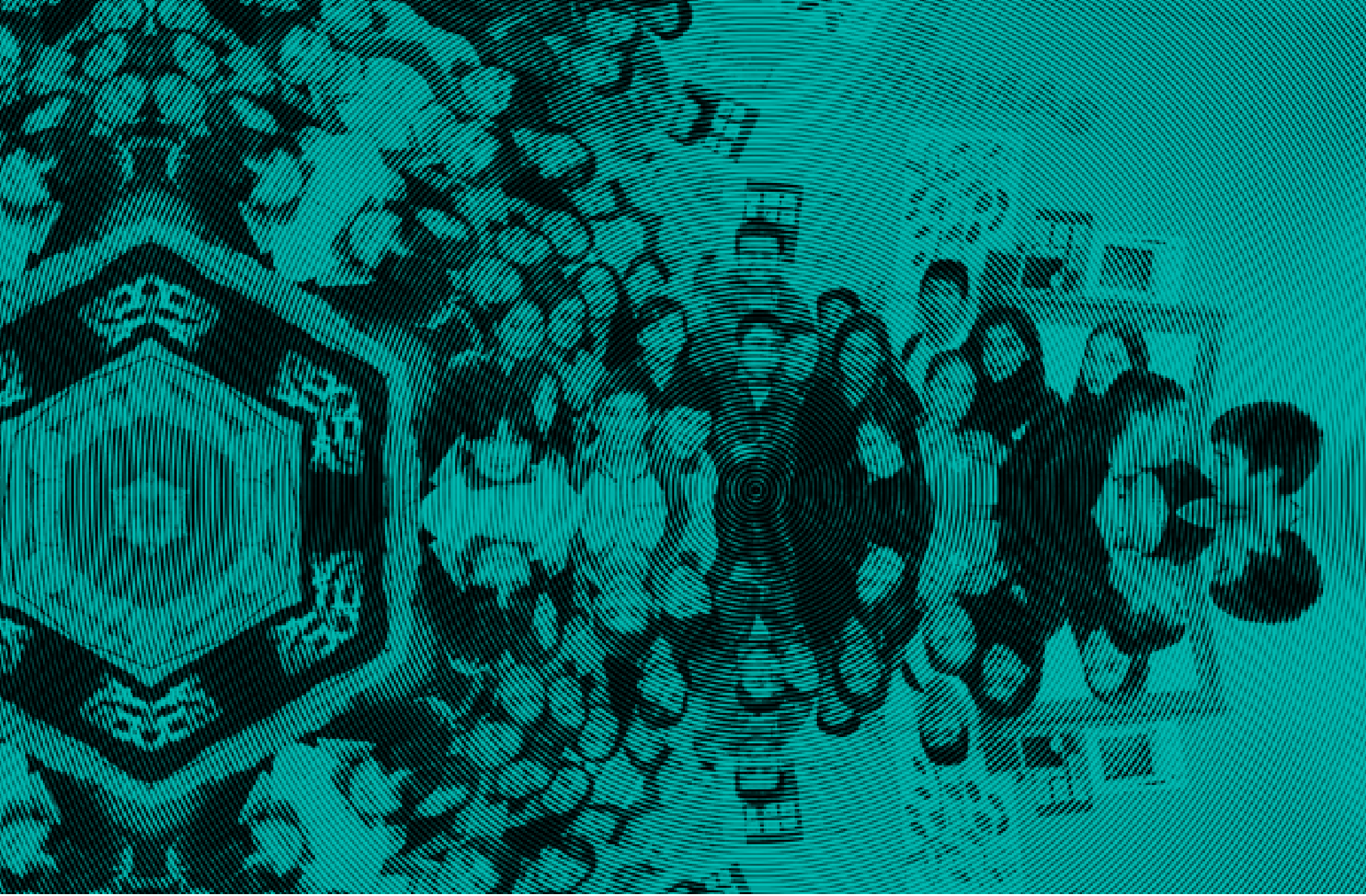

\section{Otra escuela es posible: subjetividades políticas y retos en el post-acuerdo}

Another school institucion is possible: political subjectivities and pos agreement challenges

Outra escola é possível: subjetividades políticas e desafios no pos acordo

Giordano Alvarado Silva Diana Beltrán Bermeo Enrique Blanco García Yesid González Perdomo Javier lbagón Martín 


\section{Giordano Alvarado Silva 1 \\ Diana Beltrán Bermeo 2 \\ Enrique Blanco García 3 \\ Yesid González Perdomo 4 \\ Javier Ibagón Martín 5}

1. Magister en Educación, Tesis Meritoria UPN. Especialista en Gerencia de Proyectos Educativos UDFJC. Licenciado en Lingüística y Literatura UDFJC. Actualmente es docente de planta de la Secretaría de Educación de Bogotá y profesor de medio tiempo de la Escuela de Medios para el desarrollo de la Facultad de Comunicación de Uniminuto; correo electrónico: giordhano@gmail.com

2. Magíster en Filosofía Latinoamericana, Universidad Santo Tomás. Licenciada en Educación Básica con Énfasis en Ciencias Sociales, UDFJ. Educadora popular con el Colectivo Libremente. Actualmente es docente de la Secretaría de Educación de Bogotá y profesora catedrática de la Iberoamericana; correo electrónico: anaidsoc@hotmail.com

3. Magister en Desarrollo Educativo y Social CINDE-UPN, candidato a Magíster en Filosofía Latinoamericana, Universidad Santo Tomás. Educador popular con el colectivo Libremente. Investigador asistente, Universidad Santo Tomás, Facultad de Sociología, grupo Conflictos Sociales, Género y Territorios. Docente de la Secretaría de Educación de Bogotá; correo electrónico: morambo2@gmail.com

4. Magíster en Educación, UPN. Licenciado en Educación Básica con Énfasis en Ciencias Sociales, UDFJ. Docente de la Secretaría de Educación de Bogotá y profesor catedrático e integrante del eje de paz de la UPN, activista sindical; correo electrónico: yesidgonzalezperdomo@gmail.com

5. Magíster en Historia, Pontificia Universidad Javeriana. Realiza sus estudios de doctorado en Ciencias de la Educación en la Universidad de Buenos Aires, Argentina. Docente de la Secretaría de Educación de Bogotá y Coordinador de investigaciones de la Facultad de Educación de la Universidad La Gran Colombia. Integrante del grupo de investigación Educación y Pedagogía (UGC); correo electrónico: goyobraudel@yahoo.com.ar

Fecha de recepción: 18 de abril de 2016 / Fecha de aceptación: 16 de septiembre de 2016

\section{Resumen}

El artículo analiza cinco experiencias pedagógicas desarrolladas en colegios públicos de Bogotá, las cuales reflexionan el conflicto armado, la otredad y los Derechos Humanos, con el fin de transformar las subjetividades políticas de los estudiantes. Realizadas independientemente, vienen consolidándose a través de la Red de Docentes Investigadores del Distrito (Nodo Ciudadanía). Las propuestas comparten el lenguaje artístico como posibilidad de emancipación ontológica y crítica social, necesaria en un país que prepara la finalización del conflicto armado y tiene la responsabilidad frente a los escenarios de confrontación que aún quedan pendientes.

Palabras clave: Escuela, subjetividades políticas, pos acuerdo, otredad, Derechos Humanos, arte.

\section{Summary}

The article analyzes five educational experiences in public schools in Bogotá, which reflect on topics such as the armed conflict, otherness and human rights, with the purpose to transform students' political subjectivities. Developed independently, these have been consolidating through the researchers' network conformed by public school teachers (i.e. Citizenship node). The proposals share the artistic language as a possibility for ontological emancipation and social criticism necessary in a country that is preparing for the end of the armed conflict and the responsibility towards confrontation scenarios still pending to attend.

Keywords: School, political subjectivities, pos agreement, otherness, human rights, art.

\section{Resumo}

Ortigo analisa cinco experiências educacionais em escolas públicas em Bogotá, que refletem o conflito armado, alteridade e os direitos humanos, com o fin de transformar subjetividades políticas de estudantes; Feitas de forma independente, eles são consolidados através da Rede de Professores Pesquisadores do Distrito (Node Cidadania). As propostas compartilham a linguagem artística como possibilidade ontológica de emancipação e crítica social, necessário em um país que se prepara o fim do conflito armado e responsabilidade para com cenários de confrontação ainda pendentes.

Palavras chave: Escola, subjetividades políticas, pos acordo, alteridade, dereitos humanos, arte. 


\section{A manera de introducción}

El presente texto enuncia cinco experiencias que, desde distintos contextos escolares, han venido desarrollando dos tareas fundamentales en la emergencia de la escuela hoy. En primera instancia, están abordando sus prácticas pedagógicas a partir de la experimentación que surge en los procesos de creación y el arte; mientras, al tiempo, piensan en las maneras como se legitiman otros lugares donde también se construye conocimiento. En segundo lugar, se plantean la necesidad de pensar acciones concretas de trabajo colaborativo que permitan visibilizar, fortalecer y conocer dichas experiencias a partir del trabajo en red, en tanto que no solo no están fuera de los posibles escenarios de paz planteados en las negociaciones de La Habana, sino que abordan esta coyuntura histórica desde una perspectiva que media la participación política y la reivindicación de los Derechos Humanos en la escuela.

Desde esta perspectiva, es importante mencionar que las 5 experiencias desarrolladas en este artículo buscan transformar las subjetividades políticas ${ }^{6}$ de sus estudiantes, agenciando mecanismos y estrategias que, desde las expresiones artísticas, construyen lugares posibles para abordar el conflicto armado, la otredad y los Derechos Humanos. En esa medida, visibilizar y conocer estos ejercicios de construcción de ciudadanía (que llevan un trabajo sostenido muy anterior al inicio de los diálogos de paz en Colombia y la promulgación de las leyes que reglamentan su enseñanza: Ley de víctimas y restitución de tierras y la Cátedra para la paz), significa reconocer el papel que ha tenido la escuela y los procesos de enseñanza-aprendizaje a los cuales se ven abocados los maestros y maestras que trabajan en el sector público y privado del país.

A pesar de que las experiencias son muy diversas en términos del abordaje metodológico, acercamiento teórico y producción de contenidos desarrollados por los estudiantes, sí es posible reconocer convergencias en sus intenciones, en última instancia, se trata del motor que ha llevado a escribir este artículo, que parten precisamente de imaginar que las acciones desarrolladas en la escuela, en términos de investigación educativa, tienen una apuesta política que no ha sido visibilizada y que, de manera legalista, se proponen en ejercicios como la Cátedra para la paz y la Ley de víctimas.

Desde esta perspectiva, es la Ley de víctimas la que permite dar un giro a la forma de abordar los temas relacionados con el conflicto armado y la paz, cuando invoca el deber del Estado en la reparación y garantía de no repetición, y propicia condiciones para que la sociedad en su conjunto pueda realizar ejercicios de construcción del pasado. Ahora bien, la Cátedra de la paz, promulgada por Ley 1732 del 1 septiembre del 2014, también interviene en esta tarea, al trazarse como objetivo el fortalecimiento de una cultura de la paz a través de las instituciones educativas.

Teniendo en cuenta lo anterior, es posible relacionar la gestación de las 5 experiencias a partir de realidades específicas identificadas por cada docente en su comunidad educativa. Sin embargo, el espacio académico abierto en la Red Distrital de Docentes Investigadores del Distrito, y más específicamente el Nodo de Ciudadanía, ha permitido establecer un trabajo que busca articularse y que se proyecta para visibilizar dichas prácticas como formas de resistencias a las posturas epistemológicas hegemónicas.

De esta manera, se puede entender la institución escolar desde la pérdida de su protagonismo frente a otros actores en torno al acto educativo (Gvirtz, Abregú y Grinberg, 2007), fundamentalmente en lo que concierne a la enseñanza del conflicto, donde la postura simplista y superficial de los medios masivos de comunicación se impone en la interiorización que desarrollan los estudiantes frente al mismo (Márquez, 2009); esto obliga a la escuela a enfrentar con innovación y compromiso la posibilidad de un país que está a las puertas del fin de una guerra que parecía interminable.

Así pues, podemos inferir que muchas experiencias innovadoras en las aulas de la capital y del país son respuestas anónimas a las actuales exigencias de proyectos que respondan a las negociaciones en La Habana. Sería prudente que tanto las secretarías de educación como el MEN realizarán trabajos para potenciar y sistematizar dichas experiencias, con el objetivo de facilitar el camino que en términos educativos tenemos que recorrer.

\section{Las experiencias}

De esta manera, el trabajo se ha desarrollado en 5 instituciones educativas oficiales de 4 localidades distintas en la ciudad de Bogotá, a continuación se presenta brevemente cada una de ellas:

6 Entendemos por subjetividad política: “aquella manera de estar y de actuar en la organización de su comunidad y de situarse ante ella y ante su organización y administración" (Cristancho, 2012, pp. 9-12). 


\section{Bivokonviviendo ${ }^{7}$}

El proyecto es una iniciativa encaminada hacia la formación en Derechos Humanos y construcción de ciudadanía en el Colegio Kennedy de la Localidad Octava, sus planteamientos se orientan hacia la realización del Foro anual de Derechos Humanos y a la publicación de la revista Ocio para pensar, data del año 2004, cuando se realizó un sondeo entre la comunidad educativa para analizar el conocimiento y la práctica de los Derechos Humanos, con unos resultados no tan satisfactorios.

En primer lugar, no se evidenció una apropiación, promoción y defensa de los Derechos Humanos en los miembros de la comunidad, ni mucho menos un conocimiento de organizaciones e instituciones gubernamentales, o no, que los promuevan y los defiendan; además se presenta un marcado olvido de casos emblemáticos o recurrentes de violación de Derechos Humanos en la comunidad, la ciudad y el país.

Esta problemática impulsó a un grupo de estudiantes, docentes, madres, padres y administrativos, a realizar un primer Foro titulado: "Derechos Humanos y Formación Ciudadana". El comité organizador recogió el trabajo propuesto desde la labor interdisciplinar en las aulas, destacando ponencias en torno a los imaginarios sociales de la comunidad y sus problemáticas, cerrando con un manifiesto de acciones que debía desarrollar la comunidad para mejorar la interiorización y práctica de los Derechos Humanos dentro y fuera de la institución educativa.

Vale la pena mencionar que el proyecto Bivokonviviendo ha realizado el foro de manera ininterrumpida hasta el presente año, con la participación destacada de víctimas, académicos, defensores de Derechos Humanos, funcionarios públicos, integrantes de comunidades educativas de otros colegios y, por supuesto, miembros de la comunidad educativa del colegio Kennedy IED. De la misma manera, cabe resaltar que durante los últimos 3 años las temáticas abordadas por el foro y la revista giraron en torno a la

7 La palabra Bivokonviviendo se construye haciendo alusión al griego Bios (Borisonik y Beresñak, 2012), que nos indica vida activa y defensa de la misma, el rechazo a cualquier agresión a partir de la construcción de elementos y métodos para su cuidado, desde lo individual hasta lo colectivo. La siguiente palabra es "konviviendo", término que manifiesta convivencia y respeto por la diferencia; se desarrolla en nuestra comunidad educativa, que está atravesada por tensas situaciones cotidianas, que dependen en su mayoría de los contextos sociales problémicos de los integrantes de la institución. Se escribe con la letra K por la cimentación de nuestra identidad y memoria, porque nuestro colegio acoge el apellido del asesinado Presidente de los Estados Unidos John F. Kennedy. paz y el conflicto armado, como un aporte más en la construcción de una sociedad incluyente y sin guerra.

Para el año 2010 el proyecto puso en marcha un medio de expresión y difusión, este trabajo llevó al nacimiento de la revista Ocio para pensar, una publicación llena de esperanzas y sueños que recoge las vivencias, experiencias, producción académica y éxitos de un proyecto que se consolida cada año como una manifestación alternativa, de una comunidad preocupada por la solución de las principales problemáticas del país.

\section{¿Qué tienes en la mente? Narrativas contemporáneas, prácticas artísticas y configuración de la subjetividad en jóvenes}

Este trabajo recoge la experiencia artística y audiovisual de un grupo de jóvenes que participa en el proyecto de comunicación y medios escolares del Colegio Nueva Delhi de la localidad cuarta, los cuales han encontrado en las prácticas artísticas nuevas maneras de asumir el sentido y su subjetividad. Más allá de sistematizar una experiencia, el ejercicio está encaminado a redimensionar los procesos de investigación educativa, en tanto que no solo se trata de procesos que se interesan por indagar marcos metodológicos, pedagógicos o conceptuales, sino que, incluyendo eso, también dan un lugar preponderante a la idea de la creación como un escenario donde también se construye el conocimiento.

Así, además de hacer un análisis de cómo las sociedades han configurado el sentido a lo largo de la historia (desde el mito hasta las industrias mediáticas contemporáneas), este trabajo busca conectar otros caminos y sistemas simbólicos que persisten en los procesos de enseñanza-aprendizaje. Bajo este panorama, se emplea la investigación-creación como una herramienta metodológica que permite explorar el interés, de los y las jóvenes, por el impacto de los desarrollos tecnológicos en la vida cotidiana y las maneras en que las prácticas artísticas contribuyen a construir otras formas de entender las relaciones y significados que se tiene de uno mismo y del territorio.

En efecto, esta experiencia plantea la idea de dimensionar de otro modo el papel de lo mediático en el mundo actual, y el papel de las prácticas artísticas en la configuración de los sujetos y la subjetividad. Lenguajes sonoros, plásticos y/o audiovisuales, buscan experimentar otros sistemas de representación, donde los sujetos ya no solamente se limitan a observar las producciones hechas por las industrias culturales, sino que asumen en las prácticas del arte un rol distinto dentro de la producción de nuevas maneras de narrar el mundo en el que viven. 
El proyecto de comunicación “¿Qué tienes en la mente?” es el producto de una investigación -creación que, desde 2011, ha planteado la idea de la producción de contenidos hechos por los estudiantes como un escenario de construcción de sentido. De la misma manera, año tras año se desarrolla el festival de comunicación escolar, donde se dan a conocer los trabajos hechos por los estudiantes en los diferentes lenguajes artísticos, así como la participación en convocatorias distritales con la $\mathrm{SED}^{8}$. Este trabajo asume los procesos de creación como lugares donde se construye conocimiento, porque al igual que la ciencia: "la actividad artística (...) fabrica imágenes, objetos e ideas sobre lo real" (Laiglesia, 2008).

\section{Deconstruyendo alteridades: hacia el reconocimiento histórico de lo(s) otro(s)}

A partir del reconocimiento de la alteridad como base sustantiva de procesos formativos tendientes al fortalecimiento de una cultura de paz en la escuela, desde hace dos años se viene desarrollando

8 Producción de Cortometraje de ficción en Mi Edu en Serie, en alianza con el Canal Capital y la Secretaría de Educación del Distrito. Participación en La NETT (Nuestras Escuelas Transforman Territorios), en alianza con Señal Colombia y la Secretaría de Educación del Distrito; nominada a los premios India Catalina 2016 como Mejor Programa Juvenil. un proyecto de aula con estudiantes de básica secundaria y media del Colegio Clemencia de Caycedo IED, ubicado en la localidad dieciocho, que busca identificar silencios, omisiones y "encubrimientos" (Dussel, 1994) en los discursos oficiales acerca de la historia de Colombia.

En este sentido, la iniciativa "Deconstruyendo alteridades: hacia el reconocimiento histórico de lo otro", se ha centrado en establecer escenarios escolares de discusión que propendan por la identificación de discursos y prácticas hegemónicas desde las cuales, en medio de los diversos procesos históricos de estructuración de una identidad nacional homogénea, se ha "inventado al otro" en Colombia (Castro-Gómez, 1993) negándolo y estereotipándolo.

Dicho ejercicio crítico se considera fundamental en contextos socio-políticos en los que el tema de la paz se ha configurado como un eje transversal para estructurar un horizonte de país, ya que los procesos de reconciliación que se buscan desarrollar en el presente deben estar estructurados desde la revisión y re-significación de un pasado que, discursivamente, ha servido para excluir y marginar lo(s) otro(s).

Metodológicamente hablando la propuesta se ha cimentado en la investigación-acción, sustento que ha facilitado la construcción de ejercicios de reflexión crítica que continuamente se están replanteando por parte del docente y las estudiantes. En la primera fase se ha ubicado como eje central de discusión y análisis

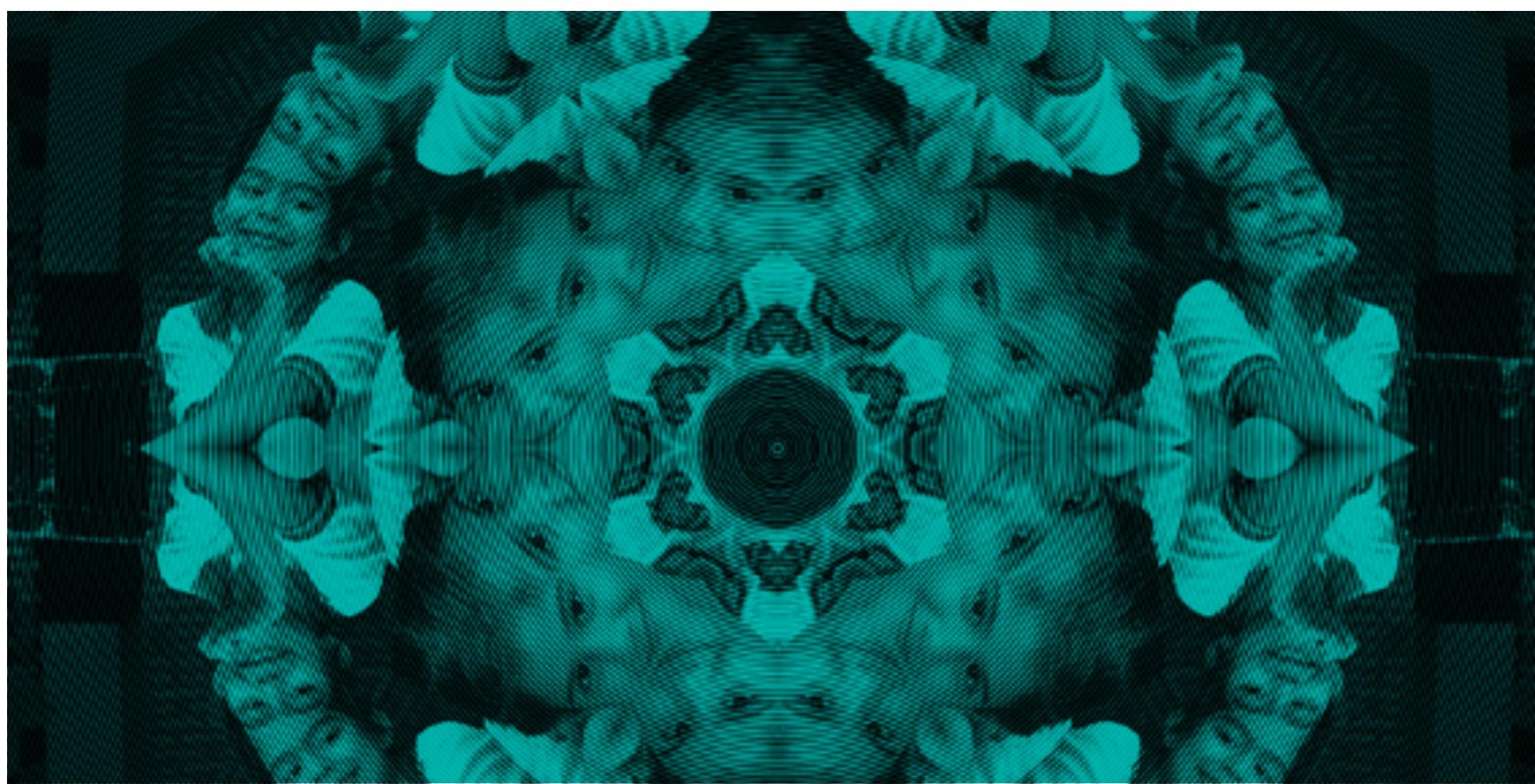


el problema de lo afrocolombiano, puesto que aunque indígenas, campesinos, mujeres y sectores populares hacen parte de los grupos que fueron negados sistemáticamente por la historia oficial, la matriz socio-cultural africana ha sido especialmente estereotipada e invisibilizada, configurándose como un "último otro" (Muteba, 2013) en la construcción narrativa de la historia del país y su posterior enseñanza.

A partir de este escenario de discusión las estudiantes han venido reconociendo críticamente otras voces y agencias, develando el discurso científico y político dominante. Crítica que se ha gestado a través del uso de diferentes lenguajes artísticos, entre los cuales cabe destacar: el teatro (adaptación de cuentos, construcción de guiones), la pintura (muestras itinerantes) y la música (recuperación de la tradición musical).

\section{Observatorio Escolar de Derechos Humanos (OEDHU)}

Este trabajo surge en 2012 en el Colegio Técnico Tomás Rueda Vargas IED, desde el área de ciencias sociales; durante este año se hizo una revisión bibliográfica, un ejercicio de diagnóstico con los estudiantes y varias reuniones entre los maestros autores de la propuesta, para indagar sobre la necesidad y pertinencia de la actividad. En 2013, con las "Iniciativas ciudadanas para la transformación de realidades", INCITAR, se presenta formalmente la propuesta, siendo evaluada y admitida. Durante 2014 y 2015 se dio el proceso de consolidación, realizando talleres, exposiciones, construcción de imágenes fotográficas, cortometrajes y una salida pedagógica al Centro de Memoria, Paz y Reconciliación. Dichas actividades produjeron un archivo que está en proceso de análisis y sistematización.

Esta experiencia se ha construido para atender la dificultad de visibilizar la práctica y el ejercicio real de los Derechos Humanos, evidenciada en las diferentes formas de violencia al interior del escenario escolar. El objetivo general es hacer visible el ejercicio y garantía de los DD.HH en la institución a partir de situaciones cotidianas. De esta forma, se identifican las prácticas sociales presentes en el currículo oculto, así como la formulación de instrumentos, alternativas y soluciones a las problemáticas presentes en el colegio y que podrían ser pensadas en espacios de integración curricular.

En primer lugar se busca poner en diálogo el paradigma de los DD.HH con la cotidianidad escolar, mediante un escenario que tenga como propósito la investigación de la realidad de los estudiantes y las múltiples expresiones de sus problemáticas. Este

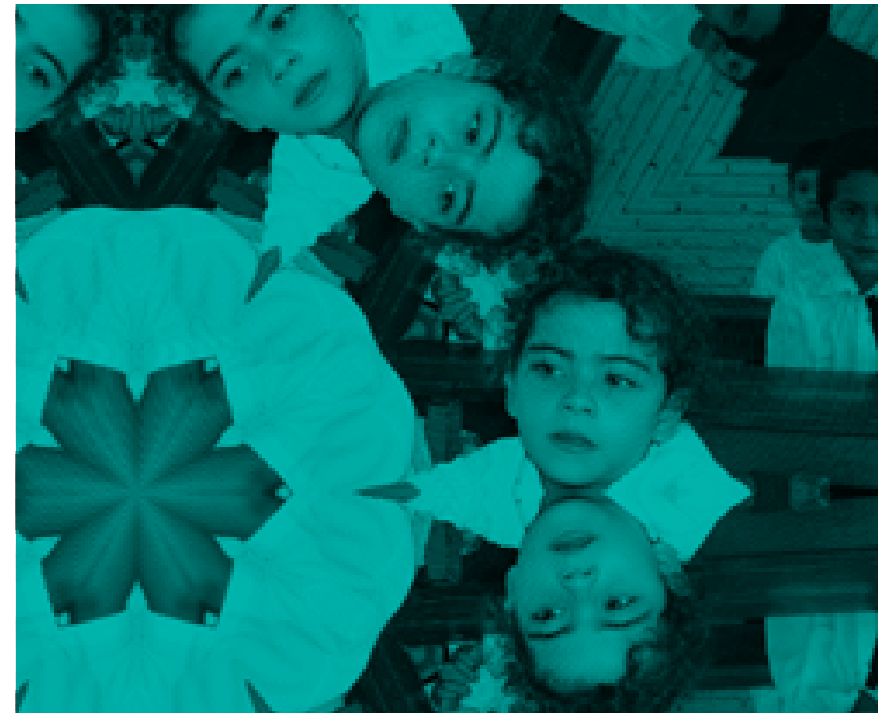

escenario se ha denominado "Observatorio Escolar de Derechos Humanos" O.E.D.H.U., y con él se busca responder la pregunta ¿Promueve el colegio la garantía y el goce pleno de los DD.HH? Los docentes y estudiantes son los encargados de planificar y organizar tiempos, actividades, resultados esperados y análisis de la información recolectada. Desde el observatorio se busca propiciar un diálogo ético, político y crítico que cuestione las relaciones sociales hegemónicas que configuran la subjetividad.

La propuesta filosófica de dialéctica del reconocimiento, la pregunta por el otro como compromiso ético y la pedagogía crítica como praxis política, fueron puestas en diálogo constante mediante una planeación que debe ser revisada y actualizada continuamente. El proyecto fue formulado tomando como discurso artístico y cultural a la fotografía, vista como herramienta de observación social y como posibilidad de producción creativa emancipadora. Si las funciones básicas de un observatorio son la observación y la intervención social, la imagen fotográfica es el dispositivo de captura de dicha realidad; Barthes, Eco, Lefebvre, Giddens, entre otros, alimentan conceptos como cotidianidad, recuerdo y representación, para dar vida al relato como el aura de la fotografía, tal como lo dijera Walter Benjamin. 
Contando y pintando: Una mirada a los Derechos Humanos y el conflicto armado colombiano a través del arte y la literatura. Una estrategia para la construcción de paz y ciudadanía

Esta propuesta pedagógica se viene desarrollando desde 2010 en el colegio Leonardo Posada Pedraza IED, localidad de Bosa, surge en el seno del área de Ciencias Sociales y su objetivo fundamental es fortalecer las capacidades ciudadanas ${ }^{9}$ bajo una apuesta ética orientada en el reconocimiento y acogida del otro; fue pensada con dos fines prácticos específicos:

- El rescate de los espacios públicos de la institución a través de actos comunicativos simbólicos y artísticos.

- La promoción de posturas críticas de los estudiantes frente a la realidad nacional, a partir de la exploración y producción textual y literaria.

La experiencia se ha desarrollado en tres etapas, las dos primeras: "Rompiendo paredes" y "El arte en la mesa" (2010-2014), centraron su atención en la apropiación y transformación de los espacios institucionales, haciendo uso del enfoque pedagógico institucional, en este caso La Enseñanza Para la Comprensión ${ }^{10}$. De acuerdo al enfoque, la fase final del proceso enseñanza-aprendizaje potencia la dimensión comunicativa por medio de proyectos finales de síntesis que dan voz a los estudiantes, quienes hacen creaciones simbólicas y artísticas plasmadas en muros y mesas de la institución, que fueron resultado de la reflexión en torno a los Derechos Humanos y el Conflicto armado colombiano. El ejercicio incrementó el uso de otros lenguajes y herramientas en las etapas de exploración e investigación; la literatura, el cine, la música y la pintura son imprescindibles, nutriendo a las ciencias sociales.

La tercera fase: "Foro Institucional de Derechos Humanos Leonardo Posada Pedraza" (2015), se transforma en una apuesta abierta a otras áreas de conocimiento, específicamente el área

9 Entenderemos por capacidades ciudadanas la definición propuesta por el Plan Integral para Ciudadanía y convivencia PIECC, como: aquellos conocimientos, actitudes, habilidades, motivaciones y prácticas que realizan los sujetos de las comunidades educativas, para reflexionar, hacer, ser, estar, conocerse y reconocer su contexto, para imaginar su transformación y actuar con otros para transformarlo (SED, 2015)

10 Esta apuesta pedagógica se desarrolla en tres etapas: exploración (Reconocimiento inicial de los conceptos a comprender); investigación guiada (Desarrollo de la comprensión de los conceptos) y desarrollo del proyecto final de síntesis (Los estudiantes sintetizan y demuestran la comprensión alcanzada respecto al tópico generativo). de humanidades, para propiciar el diálogo de saberes y potenciar la producción textual y literaria en los estudiantes, así como el diálogo con la comunidad educativa y entre pares de diferentes localidades; es un ejercicio académico que mantiene la voz de los estudiantes como eje central a través de sus múltiples manifestaciones, dando origen al primer número de la revista Mnemosine, contando y pintando por la ciudadanía y la paz, que recoge algunas producciones textuales y literarias de los estudiantes respecto al conflicto armado en Colombia.

\section{De los puntos de encuentro y los retos}

El encuentro suscitado por la convocatoria de la Red de Docentes Investigadores ha permitido el diálogo entre los profesores que lideran las anteriores experiencias, propiciando la reflexión colectiva, la discusión académica y la proyección a un futuro próximo. Las disertaciones respecto a las experiencias pedagógicas abonan a la discusión frente a conceptos y problemas que históricamente han buscado reflexionar sobre la educación, cómo se construyen las ciudadanías y el problema filosófico del conocimiento, ejes centrales del proceso de enseñanza-aprendizaje en una apuesta de educación para el desarrollo humano.

En este sentido, la escuela como institución moderna ha sido el espacio privilegiado en la formación de la subjetividad, expresada en la ciudadanía como discurso y práctica social necesaria para alcanzar las promesas de la modernidad. Sin embargo, este proceso desembocó en la homogeneidad y estandarización del sujeto escolar, invisibilizando otras formas de ser y estar en el mundo, produciendo interrogantes y una crisis innegable al interior de la escuela, expresada en la pérdida de sentido sobre la necesidad de la educación como condición para la emancipación, en la imposibilidad de responder a los retos de la sociedad y en la anulación del pensamiento crítico transformador.

De esta forma, el proyecto liberador de la escuela fue desplazado por la racionalidad de la individualidad, bajo la figura del egoísmo y el éxito cuantitativo-numérico como sinónimo de progreso en los procesos de medición y evaluación escolar, por la producción de riqueza material donde el ser económico se presenta como la única alternativa existencial, y por la competitividad como imperativo ético en un mundo cada vez más excluyente y violento.

En cambio, las propuestas enunciadas pretenden pluralizar el concepto de ciudadanía y evidenciar nuevos espacios en la 
formación de subjetividad, a partir de la creación artística como paradigma trasgresor y posibilitador de otras maneras de entender y ejercer la ciudadanía. Por lo tanto, el arte en todo su potencial humanizador sería un elemento fundamental de la práctica pedagógica, trascendiendo los requerimientos de medición y competitividad con los que se lee y evalúa la praxis educativa en la actualidad.

La ciudadanía desde esta perspectiva estaría compuesta por el agenciamiento e impacto que el estudiante pueda tener en su contexto próximo, reflexionando continuamente sobre sí en relación con otros, en un movimiento dialéctico que, a partir de la creación, pueda construir nuevas experiencias y escenarios de reconocimiento intersubjetivo, en un país que pretende hoy pensar en serio la paz y la reconciliación como horizontes de futuro.

Por consiguiente, es evidente que sin duda alguna existe, en las experiencias presentadas, una apuesta epistemológica que desborda los límites impuestos por la racionalidad occidental. Esta situación nos convoca a la reflexión respecto de la imposibilidad de un conocimiento único y limitado, y pone sobre la mesa la discusión en torno a la alternativa de construcciones epistémicas a partir de los aportes de diferentes disciplinas. La crisis innegable del paradigma epistemológico dominante durante el último siglo, parece abrir la brecha para facilitar la de-construcción del legado moderno, la endiosada razón que, en el seno del positivismo, guió los caminos del conocimiento es una condición revalidada hoy, dado que se constituye como lectura insuficiente de una realidad compleja:
Los diferentes niveles en que se nos presenta la realidad, en todos los campos, pero, de una manera especial, en la realidad de los seres vivos, exigen también diferentes niveles de la lógica a aplicar y, en nuestro caso, una dialógica transdisciplinaria y unos métodos también transdisciplinarios (Martínez, 2011, p. 15).

La posibilidad de construcción de conocimiento, de la mano con procesos creativos, nos coloca ante retos coyunturales que atraviesan la ciencia misma, y nos exige re-pensar el conocimiento y la práctica pedagógica. Los retos giran en torno a las posibilidades que nos abre hoy la escuela (sin desconocer otros escenarios y protagonistas del acto educativo), hacen evidente la necesidad de los docentes por iniciar trabajos de sistematización y socialización de las experiencias significativas en el aula, más aún cuando pretenden aportar en el desescalamiento del conflicto y la posibilidad de una generación de paz.

Por último, vale la pena mencionar la exigencia que tenemos de fortalecer los escenarios de trabajo en red, ya que además posibilitar la reflexión y escritura colectiva de las experiencias, han generado un cronograma de actividades que busca ampliar la divulgación y participación de las comunidades educativas en los distintos escenarios donde se desarrollan las experiencias. 


\section{Referencias}

Barbero, J. M. (2002). La educación desde la comunicación. Eduteka, pp. 1-17.

Borisonik, H., y Beresñak, F. (2012). Bíos y Zoé: una discusión en torno a las prácticas. Astrolabio. Revista internacional de filosofía, pp. 82-90.

Bourriaud, N. (2008). Estética relacional. Buenos Aires: Adriana Hidalgo Editora.

Castro-Gómez, S. (1993). Ciencias sociales, violencia epistémica y el problema de la "invención del otro". En Lander, E. (Comp.). La colonialidad del saber: eurocentrismo y ciencias sociales. Perspectivas latinoamericanas (pp. 145-161). Buenos Aires: CLACSO.

Cristancho A., J. G. (2012). Los conceptos, sujetos y subjetivación política-propedéutica para una reflexión. Bogotá: Universidad Pedagógica Nacional.

Dussel, E. (1994). 1492 el encubrimiento del otro. Hacia el origen "del mito a la modernidad". La paz: UMSA-Plural editores.

Eisner, E. W. (2002). La escuela que necesitamos. Buenos Aires: Amorrortu.

Goodman, N. (1976). Maneras de hacer mundos. Barcelona: Seix Barral.

Gvirtz, S., Abregú, V., y Grinberg, S. (2007). La educación ayer, hoy y mañana- El ABC de la Pedagogía. Buenos Aires: Aique.

Laiglesia, J. F. (2008). Notas para una investigación artística. Pontevedra: Universidad de Vigo, Servicio de publicaciones.

Larrosa, J. (2005). Tecnologias del Yo y educación (notas sobre la construcción y la mediación pedagógica de la experiencia de sí). Buenos Aires: Miño y Dávila Editores.
Márquez, M. (2009). Enseñanza de la historia del conflicto armado en Colombia: Fundamentos para la construcción de propuestas para su enseñanza en el ámbito universitario. Revista latinoamericana de estudios educativos, pp. 205-230.

Martínez Miguelez, M. (2011). El paradigma sistémico, la complejidad y la transdisciplinariedad como bases epistémicas de la investigación cualitativa. Revista electrónica de bumanidades. Educación y comunicación social REDHECS, 11, pp. 6-27.

Muteba, J. (2013, septiembre 25). Movimientos sociales negros en América Latina, el giro hacia el multiculturalismo y "nuevas" conceptualizaciones de la diáspora africana. En Conferencia Inaugural Terceras Jornadas de Estudios Afro latinoamericanos del GEALA, Buenos Aires: GEALA (Mimeo).

República de Colombia. (2011). Ley de víctimas y restitución de tierras. Bogotá: Imprenta Nacional.

Rincón, O. (2010). Tácticas y estrategias para contar. Bogotá: Fundación Friedrich Ebert en Colombia.

Secretaría de Educación Distrital. (SED). (2015). Planes Integrales de Educación para la ciudadanía y la convivencia. Obtenido el 21 de Agosto de 2015, desde http://www.redacademica.edu.co/archivos/redacademi$\mathrm{ca} /$ proyectos/pecc/centro_documentacion/caja_de_herramientas/ serie_1_orientaciones/06_planes_integrales_de_educacion_para_la_ ciudadania_y_la_convivencia_piecc.pdf

Thompson, J. (1998). Los media y la modernidad. Una teoría de los medios de comunicación. Barcelona: Paidós Ibérica.

Verón, E. (1993). La Semiosis Social. La Semiosis Social. Fragmentos de una teoría de la discursividad. Barcelona: Gedisa. 


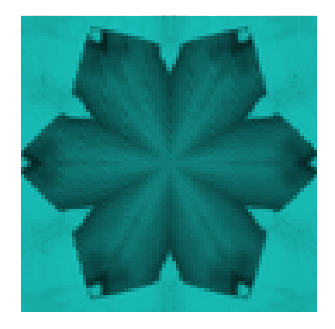


E Instituto para la Investigación Educativa y El Desarrollo Pedagógico, IDEP, invita a presentar artículos para la Revista Educación y Ciudad. El IDEP espera contribuir con esta publicación a la consolidación de una comunidad académica en educación, al

\section{Características generales}

1. Los artículos deben estar a espacio y medio, tener máximo 6.000 palabras incluidas las referencias, resúmenes y palabras clave. La fuente a utilizar será Times New Roman, 12 puntos. Todas las páginas deberán estar numeradas, incluyendo las de bibliografía.

2. Es indispensable que incluya:

a. Un resumen no mayor de 90 palabras, elaborado de acuerdo con las normas establecidas para su redacción. Deberá ir en español, inglés y portugués. Al igual que el título del artículo.

b. "Palabras clave" en español, inglés y portugués. No más de 6.

c. Fecha en la cual el texto fue enviado.

d. Nombres y apellidos completos del(os) auto(es), la institución a la que pertenecen, el último título académico obtenido, la institución en la cual lo obtuvieron, nacionalidad, número de documento de identidad (Pasaporte) y la dirección electrónica del(os) autor(es).

e. Autorización para que el artículo sea publicado en la Revista Educación y Ciudad, IDEP, desacargar de la página electrónica del IDEP.

3. Las referencias (bibliografía), notas de pie de página y citas textuales, deben presentarse de de acuerdo con normas de la American Psychological Association (APA). Cada cita debe ser referenciada citando la fuente y la página, sin excepción. Las notas de pie de página tendrán una secuencia numérica y debe procurarse que sean pocas y escuetas; es decir, que se empleen para hacer aclaraciones al texto.

4. La bibliografía deberá ajustarse a la siguiente estructura:

Libros: Apellido, letra(s) inicial(es) del nombre del (los) autor(es). (Año). Titulo y subtítulo. Ciudad: editorial y, si se referencian, las páginas citadas.

Artículos en revistas: Apellido, letra(s) inicial(es) del nombre del (los) autor(es). (Año). Título del artículo. Información sobre la publicación: nombre de la revista (en bastardillas), número del volumen, número del ejemplar, número(s) de página(s). Artículos en periódicos: Apellido, letra(s) inicial(es) del nombre del(os) autor(es). (Año), fecha de publicación). Título del fortalecimiento de una nueva identidad intelectual y profesional del maestro, a la producción de conocimiento educativo y pedagógico y a la transformación de las prácticas pedagógicas hacia la construcción de ambientes educativos de inclusión.

artículo. Nombre del periódico (en bastardillas), fecha de publicación, número(s) de página(s).

Publicaciones de Internet: Apellido, letra(s) inicial(es) del nombre del(os) autor(es). Nombre de la publicación. Dirección (URL) de la publicación. Fecha de consulta.

Para ampliar información a este respecto, favor consultar en: http://www.idep.edu.co/publicaciones.php?cual=2

5. La revista Educación y Ciudad ha previsto la recepción de artículos:

a. De Revisión (documento resultado de una investigación donde se analizan, sistematizan e integran los resultados de investigaciones publicadas o no sobre un campo en ciencia, tecnología, pedagogía, con el fin de dar cuenta de los avances y las tendencias de desarrollo). Deberá tener al menos cincuenta (50) referencias.

b. De Investigación (presenta de manera detallada los resultados originales de proyectos de investigación). Deberá tener cuatro partes: introducción, metodología, resultados y conclusiones y describir detalladamente la procedencia de la investigación o investigaciones aludidas.

c. De Reflexión (presenta resultados de investigación desde una perspectiva analítica o crítica del autor sobre un tema específico, recurriendo a fuentes originales). Deberá regirse por normas establecidas para la escritura de un ensayo.

d. Experiencias (Presenta el resulatdo del trabajo realizado en la práctica docente). su extensión será máximo de 4.000 palabras. Deberá regirse por normas establecidas para la escritura de un ensayo.

6. El formato para la compilación de fotografías, ilustraciones o bocetos debe ser capturado, escaneado o retocado a por lo menos 300 DPI y a una escala no inferior a la prevista para la impresión final. Formato: TIFF, o JPG.

7. Los artículos podrán remitirse vía correo electrónico o en formato impreso y acompañado de un CD. 


\section{Evaluación}

1. La recepción de un trabajo no implicará ningún compromiso de la Revista para su publicación.

2. El Comité Editorial selecciona los trabajos de acuerdo con los criterios formales y de contenido de esta publicación. En este trabajo de selección participan también los pares académicos y árbitros.

\section{Cesión de derechos de publicación}

1. El envío de los artículos implica que los autores autorizan a la institución editora para publicarlos en versión impresa en papel y también en versión electrónica y/o a través de otros medios mediante los cuales el Instituto promueva y difunda su consulta y acceso a diversos públicos. La cesión de derechos de publicación deberá remitirse con firma. (consultar formato en http://www. idep.edu.co/publicaciones.php?cual $=2$ )

2. Cuando el (los) autores pone(n) a consideración del Comité Editorial un artículo, acepta(n) que: 1. Como contraprestación por la inclusión de su documento en la Revista y/o en páginas web, cada autor o coautor recibirá un ejemplar de la respectiva edición. En caso de que necesite un ejemplar adicional, deberá solicitarlo por escrito a la Dirección de la Revista. 2. No presentará el mismo documento para publicación en otras revistas hasta obtener respuesta del Comité Editorial.

\section{Indexada en: \\ Latindex \\ Ulrich's \\ E revist@s \\ Iresie \\ Dialnet}

Actualidad Iberoamericana

Donde lo público

Credi

Clase

Worldcat

Rebiun

\section{Recepción de artículos}

Correo electrónico: educacionyciudad@idep.edu.co

Av. Calle $26 \mathrm{~N}^{\circ}$ 69D-91 Centro Empresarial Arrecife

Torre Peatonal, Oficinas $805-806-402 \mathrm{~A}-402 \mathrm{~B}$

Bogotá, D. C. Colombia

Tel.: 2630603 

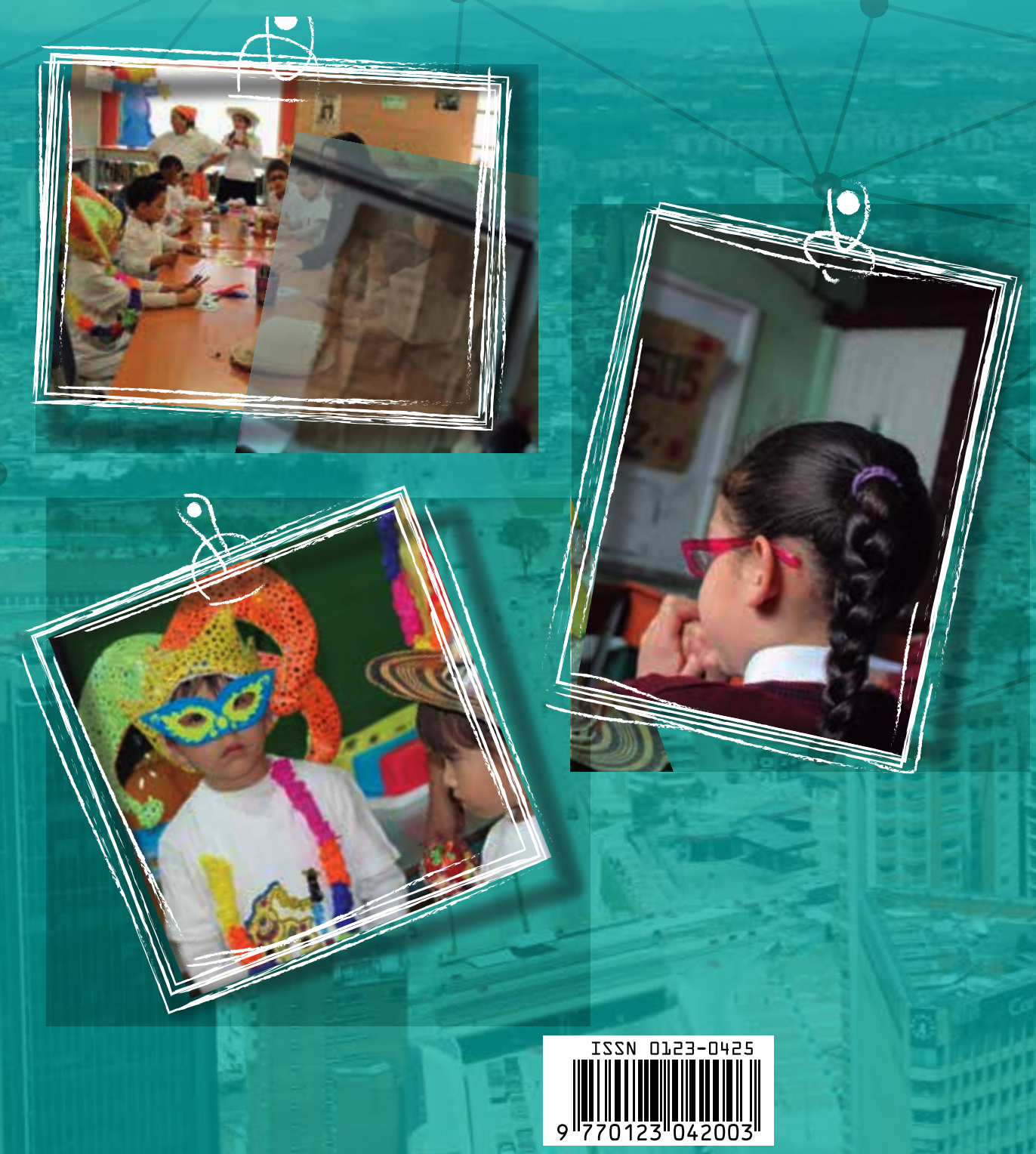
BOGOTÁ
MEJOR
PARA TODOS 